\title{
Integration of Water Resource Models with Fayetteville Shale Decision Support and Information System
}

FinAl TECHNiCAL REPORT

OCTOBER 01, 2009 - SEPTEMBER 30, 2013

\author{
Principal InVESTIGATORS \\ DR. JACKSON COTHREN, CAST (UA) \\ Dr. Greg Thoma, CHEG (UA) \\ Dr. MAuro DiLuZio, BREC (TAMU) \\ Dr. FRED LiMP, CAST (UA)
}

REPoRt Published: OCTOBER 2013

DOE AWARD NuMBER: DE-FC2609FE0000804

UNIVERSITY OF ARKANSAS

Center for Advanced Spatial Technologies

304 JBHT

FAYETTEVILLE, AR 72701
BLACKLAND TEXAS A\&M AGRILIFE

RESEARCH \& EXTENSION CENTER

720 EAST BLACKLAND ROAD

TEMPLE, TX 76502 


\section{DISCLAIMER}

This report was prepared as an account of work sponsored by an agency of the United States Government. Neither the United States Government nor any agency thereof, nor any of their employees, makes any warranty, express or implied, or assumes any legal liability or responsibility for the accuracy, completeness, or usefulness of any information, apparatus, product, or process disclosed, or represents that its use would not infringe privately owned rights. Reference herein to any specific commercial product, process, or service by trade name, trademark, manufacturer, or otherwise does not necessarily constitute or imply its endorsement, recommendation, or favoring by the United States Government or any agency thereof. The views and opinions of authors expressed herein do not necessarily state or reflect those of the United States Government or any agency thereof. 


\section{ABSTRACT}

Significant issues can arise with the timing, location, and volume of surface water withdrawals associated with hydraulic fracturing of gas shale reservoirs as impacted watersheds may be sensitive, especially in drought years, during low flow periods, or during periods of the year when activities such as irrigation place additional demands on the surface supply of water. Significant energy production and associated water withdrawals may have a cumulative impact to watersheds over the short-term. Hence, hydraulic fracturing based on water withdrawal could potentially create shifts in the timing and magnitude of low or high flow events or change the magnitude of river flow at daily, monthly, seasonal, or yearly time scales. These changes in flow regimes can result in dramatically altered river systems. Currently little is known about the impact of fracturing on stream flow behavior. Within this context the objective of this study is to assess the impact of the hydraulic fracturing on the water balance of the Fayetteville Shale play area and examine the potential impacts of hydraulic fracturing on river flow regime at subbasin scale.

This project addressed that need with four unique but integrated research and development efforts:

1) Evaluate the predictive reliability of the Soil and Water Assessment Tool (SWAT) model based at a variety of scales (Task/Section 3.5). The Soil and Water Assessment Tool (SWAT) model was used to simulate the across-scale water balance and the respective impact of hydraulic fracturing. A second hypothetical scenario was designed to assess the current and future impacts of water withdrawals for hydraulic fracturing on the flow regime and on the environmental flow components (EFCS) of the river. The shifting of these components, which present critical elements to water supply and water quality, could influence the ecological dynamics of river systems. For this purpose, we combined the use of SWAT model and Richter et al.'s (1996) methodology to assess the shifting and alteration of the flow regime within the river and streams of the study area.

2) Evaluate the effect of measurable land use changes related to gas development (well-pad placement, access road completion, etc.) on surface water flow in the region (Task/Section 3.7). Results showed that since the upsurge in shale-gas related activities in the Fayetteville Shale Play (between 2006 and 2010), shale-gas related infrastructure in the region have increase by $78 \%$. This change in land-cover in comparison with other land-cover classes such as forest, urban, pasture, agricultural and water indicates the highest rate of change in any land-cover category for the study period. A Soil and Water Assessment Tool (SWAT) flow model of the Little Red River watershed simulated from 2000 to 2009 showed a 10\% increase in storm water runoff. A forecast scenario based on the assumption that 2010 land-cover does not see any significant change over the forecast period ( 2010 to 2020 ) also showed a $10 \%$ increase in storm water runoff. Further analyses showed that this change in the stream-flow regime for the forecast period is attributable to the increase in land-cover as introduced by the shale-gas infrastructure.

3) Upgrade the Fayetteville Shale Information System to include information on watershed status. (Tasks/Sections 2.1 and 2.2). This development occurred early in the project period, and technological improvements in web-map API's have made it possible to further improve the map. The current sites (http://lingo.cast.uark.edu) is available but is currently being upgraded to a more modern interface and robust mapping engine using funds outside this project.

4) Incorporate the methodologies developed in Tasks/Sections 3.5 and 3.7 into a Spatial Decision Support System for use by regulatory agencies and producers in the play. The resulting system is available at http://fayshale.cast.uark.edu and is under review the Arkansas Natural Resources Commission. 


\section{TABLE OF CONTENTS}

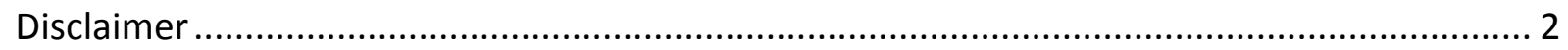

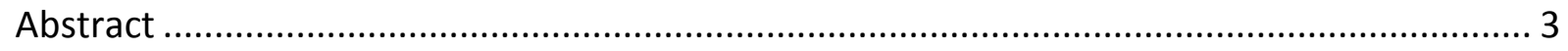

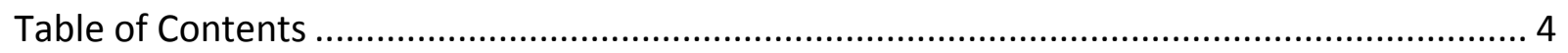

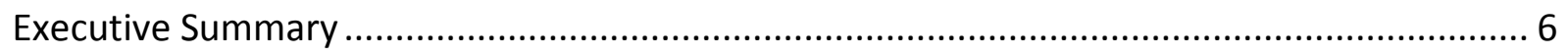

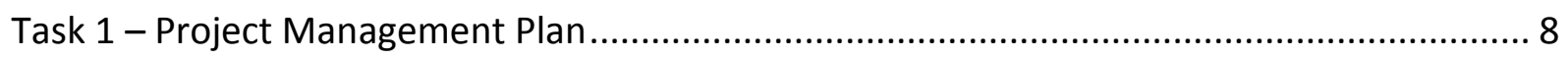

Task 2.1 - Enhance Information Site Regulations and Technology ....................................... 8

Task 2.2 - Enhance Information Site Interactive Map ........................................................ 9

Task 3.1 - Collect and Pre-process Data for SWAT Model.............................................. 11

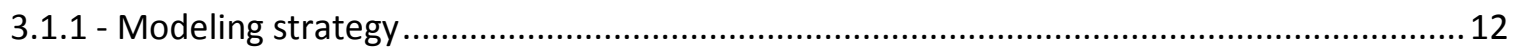

3.1.2 - Hydrologic segmentation of the study area ............................................................. 14

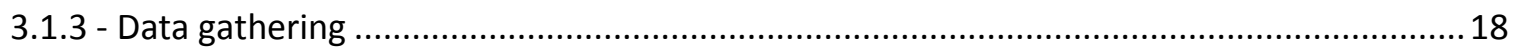

Task 3.2 - Select Representative Watersheds ............................................................. 19

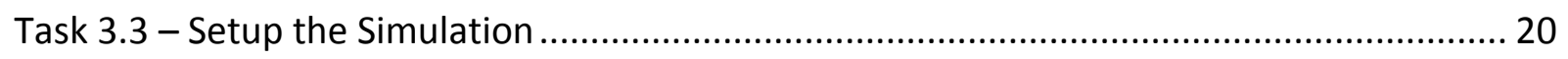

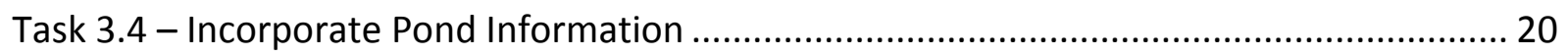

Tasks 3.5 (and 3.6) - Calibrate and Validate Stream Flow ................................................. 23

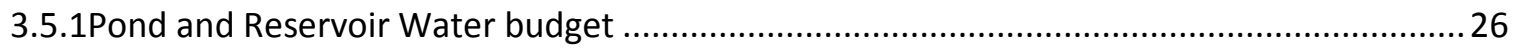

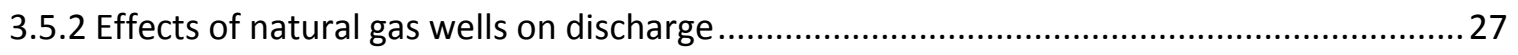

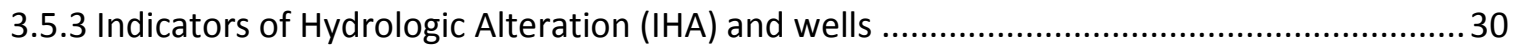

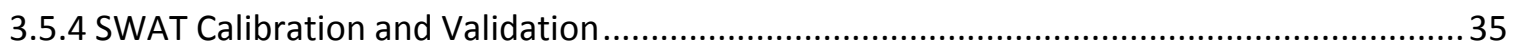

3.5.5 Impact of hydraulic fracturing on water balance ........................................................... 40

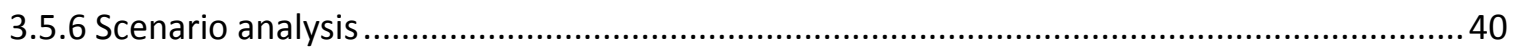

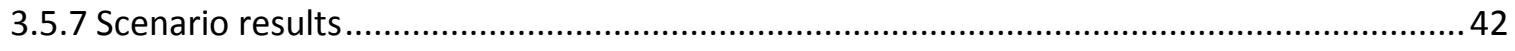

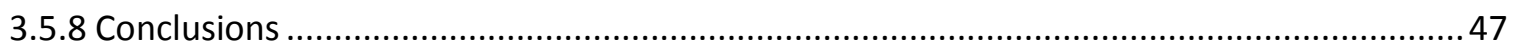

Task 3.7 - Evaluate Land Use Change Scenarios............................................................. 48

3.7.1 Land-Use Land-Cover Mapping (Image Classification) .......................................................49

3.7.2 Land-Use Land-Cover Map Accuracy Assessment ............................................................5

3.7.3 Data Bridging: Hydrologic Models and Remote Sensing Data Resolution ...........................56

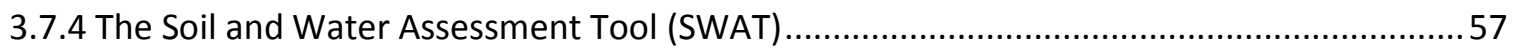

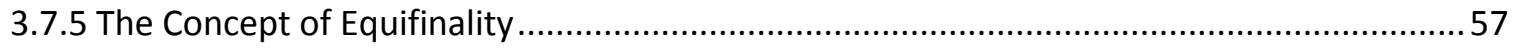

3.7.7 Prior Applications of SWAT in Best Management Practice (BMP) Implementation.............58

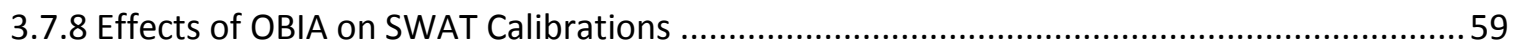

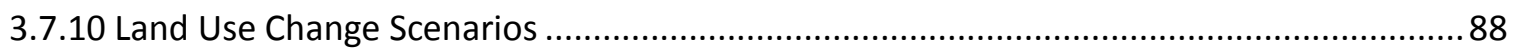

Task 4.1 - Add Weather and Stream Gage Data to FSDSS .............................................. 105

Task 4.2 - Extract Ponds from Imagery .......................................................................... 106

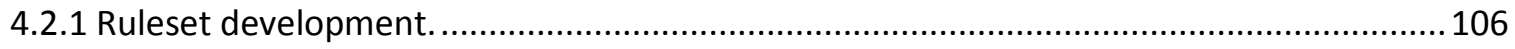

Task 5.1 - Develop Spatial Database for FSDSS/SWAT Integration .................................. 110 


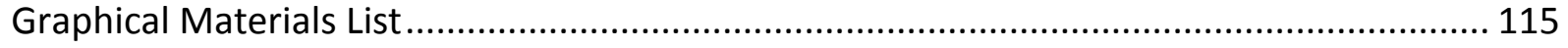

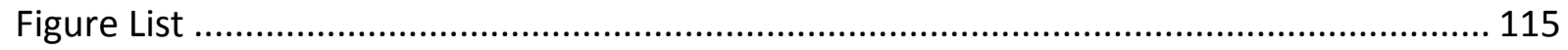

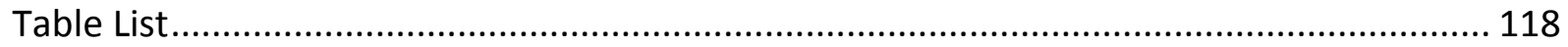

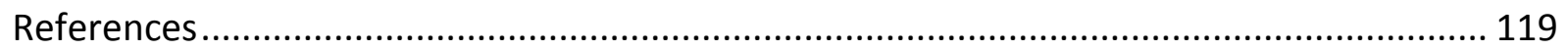

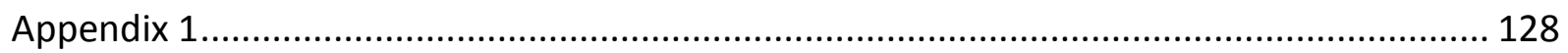




\section{EXECUTIVE SUMMARY}

In the last decade, unconventional development of energy hydrocarbon-based resource Shales has become a growing source of natural gas in the United States. Since 1998, unconventional natural gas production has increased nearly 65\% (Navigant consulting, 2008). This change in production has resulted in unconventional gas production becoming an increasingly larger component of total domestic natural gas production in the United States, shifting from $28 \%$ in 1998 to $46 \%$ of total production in 2007 (Navigant consulting, 2008). The Energy Information Administration, in its Annual Energy Outlook 2011, projects that natural gas demand in the United States could be 751 trillion liters by the year 2035 (AEO, 2012). The United States production of natural gas is expected to exceed consumption early in the next decade. The United States is projected to become a net exporter of liquefied natural gas (LNG) in 2016, a net pipeline exporter in 2025, and an overall net exporter of natural gas in 2021(AEO, 2012).

Shale gas plays are unconventional reservoirs containing gas-bearing rocks which have poor or limited natural permeability relative to the transmission of fluids (Cramer, 2008). As such, developing these resources requires a means to increase permeability through stimulation, specifically hydraulic fracturing (Cramer, 2008). Hydraulic fracturing is a well stimulation technique that has been employed in the oil and gas industry since the late 1940s and is intended to increase the exposed flow area of the productive formation, connecting the fractured area to the well by creating a highly conductive path extending a carefully planned distance outward from the well bore into the targeted hydrocarbonbearing formation, so that hydrocarbons can flow easily to the well (Schlumberger, 2008).

Current practices for hydraulic fracturing of gas Shale reservoirs are commonly sequenced events requiring thousands of barrels of water based fracturing fluids mixed with proppant materials pumped into target Shale formations above the fracture (Schlumberger, 2008). Single fracturing operation in a shallow gas well (such as a coal bed methane well) may use several hundreds of thousands of gallons of water. Slick water fracs, which are commonly used in shale gas formations, have been known to use up to five million gallons of water to fracture on one horizontal well (Burnett and Vavra, 2006). Many wells have to be fractured several times over the course of their lives.

In the U.S., an estimated 35,000 wells are hydraulically fractured annually and it is estimated that over one million wells have been fractured since the first well in the late 1940s (Bolin and David, 2007). As production from conventional oil and gas fields continues to mature and the shift to non-conventional resources increases, the importance and impact of hydraulic fracturing are expected to expand.

The Fayetteville Shale located in Central Arkansas shows great promise for continued development, partially because of successful technological advances in horizontal drilling and hydraulic fracturing. Fracture treatments in Fayetteville Shale gas wells involve an average of $5962 \mathrm{~m}^{3}$ bbls of fracture water in what might typically be applied through 4 to 8 stages (US Department of Interior, 2008).

Environmental considerations associated with water acquisition, use, and management in hydraulic fracturing operations are the source of water acquired, the volume needed and the timing of withdrawal. Availability of water for fracturing operations has received considerable attention over recent months. 
Multiple options are available for obtaining water for fracture use, such as water supply wells, private water sources including private lakes, ponds and stock tanks, surface water, and recycled flow-back water from previous fracturing operations (Chesapeake Energy, 2008).

To support its Fayetteville Shale play in Arkansas, Chesapeake Energy constructed a $616740 \mathrm{~m}^{3}$ impoundment to store water withdrawals. The objective would be to withdraw water from the Little Red River during periods of high flow (storm events or power generation releases from Greer's Ferry Dam upstream of the intake) when excess water is available. Current permits allow for up to a maximum of 1550 acre-feet annually to be collected (Chesapeake Energy Corporation, 2008). Monitoring of instream water quality and game and non-game fish species within the reach of river surrounding the intake is part of the conditions of the permit. The design provides a water storage and recovery system similar in concept to municipal water facilities. Because surface water withdrawals are limited to times of excess flow in the Little Red River, impacts on local water supplies are anticipated to be minimal.

This usage, combined with municipal and agriculture, poses water resource management concerns. Water withdrawals from sources have led non-governmental organizations (NGOs), politicians, government agencies, and the public to express concerns regarding the associated environmental implications (Veil, 2010). Additional considerations in evaluating potential impacts on the environment include the location and the availability of water, as well as the timing of withdrawals.

Understanding local water needs can help in the development of water acquisition and management plans that will be acceptable to the communities neighboring oil and gas developments. Although the water needed for drilling and fracturing operations may represent a small volume relative to other requirements, withdrawals associated with large-scale developments, conducted over multiple years, may have a cumulative impact to watersheds and/or groundwater. This potential cumulative impact can be minimized or avoided by working with local water resource managers to develop a plan of when and where withdrawals will occur and optimizing those withdrawals based upon source sustainability.

The Soil and Water Assessment Tool has gained international recognition as is evidenced by a large number of applications of this model (Gassman et al., 2007). A number of papers and reports can be found in literature providing the application of this model to study the impact on low flow condition (Cibin et al., 2010; Rahman et al., 2010; Steher et al., 2008). In Arkansas the SWAT model has been applied in different watershed, although, they deal more with water quality modeling (Baskaran et al., 2010; Gitau et al., 2010; Chaubey et al., 2005). Furthermore, emphasis has been placed upon the study of environmental flow component and hydrologic indices. This is widely documented in several studies by integrating the SWAT model and the Indicator of Hydrologic Alteration (IHA) software at subwatershed scale (Abouabdillah, et al., 2010, Jeong et al., 2011). This program, available from the Nature Conservancy (TNC), has been used by scientists and water managers in river basins throughout the United States (U.S.) and worldwide (TNC, 2005, 2007). TNC recently made substantive enhancements to the IHA to include new capabilities to support environmental flow assessments. 


\section{TASK 1 - Project MANAgEMEnT Plan}

A revised Project Management Plan was submitted by the University of Arkansas and approved by NETL. In addition, a Technology Assessment report was submitted by the UA and approved by NETL.

\section{TASK 2.1 - EnHANCE INFORMATION Site REgulations AND TECHNOLOGY}

Argonne National Laboratory, working the Center for Advanced Spatial Technologies and the University of Arkansas' Department of Chemical Engineering, identify state and federal water regulatory requirements and add these to the existing Fayetteville Shale Information Website. Argonne will also research current methods used to obtain and transport water for use in hydraulic fracturing and approaches used for disposing or reusing the flow-back water. Argonne will coordinate its activities with the other team members and with state and federal regulators and natural gas producers. The result of this task will be a natural and seamless extension of the existing website.

Co-PI John Veil has researched relevant technologies and regulations impacting surface-water in the play and produced documents describing key elements that were not part of the original site (http://lingo.cast.uark.edu). The changes and additions detailed in this research will be incorporated into the existing web-site early in the 4th quarter of Year 1. Based on Mr. Veil's research the enhanced website will provide significant additional information about the key role played by the Arkansas Natural Resources Commission in regulating surface water.

"The Arkansas Natural Resources Commission (ANRC) regulates surface water withdrawal and use. Any person or entity proposing to divert surface water for non-riparian use (including for hydraulic fracturing) is required to submit an application for use. A Non-Riparian Permit authorizes the use of excess surface water for activities on land that is not contiguous to surface water. Before issuing a permit, the ANRC determines that: the water to be used is excess surface water, the water is intended for a reasonable and beneficial use, and diversion of water will cause no significant adverse environmental impact. Operators who withdraw surface water must file a report indicating the amount of surface water that was withdrawn during the previous year."

The Arkansas Natural Resources Commission (ANRC) is considered a major stakeholder in this project and we have twice met with Mr. Ken Brazil, Engineer Supervisor for ARNCs State Water Planning Division and have exchanged documents and datasets with Ms. Danielle Gray, Program Coordinator in the same division. Both Mr. Brazil and Ms. Gray worked closely with our team to identify specific regulatory (i.e. permitting) applications of the research. Their input affects not only the public information site but has also directed the research of the modeling efforts for the decision support system.

The interactive map of the enhanced FSIW will include watershed and sub-basin delineations along with information about resources, demographics, and infrastructure pertinent to shale gas development in that particular watershed. Protocols for direct connection to the Arkansas Watershed Information System (http://watersheds.cast.uark.edu) have been established and are being added to the map. In addition to the well , permit and production information already available at this site we expect to add demographic changes, stream miles, highway miles by type, operating, terrain information and business activities organized watershed (8,10 and 12 digit hydrologic unit codes). An alpha version (left) of the enhanced site is being distributed internally at CAST for review and a beta version is expected in the 2 nd quarter. The site will include several enhancements beyond watershed related information including 
improved views of monthly production number (current and cumulative, Figure 2 ) by reporting unit (PLSS section) and across a continuous surface.

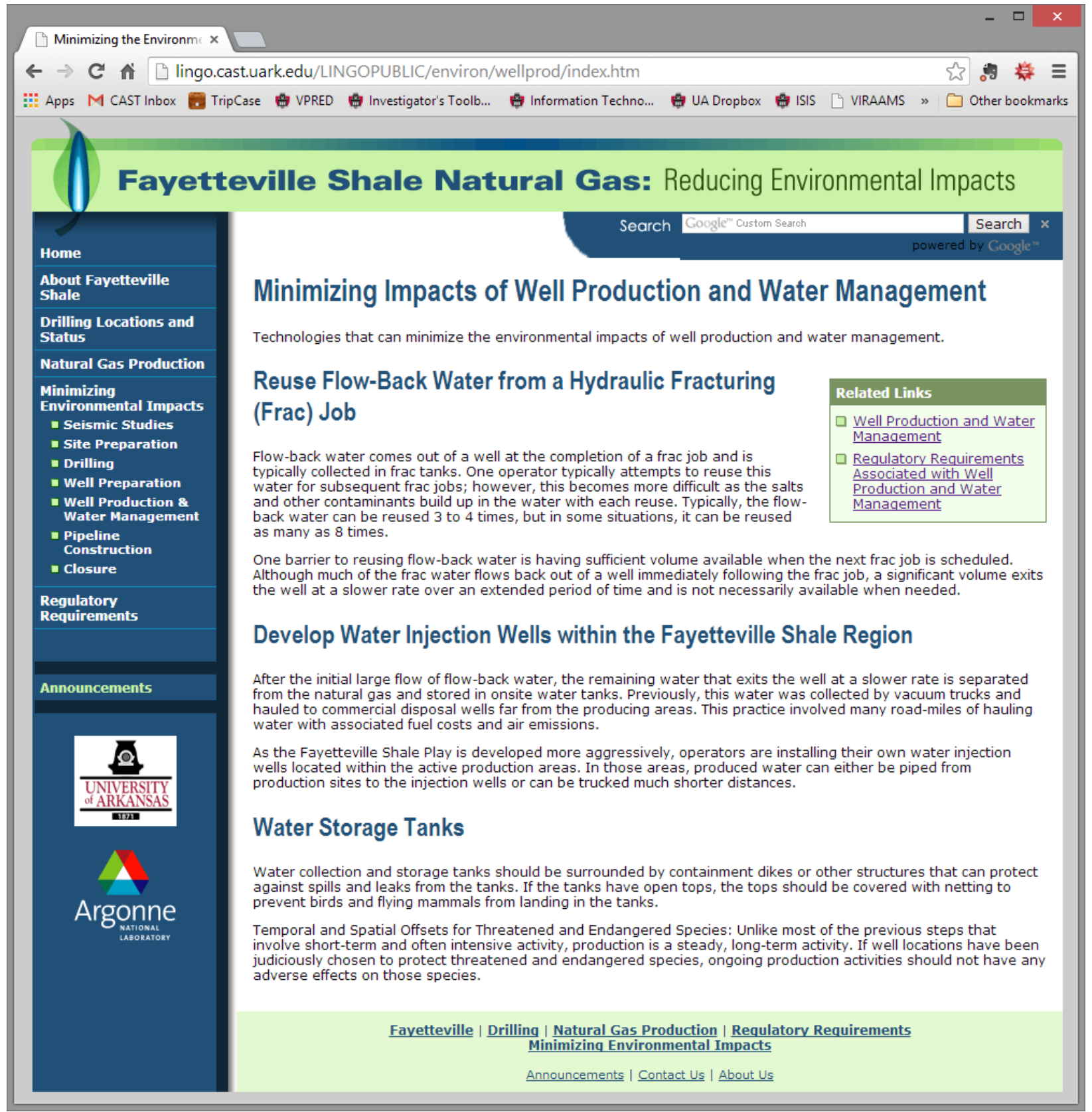

Figure 1. Fayetteville Shale Information System (http://lingo.cast.uark.edu).

\section{TASK 2.2 - ENHANCE INFORMATION Site InTERACTIVE MAP}

CAST enhanced the interactive map display to include watershed and sub-basin delineations along with information about resources, demographics, and infrastructure pertinent to shale gas development in that particular watershed. This work would leverage the Arkansas Watershed Information System 
(http://watersheds.cast.uark.edu), an existing resource developed for Arkansas by the Center for Advanced Spatial Technologies.

Production- Fayetteville Shale - 2006

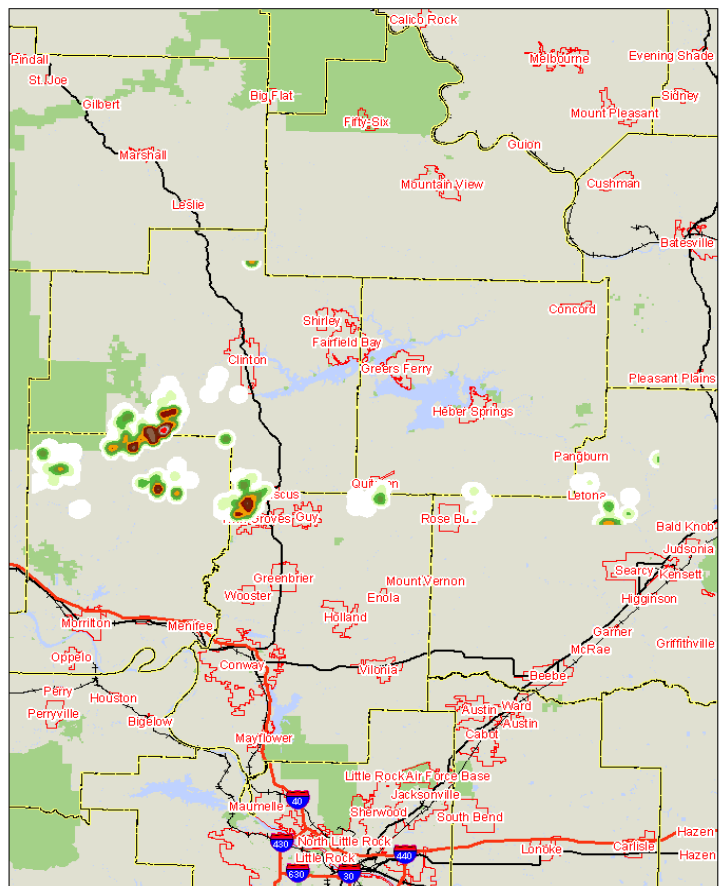

Production- Fayetteville Shale - 2008

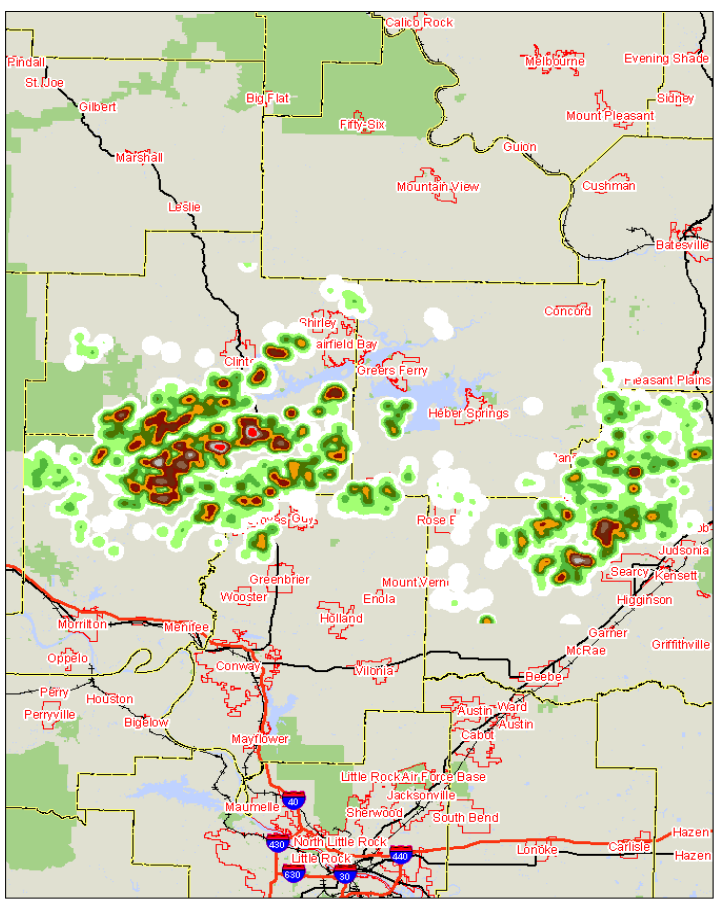

Figure 2. Interpolated production maps generated from the Fayetteville Shale Information Site. The maps are generated using Kernel Density Estimators and production numbers from active wells.

One fundamental and often visited component of FSIS is the public map viewer which shows natural gas drilling activities in the Shale Play. Currently this map displays well status (drawn from AOGC databases) and issued permits (drawn from AOGC and ADEQ databases). The new version of the map offers

1) a greatly enhanced user-interface based on the popular BING Maps API,

2) a watershed overlays which include the number and status wells and permits in a particular watershed (figure 4), and

3) historical production values aggregated to production units (PLSS sections) and interpolated to a surface map using Kernel Density Estimators (figures 3 and 4). 

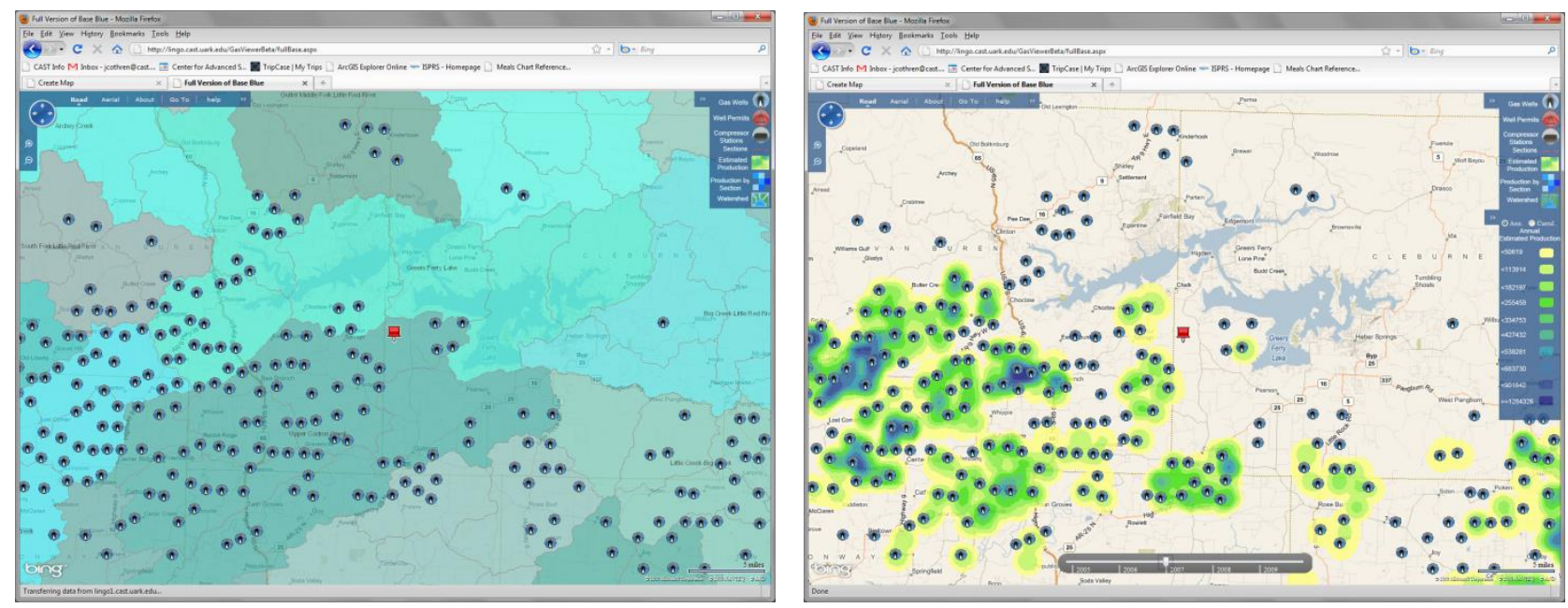

Figure 4. Enhanced Fayetteville Shale Information System screenshots showing (left) water shed layers and information and (right) well production by area.
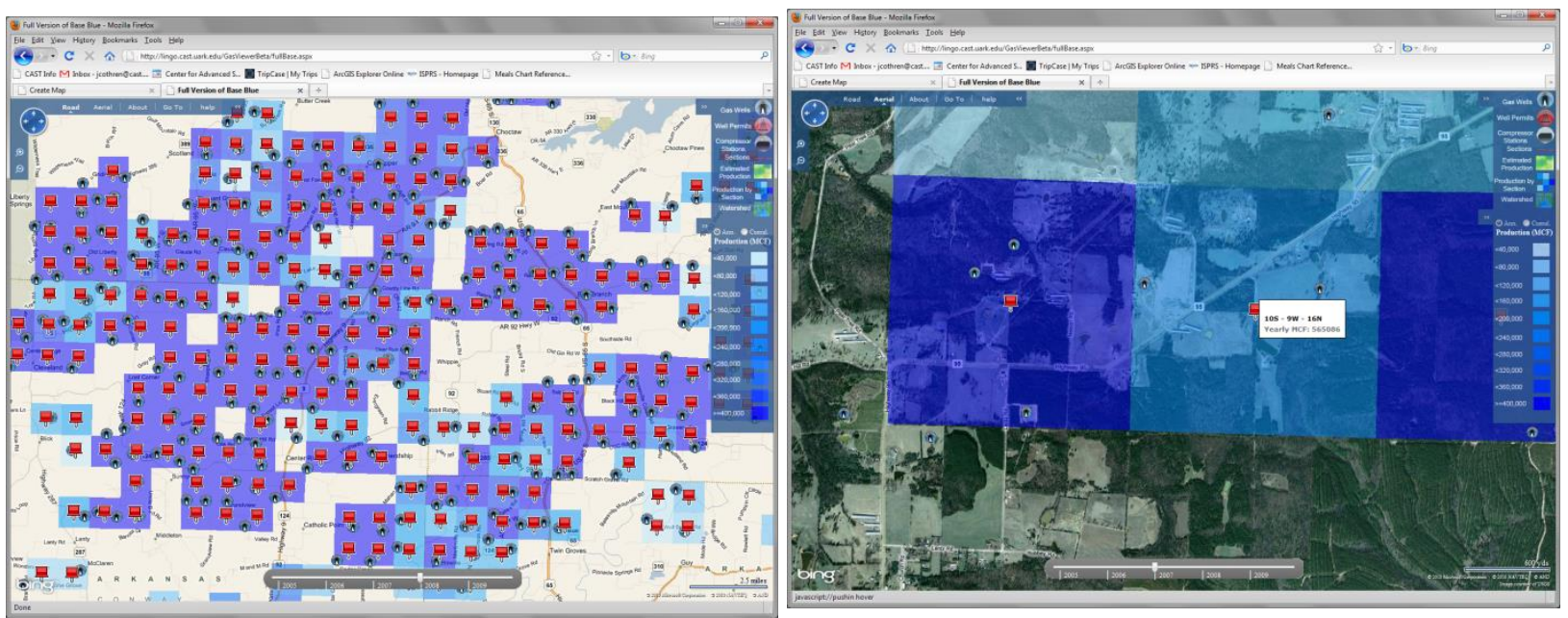

Figure 3. Enhanced Fayetteville Shale Information System screenshots showing production by section.

TASK 3.1 - Collect AND PRE-PROCESS DATA FOR SWAT MOdEL

Texas AgriLife Research Blackland Research Center and the University of Arkansas' Department of Chemical identified and implemented three (3) representative case study applications for the Soil and Water Assessment Tool (SWAT) model located within the project target area (the Fayetteville Shale). A representative case study is a watershed with distinct biophysical settings (e.g. geomorphology, groundwater, and land use/soil distribution), and of size comparable to the elementary watershed composing the proposed framework and availability of historical (at least 10-yrs) stream flow records.

The project team collected a series of observational time-series datasets: stream gage (e.g. published by USGS) daily records; daily weather records and climate data (e.g. published by the NWS); available water management operations, including reservoir outflow records and agricultural management, stream inflow (e.g. collected by state and local water related agencies). All GIS data layers, primarily the 5 meter DEM, hydrography, watershed land use / land cover, soil (NRCS-SSURGO), and geology formation maps 
are available at ftp://cast-ftp1.cast.uark.edu/DE FC2609FE0000804/. SWAT models in standard formats are also available at this site.

\subsection{1 - MODELING STRATEGY}

We expect that simulations obtained using hydrological modeling and associated GIS software will provide water resource responses related to oil and gas operations across spatial and temporal scales. In order to capture the multiple biophysical elements related to water availability and the geographic distribution of the wells within the entire Fayetteville Shale region, we selected and discussed the Soil and Water Assessment Tool (SWAT) hydrologic model.

The SWAT model is physical based model and developed by ARS-USDA to be applied at a river basin or watershed scale. The model is based upon a water balance approach applied to its simulated components (Figure 5).

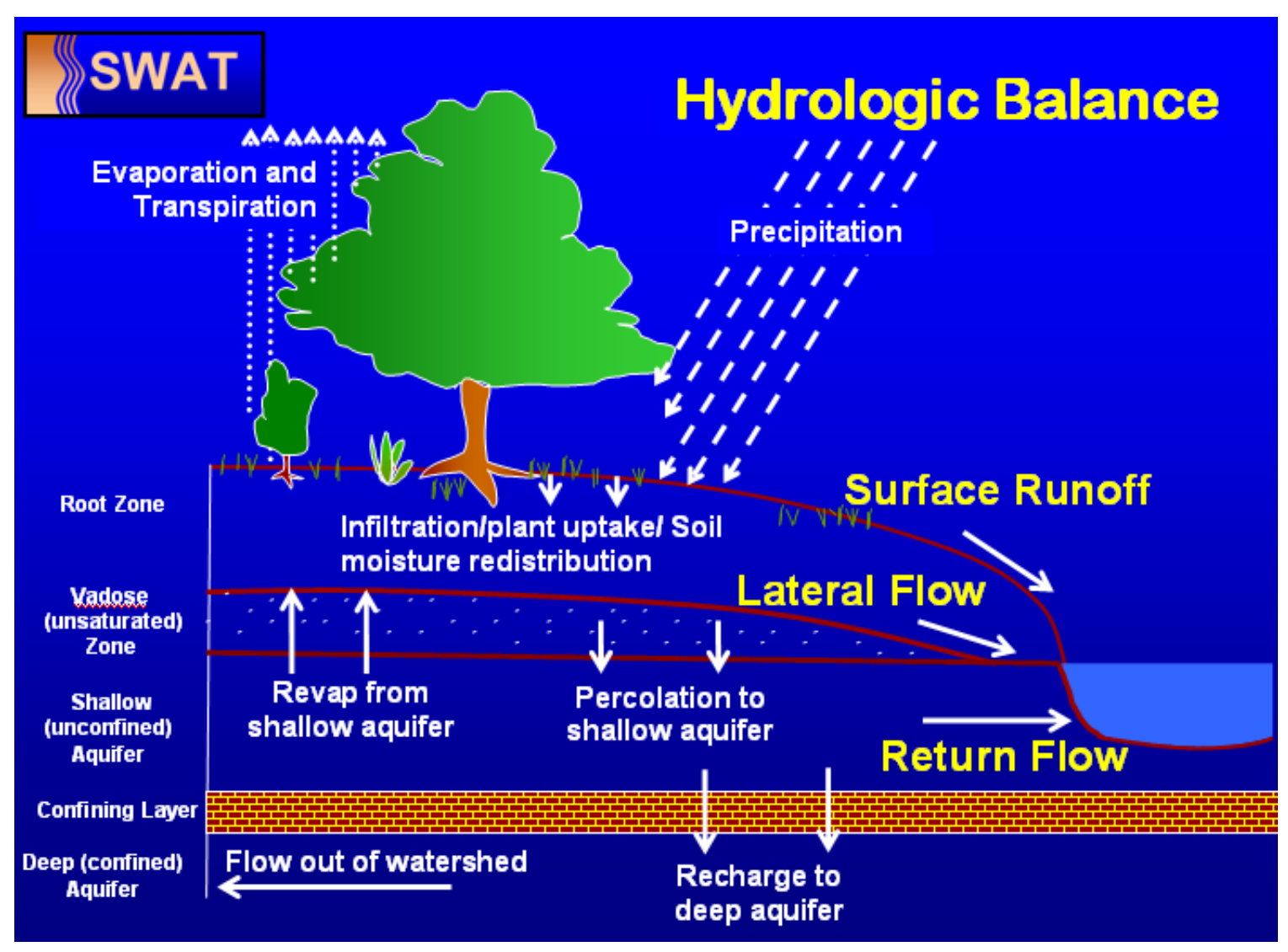

Figure 5. Hydrologic balance components in the SWAT model.

This approach allows us to apply basic hydrologic principles including interactions between precipitation, evapotranspiration, groundwater flows and terrestrial influences (soils, land use, etc.). Parameters include climate, hydrology, land cover and plant growth, erosion, nutrients, pesticides and management. Each watershed can be segmented in multiple subwatersheds or subbasins based upon a multitude of factors that can include, but are not limited to 
1) multiple tributaries within the large watershed,

2) areas of activities, and

3) other hydrologic areas of interest.

All components within the watershed are organized into categories

1) climate,

2) Hydrologic Response Units (HRUs),

3) ponds/wetlands,

4) groundwater, and

5) the main channel that drains the subbasin.

These HRUs composing the respective subbasins can be defined and lumped based upon land cover, soil and management activities. Figure 6 depicts the HRU concept as related to soil and land use/land cover. In addition the picture show the various input parameter files of SWAT model. Part of this set of files is defined at the watershed level, part at the sub-watershed level, and the remaining at the HRU level. In addition input parameters are defined for the other significant hydrologic features, such as channels, reservoirs, ponds, etc.

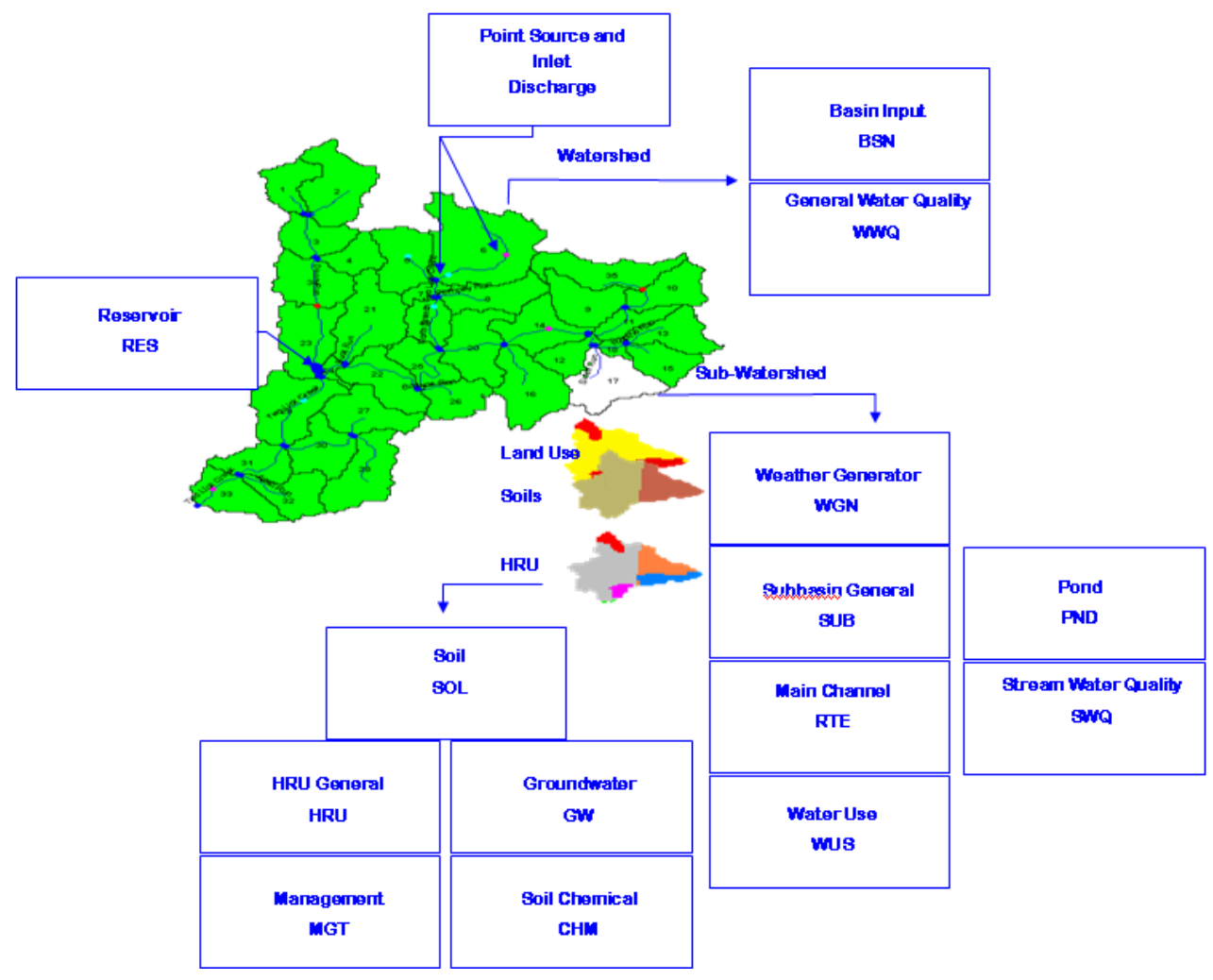

Figure 6. Spatial tessellation and input files in the SWAT model.

We are oriented toward applying the HRU definition based on detailed land use/land cover maps, which in addition will provide the spatial framework to characterize and hydrologically link significant target spatial features (i.e. well pads and ponds) along with their connection to the rest of the surrounding landscape. This approach, which is alternative to the unfeasible simulation of each individual pads (i.e. 
field scale simulation), and promises to successfully take into account of the hydrologic effects of multiple pads distributed over large basins, along with the impacts of future development (multiple pads based on permits and predicted expansion) on water quantity.

In this way we will able to capture oil and gas land management features (i.e. fracturing operations and the establishment of associated retention ponds) and their different development over the time and space. While, ponds are part of the hydrologic features simulated by SWAT model, during the project we planned to modify the model in order to simulate the well/pond association as a new hydrologic feature.

\subsection{2 - HYDROLOGIC SEGMENTATION OF THE STUDY AREA}

The Fayetteville Shale region includes around 20,000 wells. Most of the wells are located within four 8digit USGS Hydrologic Unit Codes or HUCs basins: Little Red/11010014, Lower White-Bayou Des Arc/08020301, Lake Conway-Point Remove/11110203, and Cadron/11110205 (Figure 7). They compose two independent surface water systems, which drain more downstream into the Mississippi river: 1) Little Red draining into the Lower White; and 2) Cadron drains into the Lake Conway.

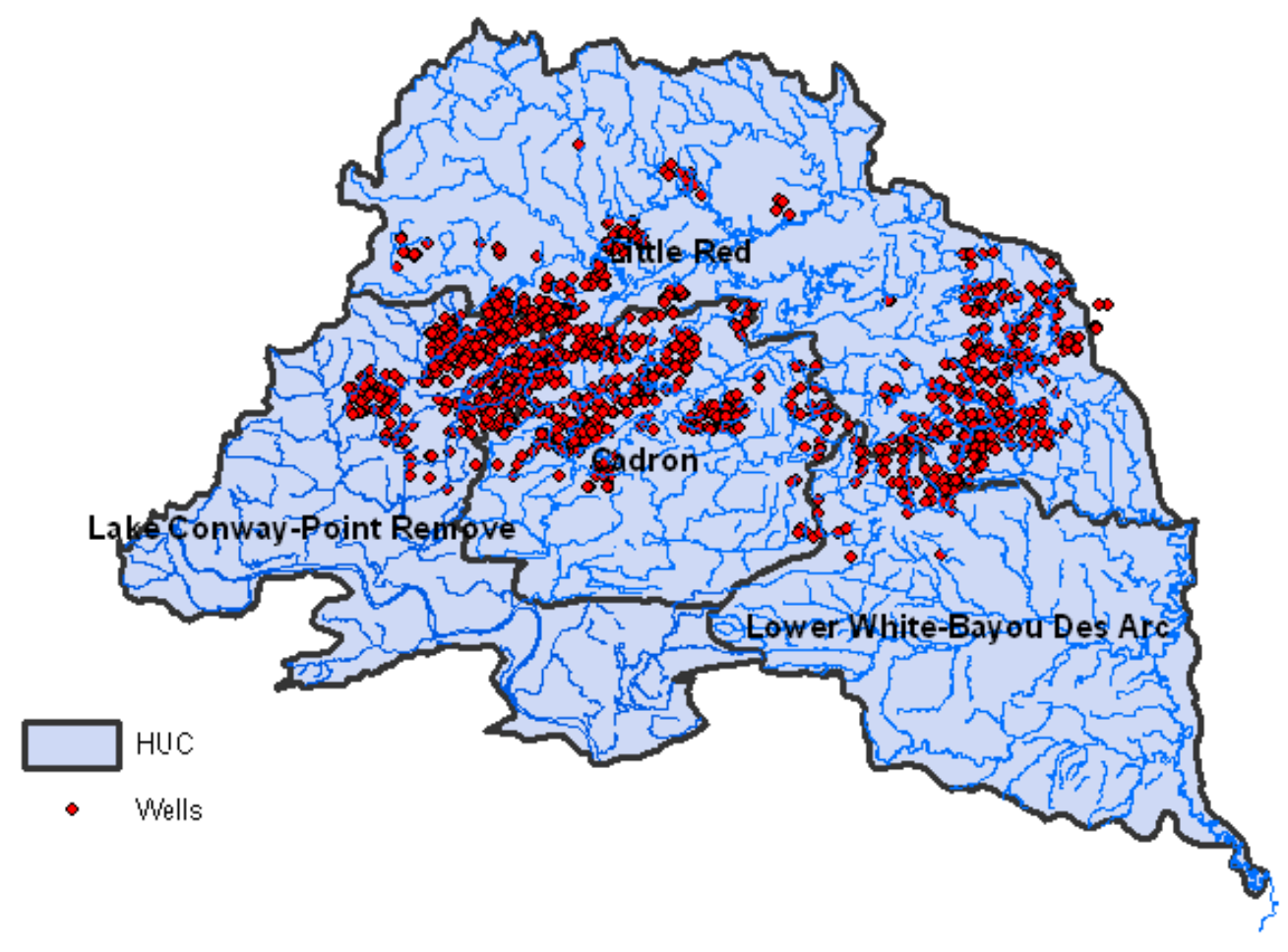

Figure 7. USGS HUCS basins and wells in the study area.

The objective of the segmentation was to identify three (3) representative case studies for the SWAT model located within the Fayetteville Shale. We consider as representative case study a watershed with distinct biophysical settings (e.g. geomorphology, groundwater, and land use/soil distribution), size comparable to the elementary watershed composing the proposed framework and availability of historical (at least 10-yrs) streamflow records. Figure 8 plots the location of the identified USGS stations within the study area. 
Out of the six stations located in the Little Red basin, four stations are currently working and provide more than 10 -yrs of continuous daily records.

\title{
USGS Surface-Water Daily Data for Arkansas
}

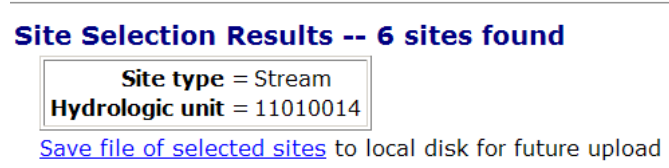

Data for individual sites can be obtained by selecting the site number below

\begin{tabular}{|l|l|l|}
\hline \multicolumn{1}{|c|}{ Agency } & \multicolumn{1}{|c}{ Site Number } \\
\hline USGS & 07075000 & Mitdle Fork of Little Red River at Shirley, AR \\
\hline USGS & 07075300 & South Fork of Little Red River at Clinton, AR \\
\hline USGS & 07075500 & SOUTH FORK LITTLE RED RIVER NR CLINTON, ARK. \\
\hline USGS & 07076517 & Little Red River near Dewey, AR \\
\hline USGS & 07076620 & LITTLE RED RIVER NEAR SEARCY, ARK. \\
\hline \hline USGS & Little Red River at Judsonia, AR \\
\hline
\end{tabular}

One station (not shown in the map) is located in the Lower White, but the period of recording stops at 1993.

\section{USGS Surface-Water Daily Data for Arkansas}

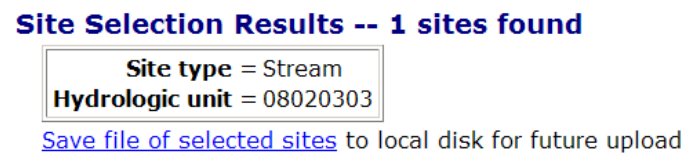

Data for individual sites can be obtained by selecting the site number below

\begin{tabular}{|l|l|l|}
\hline \multicolumn{1}{|c|}{ Site Number } & \multicolumn{2}{c|}{ Site Name } \\
\hline USGS & 07077800 & WHITE RIVER AT CLARENDON, ARK. \\
\hline
\end{tabular}

One station is located in the Cadron basin, which is currently recording since over 10 years.

\section{USGS Surface-Water Daily Data for Arkansas}

\author{
Site Selection Results -- 1 sites found

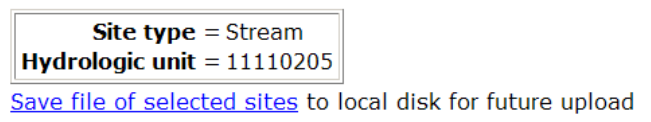

Data for individual sites can be obtained by selecting the site number below

\begin{tabular}{|l|l|l|}
\hline \multicolumn{1}{|c|}{ Agency } & \multicolumn{1}{|c}{ Site Number } & Site Name \\
\hline USGS & 07261000 & Cadron Creek near Guy, AR \\
\hline
\end{tabular}

All the three stations located in the Lake Conway-Point Remove basin are currently working and provides more than 10 -yrs of continuous daily records. 


\section{USGS Surface-Water Daily Data for Arkansas}

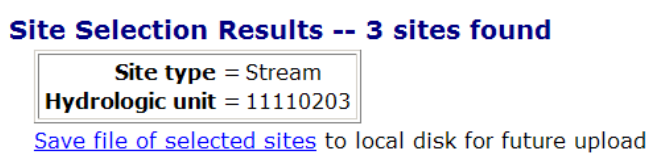

Data for individual sites can be obtained by selecting the site number below

\begin{tabular}{|l||l|ll|}
\hline \multicolumn{1}{|c|}{ Agency } & \multicolumn{2}{c|}{ Site Number } & Name \\
\hline USGS & 07258000 & Arkansas River at Dardanelle, AR \\
\hline USGS & 07260673 & West Fork Point Remove Creek near Hattieville, AR & \\
\hline USGS & $\underline{07260800}$ & Arkansas River near Morrilton, AR \\
\hline
\end{tabular}

In summary, a total of nine stations are suitable for our study (Figure 8).

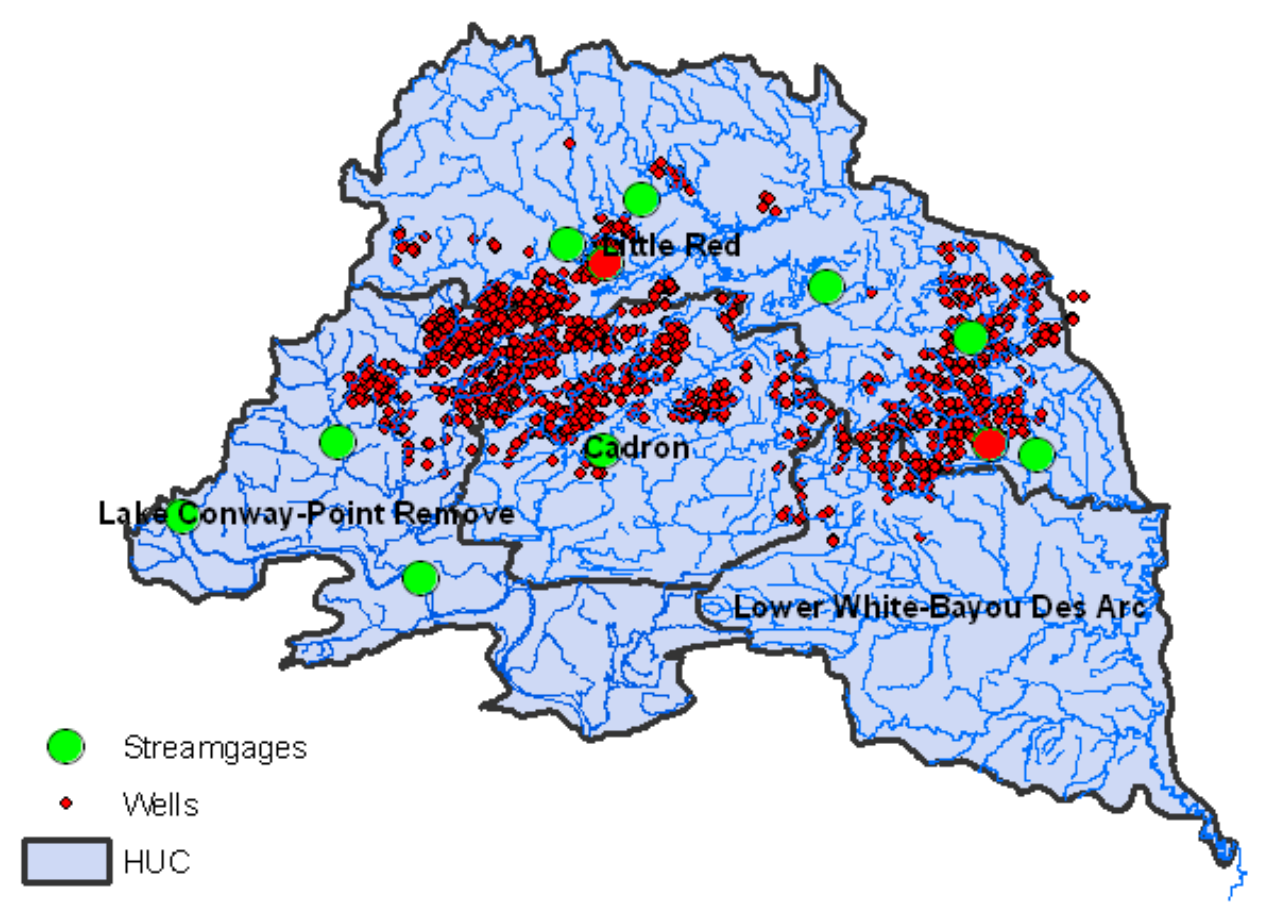

Figure 8. USGS HUCS basins, wells, and USGS stream gages in the study area. Suitable gages are plotted in green. Dismissed or unsuitable stations are plotted in red.

In addition, we also used the hydrologic landscape regions (HLRs) for the United States (Winter, 2001) geo-spatial layer to support our decisions. The concept of hydrologic landscapes proposed by Winter (2001) represents the natural landscape and climate factors expected to affect hydrologic processes. The concept of hydrologic landscapes is based on the idea that a single physical feature is the basic building block of all landscapes. This feature is termed a fundamental hydrologic landscape unit and is defined as an upland adjacent to a lowland separated by a valley side. The hydrologic system of a fundamental hydrologic landscape unit consists of (1) the movement of surface water, which is controlled by the slopes and permeability of the landscape; (2) the movement of ground water, which is controlled by the hydraulic characteristics of the geologic framework; and (3) atmospheric-water exchange, which is controlled by climate (Winter, 2001). Figure 9 shows the HLRs in our research area. 
The stations highlighted in white in Figure 6 identify our three watershed case studies, as for the objective of this task. Two nested stations located in the Little Red are particularly indicated to capture the effects of oil and gas operations on the stream flow across diverse hydrologic characteristics: from humid mountains with permeable soils and impermeable bedrock in the upper part to the humid plateaus with impermeable soils and bedrock. The stream flow recorded at the station located in the Cadron basin is drained from humid plains with permeable soils and impermeable rock. Whereas the station located upstream in the Lake Conway-Point Remove basin represents semiarid plateaus with impermeable soils and bedrock.

The location and characteristic of the stations provide great potential for the application of the SWAT model in the three drained watersheds. It is expected that their diverse landscape will provide a wide range insights across the study area.

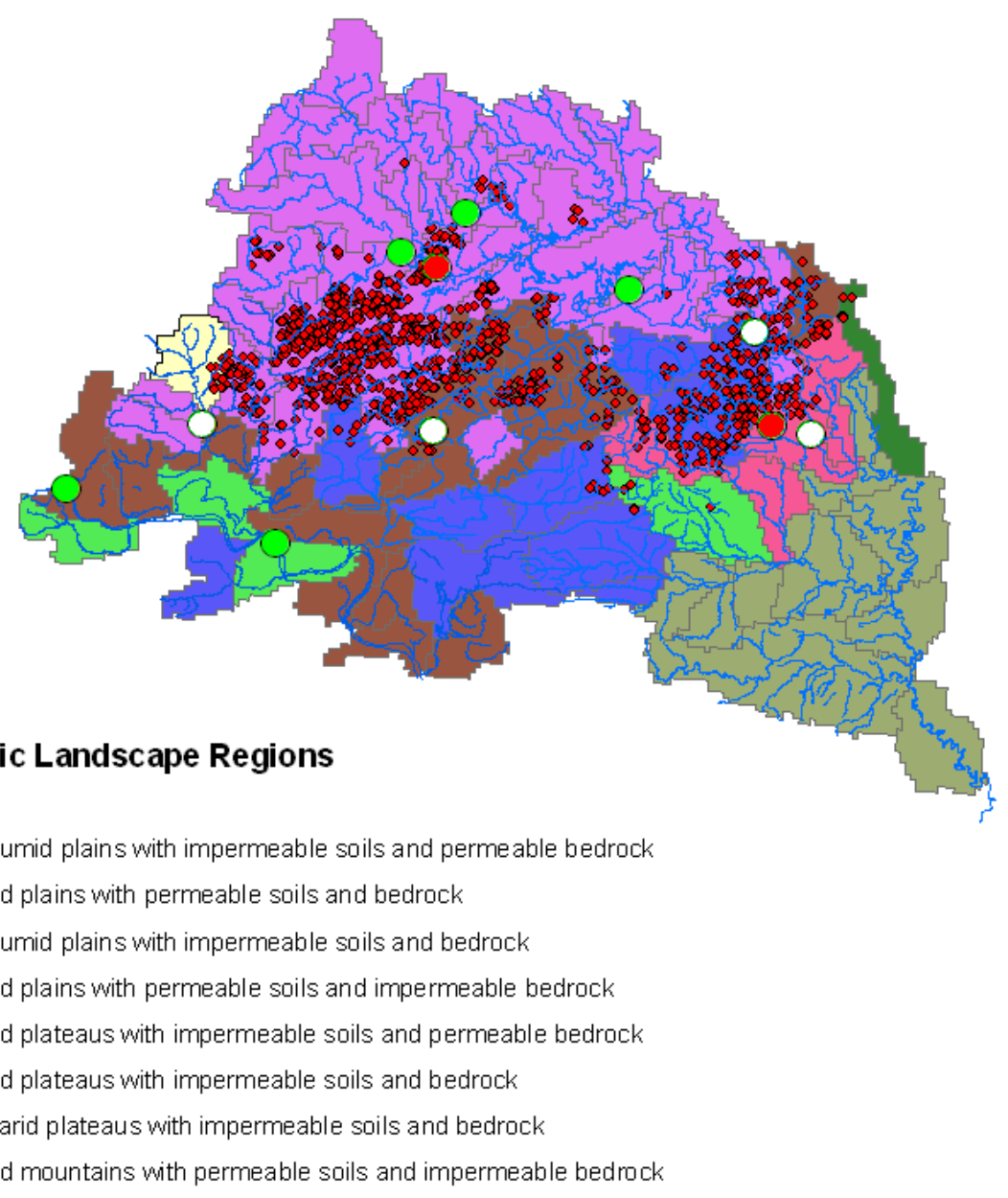

Figure 9. Hydrologic Landscape Regions in the study area. 


\subsection{3 - DATA GATHERING}

The SWAT model, being physically, based requires specific information regarding weather, soils, topography, vegetation and land management practices that occur in the watershed. Many of these information layers are spatial and available in a GIS format. Utilizing these sources of information and the SWAT approach to simulation allows the user to model watersheds where empirical data availability is minimal or lacking; and also allows the user to manipulate variables (land use, climate, vegetation, etc.) and assess the changes impacts on water quality or other variables. The SWAT model is a continuous time-step model allowing the user to simulate long-term impacts of management decisions.

In order to meet the objectives of our project, we reviewed and gathered the basic data sets the SWAT model requires as input and for the specific project area. These are the main data sets we identified and collected: a) USGS National Elevation Data Set, b) Precipitation and Temperature (COOP) + NEXRAD, c) NRCS SSSURGO, d) NHD Plus, e) Land Use/Land Cover Map, f) Pond Inventory from Task 4. Table 1 shows the complete listing of data sources used for all modeling efforts in this project.

Under this task, a comprehensive set of observational time-series (stream gage daily records, daily weather records and climate data) have been collected from the national government agencies, US Geological Survey and National Weather Service. In addition, other previously developed GIS data layers, primarily (DEM, hydrography, land use / land cover, soil and geology formation maps) were processed and prepared in a format suitable to the next two subtasks of Task 3. Two teleconference working sessions with Adobe Connect followed in the March meeting in Fayetteville, AR to further coordinate the data collection and processing efforts. Other data, such as water management operations, reservoir outflow records and agricultural management, stream inflow collected by state and local water related agencies are still under collection and process due to their publication in non-standard format. A similar issue is related to the processing of NEXRAD rainfall data, which are published in challenging (XMRG and NetCDF) formats.

Table 1. Source of input datasets.

\begin{tabular}{|c|c|}
\hline Types of data & Sources of data \\
\hline 30-meter DEM & $\begin{array}{l}\text { National hydrography dataset } \\
\text { http://www.horizon-systems.com/nhdplus/data.php }\end{array}$ \\
\hline Stream network & $\begin{array}{l}\text { National Hydrography Dataset } \\
\text { http://www.horizon-systems.com/nhdplus/data.php }\end{array}$ \\
\hline $\begin{array}{l}\text { Land use and land cover } \\
\text { LULC } 2004\end{array}$ & $\begin{array}{l}\text { Center for Advanced Spatial Technologies } \\
\text { http://www.geostor.arkansas.gov/G6/Home.html }\end{array}$ \\
\hline Soils data & $\begin{array}{l}\text { Geographic STATSGO soil map (scale of } 1: 250,000 \text {, USDA NRCS) } \\
\text { http://soildatamart.nrcs.usda.gov/ }\end{array}$ \\
\hline $\begin{array}{l}\text { Climate data } \\
\text { (rainfall and temperature): } \\
\text { NNDC }\end{array}$ & $\begin{array}{l}\text { Texas AgriLife Blackland Research Center } \\
\text { www.brc.tamus.edu }\end{array}$ \\
\hline Stream discharge & $\begin{array}{l}\text { USGS Arkansas Water Science Center (http://ar.water.usgs.gov) } \\
\text { http://ida.water.usgs.gov/ida/. } \\
\text { http://waterdata.usgs.gov/ar/nwis/sw/ }\end{array}$ \\
\hline
\end{tabular}


Types of data

1) Water bodies-NHD

2) water bodies: pond and reservoirs:

3) dams-NID-2009

Water management dams

Wells- Oil And Natural Gas
Sources of data

1) National Hydrography Dataset http://www.horizon-systems.com/nhdplus/data.php

2) Center for Advanced Spatial Technologies

3) National Inventory of Dams - NID 2009 dataset http://geo.usace.army.mil/pgis/f?p=397:1:4229727166433088::NO

U.S. Army Corps of Engineers, Little Rock District Water Management http://www.swl-wc.usace.army.mil/mcharts.htm State Of Arkansas Oil And Gas Commission http://www.aogc.state.ar.us/JDesignerPro/JDPArkansas/default.htm

\section{TASK 3.2 - SELECT REPRESENTATIVE WATERSHEDS}

After a GIS-based spatial analysis and a stream flow data records review, we successfully identified three representative case studies for the SWAT model application within the Fayetteville Shale area. A representative case study watershed provides distinct biophysical settings (e.g. geomorphology, groundwater, and land use/soil distribution), and availability of historical stream flow records (a minimum 10 year time series). Two nested stations located in the Little Red are particularly indicated to capture the effects of oil and gas operations on the stream flow across diverse hydrologic characteristics: from humid mountains with permeable soils and impermeable bedrock in the upper part to the humid plateaus with impermeable soils and bedrock. The stream flow recorded at the station located in the Cadron basin is drained from humid plains with permeable soils and impermeable rock. Whereas the station located upstream in the Lake Conway-Point Remove basin represents semiarid plateaus with impermeable soils and bedrock. The location and characteristic of the stations provide great potential for the application of the SWAT model in the three drained watersheds. It is expected that their diverse landscape will provide a wide range of insights across the study area.

In September 2011, CAST met with Ken Brazil, Engineering Supervisor of the Arkansas Natural Resources Commission (ANRC), to discuss surface water issues relevant to natural gas development. The ANRC is the state regulatory authority for surface water use, and requires permits for all "non-riparian" use, i.e. the use of excess surface water for activities on land that is not adjacent to the surface water source. ANRC has been overwhelmed with permit requests for non-riparian water use by drilling and fracturing companies since development of the Fayetteville Shale began. Although the ANRC does not wish to be a bottleneck in the natural gas development process, ANRC group is wary of over-permitting water diversions, as their currently available data is inadequate for accurately assessing surface water availability. While fracturing activity has diminished as of 2013, it is expected that re-stimulating wells in certain areas of the play could begin soon.

CAST has worked with Mr. Brazil's division at ANRC for over fifteen years on a wide variety of water and wetland related projects. Independent of this project, CAST has been working with ANRC to map current non-riparian water use permits and available surface water by 12-digit HUC, based upon data from the existing Arkansas Water Plan. During our meetings with Mr. Brazil, we examined and discussed ways in which this project may be able to provide more accurate data and interactive tools which could be 
utilized by ANRC to improve both the scientific basis for permit evaluation and the efficiency of the permit granting process. Additionally, Mr. Brazil informed us that ANRC has been working with several of the gas development companies to expand surface water monitoring by adding stream gages, which may provide improved options for model calibration as we develop these tools. As of November 2013, no new water gauges have been added to the Central Arkansas system.

Outcomes of this meeting include the following:

- CAST investigated the utility of monthly and normal precipitation data developed by the PRISM Climate Group at Oregon State University, comparing it to the data currently used in the Arkansas Water Plan. This data was eventually used as source data for the SDSS described in Section 5.1.

- $\quad$ ANRC would play an active role in advising needs and evaluating the utility of models developed in this project. ANRC is still engaged with the University of Arkansas team and is seeking funds for further development of the SDSS.

- CAST and ANRC would collaborate on model testing and calibration using current and new stream gages.

\section{TASK 3.3 - SETUP THE SimULATION}

Simulation set up is described in Section 3.5.

\section{TASK 3.4 - INCORPORATE POND INFORMATION}

Details of our efforts to include retention ponds and other small water body features extracted in Task 4.1 into the SWAT simulation framework are covered in Section 3.7
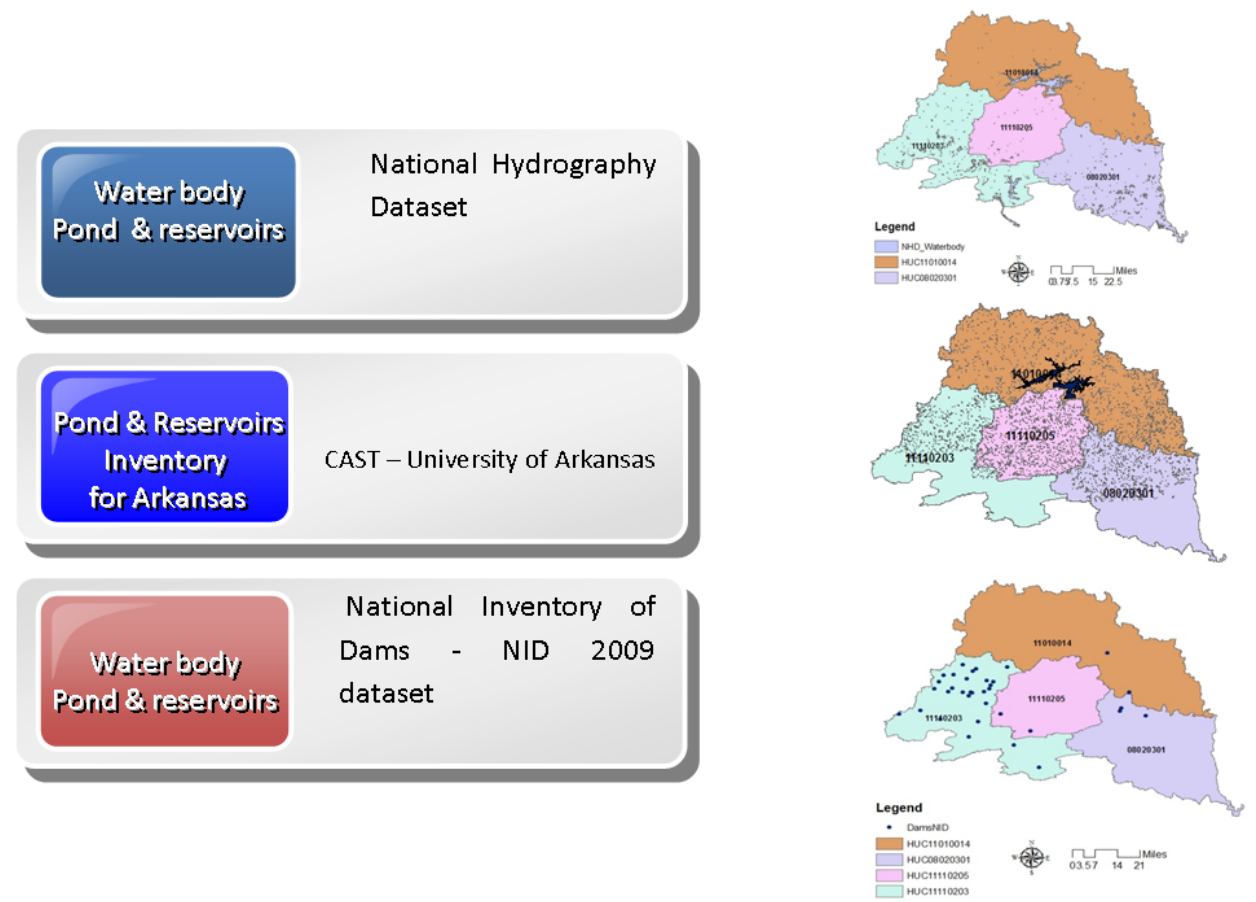

Figure 10. Data sets used to estimate the basic characteristics of ponds and reservoirs. 
GIS input layers were prepared by processing the polygons best representing water bodies (ponds and reservoirs); computing a flow accumulation grid (accumulated area flowing into each cell) from the NHDPlus datasets; and the concurrent usage of a 10-m DEM from the USGS for the calculation of the volume (Figure 11).

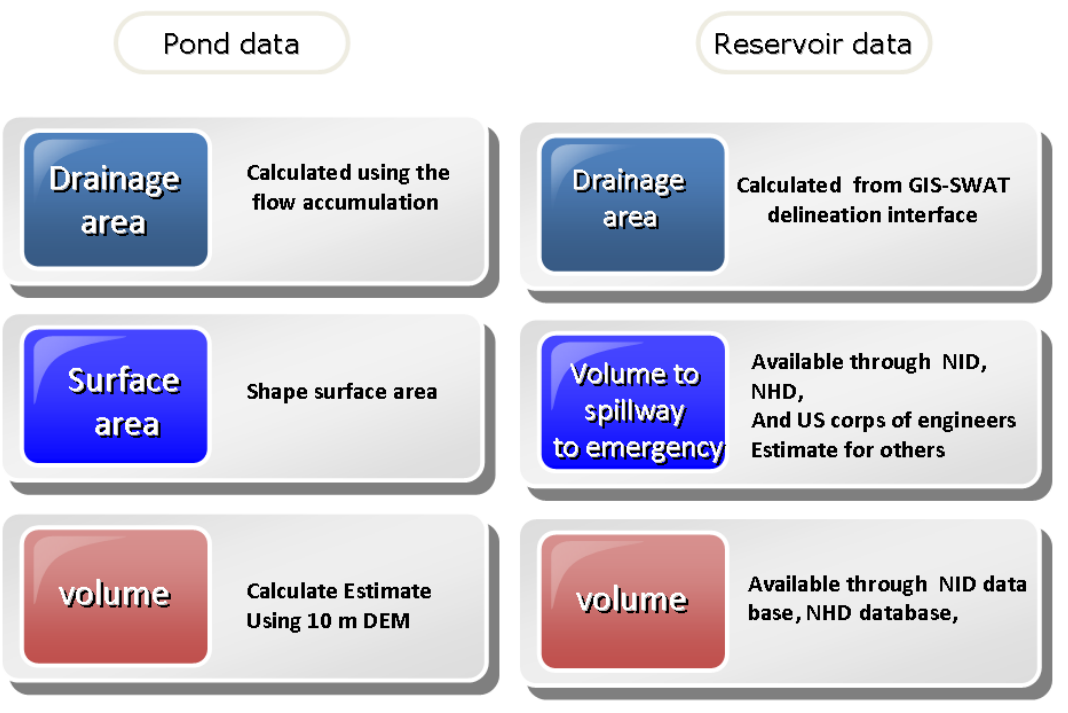

Figure 11. Procedure used to estimate the basic characteristics of ponds and reservoirs.

For reservoirs, four regression sets between the drainage area and storage volume were identified in the study area (Figure 12). These relationships provided estimates for the volume of reservoirs not included in the NID dataset.
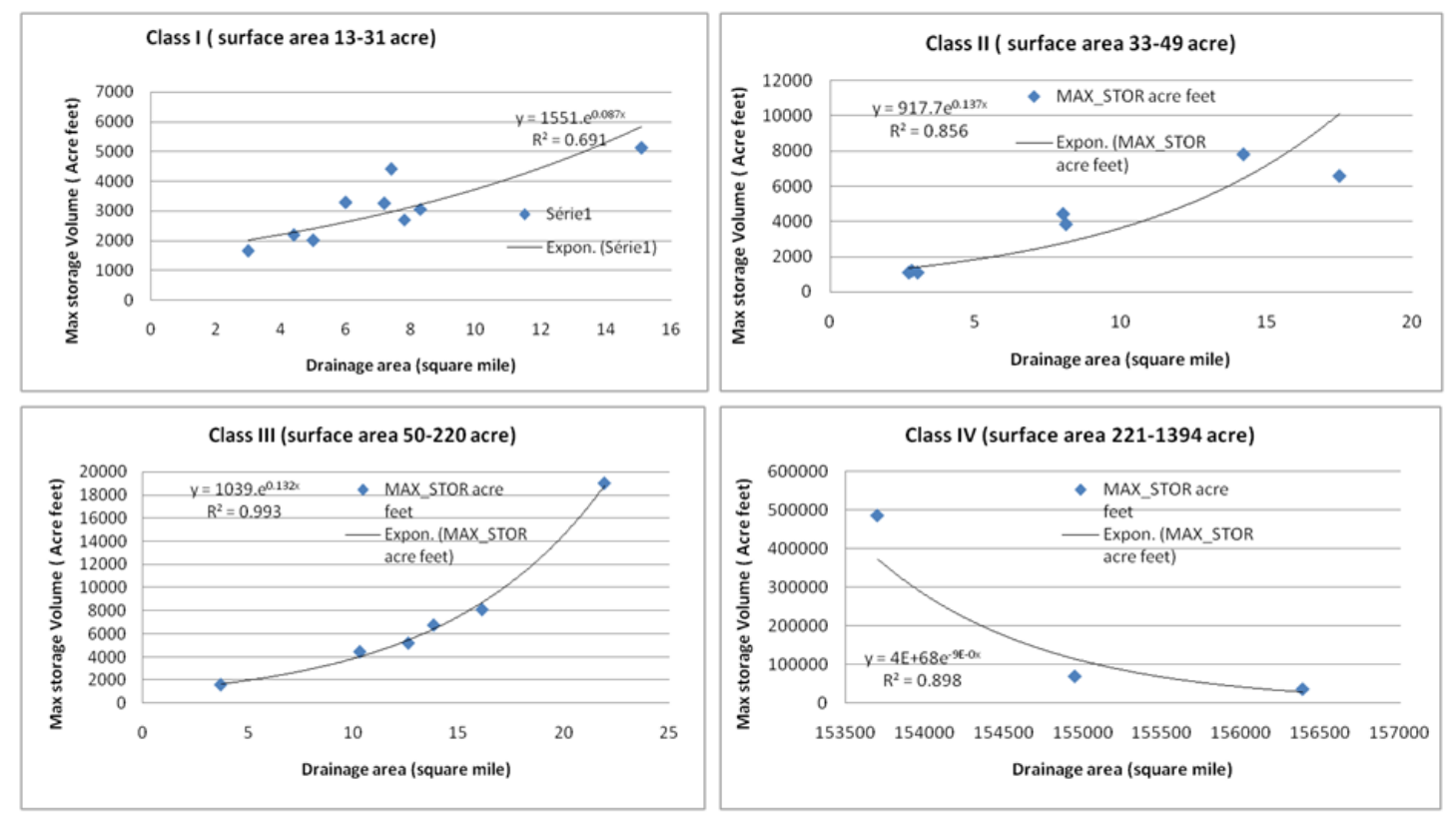

Figure 12. Drainage area-volume regressions for reservoirs in the study area. 
During this task, the reservoir configuration of the SWAT simulation input was enhanced. A subwatershed outlet was set at each stream section entering the reservoir (Figure 13).

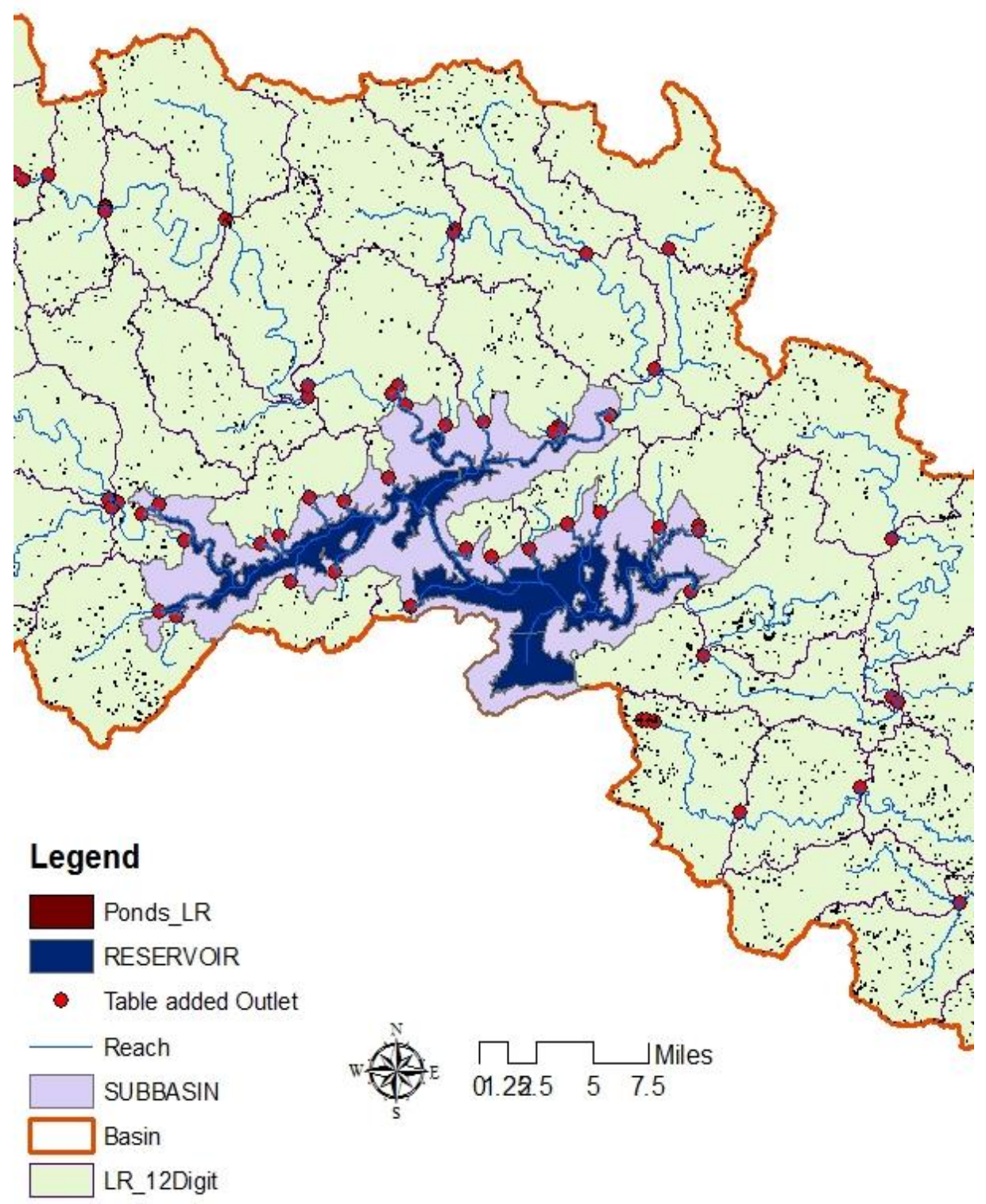

Figure 13. Landscape modeling configuration strategy for reservoirs in the study area. 


\section{TASKS 3.5 (AND 3.6) - CAliBRATE AND VALIDATE STREAm FLOW}

The SWAT model calibrated for the three case study watersheds and for a respective simulation period (a minimum 5 year history). Calibration involves the comparison of computed stream flow values to observed records and the consequent adjustment of the model parameters to attain closer agreement.

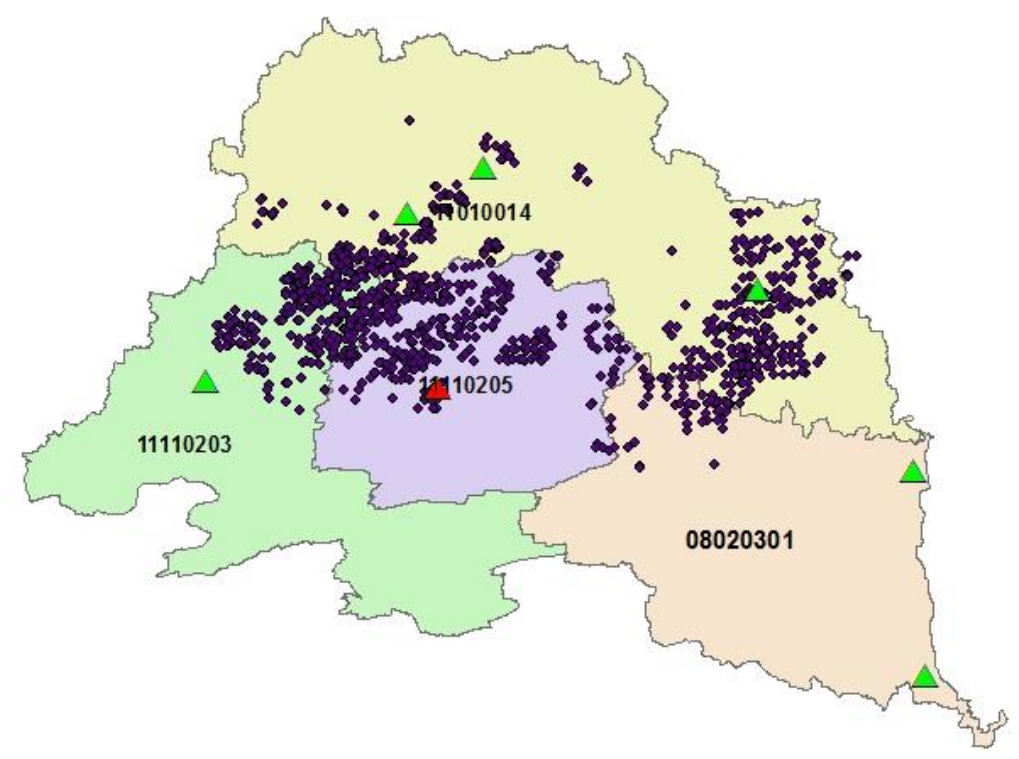

\section{Legend}

- cadron streamgage

- olland natural gas Wells

HUC11110203

HUC11110205

HUC08020301

HUC11010014

Figure 14. Stream gage stations in the study area. Cadron near Guy station is highlighted.

The water balance was manually calibrated targeting the average annual flow in the period 1984-2009. Based on modeling experience and former literature results, the most sensitive SWAT model input parameters were uniformly adjusted. Results of this first phase of calibration are summarized in Table 2.

Table 2. Average annual observed and simulated discharge at Cadron station (1984-2009).

Total Water Yield $(\mathrm{mm}) \quad$ Surface Runoff $(\mathrm{mm}) \quad$ Base flow $(\mathrm{mm})$

\begin{tabular}{llll}
\hline Observed & 332.99 & 299.49 & 33.50 \\
\hline Simulated & 369.87 & 297.63 & 33.17
\end{tabular}


Table 3 reports the annual NSE (Nash and Sutcliffe, 1970) simulation index for this station. The NSE coefficient ranges between -1 and 0.75 .

The inconsistencies in the differences between the simulated and the observed stream flow for certain years are currently due to the lack of under completion data related to ponds and reservoirs management. However the model performance is very good during some years. Based on these results the calibration was set for the period 1984-1992 and for validation the period 2008-2009. Figure 14a and Figure 14b graph simulated and measured stream flow at Cadron near Guy during the calibration (1984-1992) and validation (2008-2009) period respectively.

Table 3. Nash and Sutcliffe simulation index at Cadron near Guys station (1984-2009).

\begin{tabular}{cclllll} 
& Years & $\begin{array}{l}\text { Nash- } \\
\text { Sutcliff }\end{array}$ & $\begin{array}{l}\text { Mean } \\
\text { Nash-Sutcliffe }\end{array}$ & Years & $\begin{array}{l}\text { Nash- } \\
\text { Sutcliffe }\end{array}$ & $\begin{array}{l}\text { Mean } \\
\text { Nash- } \\
\text { Sutcliffe }\end{array}$ \\
\hline Calibration & 1984 & 0.55 & 0.5 & 1997 & -0.10 & \\
& 1985 & 0.66 & & 1998 & 0.49 \\
1986 & 0.12 & 1999 & -1.23 \\
1987 & 0.44 & 2000 & -0.28 \\
1988 & 0.55 & 2001 & 0.55 \\
1989 & 0.25 & 2002 & 0.63 & \\
1990 & 0.36 & 2003 & 0.57 & \\
1991 & 0.34 & 2004 & -0.08 \\
1992 & 0.57 & 2005 & -0.06 \\
1993 & 0.35 & 2006 & -0.14 & \\
1994 & 0.25 & 2007 & 0.10 & \\
1995 & -0.09 & 2008 & $\mathbf{0 . 7 5}$ & $\mathbf{0 . 7}$ \\
1996 & 0.39 & Validation & 2009 & $\mathbf{0 . 6 5}$ & \\
\hline
\end{tabular}



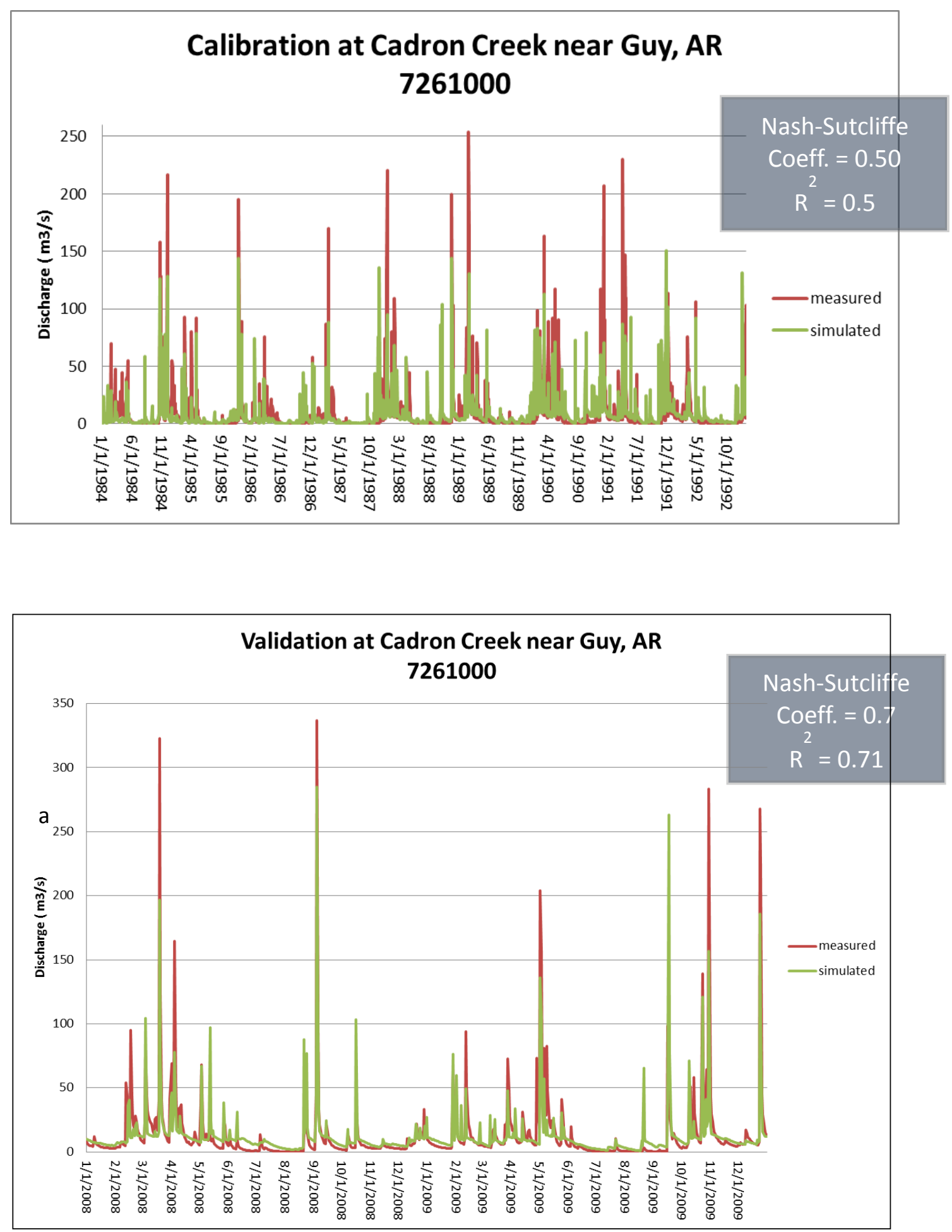

Figure 15. Observed and simulated discharge in the calibration (top) and validation (bottom) period at Cadron creek near Guy. 
Table 4. Monthly average simulated water balance from 1984 -2009.

\begin{tabular}{llllllll}
\hline & & SNOW & & & WATER & \\
MON & RAIN & FALL & SURF Q & LAT Q & YIELD & ET & PET \\
$(\mathrm{mm})$ & $(\mathrm{MM})$ & $(\mathrm{MM})$ & $(\mathrm{MM})$ & $(\mathrm{MM})$ & $(\mathrm{MM})$ & $(\mathrm{MM})$ & $(\mathrm{MM})$ \\
\hline 1 & 72.52 & 20.26 & 27.96 & 1.65 & 43.24 & 24.33 & 36.62 \\
2 & 95.19 & 14.25 & 33.63 & 1.75 & 45.71 & 33.31 & 52.5 \\
3 & 113.29 & 3.92 & 31.37 & 2.45 & 45.92 & 52.69 & 87.16 \\
4 & 105.94 & 0 & 24.88 & 2.29 & 36.75 & 63.2 & 123.65 \\
5 & 128.28 & 0 & 29.12 & 2.68 & 39.68 & 83.1 & 155.6 \\
6 & 97.17 & 1.77 & 10.32 & 2.14 & 17.02 & 81.67 & 170.94 \\
7 & 72.63 & 1.67 & 5.51 & 1.71 & 8.91 & 68.77 & 187.91 \\
8 & 78.86 & 1.7 & 10.18 & 1.6 & 11.87 & 56.45 & 175.74 \\
9 & 73.52 & 2.67 & 14 & 1.56 & 17.57 & 39.95 & 127.35 \\
10 & 104.18 & 3.67 & 25.39 & 2 & 31.13 & 38.92 & 90.5 \\
11 & 116.42 & 0.89 & 44.5 & 2.32 & 54.5 & 29.81 & 52.65 \\
12 & 113 & 18.79 & 39.81 & 2.33 & 54.79 & 23.62 & 36.04 \\
\hline & & & & & & &
\end{tabular}

Table 4 summarizes current average water components simulated in the period 1984-2009. These results show that the water balance is dominated by actual evapotranspiration ( $595 \mathrm{~mm} / \mathrm{year}$ ) that presents approximately $50 \%$ of annual rainfall. Potential evapotranspiration (ETP) calculated with Hargraves-Samani method ( $1295 \mathrm{~mm} /$ year). The surface runoff presents only $25.5 \%$ of the total annual rainfall, while the base flow is the $11 \%$.

\subsubsection{POND AND RESERVOIR WATER BUDGET}

The natural hydrological regime is continuously altered by the construction of small dams (ponds) and large dams (reservoirs). In order to assess the impact of these features on the hydrological regime, a simulation scenario was built removing them from the modeling framework. Figure 15 shows the pond and reservoir budget and the difference in the water balance when removing them from the simulation. In general, when removing these features, the total flow increases by $4 \%$ and the groundwater storage in the shallow aquifer decreases by $22 \%$. 
POND
BUDGET

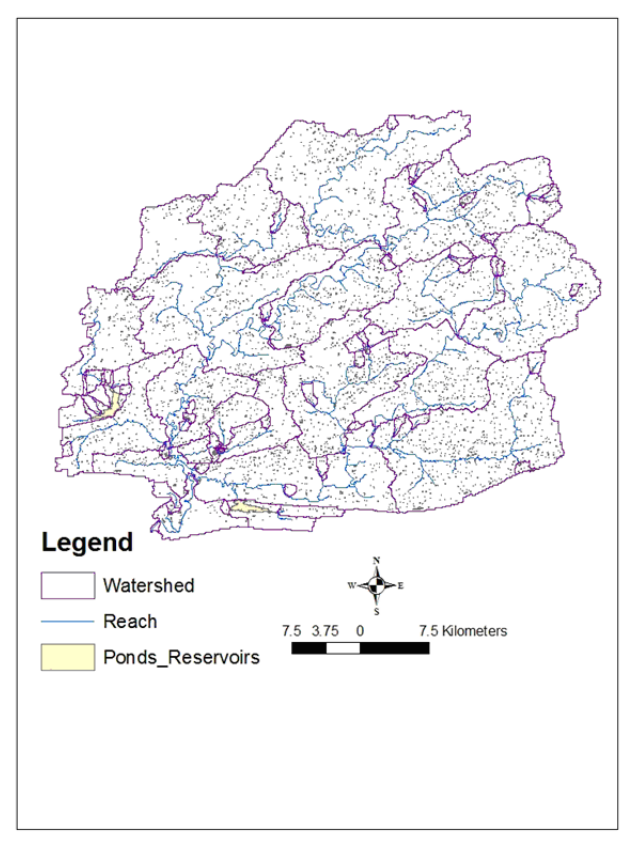

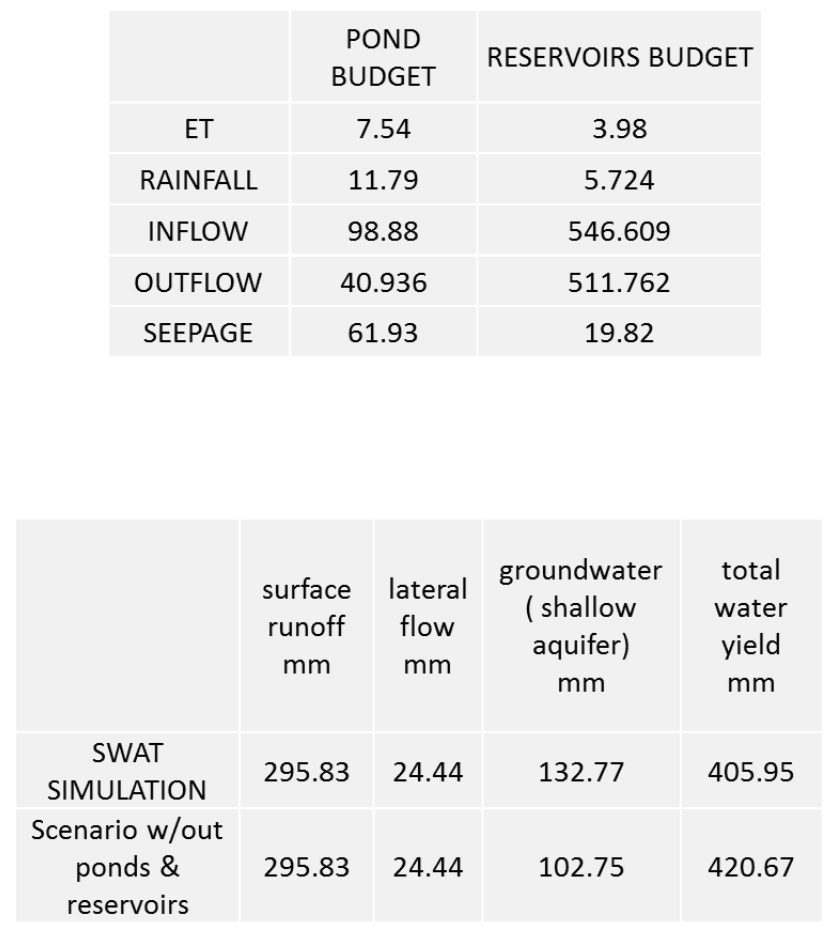

Figure 16. Average annual ponds and reservoirs water budget at Cadron creek near Guy watershed.

\subsubsection{EFFECTS OF NATURAL GAS WELLS ON DISCHARGE}

Natural gas production in the Fayetteville shale area (Central Arkansas) might create critical levels of water discharge due to techniques used for horizontal hydraulic fracturing. In fact, while in the near future the total number of wells is expected to grow, each well requires between 3 and 7 million gallons of water for hydraulic fracturing. In the following early analysis of the discharge records, it was assumed that each well fracturing operation started 2 months before the first production (current best information available from the State of Arkansas Oil and Gas Commission) and that the water (4 million of gallons) was withdrawn from the nearest stream network. Figure 16 shows the percentage of yearly discharge used for hydraulic fracturing for 7 stream gages/watersheds in the Fayetteville shale area.

The water quantity used for fracturing resulted low compared to the overall discharge and it ranged between 0.01 and $1.11 \%$. A more detailed analysis at the monthly base of the $\%$ of water used was obtained for stream gages 07261000 (Cadron near Guy) and 07260673 (West Fork Point Remove Creek near Hattieville). The first stream gage station drains an area of $437 \mathrm{~km}^{2}$, which includes 93 wells. Noticeable percentages of the respective monthly discharge (Figure 17) were identified in August 2009 (3.7\%), November 2008 (5.0\%), and November 2007 (5.7\%). The second stream gage station drains an area of $575 \mathrm{~km}^{2}$, which includes 114 wells.

Remarkable percentages of the respective monthly discharge (Figure 18) were identified in November 2005 (15\%), January 2006 (15\%), and November 2008 (60\%). 


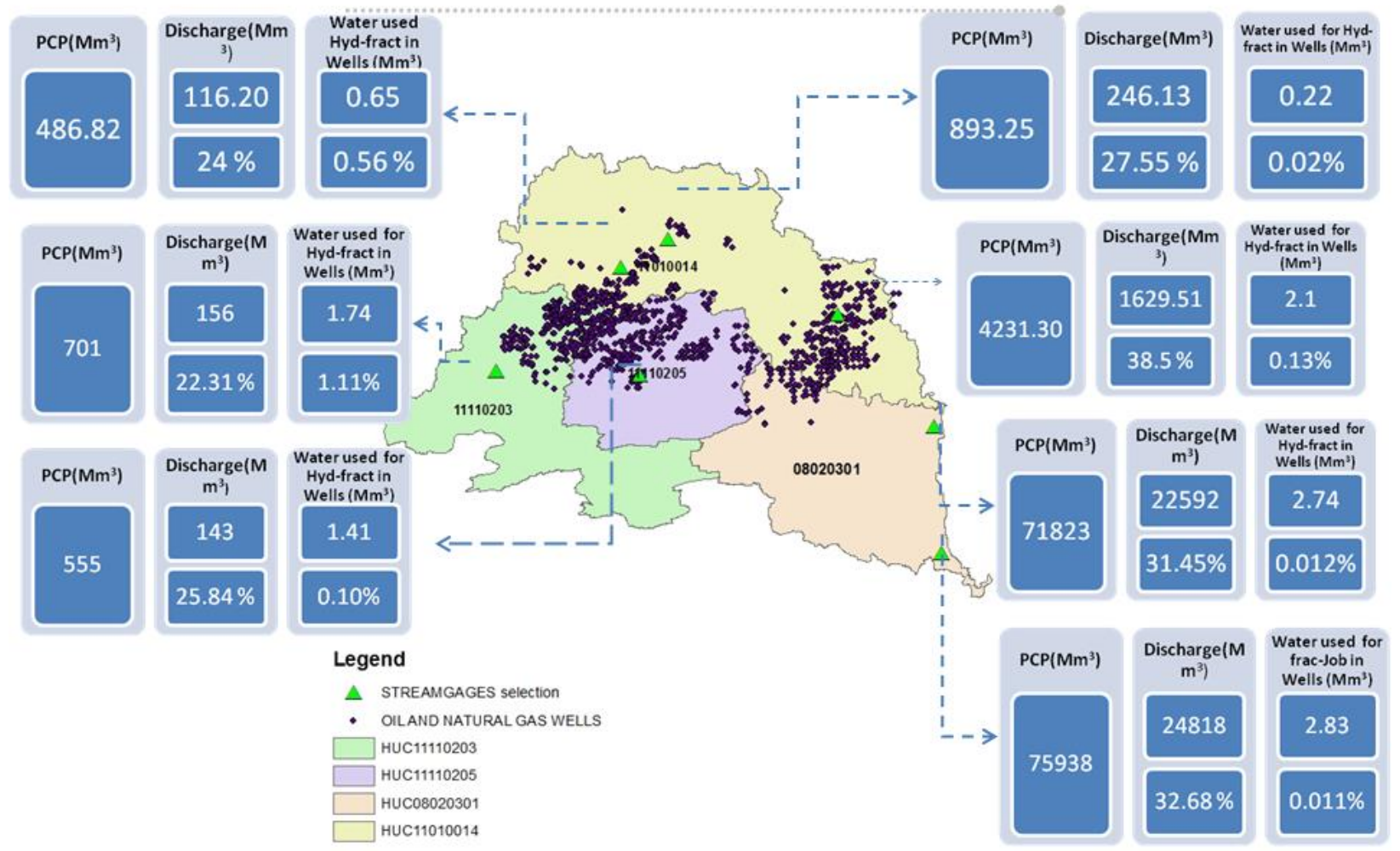

Figure 17. Mean annual discharge as percentage of precipitation and mean annual water used for hydraulic fracturing as percentage of discharge for seven watersheds/stream gages in the Fayetteville shale area. 


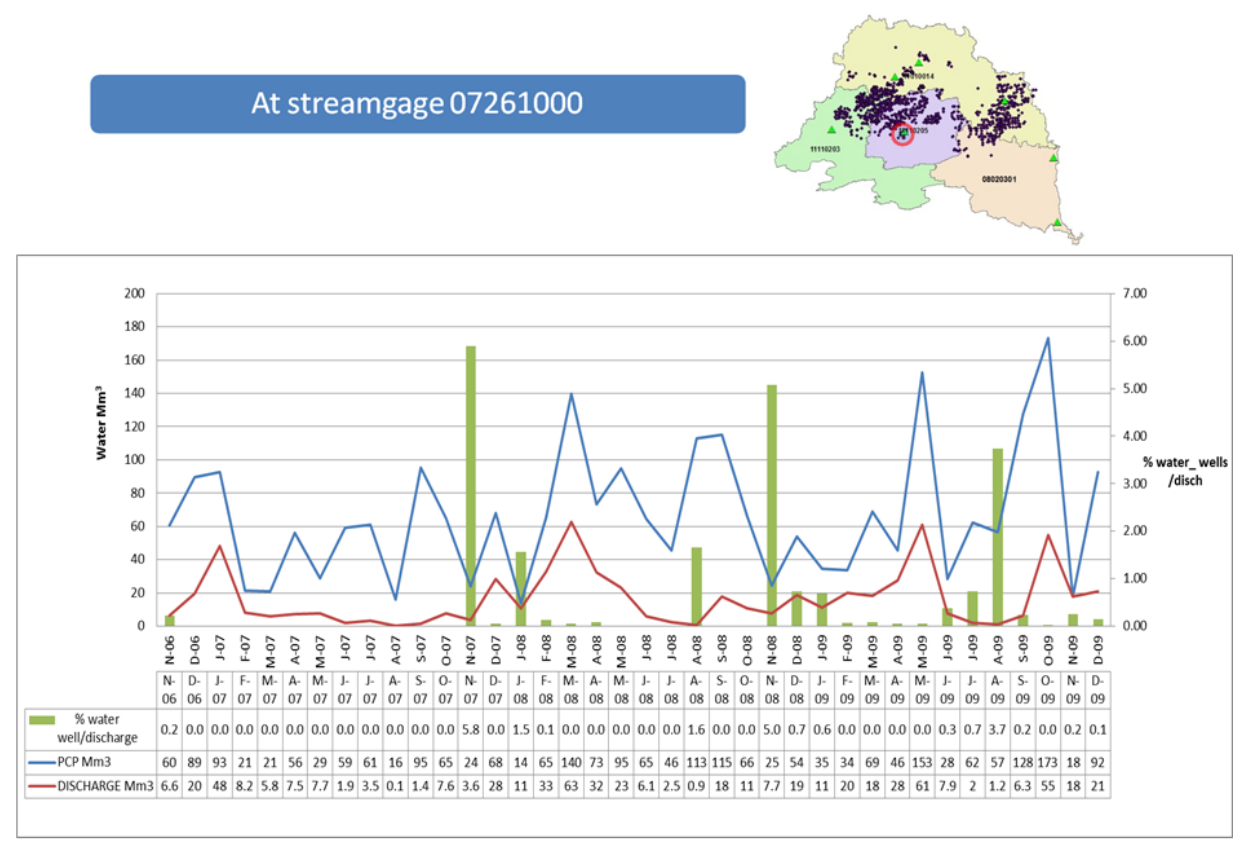

Figure 18. Mean monthly discharge, as percentage of precipitation, and mean monthly water used for hydraulic fracturing as percentage of discharge for the stream gage station 07261000 (Cadron near Guy).

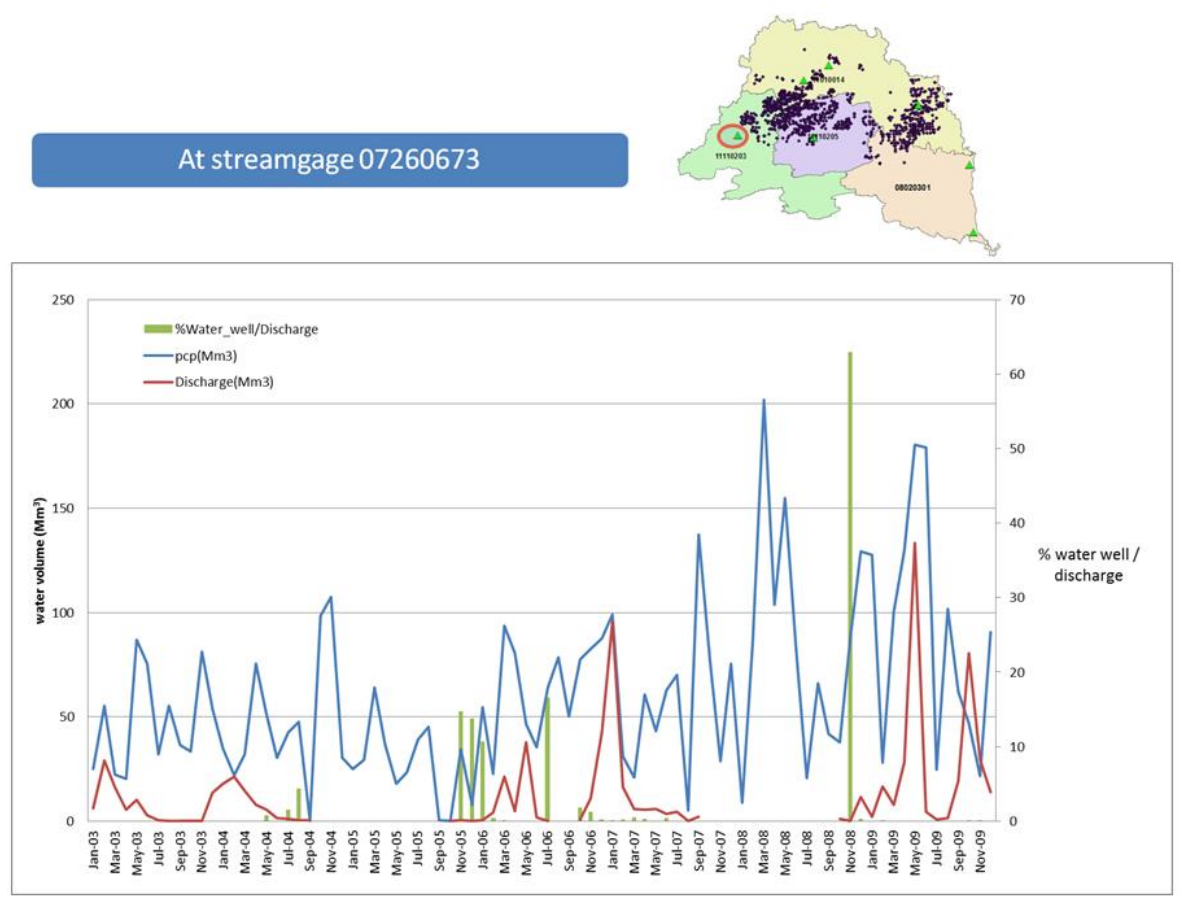

Figure 19. Mean monthly discharge and mean monthly water used for hydraulic fracturing as percentage of discharge for the stream gage station 07260673 (West Fork Point Remove Creek near Hattieville). 


\subsubsection{INDICATORS OF HYDROLOGIC ALTERATION (IHA) AND WELLS}

In order to observe potential impact of natural gas wells and associated fracturing operations to the river ecosystem and more specifically to the environmental components of the flow, the discharge was separated into different types using the IHA method. The IHA calculates parameters for five different types of Environment Flow Components (EFCs): low flows, extreme low flows, high flow pulses, small floods, and large floods. This distinction is based on the realization that flow regime patterns are ecologically relevant. The full spectrum of flow conditions represented by these five types of flow events must be maintained in order to sustain riverine ecological integrity. In addition, adequate flow during low flow periods, higher flows and floods, and extreme low flow conditions perform important ecological functions. Low flows are the dominant condition in most rivers. In natural rivers, after a rainfall event or snowmelt period has passed and associated surface runoff from the catchment has subsided, the river returns to its base- or low-flow level. These low-flow levels are sustained by groundwater discharge into the river. The seasonally-varying low-flow levels in a river impose a fundamental constraint on a river's aquatic communities because it determines the amount of aquatic habitat available for most of the year. In this early evaluation the daily discharge simulated at the outlet of the USGS 12-digit watersheds after the previous initial calibration was analyzed. Figure 21 shows the resulting flow duration curve at Cove Creek-Cadron Creek (111102050106 - Figure 20a) in the period from 1980 to 2009. Flows over the value at $75 \%$ daily exceedance $(5 \mathrm{m3} / \mathrm{s})$ are here considered as high flow and the others are considered as low flows. An extreme low flow is here considered a flow below the $10 \%$ value (over $15 \mathrm{~m} 3 / \mathrm{s}$ ).

a)

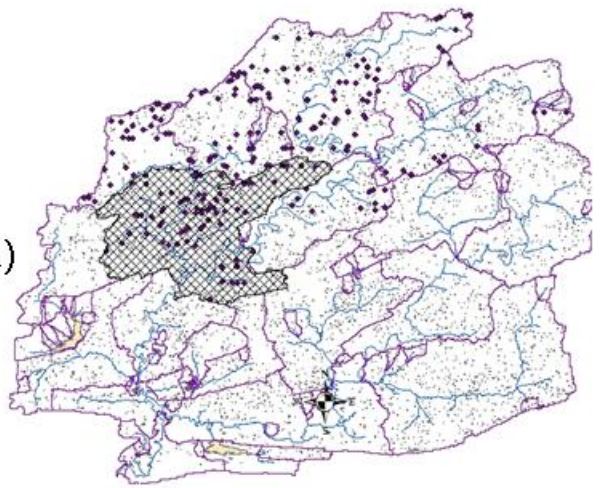

b)

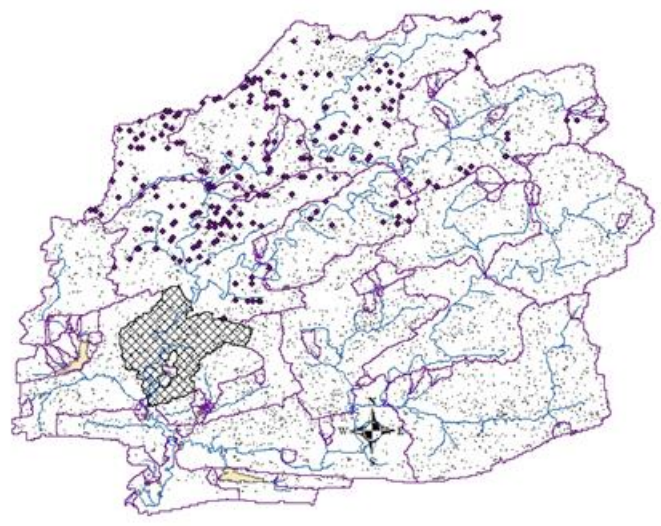

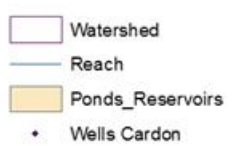

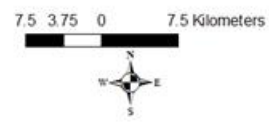

- Wells Cardon

Figure 20. a) Cove Creek-Cadron Creek (111102050106) and b) Jacks Fork-Upper Cadron Creek (111102050107) 12-digit watersheds. 


\section{Flow Duration Curve}

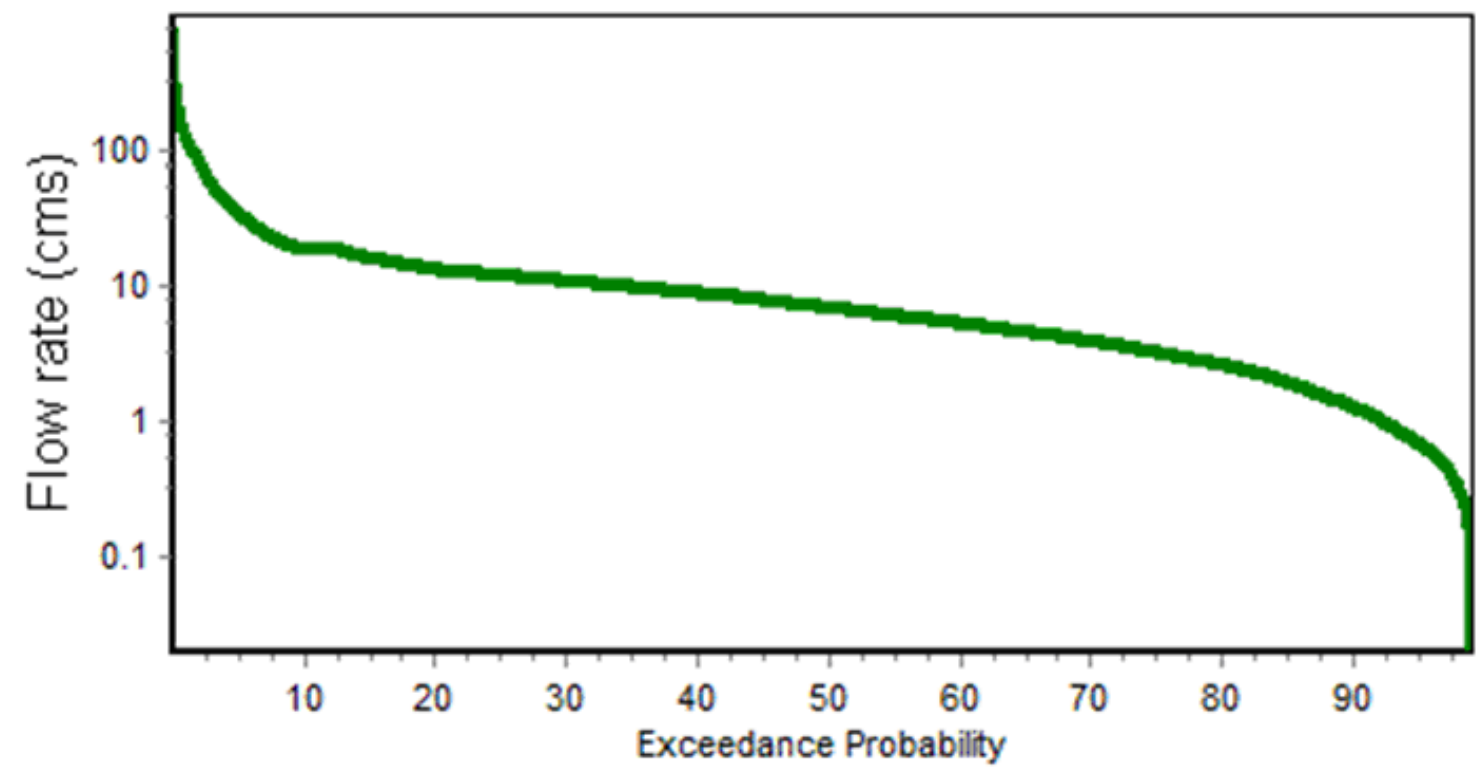

Figure 21. Flow duration curve from SWAT model simulation at Cove Creek-Cadron (1980-2009).

These thresholds were then considered variable month to month and season to season. Monthly flow duration curves were derived for each 12-digit watershed in this area. Figure 22 depicts the monthly grouped flow duration curves at Cove Creek-Cadron Creek (111102050106 - Figure 20a) and Jacks ForkUpper Cadron Creek (111102050107 - Figure 20b). In both sub-watersheds, the low flow threshold ranges from 1 to $5 \mathrm{~m} 3 / \mathrm{s}$ during the summer period (July-September), from 6 to $12 \mathrm{~m} 3 / \mathrm{s}$ during spring (April-June), and from 10 to 25 during for the rest of the year.

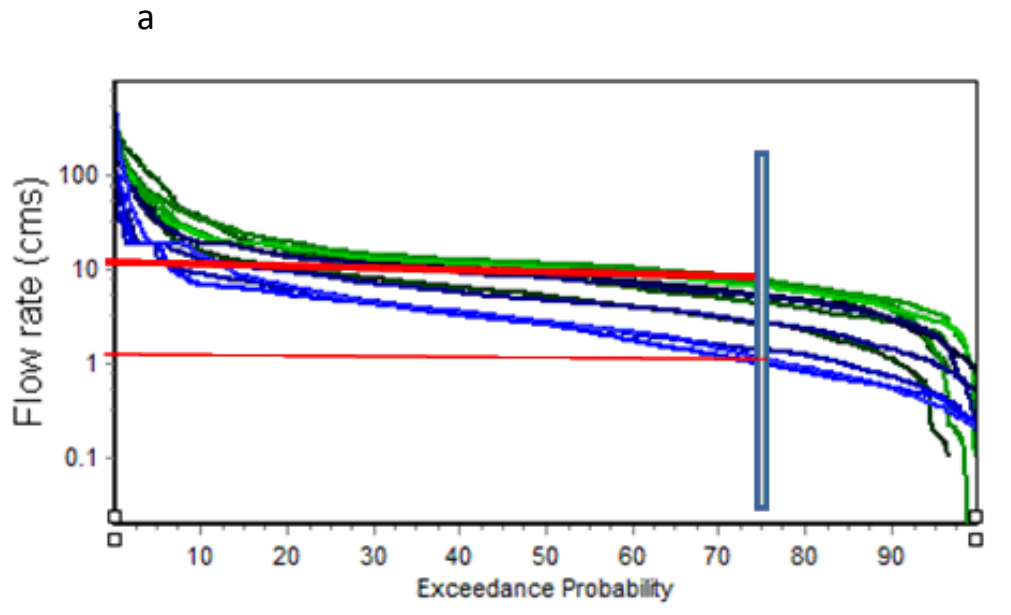

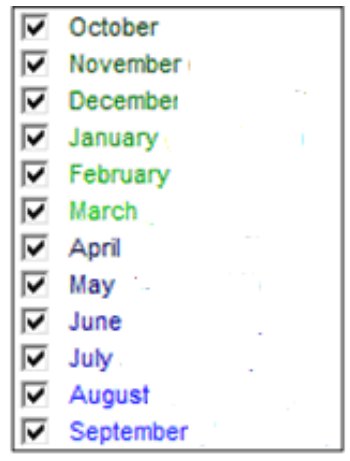


b

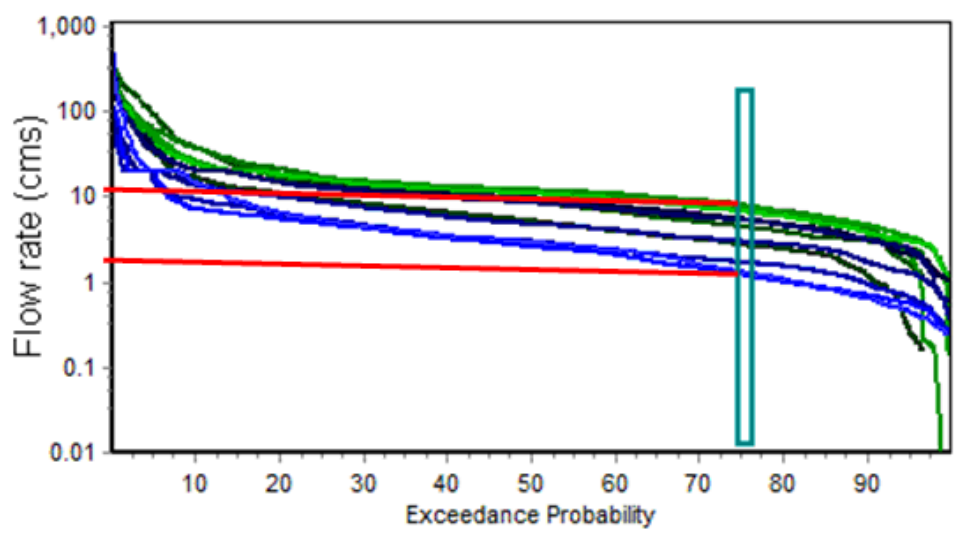

$\sqrt{\square}$ October

$\checkmark$ November

$\sqrt{\checkmark}$ December

$\sqrt{\checkmark}$ January

$\sqrt{\checkmark}$ February

I March

$\sqrt{\checkmark}$ April

ॠ May

$\sqrt{ }$ June

$\sqrt{\checkmark}$ July

$\sqrt{\checkmark}$ August

$\checkmark$ September

Figure 22. : Monthly grouped flow duration curve at a) Cove Creek-Cadron Creek and b) Jacks Fork-Upper Cadron Creek.

Figure 23 shows the five flow components (Environment Flow Components, EFCs) mentioned above as simulated on the daily time step by SWAT and grouped on monthly basis during the period (1980-2009) at the Cove Creek-Cadron station. These areas seem to be characterized by small floods and high flow pulses. Figure 24 and 25 graph the low end extreme low flows and show that previously identified thresholds are not maintained just for a few days.

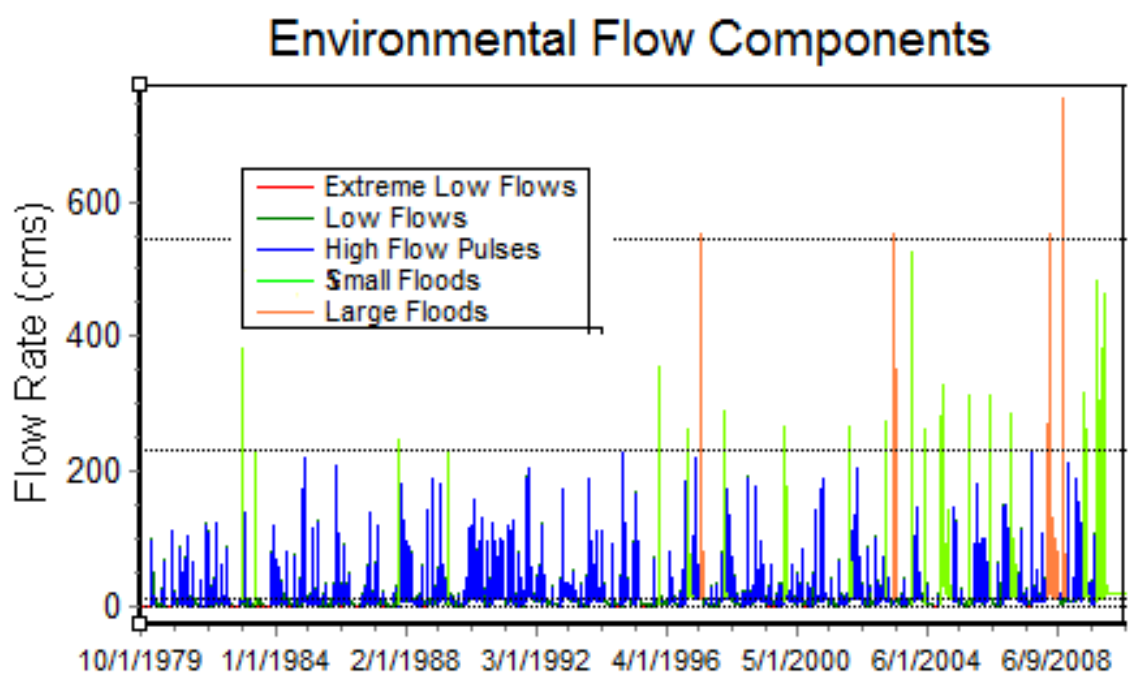

Figure 23. Environmental Flow Components (EFCS) simulated at Cove Creek-Cadron Creek (1980-2009). 


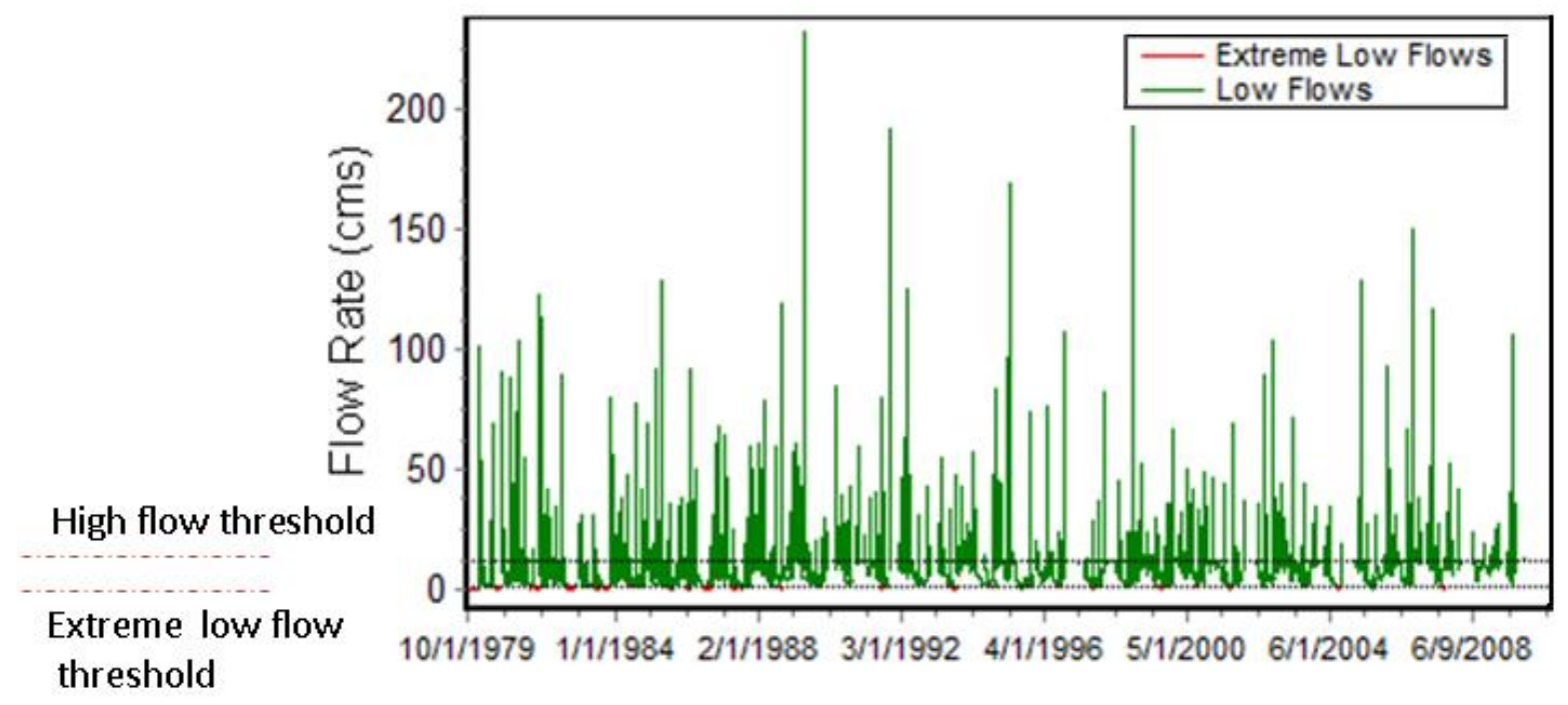

Figure 24. Extreme and low flows simulated at daily time steps at Cove Creek-Cadron Creek (1980-2009). Extreme low flow threshold identified on monthly values is highlighted.

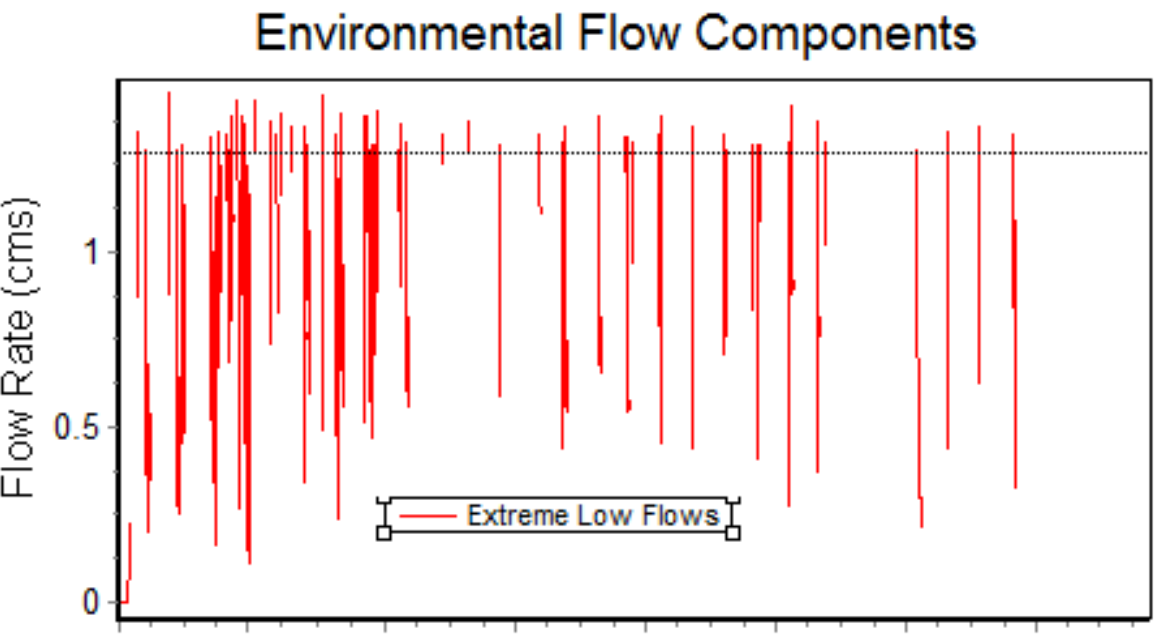

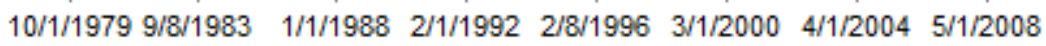

Figure 25: Extreme low flows simulated at daily time steps at Cove Creek-Cadron Creek (1980-2009).

The Cove Creek-Cadron Creek sub-watershed presents the highest density of wells in the area. An extreme scenario with SWAT model simulation was generated by considering 7 Million gallons per well as the amount of water withdrawn for each well (150 total) hydraulic fracturing, which was assumed happening lumped in the same month. The same scenario was repeated for each month of the period November 2004-December 2009. Figure 26 plots the monthly discharge, the monthly low flow and the percentage of water discharge that would be used for the hydraulic fracturing with this scenario. The 
results show that the percentage of used monthly discharge would range from $1 \%$ to more than $100 \%$, with major frequency in summer periods, and that low flow condition are reached several times.

For low flow conditions the graph in Figure 27 illustrates the percentage of water withdrawn as percentage of monthly low flow discharge. High percentages from 15 to 70.5 of the flow discharged in low flow conditions are noticeable. This analysis showed the potential of SWAT modeling in detecting situations of critical low flows. Critical low flows might have damaging effects to the river and the aquatic communities, such as their diversity and number of organisms suitable to live in the river.

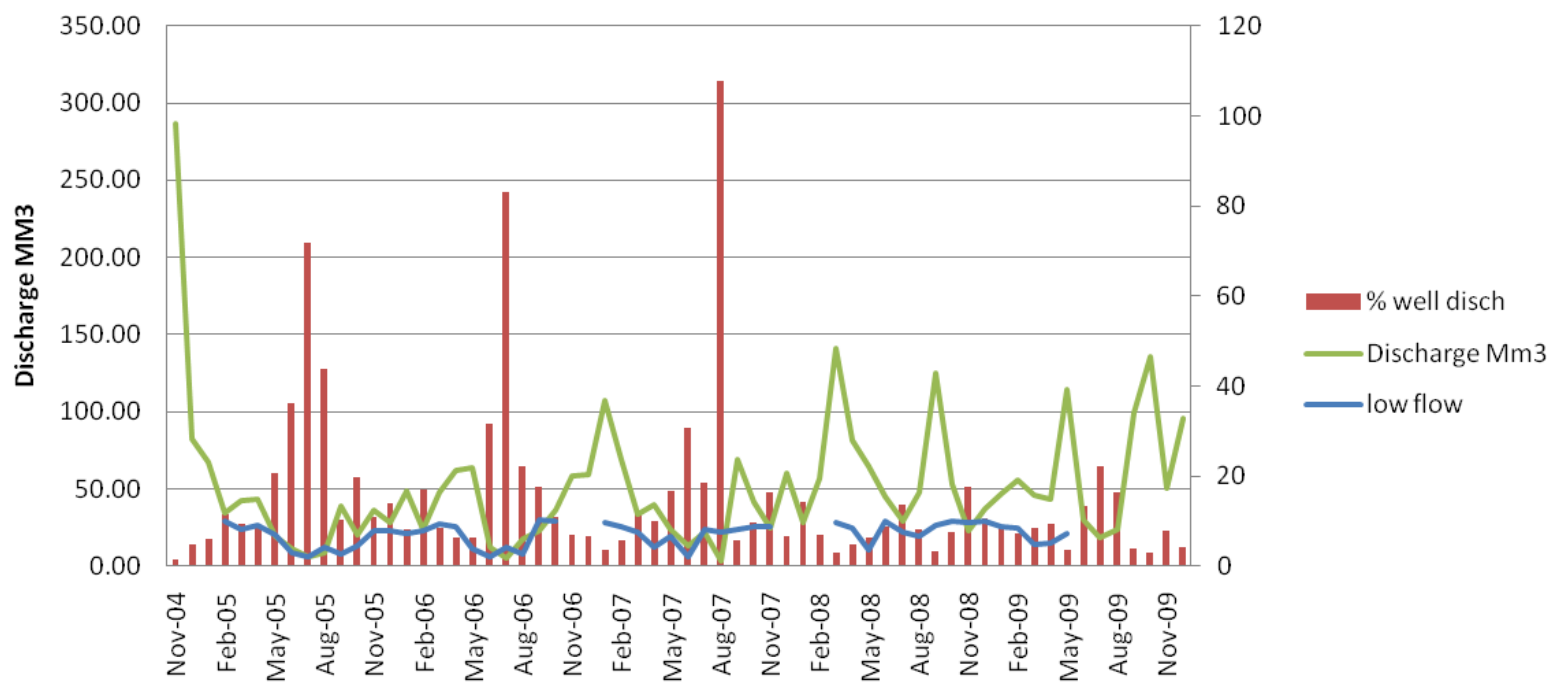

Figure 26: Monthly low flow discharge, monthly discharge and monthly water used for hydraulic fracturing as percentage of discharge for the simulated location at Cove Creek-Cadron Creek. 


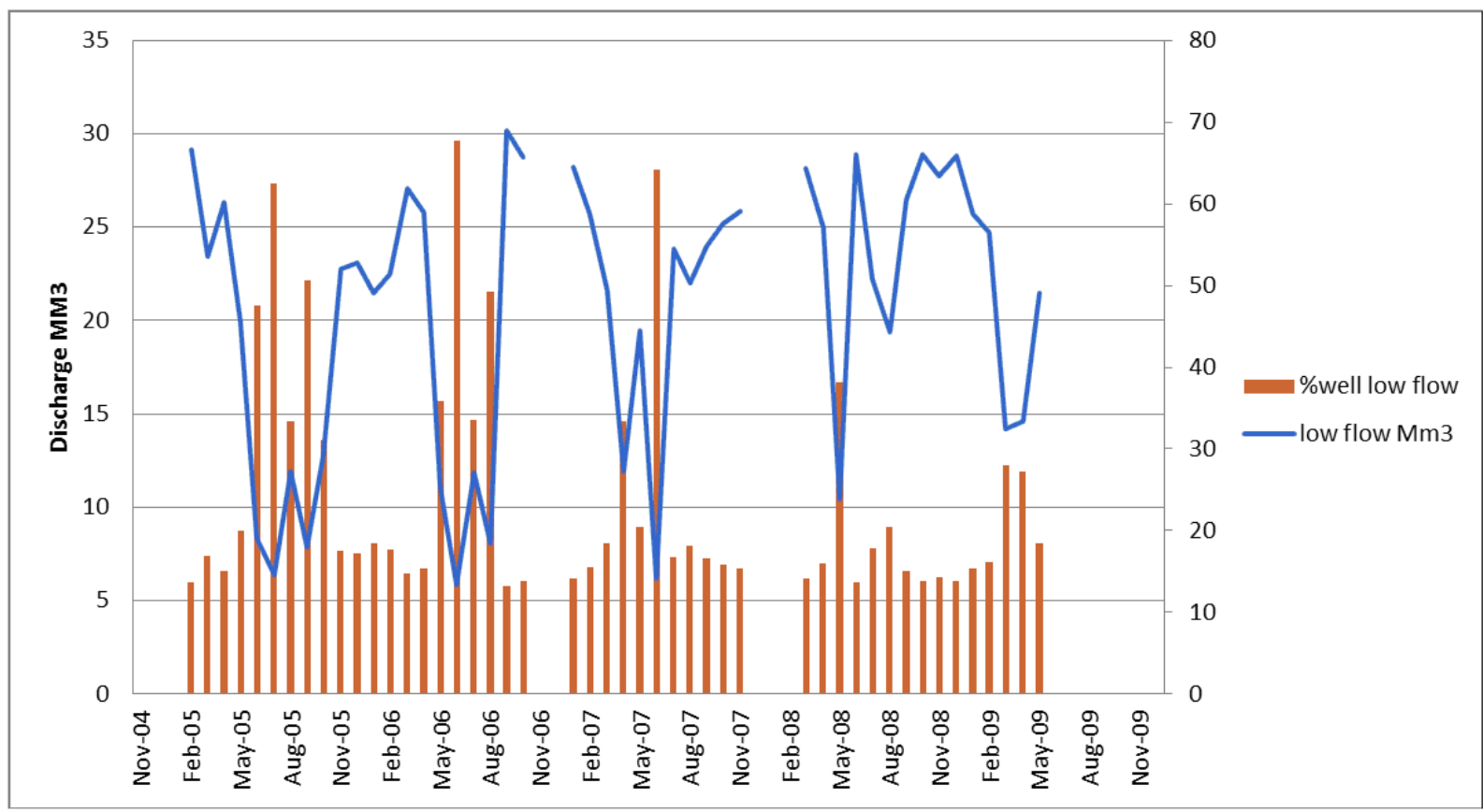

Figure 27: Monthly low flow discharge and monthly water used for hydraulic fracturing as percentage of low flow discharge for the simulated location at Cove Creek-Cadron Creek.

\subsubsection{SWAT CALIBRATION AND VALIDATION}

While it is clear and well documented that natural gas production requires only a very small percentage $(<0.1 \%)$ of the total surface water use in the Fayetteville Shale Play, It is nevertheless possible that hydraulic fracture could locally create critical levels of water discharge due. In fact, while in the near future the total number of wells is expected to grow, each well requires between 3 and 7 million gallons of water for hydraulic fracturing. This usage combined with drinking and farming needs, poses water resource management concerns. Within this context the objective of this study is to assess the impact of the hydraulic fracturing on the water balance at as fine a scale as possible given the instrumentation in place and the available modeling techniques. For this purpose, the Soil Water Assessment Tool (SWAT) model has been applied in the Fayetteville Shale area located in Central Arkansas. Figure 1 summarizes the study area with the location and number of wells in each of the watersheds. 


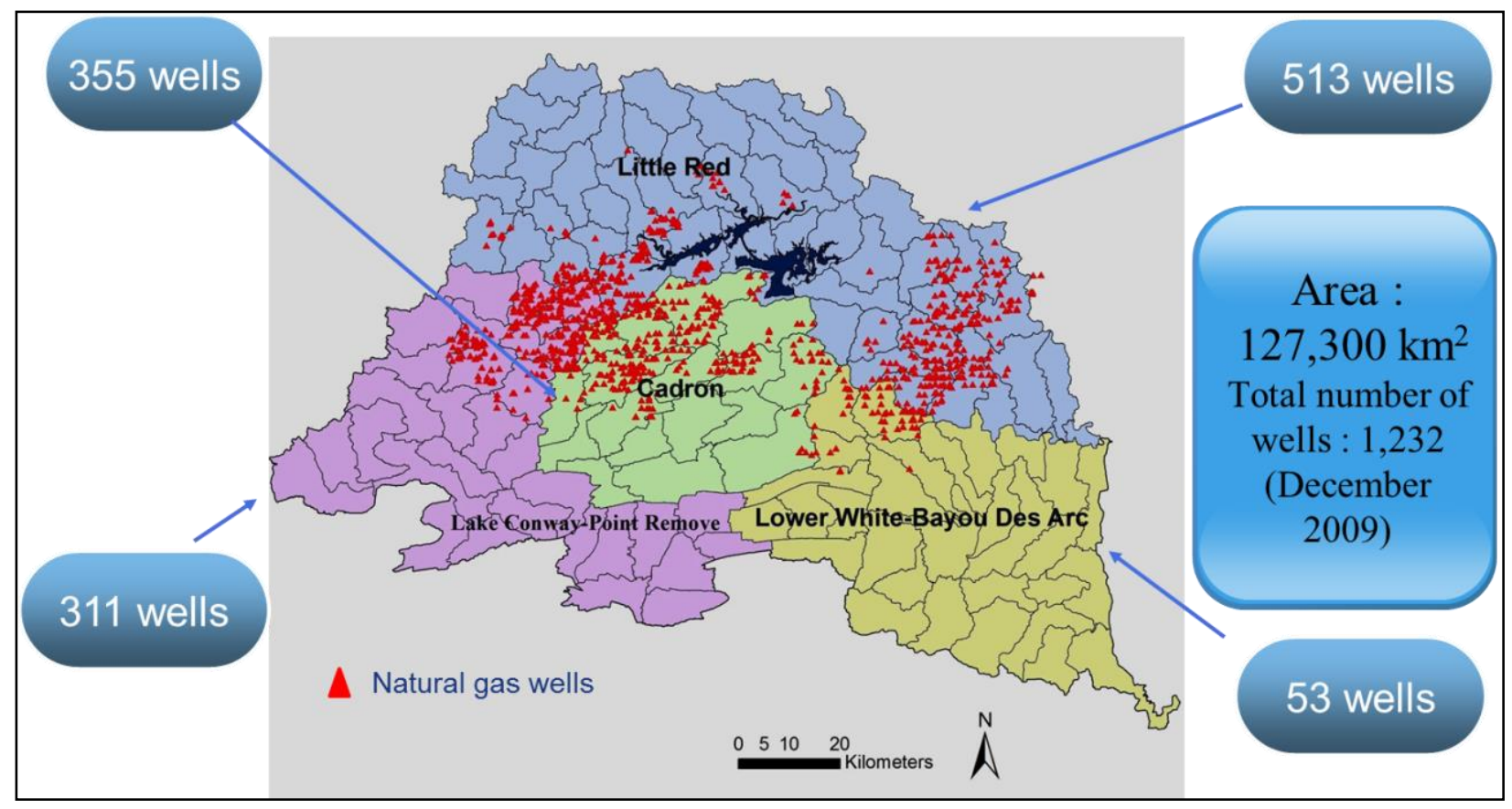

Figure 28: Fayetteville Shale, Arkansas.

The hydrologic calibration procedure was carried out using daily discharge flow data at different USGS stream gages located within the region (Figure 28). The calibration for the water balance and stream flow was initially performed for average annual condition. Some parameters (such as curve number, available water capacity, and threshold depth of water in the shallow aquifer for water moving into the soil zones), were adjusted manually to reach the best match between measured surface and base flow and the predicted values by the model during the period 2002-2009. 


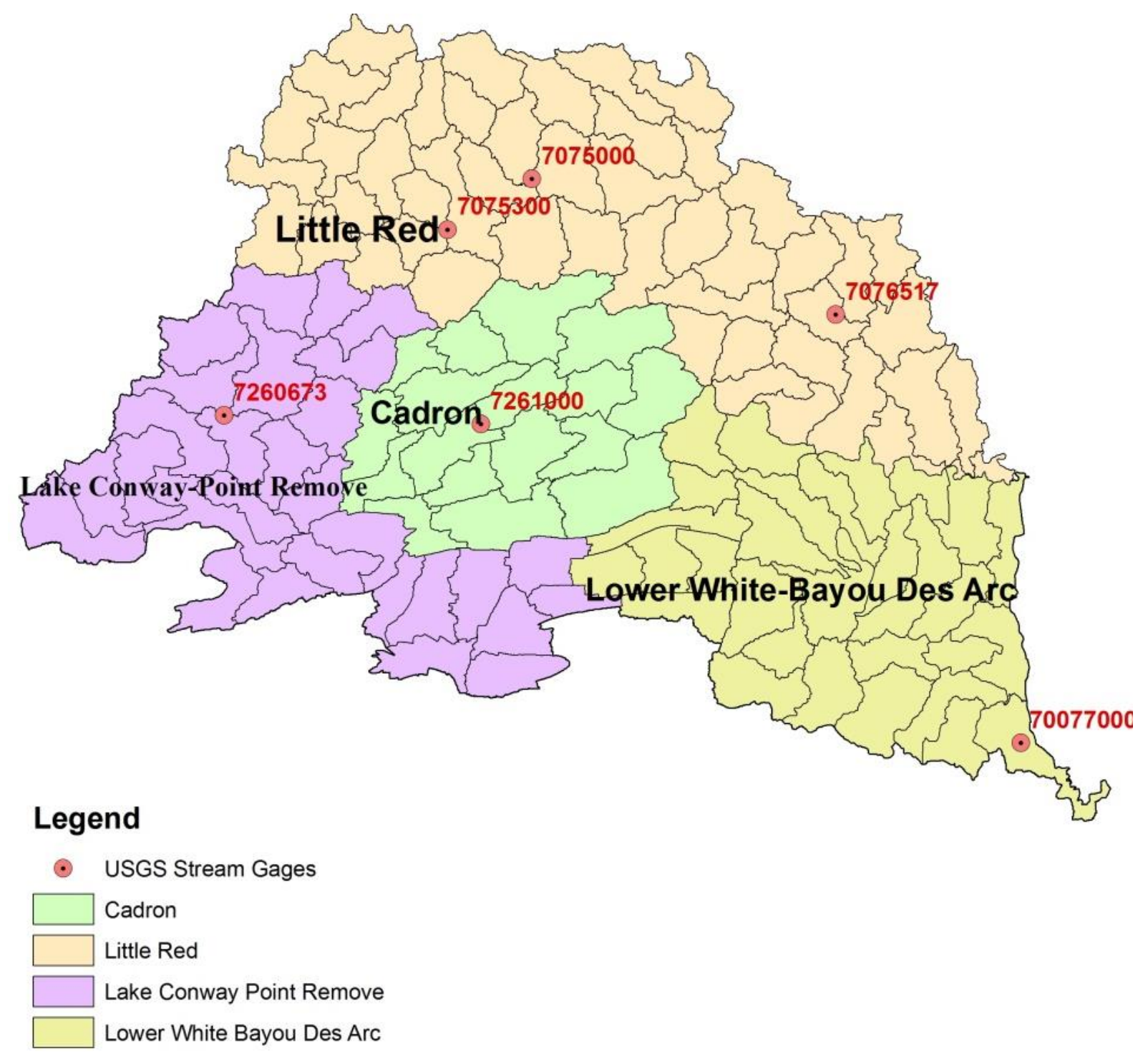

Figure 29: Location of the USGS stream gages in the Fayetteville shale area.

A deeper calibration was applied again manually and then automatically using daily discharge records for the period 2002-2007. The automatic calibration was based on the application of an optimization procedure, which generates optimum parameters for each hydrologic Response Unit (HRU). This procedure is accomplished in a succession of runs. Each run uses a specific combination of model parameters. These runs were repeated several times ( 3000 times) until satisfactory calibration results were obtained. The optimum parameter set was used to validate the model off the calibration period (2008-2009).

The model performance was evaluated using two statistical indicators such as the coefficient of determination $\left(R^{2}\right)$ and the Nash-Sutcliffe model efficiency (NSE) (Nash et al., 1970). The calibration and validation results for the six (6) stream discharge gages are reported in Table 5. 
Table 5. Calibration and validation results.

\begin{tabular}{|c|c|c|c|c|c|c|c|}
\hline \multirow{2}{*}{$\begin{array}{l}\text { Watershed } \\
\text { name }\end{array}$} & \multirow{2}{*}{$\begin{array}{l}\text { USGS } \\
\text { Station ID }\end{array}$} & \multirow{2}{*}{$\begin{array}{l}\text { Calibration } \\
\text { period }\end{array}$} & \multicolumn{2}{|c|}{ Calibration } & \multirow{2}{*}{$\begin{array}{l}\text { Validation } \\
\text { period }\end{array}$} & \multicolumn{2}{|c|}{ Validation } \\
\hline & & & $\begin{array}{l}\text { Nash } \\
\text { Sutcliffe }\end{array}$ & $\mathbf{R}^{2}$ & & $\begin{array}{l}\text { Nash } \\
\text { Sutcliffe }\end{array}$ & $\mathbf{R}^{2}$ \\
\hline \multirow{3}{*}{$\begin{array}{l}\text { Little Red } \\
\text { watershed }\end{array}$} & 07075300 & $2002-2006$ & 0.56 & 0.57 & 2007-2009 & 0.61 & 0.67 \\
\hline & 07075000 & $2006-2008$ & 0.72 & 075 & 2009 & 0.45 & 0.5 \\
\hline & 07076517 & $2002-2007$ & 0.78 & 0.78 & 2008-2009 & 0.77 & 0.79 \\
\hline $\begin{array}{l}\text { Lower } \\
\text { White } \\
\text { Bayou Des } \\
\text { Arcs }\end{array}$ & 07077000 & 2001-2004 & 0.22 & 0.42 & $2005-2008$ & 0.14 & 0.31 \\
\hline Cadron & 07261000 & $2002-2006$ & 0.42 & 0.5 & $2007-2009$ & 0.62 & 0.71 \\
\hline $\begin{array}{l}\text { Lake } \\
\text { Conway } \\
\text { Point } \\
\text { Remove }\end{array}$ & 07260673 & $2005-2008$ & 0.21 & 0.29 & 2009 & 0.26 & 0.34 \\
\hline
\end{tabular}

The model performance was very good for 3 stream gages (Station ID: 07075300, 07075000, 07076517) located on the Little Red watershed. This is mainly due to the availability of daily water release data at the Greer's Ferry Dam. Reservoir data are not comprehensive in the other watersheds. Figures 30 and 31 show the calibration and validation results at the stream gage (ID 07076517) located downstream the Little Red watershed. 


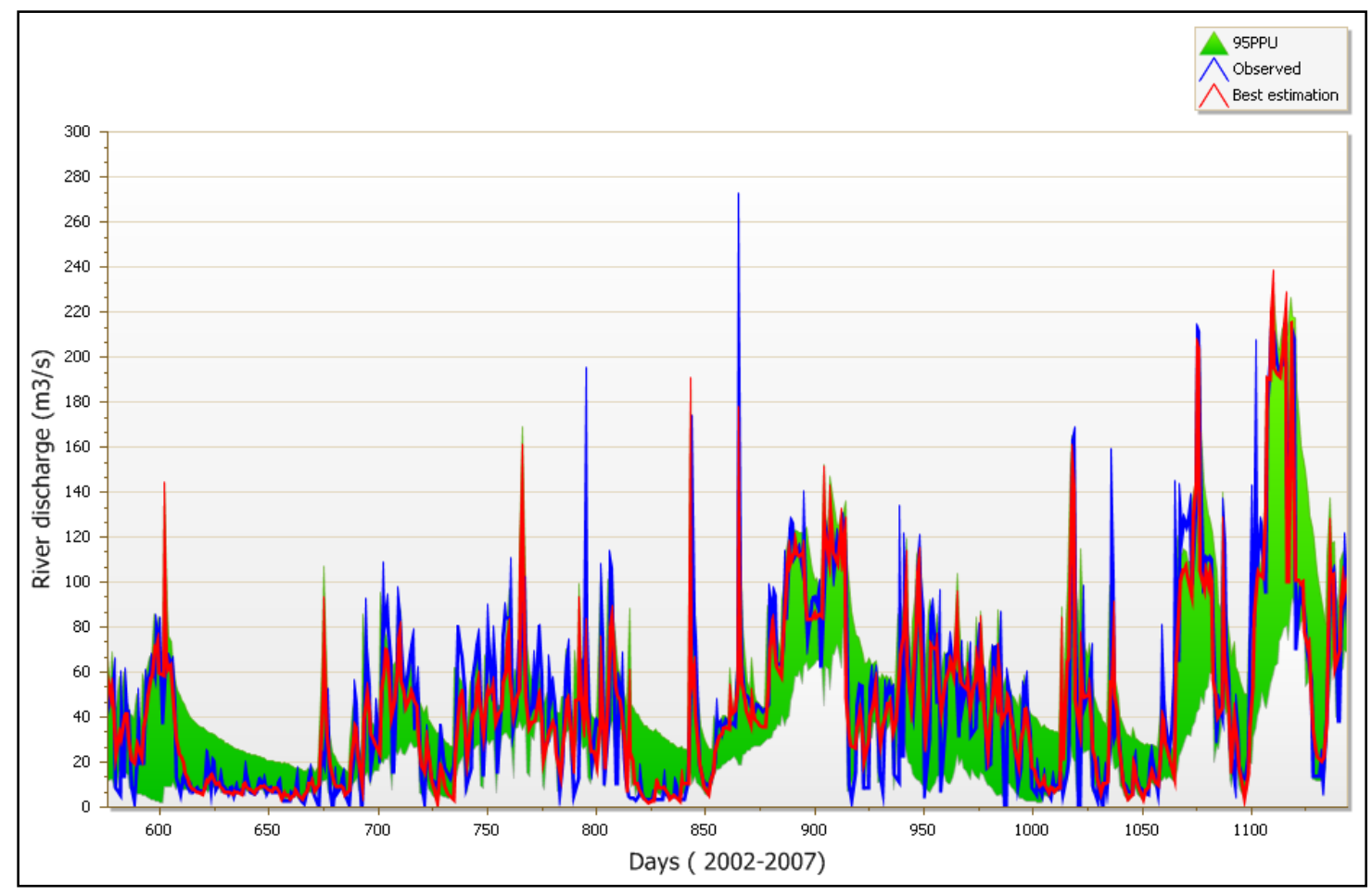

Figure 30: Calibration in the Little Red watershed at the stream gage ID 07076517 during the period (2002-2007).

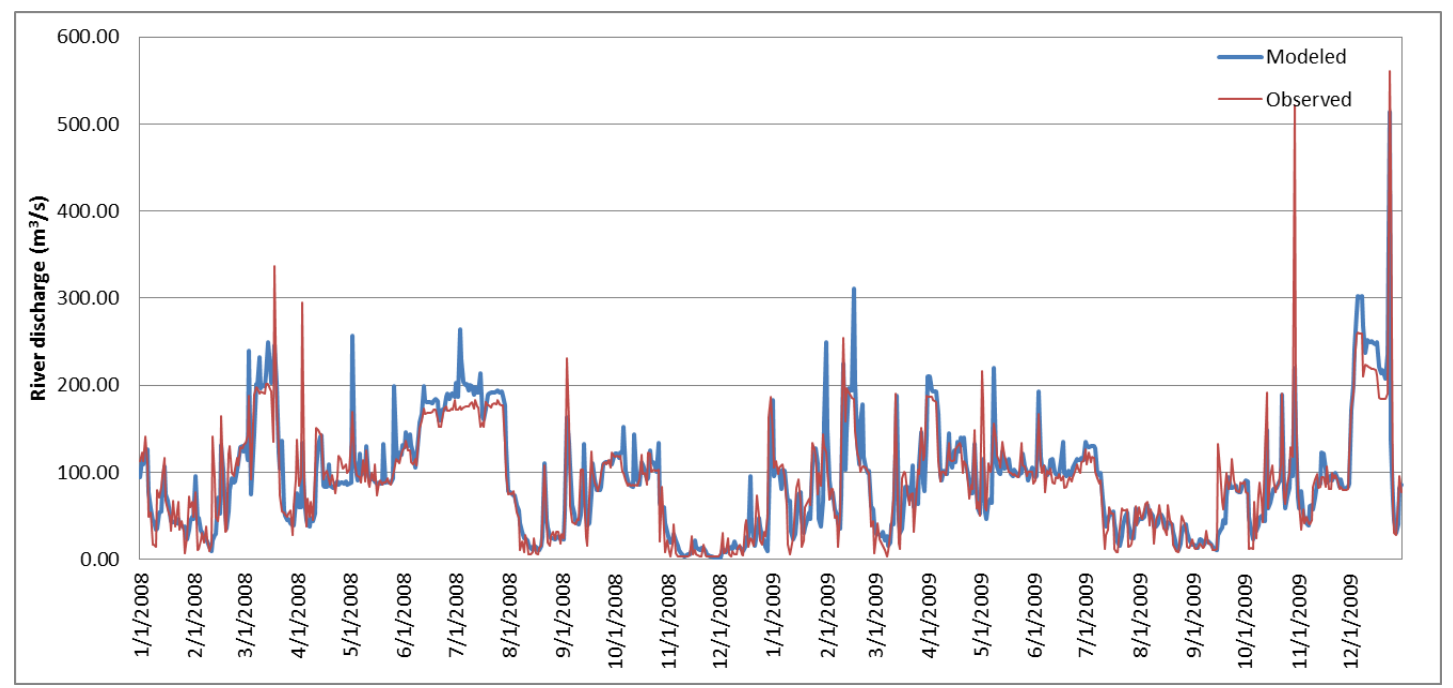

Figure 31: Validation Calibration in the Little Red watershed at the stream gage ID 07076517 during the period (2008-2009).

In the remainder of this report the analysis will be focused on the Little Red watershed. A total of three stream gages are located within it, which includes the largest portion of wells (513) of the region. 


\subsubsection{IMPACT OF HYDRAULIC FRACTURING ON WATER BALANCE}

The annual impact of hydraulic fracturing on the water balance was evaluated at the stream gage 07075300 and the year 2008 (Figure 32). Based on the available data (Arkansas Oil and Gas Commission), during 2008, fifty (50) wells were drilled upstream of this station. Assuming 5 million gallons (MG) as the water quantity required to fracture each well represents only $0.17 \%$ of the respective annual stream discharge. The impact is apparently not critical at this temporal and spatial scale. A further analysis was operated at lower scale with the following simulation scenario.

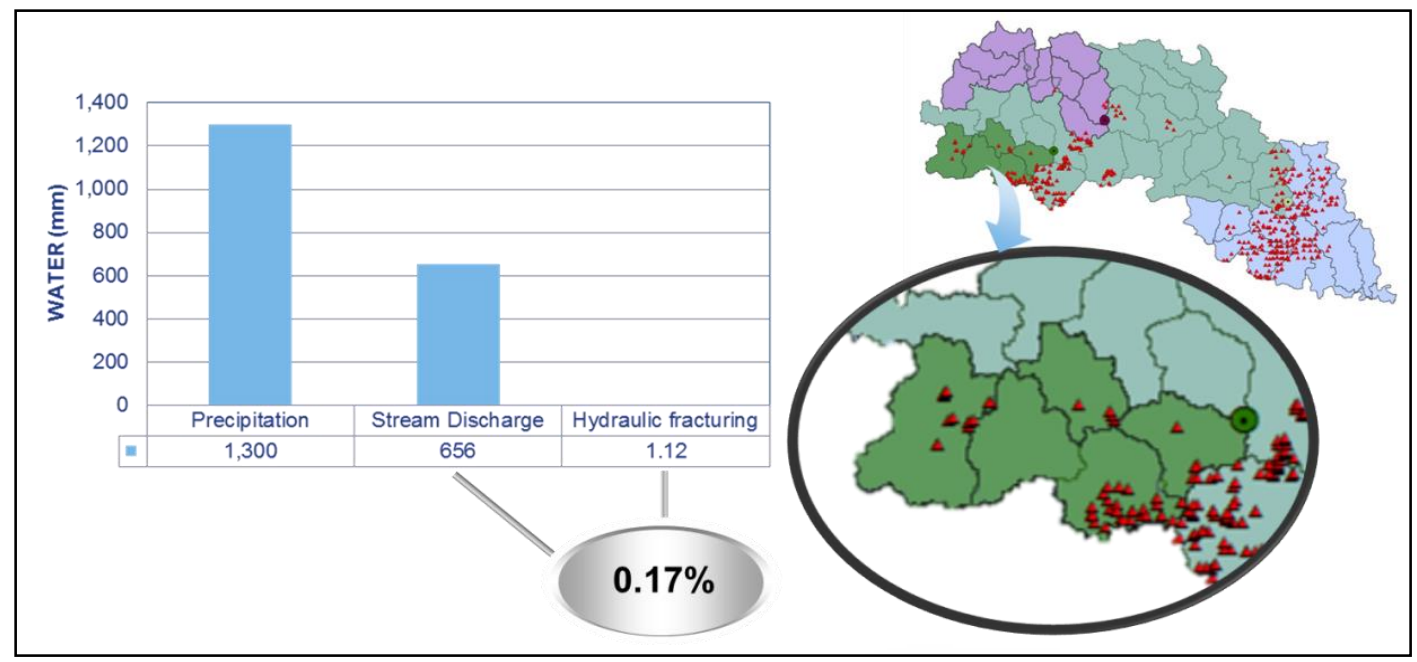

Figure 32: Impact of hydraulic fracturing at large scale using measured stream discharge data.

\subsubsection{SCENARIO ANALYSIS}

A scenario was generated based on:

a) Quantity: 5 MG of water withdrawn for each well.

b) Water Source: among the options (stream, reservoir, ponds, lake, or impoundment created by producer), it was assumed that water was withdrawn from the closest stream reach (least favorable scenario).

c) Time distribution: the hydraulic fracturing occurs in different stages. An average of 5 months is noted between the SPUD date (the date selected by the Arkansas Oil and Gas Commission as the date on which the ground was first penetrated for the purposes of drilling the well.) and the first production date. During these months the hydraulic fracturing takes place. It was assumed that 1 MG of water was uniformly withdrawn during 5 consecutive months.

Figures 33 and 34 summarize these assumptions. 


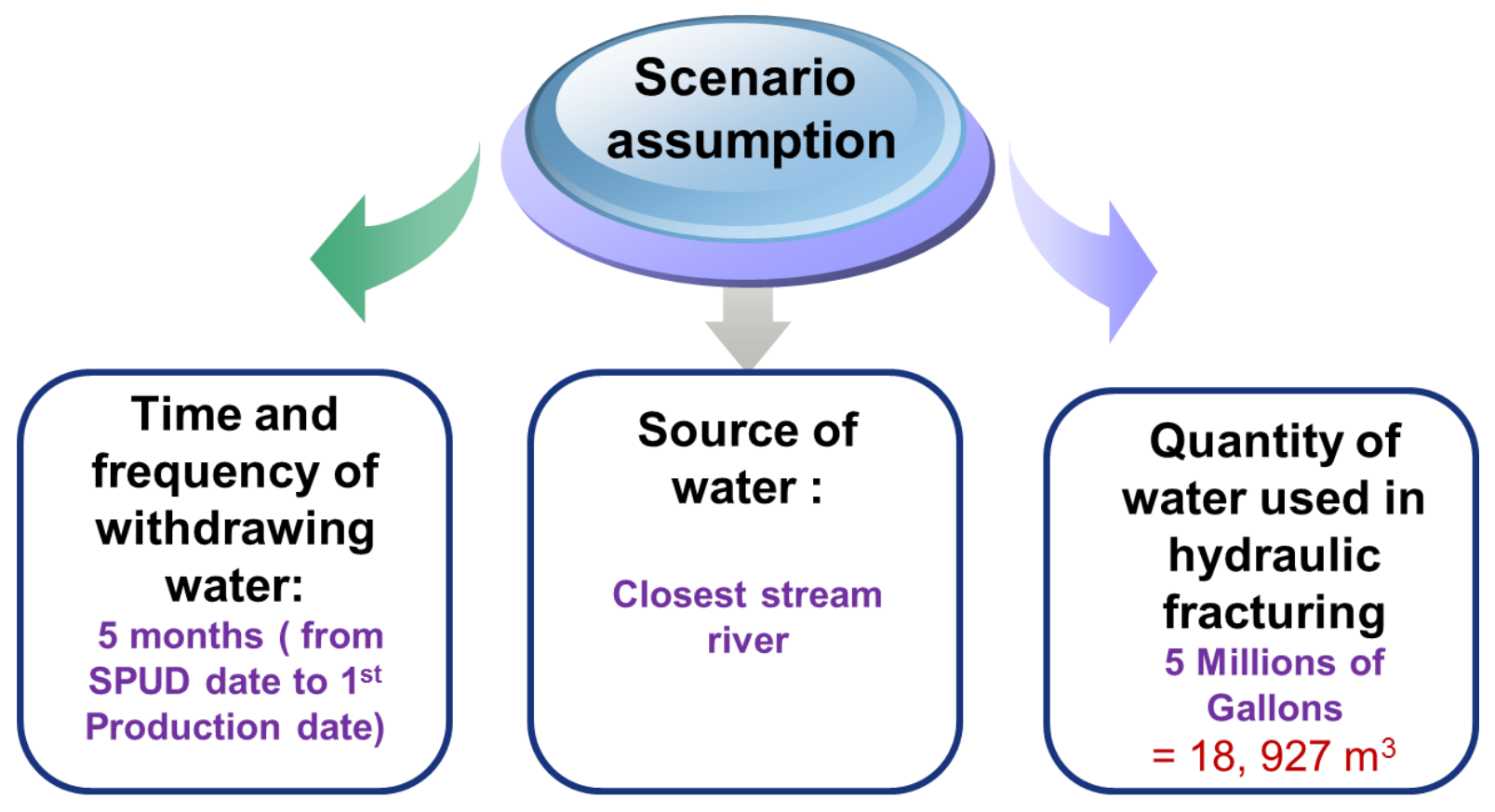

Figure 33: Hydraulic fracturing scenario assumptions.

For each natural gas well

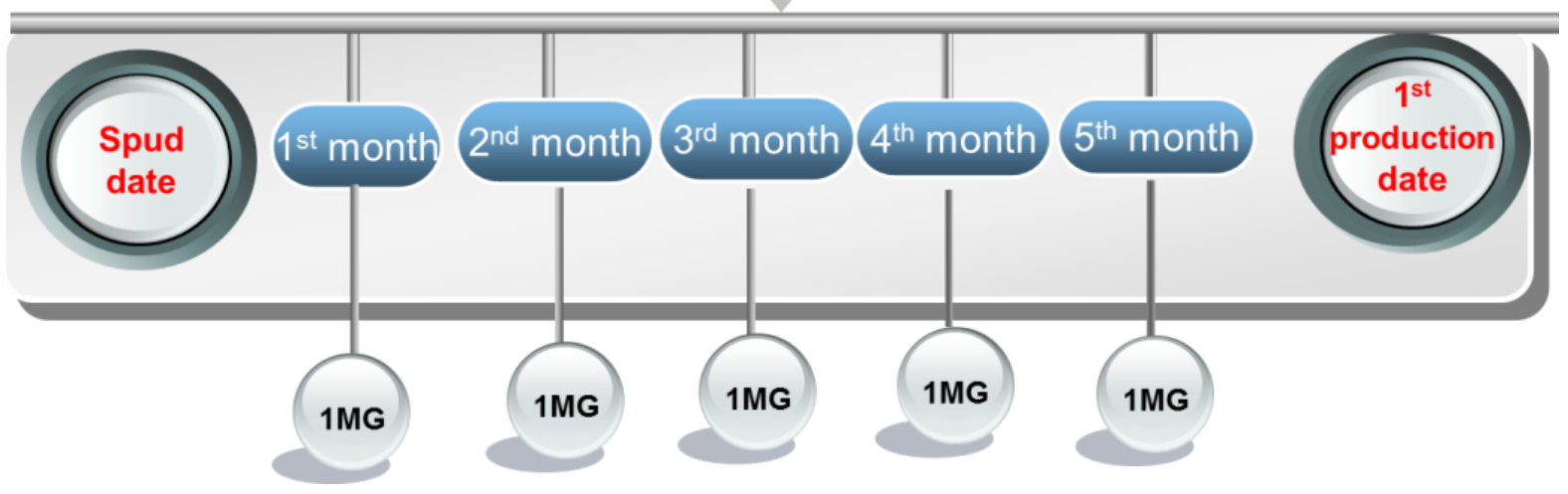

Figure 34: Hydraulic fracturing scenario: time and frequency of water withdrawn. 


\subsubsection{SCENARIO RESULTS}

At a large scale, no difference is noted comparing the water balance components of the baseline (without withdrawing the water) and the generated scenario (with water withdrawn) (Figure 35).

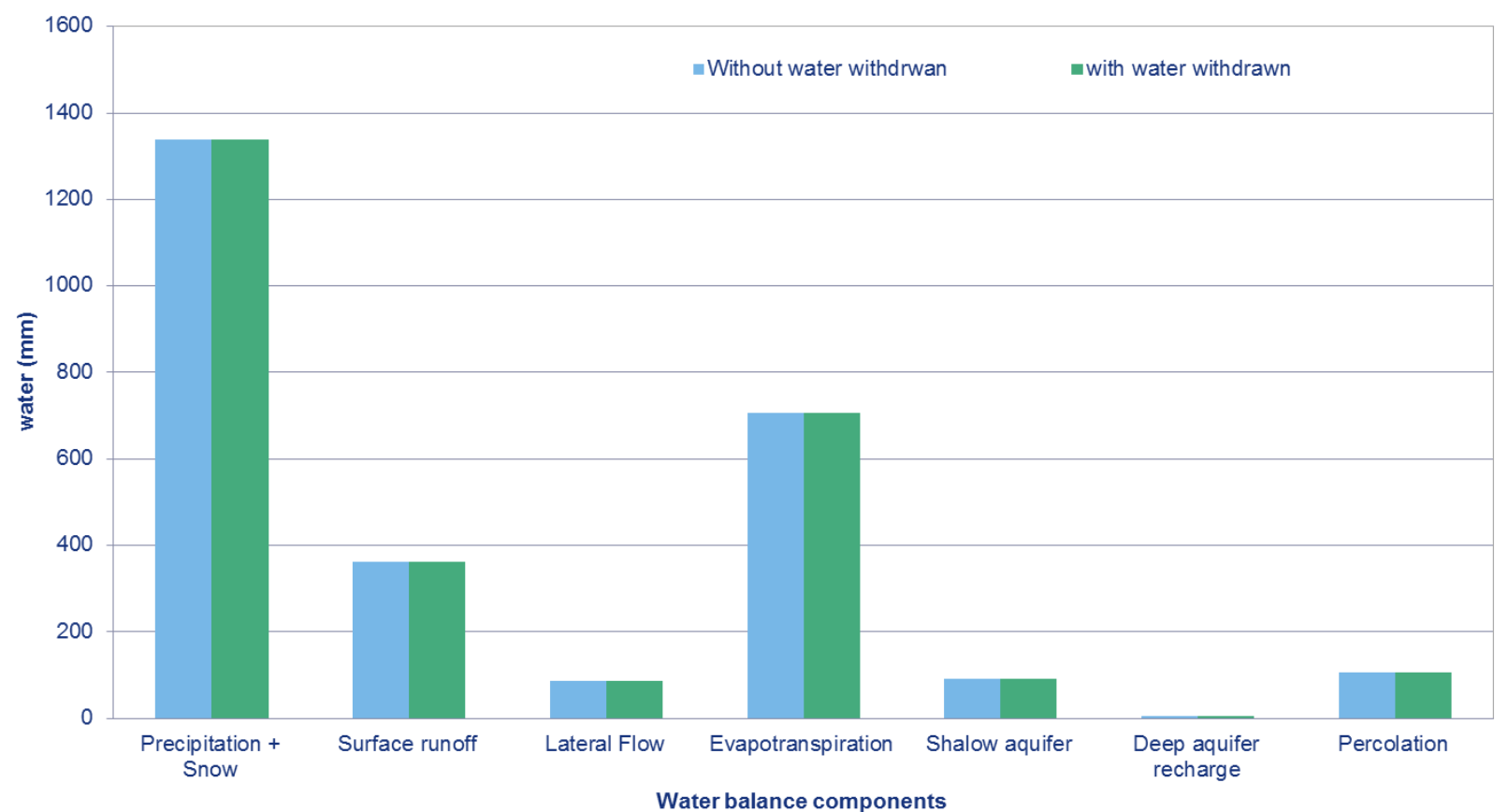

Figure 35: Water balance components for the baseline and the generated scenario.

\subsubsection{IMPACT OF HYDRAULIC FRACTURING ON FLOW ALTERATION}

The Indicators of Hydrologic Alteration (IHA) procedure developed by The Nature Conservancy (TNC) was applied to establish different types of Environment Flow Components (EFCs): low flows, extreme low flows, high flow. This delineation of EFCs is based on the realization by research ecologists that river hydrographs can be divided into a repeating set of hydrographic patterns that are ecologically relevant. It is the full spectrum of flow conditions represented by these three types of flow events that must be maintained in order to sustain riverine ecological integrity.

These EFCs components (Figure 36) are defined as follow:

- High flow: All flow that exceed $75 \%$ of daily flows of the period

- Low Flows: All flows between $75 \%$ and $90 \%$ of daily flows of the period

- Extreme low flow: All lows below $90 \%$ of daily flows of the period. 


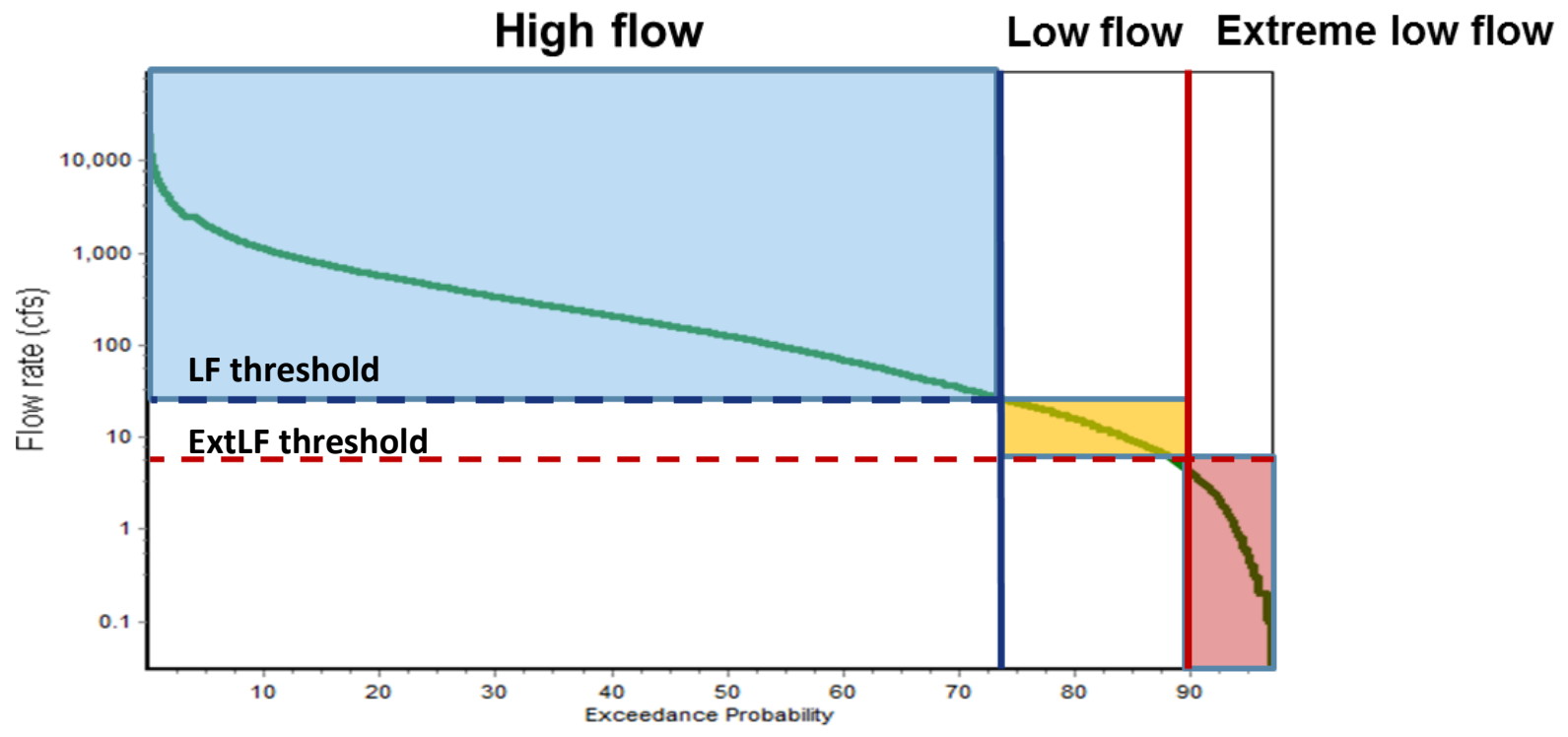

Figure 36: Flow duration curve: Environmental flow components and thresholds.

Low flows - This is the dominant flow condition in most rivers. In natural rivers, after a rainfall event or snowmelt period has passed and associated surface runoff from the catchment has subsided, the river returns to its base- or low-flow level. These low-flow levels are sustained by groundwater discharge into the river. The seasonally varying low-flow levels in a river impose a fundamental constraint on a river's aquatic communities because it determines the amount of aquatic habitat available for most of the year. This has a strong influence on the diversity and number of organisms that can live in the river.

Extreme low flows - During drought periods, rivers drop to very low levels that can be stressful for many organisms, but may provide necessary conditions for other species. Water chemistry, temperature, and dissolved oxygen availability can become highly stressful to many organisms during extreme low flows, to the point that these conditions can cause considerable mortality.

High-flow pulses - During rainstorms or brief periods of snowmelt, a river will rise above its low-flow level. As defined here, high-flow pulses include any water rises that do not overtop the channel banks. These pulses provide important and necessary disruptions in low flows. Even a small or brief flush of fresh water can provide much-needed relief from higher water temperatures or low oxygen conditions that typify low-flow periods, and deliver a nourishing subsidy of organic material or other food to support the aquatic food web. High-flow pulses also provide fish and other mobile creatures with increased access to up- and downstream areas.

The Environmental Flow Components were evaluated using the daily-simulated discharges obtained after calibration for each sub-basin of the study area. This allowed defining respective thresholds (Extreme Low Flow and Low Flow). Figure 37 shows the distribution of the low flow limits within the Little Red watershed. 


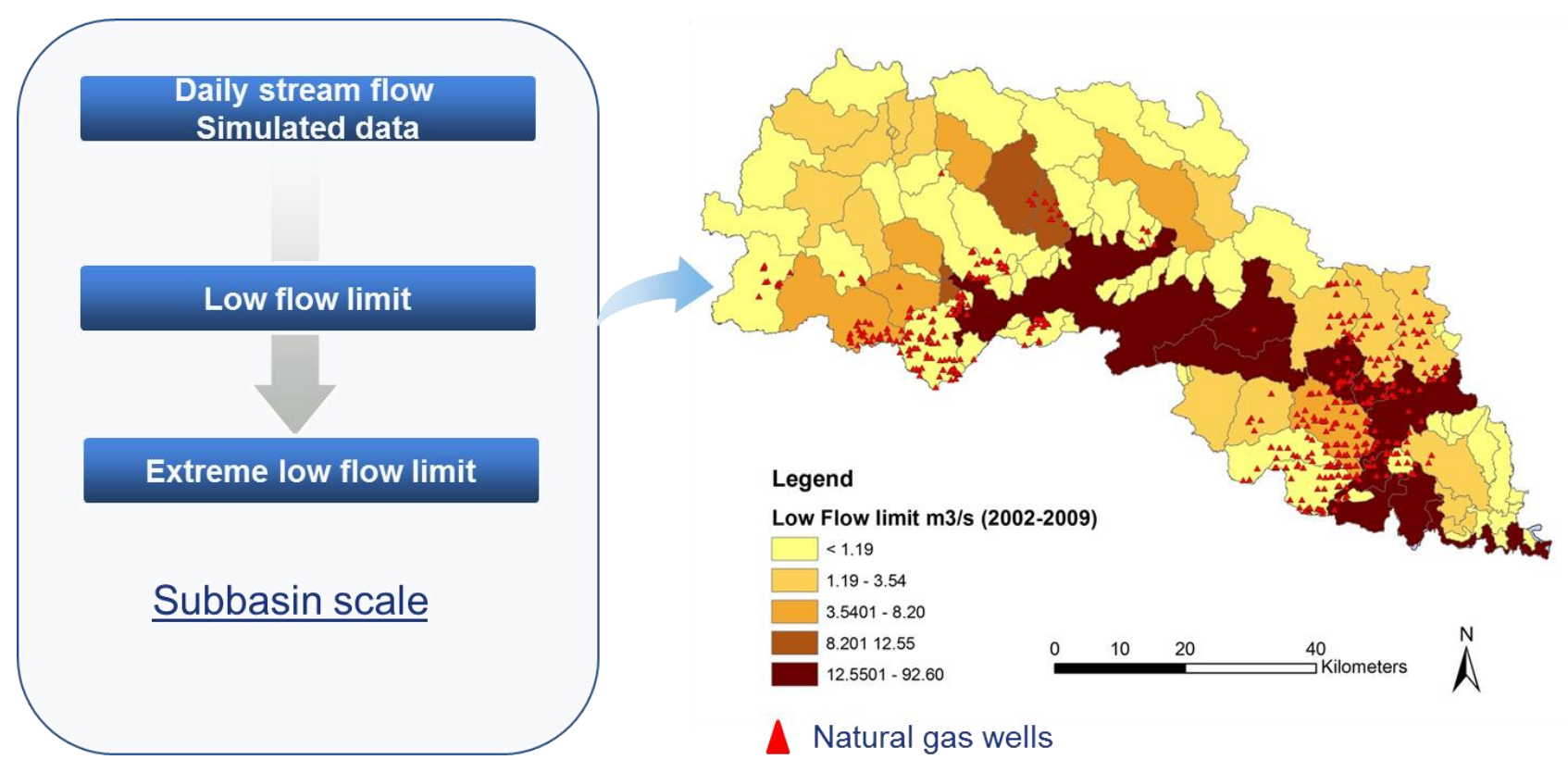

Figure 37: Low flow limits in the Little Red watershed.

\subsubsection{IMPACT OF HYDRAULIC FRACTURING AT SUBBASIN SCALE (12-DIGIT HUC)}

On the monthly time step and subbasin scale, the change of discharge is more significant. Figure 38 shows change in the stream discharge at one of the subbasins with a large number of wells located upstream. This change is notable during some periods of the year (November 2007 and January 2008) when the stream discharge decreases of $34 \%$ and $67 \%$ respectively (Figure 39). The decrease recorded on January 2008 led to an alteration of the flow from low flow condition to extreme low flow condition, which can cause a strong impact on the diversity and number of organisms that can live in the river. 


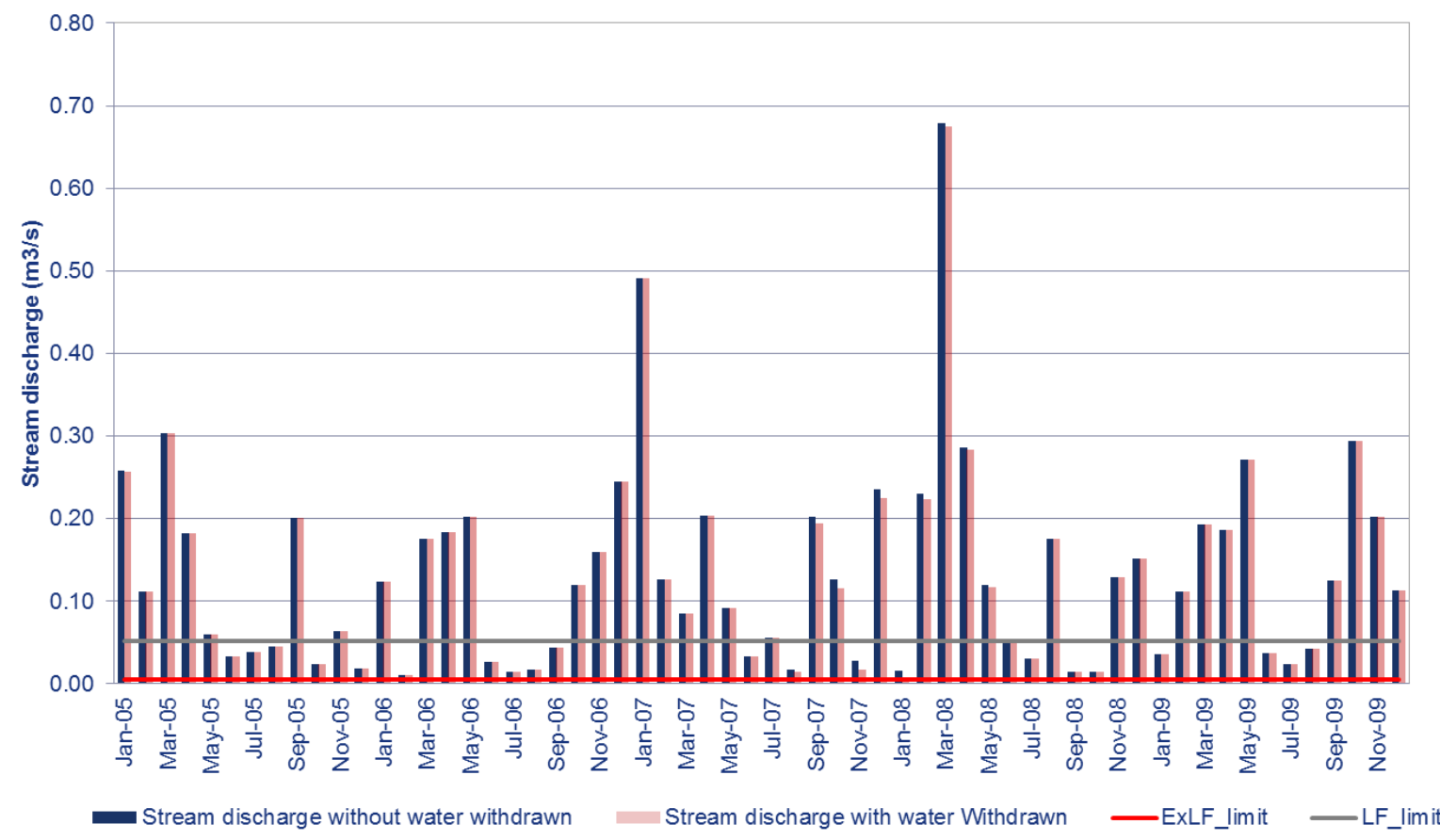

Figure 38: Impact of hydraulic fracturing on monthly stream discharge.
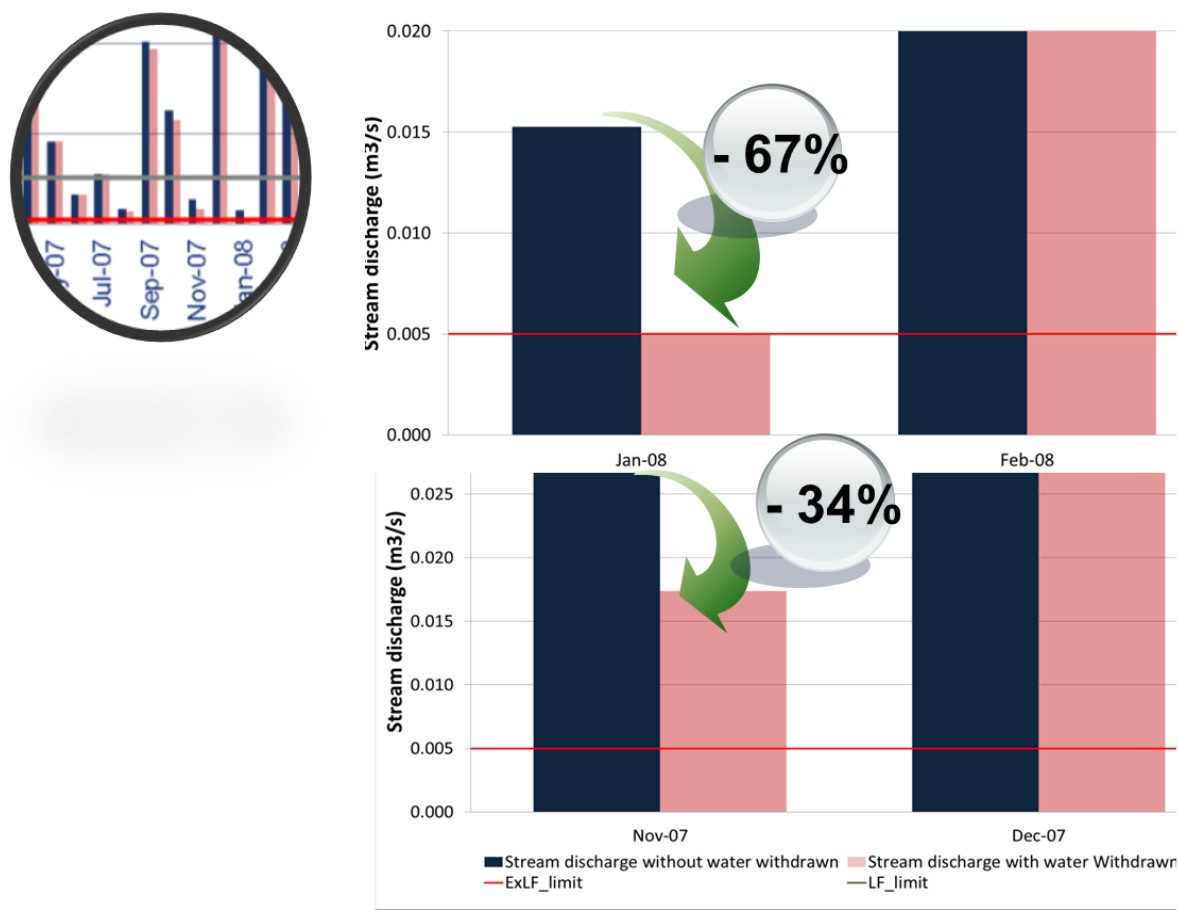

Extreme low flow limit

Extreme low flow limit

Figure 39: Monthly stream discharge change during specific months of the year. 
On the daily time step, the hydrologic regime changed 90 times from high flow to low flow condition and 190 times from low flow to extreme low flow. Figure 40 shows the yearly repartition of the alteration frequency in the Little Red watershed. The frequency is high during the years 2007 and 2008 when the number of natural gas wells in the Little Red watershed has increased dramatically. The change from low flow to extreme low flow occurred 85 times in 2007, and the change from high flow to low flow reaches occurred 62 times in 2008.

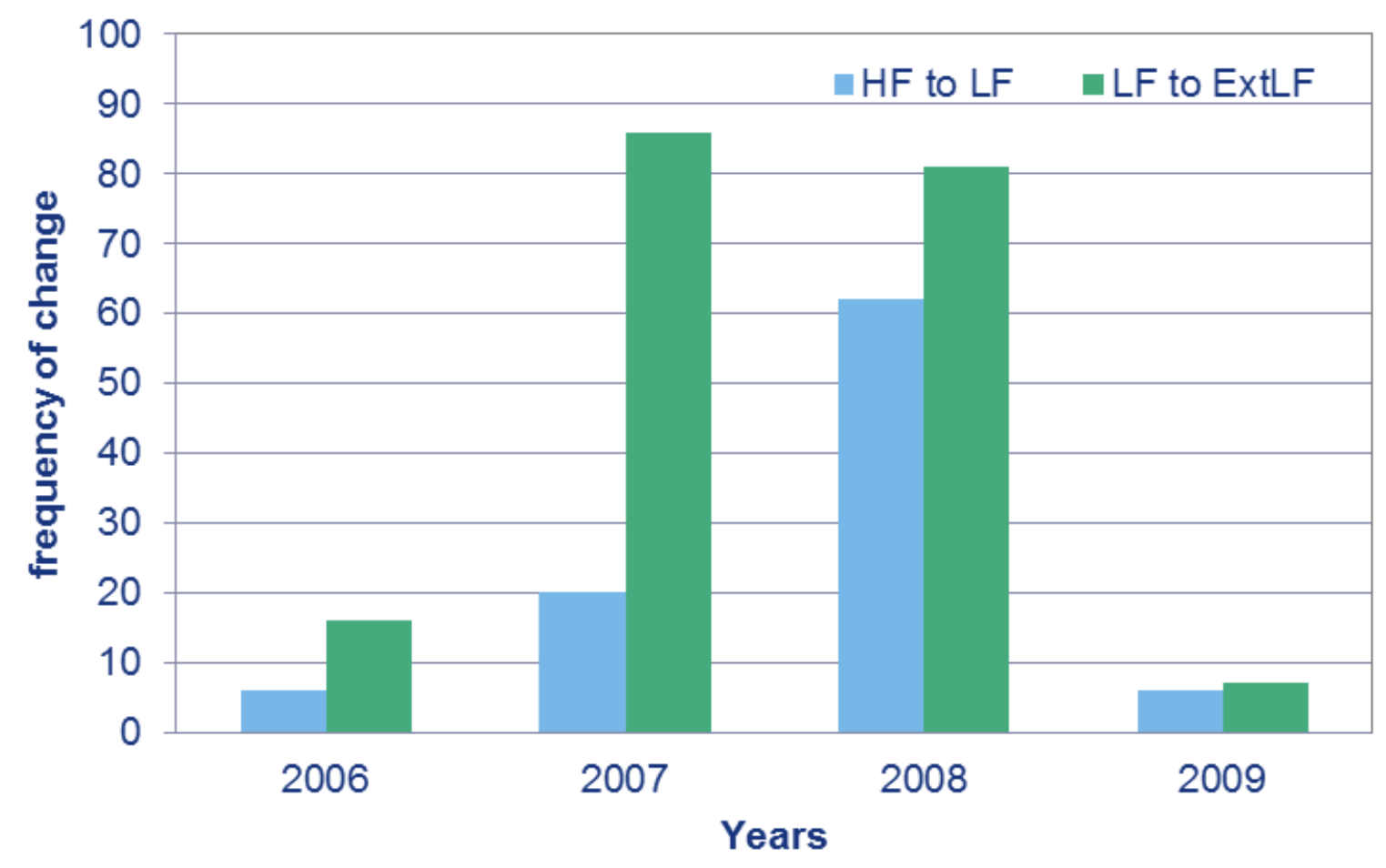

Figure 40: Frequency of change of the flow condition.

The frequency of the flow alteration due to the increase of hydraulic fracturing operations in the Little Red watershed and in the period 2006-2009, is diverse across subbasins. Figure 41 shows the spatial distribution of this frequency. The maximum number of changes from low flow condition to extreme low flow condition occurred 20 times and from high flow condition to low flow condition occurred 9 times. 


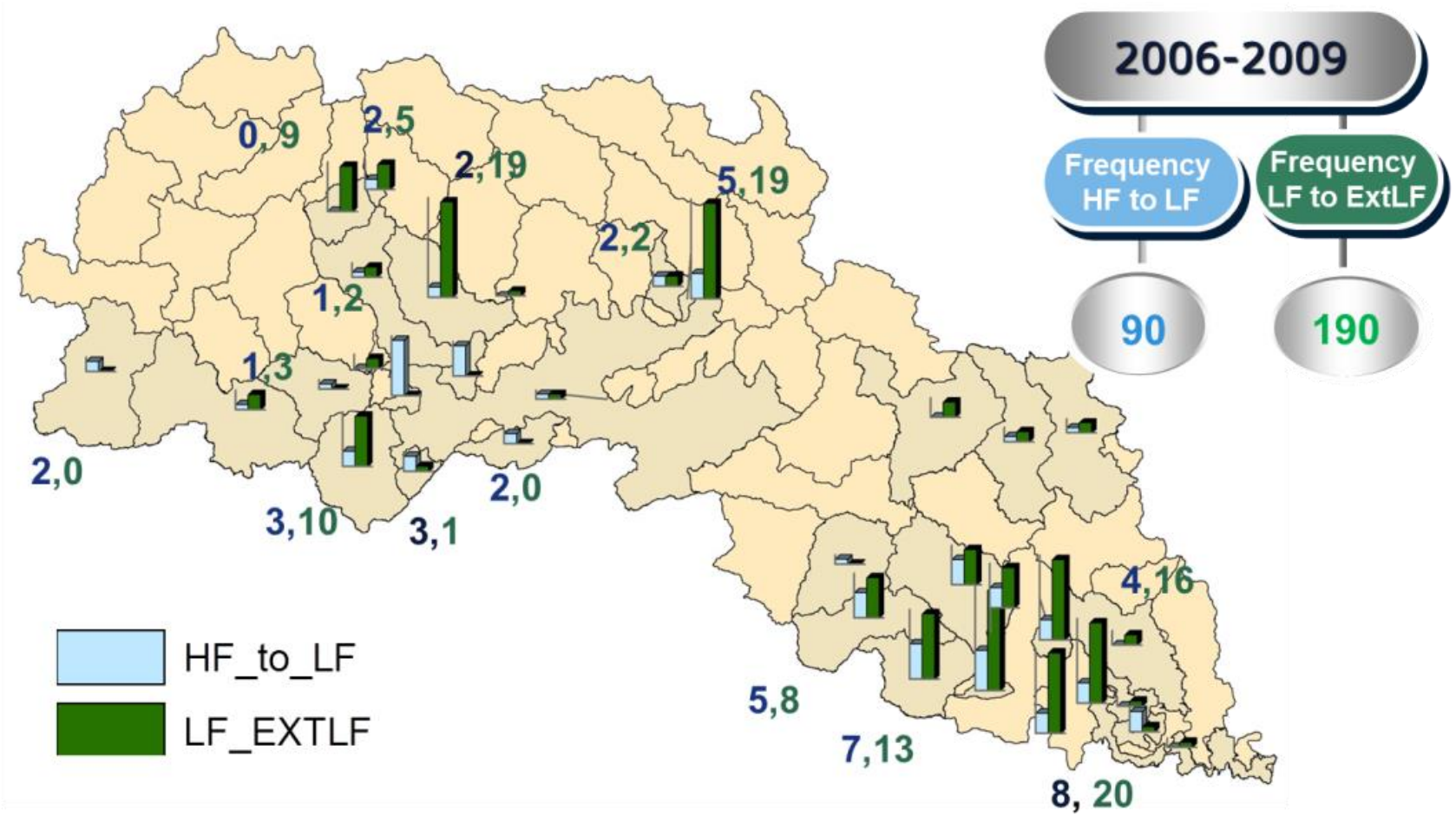

Figure 41: Spatial repartition of flow alteration frequency on the Little Red watershed.

\subsubsection{CONCLUSIONS}

The SWAT model provides good stream flow simulations in the study area. Simulation records in ungaged areas can be used to generate scenarios to assess the impact of hydraulic fracturing on the water balance and discharge. The current analysis of this impact was based on a scenario in which was assumed:

1) The quantity of water withdrawn equal to 5 MG per well.

2) The source of water is the closest river stream.

3) The time of withdrawing during the first 5 months after the SPUD date separated on 1MG per month per well.

4) This scenario will be properly modified based on data availability, which could provide more accurate results.

5) The use of the above scenario has shown different impact of hydraulic fracturing on the water balance and on the flow regime in different temporal and spatial scales. At the large scale, the impact appear not significant, while on small scale and in specific periods, the hydraulic fracturing could lead to a number of occurrences of flow changes, which have the potential to alter the equilibrium of the aquatic community in the river.

Based on the analyzed scenario, the alteration from high flow to low flow and from low flow to the extreme low flow was more remarkable in 2007 and 2008 particularly during the summer period.

Improvement of data about the source of withdrawing, the timing and the quantity could generate the best realistic scenario related to the hydraulic fracturing. Predicting critical period of low flow and 
extreme low flow will help to maintain a sustainable management and generate the adequate scenario of hydraulic fracturing scheduling.

\section{TASK 3.7 - Evaluate LAND USE ChANGE SCEnARIOS}

Land-use is a term used to refer to the specific human or economic activity associated with a geographically defined piece of land (Lillesand, 2001). Therefore the land-use of a particular area could be said to be agricultural, transportation, commercial etc. The above shows that the land-use of a particular area is typically influenced by human activity but above all by the geographic location of the specific piece of land as well.

Land-cover is used to describe the type of feature that is present on the surface of a specific geographically defined area such as region, watershed, state etc. The land-cover description of any area can therefore be done with terms such as corn, bare land, grass, concrete etc. Land-use land-cover forms one of the major components of studies in the earth sciences (Townsend et al, 1994).

Land-use land-cover (LULC) change however, is a continual and dynamic process that is a major driving force in environmental change (Lambin, et al., 2000). This change can be driven by economic, cultural and political factors (Brown et al., 2000) and in most cases are known to have improved conditions relating to cultural and economic aspects of people. However, there are negative implications of this change which is mostly seen in the environment relating to weather patterns (Chase et al., 1999; Stohlgren et al., 1998), changes in hydrologic regimes (Barr, 2008; Mejia, 1998), water quality and quantity (Tong and Chen, 2002; Faney et al., 2001; Aylward, 2002).

LULC change detection is there of critical importance in understanding the myriad of environmentally dependent factors in a region. Several methods of LULC change detection have been developed in literature. The major underlying principle is classification of multi-temporal remotely sensed data into land-use land-cover maps and subsequently performing statistical analyses of the relative change of the respective classes at the different acquisition times. The development of object-oriented image analysis methods has led to corresponding change detection methods such as presented by Das (2009). Niemeyer and Canty (2003) also detail pixel-based and object-based methodology for change analysis intended to take advantage of high-resolution imagery. Their approach involves the use of canonical correlation analysis in order to enhance the change information in the difference images and the use of bayesian techniques for the determination of significant thresholds. Changes that are determined to be significant are then analyzed explicitly with object-oriented techniques.

Advances in LULC change detection analysis have implications on hydrologic model interpretation and an understanding of the modeled system as well. For example, Wegehenkehl et al. (2006) found that a change of $\sim 69 \%$ (2.9\% to $4.9 \%$ ) in the developed land class resulted in a $70 \%$ increase in surface runoff predictions. This makes it imperative to perform critical analyses in LULC regarding environmental studies so as to ensure an understanding of the linkages between local environmental changes (hydrologic, weather, water quality etc) and LULC change detection. There are a number of studies in literature that deal with LULC change detection and others that explicitly tackle the relationship between LULC change and the attendant impact on hydrologic model simulation. In all, these studies either employ pixel-based or object-oriented classification techniques in their respective methodologies. Singh(1989) presents a comprehensive review of literature, methods and the theoretical basis of some outlined change detection techniques. Of particular importance in land cover change detection is the 
concept of thresholding. This basically involves decisions as to where to place threshold boundaries in order to separate areas deemed to have changed from those of no change. For example if in an image $I(x, y)$, a light object (represent a change) is found in a dark background (an area of no change) then these objects may be expressed by the simple mathematical thresholding equation

$$
I(\mathrm{x}, \mathrm{y})= \begin{cases}1 & I(\mathrm{x}, \mathrm{y})>T \\ 0 & I(\mathrm{x}, \mathrm{y}) \leq \mathrm{T}\end{cases}
$$

where $T$ is the threshold value that is determined by empirical or statistical means. (Singh, 1989). Nelson (1983) also presents a tabular presentation of a variety of change detection approaches and details other studies that have used the respective approaches. A comparison of change detection techniques is also given in Maas (1999).

The ability to more closely depict responses in hydrologic processes due to changes in land cover has been a key research goal in remote sensing and hydrology (Miller et al., 2007) and a number of studies have touched on land cover change and the impact on hydrologic model outputs (Norbert and Jeremiah, 2012; Koch et al., 2012; Scott et al., 1993). A key similarity in such studies is that a variation or alteration in land cover data ultimately leads to noticeable change in runoff and in some cases sediment yield. For example Alibuyog et al. (2009) showed with a SWAT model simulation of a catchment in the Philippines that land use change can impact the hydrology and sediment yield by between $3 \%$ to $14 \%$ and $200 \%$ to $273 \%$ respectively (Kock et al., 2012). Upward changes of $70 \%$ in runoff simulations have been reported in a study done in the Ucker Catchment in North-East Germany.

\subsubsection{LAND-USE LAND-COVER MAPPING (IMAGE CLASSIFICATION)}

To better understand the basic concept of image classification there is the need to have an idea of the concept of feature space. This is a concept that illustrates with graphical plots the values of pixels in specific bands that make up a remotely sensed image. 

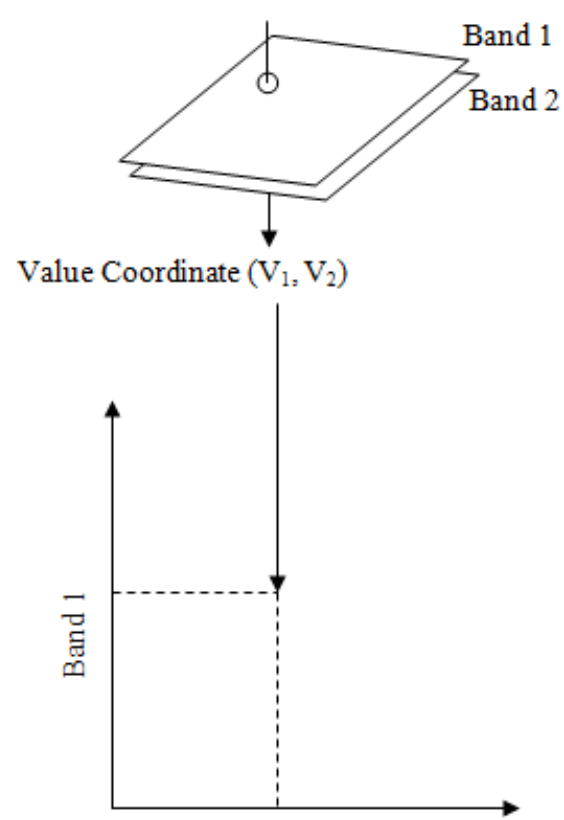

Band 2

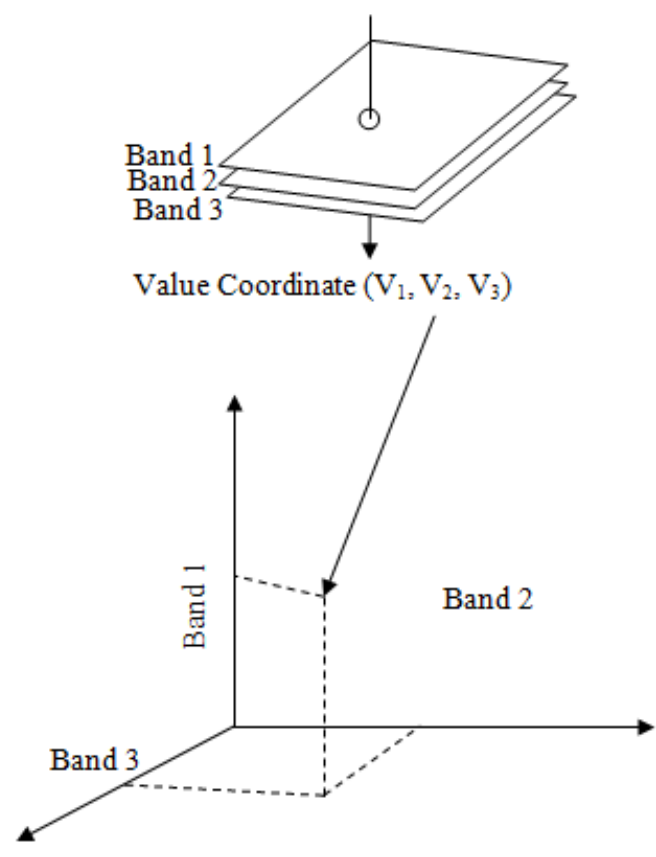

Figure 42: Feature space illustration (Jensen, 2001) as depicted in Gao (2003).

The number of bands in the image is effectively termed the dimensionality of the image. The illustrations below show feature space plots for 2-dimensional and 3-dimensional images (Gao, 2003). The underlying assumption in image classification is that a specific part of the feature space is representative of a specific class in the image data. Pixels are then compared to the identified classes in the feature space and a decision on pixel assignment is made based on a specific classification rule (Jensen, 2005).

\subsubsection{PIXEL-BASED IMAGE CLASSIFICATION}

Pixel-based image classification refers to the classification of remote sensing data based on spectral properties of individual pixel that make up the image. It is sometimes referred to as "pixel by pixel" $(G a o, 2003)$ manner of image classification in which a pixel can belong or be assigned to only one class. The two main criteria to be discussed under this method of image classification are the supervised and unsupervised classification methods.

\subsection{SUPERVISED CLASSIFICATION}

In supervised classification the location and specific spectral characteristics of the land-cover classes of interest (urban, forest, agriculture, water etc) are known apriori (Jensen, 2005). This knowledge is acquired through and combination of field surveys and aerial image interpretation and personal experience (Hodgson et al., 2003). An analyst locates specific sites in the remotely sensed data that are representative of homogenous areas in the known land-cover types. These representative samples of class types are known as training sites (Jensen, 2001). The spectral characteristics of these known homogenous areas are used to train classifier for application in classifying the entire image. Also 
multivariate statistics such as means, standard deviations, and covariance and correlation matrices are calculated for each training class or site. Pixels are evaluated with these training classes based on the respective statistics to determine the maximum likelihood of that individual pixel belonging to that specific class. The importance of training classes in this regard requires that training samples of each class should be typical and encompass the spectral variability that class type (Mather, 1987). There is no known defined limit of pixels to be used in formulating a training class. However, in order to use statistically based classifiers, it is recommended that a theoretically lower limit of $n+1$ (where $n$ is the spectral bands) number of pixels must be used in a training class (Lillesand, 2001).

Pixel-based image analysis classifiers are classically hard classifiers that assign pixels membership to a class as either 1 or 0 . With 1 expressing a pixel's membership to a class whiles 0 denotes that an individual pixel bear no membership to a particular class hence the term "hard classifiers" as they express in binary (yes or no) terms whether a pixel is a member or not a member of a class. The maximum-likelihood decision rule (classifier) is one of the most widely used of such a supervised classifier (Wu and Shao, 2002). It is a classification rule that is based on probability: it assigns each individual pixel to a specific class whose units are most probable or likely to have given rise to the feature vector (Atkinson and Lewis, 2000). The method assumes that the statistics of the training data for each class in each class is normally distributed. Therefore training data of $n$-modes in the histogram is not ideal and such a case implies the existence of unique classes (Jensen, 2005).

\subsection{UNSUPERVISED CLASSIFICATION}

This method of image classification also referred to as clustering, partitions remote sensing data into multispectral feature space and subsequently extracting land-cover data (Loveland et al., 1999). Unlike supervised classification, this method only requires minimum input from the analyst; mainly because there is no requirement for training data. Therefore, the algorithm searches for natural groupings of the spectral characteristics of the pixels in a specific band as is evident in the feature space. The process results in a classification map that consists of a number of spectral classes after which the analyst attempts an after the fact transformation of the spectral classes into class types (Jensen, 2001).

Among the numerous classification algorithms that are used to determine the natural groupings in an image is the "K-means" method. The approach in this algorithm requires the analyst to specify the number of clusters or data centers representing the potential individual classes. The algorithm then locates these number of cluster points in the multidimensional feature space. This is followed by assigning each pixel to the cluster based on the closest distance between the mean vector of the cluster and the pixel. The mean vectors of the clusters are then revised and are then used as the base to reclassify the data (Gao, 2003).

\subsubsection{OBJECT-ORIENTED IMAGE CLASSIFICATION}

Unlike the "per-pixel" classification which is mainly based on processing an entire image on pixel by pixel basis (Blaschke and Strobl, 2001), the object-oriented image analysis procedure allows for the decomposition of the image into many homogeneous objects known as segments. These segments are created at varying scales in the image leading to what is termed multi-resolution image segmentation (Baatz and Schape, 2000). Statistical characteristics of the defined objects are then used in traditional statistical or fuzzy logic classification algorithms. This method is often used on high-resolution imagery such as $1 \mathrm{~m}$ IKONOS or $0.6 \mathrm{~m}$ Quickbird Imagery. 


\subsubsection{IMAGE SEGMENTATION}

Image segmentation is the process of aggregating pixels into homogenous image objects. Homogeneity in this sense is defined in terms of the spatial and spectral characteristics of the discrete objects (Ryherd and Woodcock, 1996) and basically refers to the fact that within object variance is less than the variance between objects (Lalliberte et al., 2004). This process is the first step in a method that attempts to replicate the way humans perceive objects in the real world (Lang, 2008). There are several methods of image segmentation which can broadly be categorized into region-growing, spatial clustering, edgebased, area-based algorithms etc (Haralick and Shapiro, 1985; Blaschke and Strobl, 2001). More recent developments have yielded the Fractal Net Evolution Approach (FNEA) (Baatz and Schape, 2000) which is a multifractal approach to segmentation that is implemented in the eCognition software.

FNEA is a pair-wise clustering process that determines object areas of least spectral and spatial heterogeneity at a given scale, spectral and shape parameter set (Benz et al., 2004). Images are thus segmented at different scales which add a scale hierarchy to the analysis (Burnett and Blaschke, 2003). This multiscale approach determines the size of the image object which is also dependent on the inherent resolution of the image. With the scale parameter increase, so does the object size (Platt and Rapoza, 2008); therefore a specific scale level produces objects of specific sizes hence the term multiresolution segmentation. The process of segmentation stops when the smallest object exceeds the threshold that is set by the scale parameter (Lalliberte et al., 2004). Multiresolution segmentation as implemented in ecognition software is governed by the concept of minimizing the spectral heterogeneity between pixels making up an image object - thus minimizing within object spectral heterogeneity. Taking the size of objects into consideration the following simple equation that can be used to optimize the criterion of minimizing the spectral heterogeneity (Baatz and Schape, 2000)

$$
h_{\text {diff }}=n_{1}\left(h_{m}-h_{1}\right)+n_{2}\left(h_{m}-h_{2}\right)
$$

where $h_{\text {diff }}$ is the difference in spectral heterogeneity, $h_{m}$ is the spectral heterogeneity of the merged object, $h_{1}$ and $h_{2}$ are the spectral heterogeneities of the objects 1 and 2 to be merged with sizes $n_{1}$ and $n_{2}$ respectively.

The object-oriented image classification paradigm embedded in eCognition software employs nearest neighbor in addition to expert knowledge to assign objects to respective class types. The nearest neighbor classifier computes the Euclidean distance from the object to be classified to the nearest training data mean vector in feature space (as is applied in per-pixel method). Classification is subsequently done by assigning each object to the class that is closest to it in feature space (Schowengerdt, 1997).

Another classification method used in object-oriented image analysis is the fuzzy classification based on fuzzy logic theory. This is achieved through the use of membership functions. A membership function has output ranges from 0 to 1 for each object's feature values in relation to the object's assigned class (Lalliberte et al., 2004). The fuzzy rules allows for the definition of such criteria such as "all image objects with spectral values larger than $x$ are natural gas well-pads". 


\subsubsection{LAND-USE LAND-COVER MAP ACCURACY ASSESSMENT}

Land-use land-cover map accuracy assessment is necessary in order to provide a measure of certitude associated with the classified land-cover map. Perhaps the most important aspect of accuracy assessment is to clearly state the objective of the accuracy assessment in respect of the problem at hand, the classes of interest and method of data sampling (Jensen, 2005). In this research the object of accuracy assessment is to provide a degree of confidence that can be associated with the final classes in the produced land-cover map. There are many sources of error when it comes to the accuracy of the final thematic map. The most widely used method of thematic map accuracy assessment; the error matrix is plagued with several sources of error. Congalton and Green (1993) detail these errors and explain how they affect the implications of the error or the accuracy assessment. In order to assess the accuracy of remotely sensed data or for that matter classified remotely sensed data, it is essential to evaluate both positional and thematic accuracy (Congalton, 2005).

\subsubsection{POSITIONAL ACCURACY}

The most common measure of map accuracy is the measure of how closely the images represent the existing features on the ground. This is known as the positional accuracy (Congalton, 2005). The most important factor that affects positional accuracy is topography. The effect of topography on positional accuracy can be seen in Figure 43.

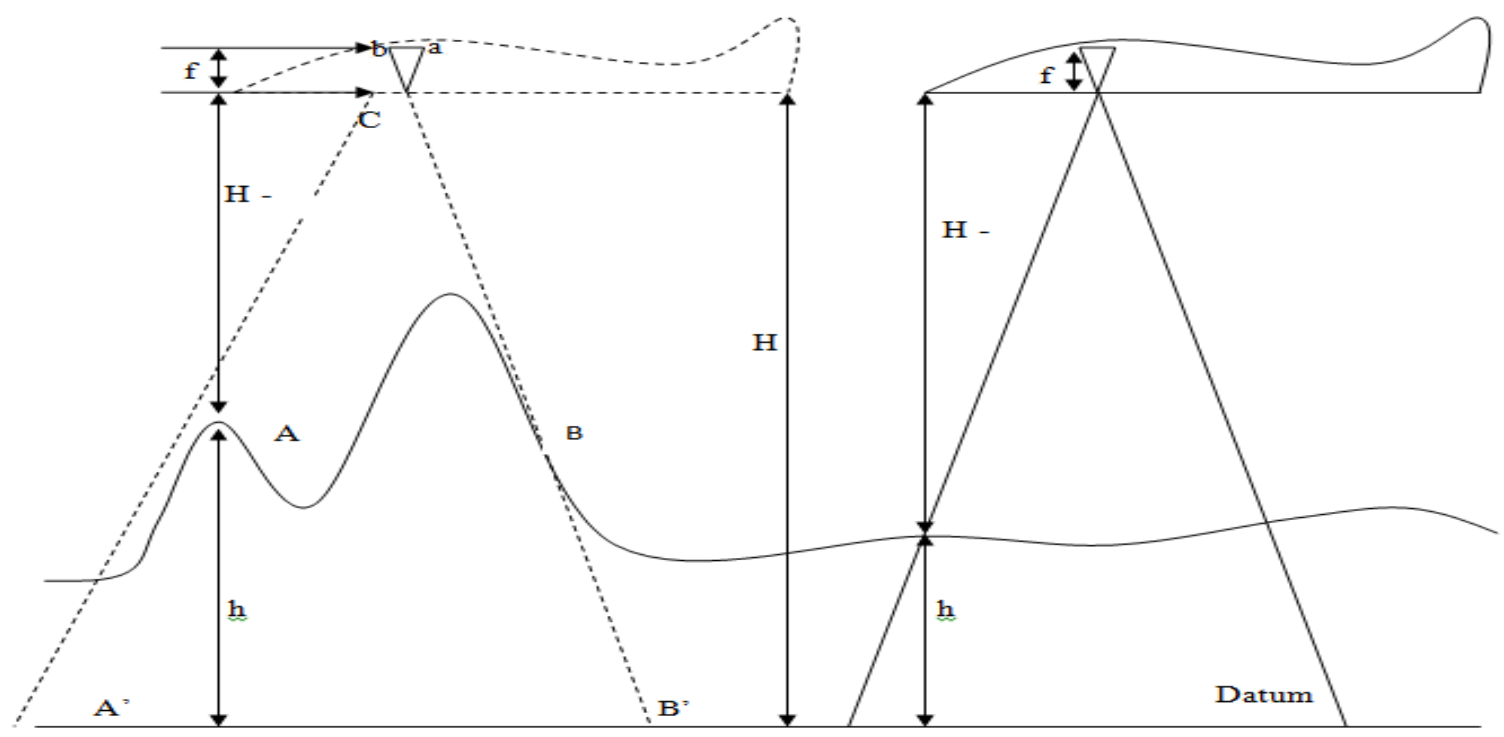

Figure 43: Illustration of terrain elevation differences on scale effects in aerial image acquisition.

Sequence B Sequence A

To achieve positional accuracy it is imperative that the same exact location can be determined both on the image and on the ground and that scale effects are minimal. However as illustrated in figure 2 , the relative scale in the images are at positions $A$ and $B$ are compromised due to terrain elevation effects. To better understand this one needs to understand the concept of scale as applied to aerial images. By using similar triangles

$\triangle a b C \approx \triangle A B C$ since $\overline{a b}: \overline{A B}$ Image distance is proportional to object (ground) distance 
Again $f: H$ (focal length of camera is proportional to height above datum)

Therefore,

where $S$ = scale of image

$$
\frac{f}{H-h}=\frac{\mathrm{ab}}{A B}=\frac{1}{S}
$$

From the above it can be seen that the height or elevation, $h$, above the datum is the controlling factor in the scale for a given focal length at a specific pixel in an image. Therefore in figure 2 , the pixel for image position $A$ in sequence $A$ will have a much different scale than the same pixel for image position $A$ in sequence $B$. This phenomenon will invariably affect the positional accuracy of the acquired image as well.

Positional accuracy holds an important aspect of thematic map accuracy assessment. For example if a position is registered to the ground to within half a pixel size, using GPS in locating such a place on the ground to $15 \mathrm{~m}$ for instance, then using a single pixel as a sampling unit becomes impossible for assessing the thematic accuracy of such a map (Congalton, 2005). In this situation the GPS location must be located with a high degree of accuracy so as to prevent significant problems with regards to positional accuracy. Positional accuracy is measured in root mean square error (RMSE) computed as the sum of the squares of the differences between point positions in one image layer in comparison to the point positions in another image layer (usually the ground) with the same data that has been used to register the images layers (Congalton, 2005).

\subsubsection{THE ERROR MATRIX}

Another measure of the accuracy of classified maps obtained from remotely sensed data is the thematic accuracy. This refers to the accuracy of a classified or mapped land-cover map obtained at a particular time in relation to the prevailing conditions on the ground at the time of classification (Congalton, 2005). This definition brings to the bear the fact that knowledge of the accuracy associated with a reference or ground-truth data is vital and that the reference data should in the least of cases have higher accuracy in order to ensure a fair accuracy assessment (Congalton, 1991).

The most common measures of accuracy assessment in classified remotely sensed imagery are the producer, user and overall accuracy (Story and Congalton, 1986); all based on the error or confusion matrix. The error matrix consists of a square array of numbers set out in rows and columns to express the number of pixels assigned to a particular classification category in relation to the actual category as determined using ground-truth (Congalton, 1991). The error matrix essentially provides a systematic way to compare pixels in the classified map and ground-truth data. The relationship between the two sets of data is expressed or summarized in the error matrix (Jensen, 2005). Table 6 is an error matrix used to illustrate the producer, user and overall accuracy measures. The columns represent the groundtruth data as the rows of the matrix correspond to the classified pixels. The diagonal of the matrix represents the number of pixels in each category that is deemed to be accurately classified as the offdiagonals represents the errors in each classification class with respect to the ground-truth data (thus assuming the ground-truth data is error-free). 
Table 6: Example of an error matrix (for demonstration purpose): modified from Congalton (1991).

\begin{tabular}{llllll}
\hline & Forest & Corn & Bare Soil & Well pad & Row Total \\
\hline Forest & $\mathbf{9 6}$ & 4 & 15 & 21 & 136 \\
\hline Corn & 3 & $\mathbf{8 9}$ & 5 & 10 & 107 \\
\hline Bare Soil & 2 & 5 & $\mathbf{9 2}$ & 43 & 142 \\
\hline Well pad & 21 & 7 & 34 & $\mathbf{9 7}$ & 159 \\
\hline Column Total & 122 & 105 & 146 & 171 & $\mathbf{5 4 4}$ \\
\hline
\end{tabular}

Overall Accuracy $=374 / 544=68.75 \%$

Producer's Accuracy (probability of a reference pixel being correctly classified)

Forrest: $96 / 122=78.69 \%$ Corn: $89 / 105=84.76 \%$ Bare Soil: $92 / 146=63.01 \%$ Well pad: $97 / 171=56.73 \%$

User's Accuracy (probability of a classified pixel representing the category on the ground)

Forrest: $96 / 136=70.59 \%$ Corn: 89/107= 83.18\% Bare Soil: 92/142=64.48\% Well pad: 97/159=61.01\%.

\subsubsection{LAND-USE LAND-COVER CHANGE DETECTION}

Change detection is a remote sensing procedure that is intended to find alterations or changes in objects or phenomena of interest from images acquired at separate times $\left(t_{1}, t_{2}, t_{3}, \ldots . t_{n}\right)$ (Niemeyer, 2003). Traditionally this has been achieved by comparing pixels from multitemporal images for time $t_{1}$ and $t_{2}$ and subsequently performing some sort of statistical analyses on difference data to determine a descriptive statistic with which to report change. Change detection algorithms mainly fall under;

Write function memory insertion: This method involves the insertion of each individual band or any derivative of it acquired at different times, into each of the three write function memory (WFM) banks (red, green or blue) to identify changes in the scene (Jensen, 2005).

Multi-date composite imagery: this mostly involves the subjection of the images to principal component analysis (PCA) to determine change (Fung and LeDrew, 1987; Maas, 1999).

Band differencing: This in its simplest form can be explained as subtracting the brightness values of one image acquired at a specific time from the brightness values of another image acquired at a different time of the same scene. The normalized difference vegetation index method is perhaps one of the popular examples of this change detection method.

Post-classification comparison: This involves performing a comparison on a pixel-by-pixel basis through the use of a change detection matrix obtained from a rectified and subsequently classified imagery data of the same scene at separate time periods (Yuan and Elvidge, 1998; Civco et al., 2002; Jensen et al., 1995).

There are a number of studies that have been done on change detection using the object-oriented approach as well (Tanathong et al., 2009; Lefebvre et al., 2008; Yuan and Elvidge, 1998; Chen et al., 2012). Tanathong et al., (2009) used the object-oriented approach to for post-disaster building 
assessment. Their approach mainly relies on knowledge based intelligent agents (Tenuci, 1998) for the recognition of buildings pre and post disaster. The process creates building objects (Jacobson, 1998) corresponding to the individual buildings in the image. The building objects not only contain properties of the building but also the computational process that are used as decision rules for common properties of the buildings. The detection of change is achieved by interacting the individual building objects with each other to obtain matched-up pairs of pre and post disaster objects. Differences in the matched up pairs constitute the change in the scene. To more specifically address the issue of the choice of the above-named methods and algorithms for a particular task, it is essential to understand the rudimentary steps and scope of application. It is also important to note that each of the algorithms is optimized for a particular phenomenon of interest. Hence it becomes important to relate the choice of a specific algorithm to the dominant change theme or class in a change detection analysis of a scene or area. For example in this research land-use land-cover change of interest are particular related to urban, agricultural, forest and industrial (shale-gas related industrial change).

\subsubsection{DATA BRIDGING: HYDROLOGIC MODELS AND REMOTE SENSING DATA RESOLUTION} Integration of remote sensing data in hydrologic modeling has received some research attention. Notable among these are Gupta et al. (2011), Andersen (2008), Blankenship and Crosson (2012) and Schultz (1988). In this research what is of particular attention is the land-use land-cover (LULC) data of varying resolutions obtained from two fundamentally different methods of production. The role of LULC data is more prominent in distributed hydrologic models where the concept of hydrologic response unit (HRU) is a key driving factor in model set-up and parameterization. The HRU concept basically allows for the conceptualization of models in order to take account of the distribution of the physical characteristics of the watershed without having to resort to fully represent and perform model calculations at each individual discretization of the physical state of the watershed (Beven, 2005).

HRU discretization is highly aided by the introduction of geographic information science (GIS) in hydrological modeling. This is achieved through overlaying different hydrologic descriptive indicators such as soil, land-use data and slope classes which have been properly spatially registered to the geographic region of interest. The definition of HRU in this way ultimately leads to irregular patterns as overlays are performed with vector and raster data layers. For calculation purposes, this concept has a significant advantage in that similar HRUs are grouped together into single units thereby simplifying calculations and reducing computing resource requirement. The crux of the concept is that sections of the catchment with similar characteristics will have similar responses and it is based on this that the predictions of the distribution of individual catchment responses are made (Beven, 2005).

The level of detail that a remotely sensed image is able to capture within an area is a measure of the resolution of the image. Therefore, in distributed or semi-distributed hydrologic models such as the Soil and Water Assessment Tool (SWAT), where model results have been shown to be dependent on the resolution of such data such as soils (Geza and McRay, 2008; Mukundan et al., 2010; Kumar and Merwade, 2009 ), DEM (Chaubey et al., 2005), land-cover data (Chen et al., 2005; Bosch et al., 2004), it becomes important to investigate the effect that methods of LULC data classification applied with the high resolution imagery in obtaining high resolution land-cover map. This is particularly important as computations in distributed surface hydrologic models such as SWAT depend to a large extent on the input land-cover data (Kepner et al., 2013; Arnold et al., 1998). 


\subsubsection{THE SOIL AND WATER ASSESSMENT TOOL (SWAT)}

The Soil and Water Assessment Tool (SWAT) is a continuous-time physical process-based model for the simulation of landscape processes at the watershed scale (Neitsch et al., 2005; Arnold et al., 1998). As described in the preceding section, the watershed is divided into discrete regions known as hydrologic response units (HRUs) based on the soil types, slope and land-use land-cover classes thus allowing for spatial detail in the simulation (Betrie et al., 2011). The major components of the model are hydrology, soil temperature, weather, soil erosion, crop growth, agricultural management etc.

Hydrologic prediction is done at the HRU level using the water balance equation (Arnold et al., 1998):

$$
S W t=S W o+\sum_{i=1}^{n}(R d a y-Q s u r f-E a-w s e e p-Q g w)
$$

where

$\operatorname{Rday}(\mathrm{mm})=$ rainfall on day $i$

$Q \operatorname{surf}(\mathrm{mm})=$ amount of surface runoff on day $i$,

$E a(\mathrm{~mm})=$ amount of evapotranspiration on day $i$,

wseep $=$ amount of water that enters the vadose zone on day $i$,

Qgw = the amount of return flow on day $i$.

Surface runoff can be computed with a choice between the Green and Ampt infiltration method (Green and Ampt, 1911) or the Natural Resource Conservation Service Curve Number (CN) method (USDA-SCS, 1972; Betrie et al., 2011). Flow is calculated at the various HRUs and routed to the nearest channel (Arnold et al., 1995) using either the variable storage coefficient method (Williams, 1969) or the Muskingum method (Chow, 1959).

\subsubsection{THE CONCEPT OF EQUIFINALITY}

An important aspect of hydrologic modeling or any modeling exercise is the need to address the problem of model parameter calibration. Most calibrations involve the optimization of some parameter values through the comparison of simulated values with observed data until some "best-fit" parameter set satisfying an evaluation criterion or criteria are achieved (Beven, 2005; Chaubey and White, 2005; James and Burgess, 1982).

This method of calibration by optimizing parameter values assumes that observed data are error-free and the model at the end of a calibration exercise is a true representation of the system or data. However, in hydrologic modeling there can be significant errors in both observed data and model conceptualization (Beven, 2005). While one optimum parameter set may satisfy an objective function with a given threshold criterion, there may also be several other optimum parameter sets that may well present acceptable model simulations. This brings into focus the concept of equifinality that basically points out that the choice of one calibration optimum parameter set over another is at best described as arbitrary. Hence equifinality explains the concept that for a specific hydrologic model simulation there 
may be several optimum parameter sets that could produce acceptable fits to the observation data (Beven and Binley, 1992; Beven and Binley, 2001).

Accounting for the limitations in distributed hydrologic models in terms of the calibration and the issue of equifinality has led to the development of methods that are based on the realistic estimation of the prediction uncertainty (Beven, 1989a). To this end, Binley and Beven (1991) outlined a general strategy for model calibration and uncertainty estimation in such complex distributed hydrologic models. The Generalized Likelihood Uncertainty Estimation (GLUE) method assumes that before any quantitative or qualitative information is added to any modeling exercise, any parameter set combination meant for the prediction of a specific model output should be deemed equally likely as a simulator of the system (Beven, 1989b). The glue method attempts to account for parameter non-uniqueness as there is no unique solution to a model outcome. The approach is to estimate degrees of belief that can be associated with models and parameter sets (Beven, 2005).

The method is simple and easy to implement. The base of the technique relies on the estimation of probabilities associated with different parameter sets. A posterior probability function is derived from a chosen likelihood function (mostly the Nash-Sutcliffe Index) which subsequently becomes the measure used to derive the predictive probability of the output variables (Abbaspour, 2011). The choice of a likelihood measure is somewhat subjective and can partly depend on the observational data available. Beven (2005) details the criteria for selecting an appropriate likelihood measure.

A GLUE analysis generally consists of the following steps:

1) Define a "generalized likelihood measure", $L(\alpha)$

2) Sample (Monte Carlo or Latin Hypercube or any appropriate sampling strategy) a large number of parameter sets from a prior distribution

3) Define a threshold value for a "likelihood measure"

4) Assess parameter sets as either acceptable (behavioral) or unacceptable (non-behavioral) based on a comparison with the give threshold value for the likelihood measure

5) Assign weights to each behavioral parameter set using

$$
W i=\frac{L(\alpha \mathrm{i})}{\sum_{j=1}^{n} L(\alpha \mathrm{j})} \text { (where } \mathrm{n} \text { is the number of acceptable parameters). }
$$

The prediction uncertainty is then presented as a quantile from the cumulative distributions of all the weighted parameter sets. (Abbaspour, 2011; Beven, 2005)

Implementing the method ultimately requires key decisions to be made regarding the choice of a sampling strategy, appropriate likelihood measure, feasible parameter range and behavioral model threshold. Details regarding these are further discussed in Beven (2005).

\subsubsection{PRIOR APPLICATIONS OF SWAT IN BEST MANAGEMENT PRACTICE (BMP) IMPLEMENTATION}

The SWAT model has been used in several studies to evaluate the Best Management Practices (BMPs). These studies encompass areas such as nutrient loading of water bodies, application of agricultural chemicals (YunSheng et al., 2005), fate and transport of chemicals and sediments (Zhang and Minghua, 2011), sediment control (Betrie et al., 2011), storm-water control etc. The model was used to evaluate 
the effectiveness of five BMPs scenarios in reducing nutrient loading in a watershed located in the Inland Bays in southern Delaware (Sood and Ritter, 2010). It has also been used in predicting non-point source pollution nitrates nitrogen and total phosphorous loading through evaluation and assessment of large number of scenarios in a watershed in Greece (Panagopoulos et al., 2012).

The model has also been adopted by the United States Environmental Protection Agency's (USEPA) Better Science Integrating Point and Non-Point Sources (BASINS) software package for analyses pertaining to development of Total Daily Maximum Load (TMDL) guidelines for various water bodies in the United States. A review presented by Kalin and Hantush (2003) regarding key features of hydrologic models widely cited for the ability of the models to represent BMPs indicated that the SWAT model offers the largest number of management alternatives.

Perhaps a short fall to the use in management representation is that it offers no numerical guidelines for the representation of management scenarios. The lack of numeral representation of practice performance has been addressed as a vital research need in Nietch et al., (2005) and Arabi et al., (2007).

The aim of this study is to evaluate the respective impacts of high-resolution land-use land-cover (LULC) data classified with the Object-Oriented Image Analysis (OOIA) method and a relatively lower-resolution LULC data classified with the maximum-likelihood method on stream-flow predictive reliability of the Soil and Water Assessment Tool (SWAT) model. In essence, the objective was to investigate how the model performs with methods of LULC data classification and LULC data type resolution. The predictive reliability of the model as used in this study is primarily evaluated with two descriptive statistic measures; the $p$-factor and the r-factor. The $p$-factor is used to quantify the percentage of the observed data that a calibrated model is able to capture whiles the $r$-factor quantifies the level of uncertainty associated with the calibrated model. Statistically, the r-factor measures the thickness of the uncertainty band around the best possible model simulation divided by the standard deviation of the observation values. The hypothesis was that a combination of GIS-based hydrologic modeling and the promise of LULC data obtained from object-oriented image classification method significantly improve SWAT flow predictive reliability. Two SWAT models were set-up and calibrated at a gaging station located within the study area. The study area is the Little Red River Watershed (LRRW) with an approximate area of close to $4700 \mathrm{~km}^{2}$ located in the north-central portion of Arkansas within the Fayetteville Shale Play. After manual and auto-calibration, results showed that the high-resolution data classified with objectoriented image analysis method does not present any significant advantage in terms of predictive reliability.

\subsubsection{EFFECTS OF OBIA ON SWAT CALIBRATIONS}

The object-oriented image analysis method (Baatz et al., 2001) is a method of land-use land-cover (LULC) classification that was developed to optimize classification accuracy by utilizing the inherent spectral characteristics and image resolution of remotely sensed images. This method has been shown to yield better results in studies regarding LULC change analyses (Gao, 2003; Rutherford and Platt 2008). The resultant classified image can be ultimately used in investigations concerned with the corresponding environmental impacts such as changes on the hydrologic balance of watersheds.

The change to the hydrologic balance can be assessed using hydrologic modeling methods (Conly and van der Kamp, 2001; Peterson et al., 2000; Zhang et al., 1999). Also, results of hydrologic models such as the Soil and Water Assessment Tool (SWAT) (Arnold et al., 1998) have been shown to be affected by the input LULC data (Bosch et al., 2004; Huang et al., 2013). However, there is a lack of assessment of the 
resolution and methods of LULC data classification on SWAT model simulations particularly in a shalegas impacted watershed. The objective of this study is to evaluate the impact of LULC data method of classification performed on imagery of different spatial resolutions on the predictive reliability of SWAT flow models. Specifically, this study aims to show the difference (if any) in the predictive reliability of SWAT flow models simulated with high resolution LULC data that is classified with the object-oriented image analysis method and low-resolution LULC data classified with the maximum-likelihood method in a shale-gas impacted watershed.

\subsubsection{BACKGROUND AND SIGNIFICANCE}

Generally, research on the effect of high-resolution LULC input data on various SWAT outputs seem to show that, high-resolution data do not necessarily result in better SWAT stream-flow simulations (Chen et al., 2005). This result may arise in part from the fact that traditional pixel-based image classification methods designed for low-resolution images are not well-suited to deal with the spectral variance inherent in higher resolution images. More modern computer-vision based classification methods have shown great potential and one, object-oriented image analysis (OOIA) method, has been used extensively in small and large scale studies (Laliberte et al., 2004; Rutherford and Platt, 2008).

This method is based on a hierarchical, multi-scale segmentation and subsequent classification using shape, texture and spectral properties of the segmented image. OOIA is particularly optimized for highresolution data with particular emphasis on spatial and spectral homogeneity of the underlying data. Although the differential effect of high or low-resolution LULC data on SWAT outputs has been studied (Bosch et al., 2004), we are currently not aware of any study that deals with the impact of the respective classification methods and how the accuracy with which the respective methods of classification can be used to correctly extract land use related to local LULC changes such as shale-gas-related infrastructure (Myint et al., 2011) affect the reliability of model outputs.

Several studies have reported that combined with high-resolution data, OOIA produces LULC data of significantly better classification accuracy than traditional pixel-based maximum-likelihood (PBML) methods (Devi and Krishna, 2012; Pham et al., 2009; Yan, 2003). Furthermore, it is also known that the relative increase or decrease in a particular land-use class can have significant impacts on distributed hydrologic model results. For instance Wegehenkel et al. (2006) found that a two percentage increase $(2.9 \%$ to $4.9 \%)$ in the developed land class of a watershed resulted in $70 \%$ increase in the surface runoff predictions in their study. This implies, in particular reference to this study that, it is important to consider the spatial resolution, accuracy and the method of classification of LULC data in evaluating the model's predictive reliability based on LULC datasets obtained from high and low-resolution imagery and classified with different methods (in this case the object-oriented and pixel-based methods respectively).

In considering major economic activities that drive LULC changes in this study, general agriculture and urbanization activities have in addition to the increase in shale-gas related activities resulted in significant LULC change in the general area of the Fayetteville Shale Play (FSP) located in north-central Arkansas. Such LULC change has also been shown to have negative impacts on stream water quality (Tang et al., 2005; Zampella et al., 2007) and water quantity (Bronstert et al., 2002; White and Greer, 2006).

Albeit there have been rapid changes in LULC mostly related to urban, residential, commercial and agricultural activities, higher projected economic growth rate for the counties with oil and gas 
operations (Deck and Riiman, 2012) can lead to land-cover changes that will be exacerbated as well. Land-cover change in forested watersheds mostly leads to the exposure of the land; this is known to have negative impacts such as decreased water quality, increase runoff velocity and volume, reduced groundwater recharge, greater peak flows, increased flood frequency etc. (Scanlon et al., 2005; Carlson and Arthur, 2000; Pitman and Narisma, 2004). The increase in shale-gas related activities requires that studies be done on the respective shale-plays to determine an adequate balance between the need for the energy resource whilst sustaining minimal change to the watershed's hydrology. This requires the development of accurate hydrologic models to study the impacts of several LULC change scenarios on stream flow. To achieve this there is the need to investigate the applicability of methods, input data and the hydrologic models to be used in such settings.

\subsubsection{STUDY AREA DESCRIPTION}

Located in north-central Arkansas, the Little Red River watershed (LRRW) is one of the biggest watersheds which see significant activities from shale-gas operators in the Fayetteville Shale Play (Figure 44). The watershed is completely located within the Fayetteville Shale play and is approximately $4668 \mathrm{~km}^{2}$ in area with roughly $70 \%$ of this area being classified as mixed forest land (CAST, 2006). The area has an average annual precipitation range of $1270-1320 \mathrm{~mm}$ with winter and summer average temperatures of $2^{\circ} \mathrm{C}$ and $30^{\circ} \mathrm{C}$ respectively. Mean annual high and low temperatures are $5^{\circ} \mathrm{C}$ and $17^{\circ} \mathrm{C}$ respectively (NOAA, 2012). Precipitation normally occurs less frequently during the months of June, July and August; summers are hot and humid while winters are relatively mild and short. A 2006 LULC analysis revealed that the watershed is approximately $70 \%$ forest land, $16 \%$ pasture, $2 \%$ cropland, $3.69 \%$ Urbanized, 3.33\% water and $5 \%$ herbaceous (CAST, 2006). There are three main population centers within the watershed; namely Searcy, Heber Springs and Clinton with population density of 44 persons per square mile (CAST, 2006); averaged for the combined area of the three counties encompassing the centers. The watershed lies within the physiographic regions of Mississippi Alluvial Valley, Arkansas River Valley and Ozark Plateaus, with an elevation range of roughly 52 to $630 \mathrm{~m}$ respectively. The Ozark Plateau Region is made up of steep valleys; it is further divided into three broad plateau surfaces (Springfield Plateau, Salem Plateau and Boston Mountains) mainly based on elevation and age of surface rock. The Arkansas Valley is a low-lying region surrounding the valley of the Arkansas River and the Mississippi Alluvial Valley which is relatively level plain land (Arkansas Geological Survey, 2012). The main river in the watershed is the Little Red River which flows in a mainly south-east direction. 

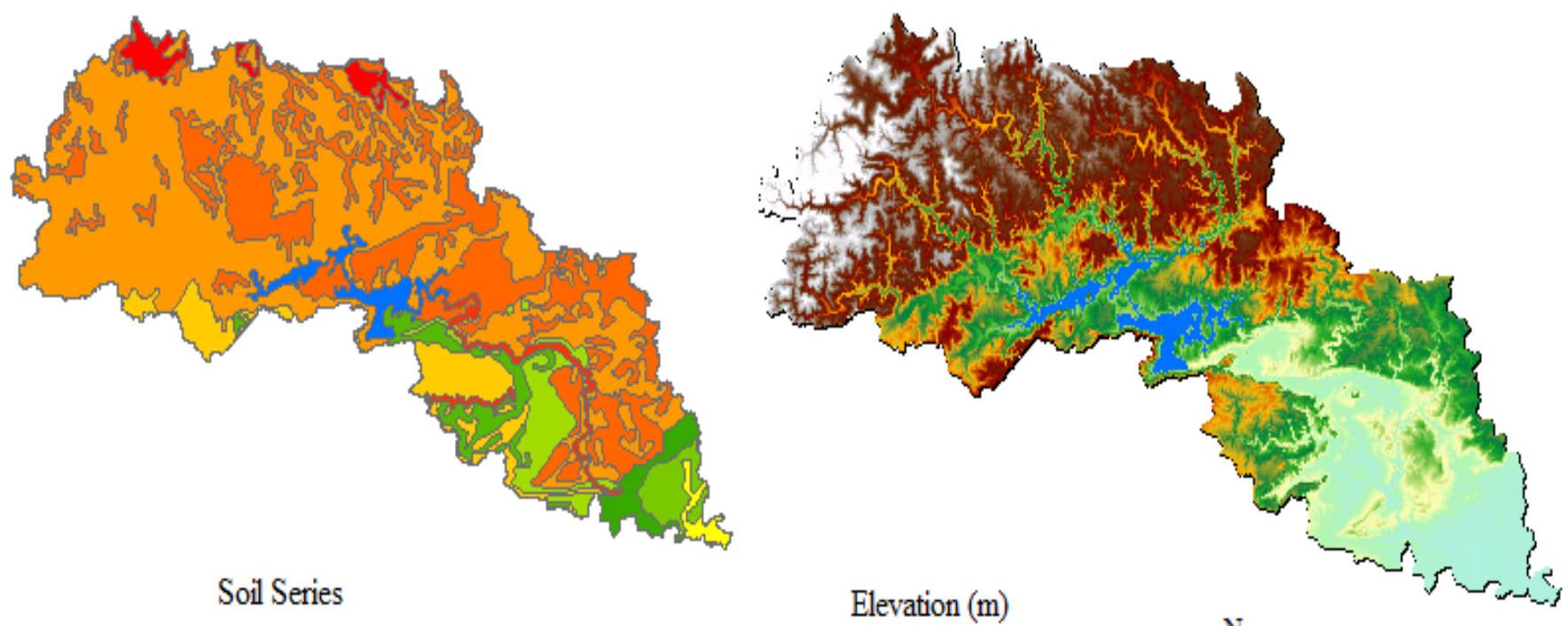

$\begin{array}{ll}\square \text { CALLOWAY- } & \square \text { LINKER-EN } \\ \square \text { ENDERS-LI } & \square \text { LINKER-MO } \\ \square \text { ENDERS-NE } & \text { NEWNATA-E } \\ \square \text { FOLEY-JAC } & \text { SPADRA-GU } \\ \square \text { KOBEL-COM } & \text { WATER (AR } \\ \square \text { LEADVALE- } & \end{array}$
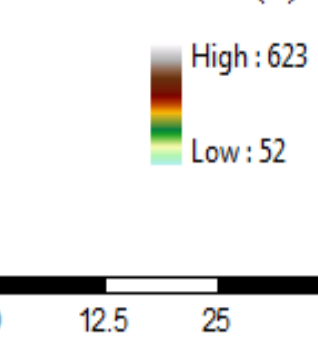

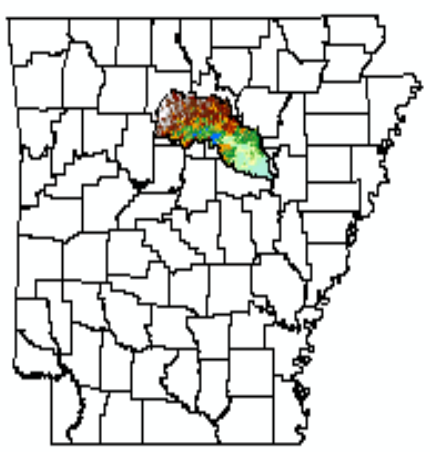

Figure 44: Soils and elevation characteristics of the study area: Little Red River Watershed (LRRW). 


\subsubsection{METHODOLOGY}

To determine the impact of high and low-resolution LULC data and their respective methods of classification on SWAT flow model predictive reliability in a shale-gas watershed, we used a combination of Geographic Information Science (GIS), digital image analysis and hydrologic modeling.

\subsection{IMAGE CLASSIFICATION}

Two main datasets were used as the input LULC data for the LRRW flow models. A low-resolution $(28.5 \mathrm{~m})$ data produced by the University of Arkansas Center for Advanced Spatial Technologies (CAST) through maximum-likelihood classification from a 2006 Landsat 5 thematic mapper UTM orthorectified imagery and a high-resolution ( $4 \mathrm{~m}$ ) LULC data classified with object-oriented image analysis acquired from a 2006 National Agricultural Imagery Program (NAIP) orthorectified aerial imagery. This pixel-based maximum-likelihood method essentially identifies the class of each pixel by comparing the value of individual pixels with sampled training classes and assigns the pixel to a specific class based on a set algorithm (Lillesand et al., 2004). The map which was created from the Landsat 5 TM data depicts the land cover of the study area and was considered to represent current conditions. The classification was obtained from Landsat 5 TM scenes of the watershed with the following classes; agriculture, urban, forest, crops, water and grasses.

The high-resolution (4 m) LULC data was derived from the National Agricultural Imagery Program (NAIP) aerial imagery of $1 \mathrm{~m}$ pixel size that was resampled to $4 \mathrm{~m}$ and classified with object-oriented image analysis method using Trimble eCognition Developer 8 (Trimble, 2012). Object-oriented image analysis incorporates a multi-scale segmentation approach that groups pixels into homogenous image objects based on defined shape, texture, spatial and spectral characteristics of the pixels (Baatz et al., 2001). This approach results in discrete regions that are spectrally and spatially homogenous and allows for the identification of object features at specific scales of segmentation. Homogeneity in this regard refers to the fact that the spectral variance within an object is less than the spectral variance between objects (Laliberte et al., 2004). A segmentation procedure known as multi-resolution segmentation based on defined scale parameters was used. The scale of a particular segmentation process determines the size of objects created at that scale. Through a trial and error method, we determined appropriate parameter values for scale, compactness and smoothness for four main levels of segmentation; 350 , 150,35 and 5 (depending primarily on scale).

The objective of the classification at level 350 of the object hierarchy was to determine the largest size of objects in the imagery that represent the aggregated homogenous pixels. The subsequent levels of segmentation were determined to break down the super objects at the previous scale in order to attain objects of interest belonging to specific classes of interest for accurate classification. In general, classifications of segmented objects into their respective classes were done by an assignment classification based on the mean spectral properties of the various image channels, specific homogeneity criteria and thematic data attribute values. Other classification rules were determined by using either the nearest-neighbor or membership function classifier based on fuzzy-logic and supplemented with user supplied knowledge. For example, the classification of urban area and road networks were aided with a thematic layer containing urban areas and road networks within the area of classification. The land-use classes were broadly categorized to include all the classes as used in the lowresolution data; which are agriculture, barren, forest, roads, transitional, urban and water. 
The most common measures of accuracy assessment in classified remotely sensed imagery are the producer, user and overall accuracy (Story and Congalton, 1986); all based on the error or confusion matrix. The error matrix is simply a square array of numbers set out in rows and columns to express the number of pixels assigned to a particular classification category in relation to the actual category as seen on the ground (Congalton, 1991). A maximum of 30 sample objects were selected for each classification category for the creation of test and training area (TTA) mask. The TTA mask (which essentially represents ground reference data) was used to generate an error matrix for accuracy assessment in eCognition software.

\subsection{SWAT MODEL DESCRIPTION}

SWAT is a physically based and continuous time semi-distributed parameter model that is developed to simulate the effects of land management practices on water, sediment, and agricultural chemicals in large and complex watersheds over long periods of time (Arnold et al., 1998). The version of the model that was used for this study is SWAT2009; an ArcGIS extension (ArcSWAT) that provides a graphical user interface for SWAT was used as a means of coupling the modeling framework within a GIS. Albeit newer versions of SWAT were available, we used this version due to GIS software compatibility issues and also the fact that the newer versions did not include significant changes in flow simulation. The model requires input data in DEM, land use data, soils and slope classes for the delineation of Hydrologic Response Units (HRUs). HRUs are created through an overlay of respective slope classes, soils and landuse data. Aggregations of overlays of the same slope class, land-use and soil type are grouped into the same HRU. Figure 2 illustrates the creation of HRUs in the ArcSWAT environment.

The HRU is the basic computational unit of the model and helps to ensure efficient computation. SWAT simulates the hydrology at each HRU using the water balance equation, comprising precipitation, runoff, evapotranspiration, percolation, and base flow components. Runoff is computed with either the Soil Conservation Service Curve Number method (USDA-SCS, 1972) or the Green and Ampt infiltration method (Green and Ampt, 1911) and routed to the closest channel using the Muskingum method (Chow, 1959).

\subsection{SWAT MODEL SETUP}

The models were was set-up in a GIS framework with the ArcSWAT extension of SWAT version 2009 is as shown in Figure 45. The watershed was delineated based on an input $10 \mathrm{~m}$ digital elevation model (DEM). Soils data for all the counties in the study area were obtained from the Soils Survey Geographic database (SSURGO) of the Natural Resources Conservation Service (NRCS). The respective high and lowresolution LULC input data models were subsequently divided into hydrologic response units (HRUs) with specific threshold values based on soils, slope and land-use. These thresholds were obtained through a trial and error procedure to pick the optimum values for the data categories so as to ensure that significant areas of land-use and soils are not excluded and insignificant areas are not included; thus reducing computational overhead and presenting the most likely accurate representation of the watershed in the model. To ensure that the land-cover classes were uniform in both datasets, the landuse refinement option in the HRU definition component was used to refine the land-use categories in both models. The overlay of soil, slope and land-use and subsequent HRU definition operation resulted in the creation of a total of 735 and 367 HRUs for high and low-resolution LULC data models respectively. SWAT formatted observed daily rainfall and temperature data from 1950 to 2010 were obtained from the United States Department of Agriculture's Agricultural Research Service (USDA-ARS) climate database (USDA-ARS, 2012) for the weather stations shown (Figure 46). Greers Ferry Lake, 
located in the mid-section of the watershed was simulated as a reservoir with estimated monthly outflow derived from the reservoir daily outflow data. This data was obtained from the National Inventory of Dams database of the United States Army Corps of Engineers (NID-USACE, 2011).

A third model was added purposely to further evaluate and place the analysis in a broader perspective in terms of the results of the above-described data and in respective of the methods of classification. This model was set-up with LULC obtained from the 2006 National Land Cover Data (NLCD). The NLCD LULC is a $30 \mathrm{~m}$ Landsat 6 enhanced thematic mapper+ $(E T M+)$ with classification based on unsupervised classification method (NLCD2006, 2011). The models were calibrated from 1997 to 2006 and validated from 2007 to 2009 with the data from January-1997 to December-1999 serving as the period for computation of model initial (warm-up period) parameters.

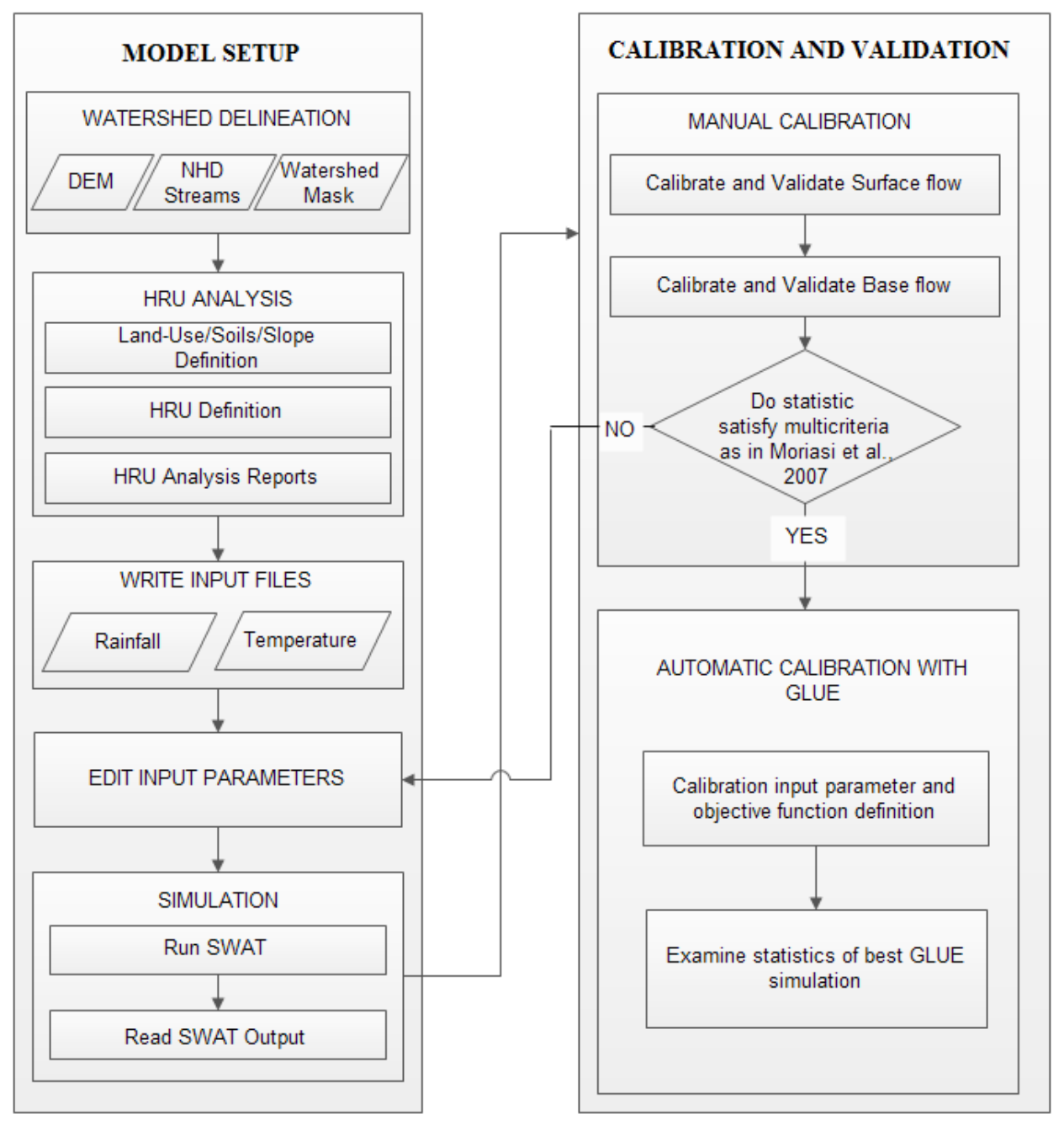

Figure 45: Workflow of modeling framework. 


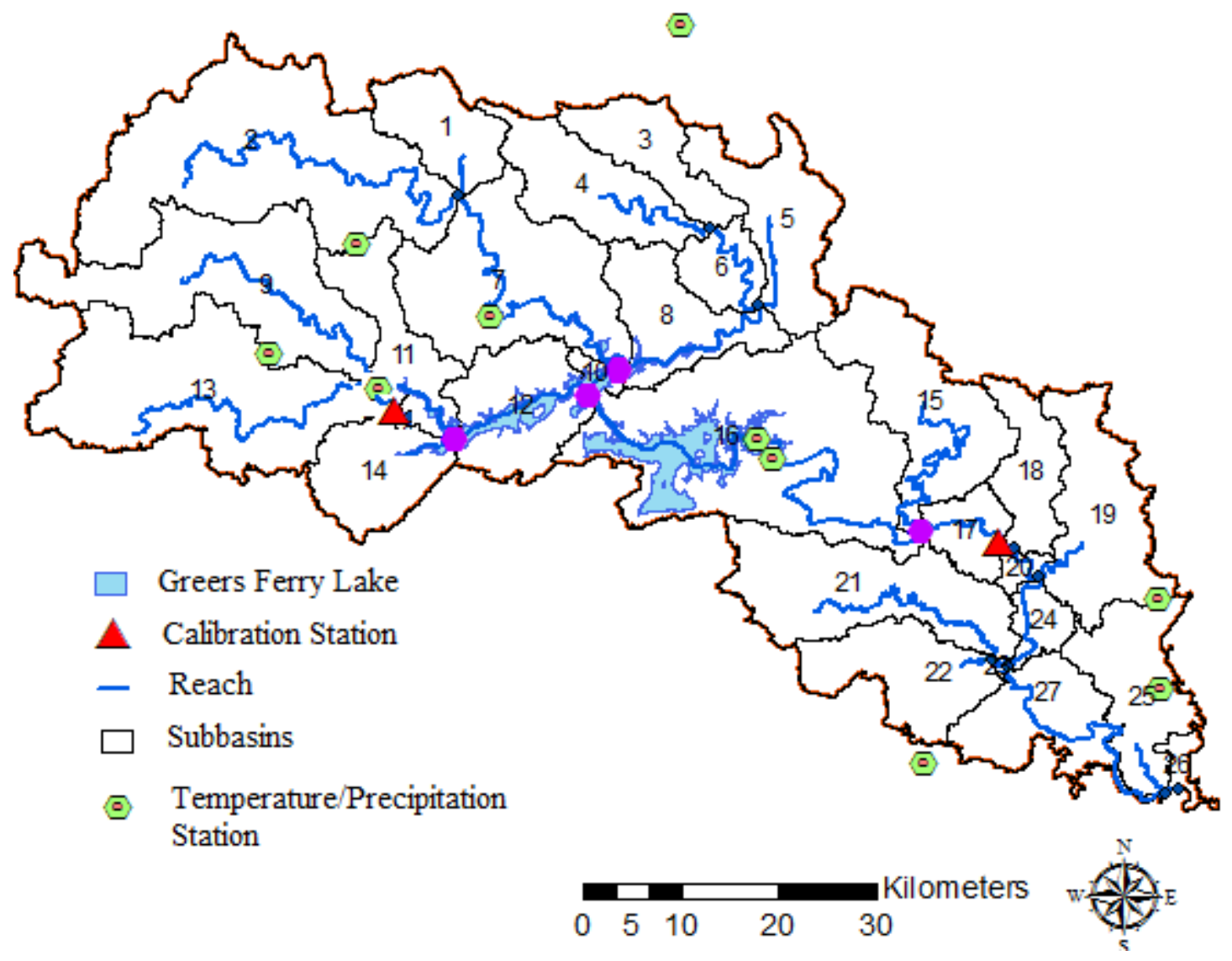

Figure 46: General model Set-up parameter and features. 

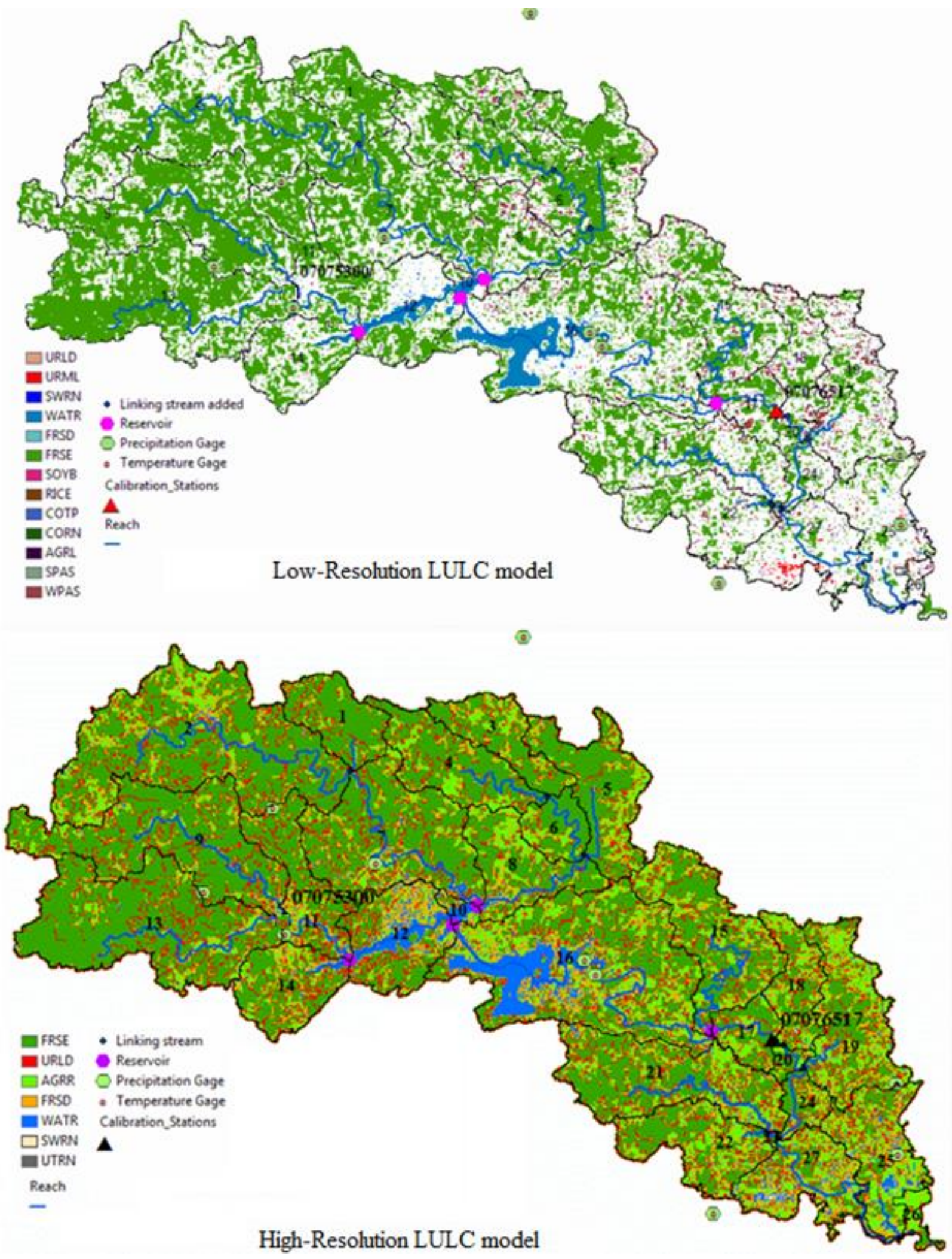

Figure 47: Low and High-Resolution LULC data models after model set-up. 


\subsection{MODEL CALIBRATION}

The model was calibrated against observed data obtained from January 1997 to December 2009 for the calibration station located near Dewey, AR with USGS station number 07076517 (indicated on study area map with red triangle). For manual calibration, parameters identified from literature to be sensitive to flow were iteratively changed till the simulated output satisfied the best fit scenario as defined by the multi-criteria in Moriasi et al., (2007). According to Moriasi et al., (2007), model simulations for streamflow are determined to be satisfactory if NSE $>0.5$ and PBIAS $= \pm 25 \%$. The stages and steps for the model calibration are as shown in figure 2. Total-flow is expressed in SWAT as a combination of surfaceflow and subsurface-flow components. A base-flow filter program obtained from the SWAT model website was used to separate observed total stream-flow into surface and subsurface components for calibration purposes. This program uses an automated base-flow separation method using a digital filter which has been tested to be comparable to manual hydrograph separation methods with an efficiency of $74 \%$ (Arnold et al., 1995).

Calibration was sequentially performed on surface-flow and base flow components. Parameters identified to be sensitive to surface-flow from literature search were canopy maximum storage (CANMX), soil evaporation compensation factor (ESCO), curve number, threshold depth in the shallow aquifer required for return flow to occur (GWQMIN), soil available water content (AWC) etc, (White and Chaubey, 2005; Betrie et al., 2011). We further performed sensitivity analysis to verify the above literature identified flow sensitivity parameter as we could not locate any such study done in a shale-gas impacted watershed. Surface-flow calibration was subsequently followed by subsurface-flow calibration.

Auto-calibration was added to the modeling protocol after manual calibration. In models such as SWAT, no one set of parameter values can be considered as the optimum parameter set as there are several sets of parameter values that can provide an "acceptable" fit for the objective function. This problem is known as equifinality (Beven and Binley, 1992). To account for this problem, a method known as generalized likelihood uncertainty estimation (GLUE) (Beven and Binley, 1992) is applied.

GLUE is coupled with SWAT in a software of uncertainty estimation programs known as SWAT-CUP (SWAT Calibration and Uncertainty Programs), (Abbaspour, 2011). The basic approach of the GLUE program is to estimate uncertainties associated with model predictions through the prior determination of respective probabilities associated with each individual parameter set which are all part of a large collection of parameter sets. The exact algorithm as implemented in the coupling of GLUE with SWAT can be found in Abbaspour (2011). The Nash-Sutcliffe efficiency (NSE) criterion of model performance evaluation was selected as the objective function with a threshold value of 0.5 and a maximum number of 7000 GLUE simulations for both models respectively.

\subsubsection{RESULTS}

\subsection{IMAGE CLASSIFICATION}

During the image classification stage, only object-oriented image analysis was performed as the lowresolution LULC data obtained from the Center for Advanced Spatial Technologies (CAST) was classified with the pixel-based maximum-likelihood classification method. The pixel-based method operates at the pixel level and does not involve the incorporation of any user supplied knowledge of the inherent spectral and spatial difference in the scene. The primary classifier uses the optimized feature space spectral variances. The relative proportion of the total watershed area occupied by each class category as determined from each classification method is presented in Table 7. 
Table 7: Percentage of the total watershed area occupied per class from both methods.

\begin{tabular}{lll}
\hline CLASS NAME & PIXEL-BASED & OBJECT-ORIENTED \\
\hline Agriculture & 17.80 & 20.26 \\
Barren & 0.07 & 0.002823 \\
Forest & 75.17 & 70.45 \\
Water & 3.31 & 4.32 \\
Urban & 3.65 & 4.97 \\
\hline
\end{tabular}

\subsection{ACCURACY ASSESSMENT}

The low-resolution classified data had a reported overall classification accuracy of roughly $88 \%$; however to derive the respective user's and producer's accuracy measures, the classified data was reassessed for accuracy with a minimum of 30 selected reference points per class in the original image and was subsequently used as ground-truth data to derive the error matrix (Gorham, 2013). Further information concerning accuracy assessment of the low-resolution data can be obtained from CAST (2007).

Table 8: Error matrix for accuracy assessment of object-oriented classification.

\begin{tabular}{|c|c|c|c|c|c|c|c|c|}
\hline User \Reference & Forest & Urban & Agriculture & Transitional & Water & Barren & Roads & Sum \\
\hline Forest & 6113 & 1 & 802 & 274 & 0 & 9 & 64 & 7263 \\
\hline Urban & 0 & 5236 & 0 & 350 & 0 & 3 & 277 & 5866 \\
\hline Agriculture & 299 & 774 & 3978 & 236 & 160 & 66 & 136 & 5649 \\
\hline Transitional & 255 & 0 & 9 & 2479 & 0 & 0 & 74 & 2817 \\
\hline Water & 0 & 0 & 2 & 0 & 9491 & 127 & 0 & 9620 \\
\hline Barren & 0 & 0 & 0 & 0 & 0 & 219 & 0 & 219 \\
\hline Roads & 52 & 154 & 806 & 78 & 0 & 57 & 3206 & 4353 \\
\hline Sum & 6719 & 6165 & 5597 & 3417 & 9651 & 481 & 3757 & \\
\hline \multicolumn{9}{|c|}{ Accuracy } \\
\hline Producer & 0.910 & 0.849 & 0.711 & 0.725 & 0.983 & 0.455 & 0.853 & \\
\hline User & 0.842 & 0.893 & 0.704 & 0.880 & 0.987 & 1.000 & 0.737 & \\
\hline Overall & 0.858 & & & & & & & \\
\hline $\operatorname{KIA}(\overline{\boldsymbol{K}})$ & 0.826 & & & & & & & \\
\hline
\end{tabular}


Table 9: Error matrix for accuracy assessment of maximum-likelihood classification.

\begin{tabular}{|c|c|c|c|c|c|c|c|c|}
\hline User $\backslash$ Reference & Agriculture & Forest & Urban & Roads & Transitional & Barren & Water & Sum \\
\hline Agriculture & 33903 & 0 & 8324 & 1766 & 3631 & 73 & 332 & 48029 \\
\hline Forest & 0 & 32957 & 719 & 0 & 1132 & 0 & 0 & 34808 \\
\hline Urban & 0 & 0 & 18797 & 0 & 0 & 0 & 356 & 19153 \\
\hline Roads & 0 & 0 & 797 & 155 & 0 & 0 & 0 & 952 \\
\hline Transitional & 0 & 4199 & 0 & 0 & 19285 & 0 & 736 & 24220 \\
\hline Barren & 0 & 0 & 0 & 0 & 0 & 128 & 0 & 128 \\
\hline Water & 0 & 0 & 0 & 0 & 1374 & 0 & 28541 & 29915 \\
\hline Sum & 33903 & 37156 & 28637 & 1921 & 25422 & 201 & 29965 & 151205 \\
\hline \multicolumn{9}{|c|}{ Accuracy } \\
\hline Producer & 1.000 & 0.887 & 0.656 & 0.081 & 0.759 & 0.637 & 0.952 & \\
\hline User & 0.706 & 0.947 & 0.981 & 0.163 & 0.796 & 1.000 & 0.952 & \\
\hline Overall Accuracy & 0.885 & & & & & & & \\
\hline $\operatorname{KIA}(\overline{\boldsymbol{K}})$ & 0.853 & & & & & & & \\
\hline
\end{tabular}

For the object-oriented image analysis, we used the test and training area utility embedded in eCognition software with random sampling of a minimum of 30 training areas per class for accuracy assessment. Training areas were selected for each classification category and used as the ground reference data. Accuracy assessment was evaluated in terms of the user's, producer's and overall accuracies. The user's and producer's accuracies were above $70 \%$ for all classes except the agriculture class which had the lowest accuracy in both measures. The average user's and producer's accuracies were approximately $78 \%$ and $86 \%$ respectively. The overall classification accuracy was also approximately $86 \%$ as compared to $88 \%$ of the low-resolution data classification. The respective error matrices are presented in Tables 8 and 9.

To determine if the values for the respective overall accuracies were significantly different (statistically significant), the Kappa index of agreement (KIA) and a pairwise Z-score test (Congalton and Green, 1999; Weih and Riggan, 2013) were calculated for both methods of classifications based on the following equations.

$$
\begin{gathered}
\bar{K}=\frac{\mathrm{Po}-\mathrm{Pc}}{1-\mathrm{Pc}} \\
Z=\frac{|\overline{\mathrm{Ka}}-\overline{\mathrm{Kb}}|}{\sqrt{\operatorname{var}(\overline{\mathrm{Ka}})+\operatorname{var}(\overline{\mathrm{Kb}})}}
\end{gathered}
$$

Where Po and Pc are the respective overall and chance classification measures, $\bar{K}$ is the kappa index (with a and $\mathrm{b}$ subscripts designating the respective error matrix measures) and $\operatorname{var}(\overline{\mathrm{Ka}}), \operatorname{var}(\overline{\mathrm{Kb}})$ are the respective variances related to the two kappa indices. The KIA index measures the agreement between two observed and predicted values and is also used to determine whether the agreement is by chance; the index ranges from 0 to 1 with values closer to 0 indicating chance agreement (Congalton and Green, 1999). KIA values that are higher than 0.8 represent a strong agreement between the 
classified and the reference data while those between 0.4 and 0.8 indicate moderate agreement (Congalton and Green, 1999; Congalton, 2005).

For the low-resolution data classification, the derived KIA was 0.85 while that for the high-resolution object oriented classification was 0.82 . This indicates a slightly stronger agreement between the maximum-likelihood method classification and reference samples than the object-oriented method and its corresponding reference data. Additional calculations were performed on variances relative to the kappa statistic using a method outlined in (Congalton and Green, 1999) and obtained values of 0.23 and 0.16 for the object-oriented and maximum-likelihood methods respectively. This further showed that the maximum-likelihood classification yielded a slightly better agreement with the reference data.

In comparing the two methods by their respective error matrices, the pairwise Z-value computed from the stated equation was 0.032 which is less than 1.96, taking a confidence level of $95 \%$ on the standardized normal distribution. This shows that there is no statistically significant difference (at the 95\% confidence level) between the classification methods as applied in this study.

\subsection{IMAGE CLASSIFICATION DISCUSSION}

The feature space optimization algorithm of the maximum-likelihood method results in pixels that are spectrally more homogenous within a specific class than they are to other classes. Therefore the classification is based on pixels within a land-cover class that are spectrally similar in the feature space. However, this is not always true in complex environments (Burnett and Blaschke, 2003) like in our study area. This is seen in the pixel-based method classified data in Figure 44. It can be seen that spatial continuity of the classified classes is not as strong as that of the object-oriented classified image on the left. This is also attributable to the fact that no spatial relationship is used in the maximum-likelihood classification method. Another feature which is apparent from the pixel-based classified image is that the data appears to depict more isolated pixels are classes within the land surface. This effect known as the "salt and pepper effect" (Lang et al., 2006) arises from the fact that pixels are potentially classified differently but that they may actually belong to the same class. Thus as this method accounts for spectral autocorrelation, the lack of spatial knowledge in the classification algorithm potentially leads to wrongful classification. This is eliminated in the object-oriented classified image through segmentation.

Segmentation in the object-oriented classification uses spatial, textural, shape and spectral information to group pixels into object for subsequent classification. This increases the probability of a reference pixel being accurately classified (producer accuracy). The forest cover therefore had the highest producer's accuracy (table 3 ) due in part to the fact that the watershed is predominantly forested and was well aggregated than the other classes based on the previously stated factors used in the segmentation. This also in part, explains the low producer's accuracy obtained for the barren land class (table 3). Another reason for this low value for the barren class is that the barren land bears similar spectral, spatial and textural qualities to the urban class.

However in this study the similar overall accuracy values obtained from both methods of classification represent a marked difference from studies such as Gao (2003) and Rutherford and Platt (2008) that reported significantly higher accuracies for the object-oriented method than the pixel-based method. Generally, the object-oriented image classification method is known to offer higher overall classification accuracy. This departure from the general trend could be as a result of the lack of heterogeneity in the greater percentage of the study area. As mentioned the study area is predominated forested, therefore 
an approach such as the object-oriented method as used in this study with a ruleset which optimizes characteristic of the scene with a much higher precedence than the spectral signature may not prove significantly advantageous.

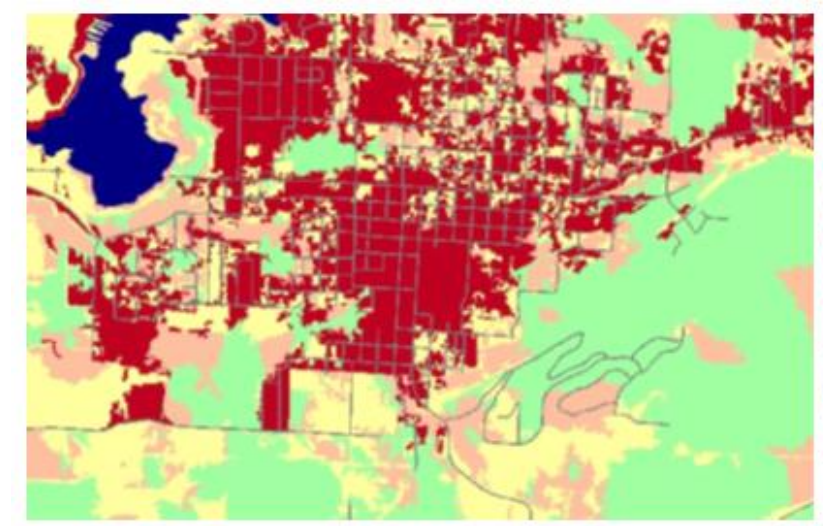

Object-Oriented/high-resolution classified image of study area

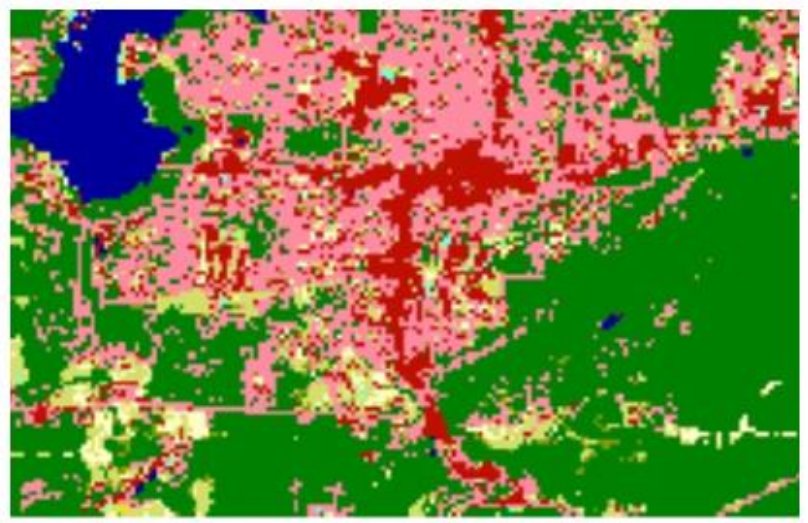

Maximum-likelihood/low-resolution classified image of study area

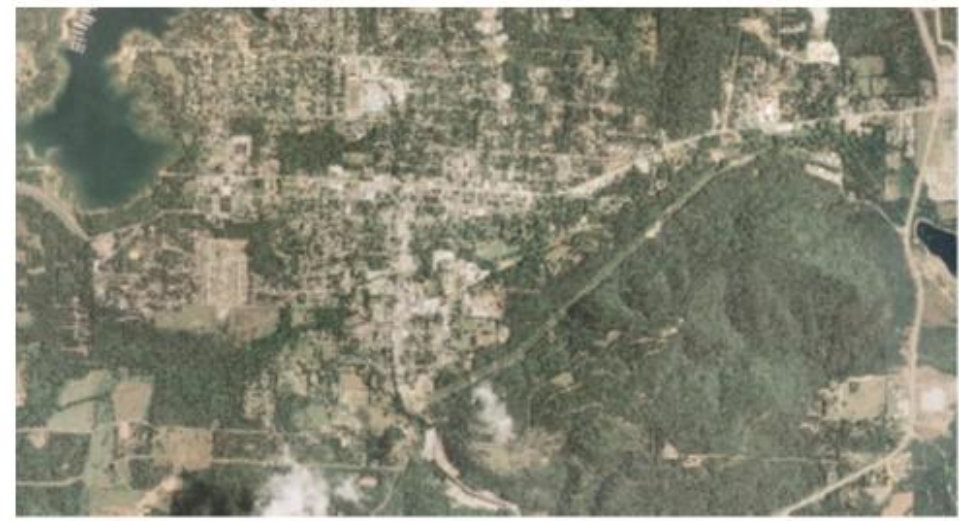

Raw image of part of study area

Figure 48: Illustration of high- and low- resolution LULC data as derived with both methods.

\subsection{PRE-CALIBRATION MODEL RESULTS}

As the separate models are set-up with LULC data of different spatial resolutions, the discretization of $\mathrm{HRUs}$ are consequently different and results in separate numbers for each model - ideally higher for high resolution data of all categories (soils, land-cover etc.). This has the potential to affect the objectivity of the comparisons to be made among the models (DiLuzio, 2013). This effect was accounted for on the comparison by the use of the GLUE methodology (Beven and Binley, 1992) in the autocalibration stage in order to minimize the effect of equifinality. Table 10 gives the results of precalibrated output from each model. 
Table 10: Pre-Calibration Results for Models with different LULC data.

\begin{tabular}{|c|c|c|c|}
\hline Criteria & 30 m Landsat 6 ETM+ & $28.5 \mathrm{~m}$ Landsat 5 & $1 \mathrm{~m}$ NAIP \\
\hline \multicolumn{4}{|l|}{ Calibration Period } \\
\hline NSE & -2.06 & -2.44 & -2.40 \\
\hline $\mathrm{R}^{2}$ & 0.27 & 0.26 & 0.24 \\
\hline PBIAS & -90.95 & -100.42 & -94.27 \\
\hline RSR & 8.27 & 8.04 & 8.72 \\
\hline RMSE & 5.74 & 6.09 & 6.05 \\
\hline Total Water Yield /mm & 665.94 & 703.10 & 672.15 \\
\hline \multicolumn{4}{|l|}{ Validation Period } \\
\hline NSE & -0.85 & -1.00 & -0.97 \\
\hline $\mathrm{R}^{2}$ & 0.35 & 0.33 & 0.32 \\
\hline PBIAS & -59.63 & -63.29 & -59.57 \\
\hline RSR & 1.02 & 1.06 & 1.03 \\
\hline RMSE & 73.95 & 76.80 & 76.26 \\
\hline Total Water Yield /mm & 119.66 & 117.67 & 115.20 \\
\hline P-Factor*/\% & 36 & 37 & 32 \\
\hline R-Factor* & 0.14 & 0.14 & 0.17 \\
\hline Number of HRUs & 522.00 & 367.00 & 735.00 \\
\hline
\end{tabular}

*Determined through auto-calibration with GLUE

The addition of the $30 \mathrm{~m}$ Landsat 6 ETM+ model provides more information that ultimately gives further insight into model behavior regarding different HRU discretization and hence different number of calculation points.

\subsection{MANUAL CALIBRATION AND VALIDATION RESULTS FOR LOW-RESOLUTION LULC DATA MODEL}

The low-resolution LULC model was manually calibrated against monthly flow data from 2000 to 2006 and subsequently validated from 2007 to 2009. Observed stream-flow data constituted the observed total water yield from the contributing sub-basins to the gaging (calibration) station location (Figure 49). The proportion of total water yield contributed by subsurface-flow was estimated to be an average of $42 \%$ from the base-flow filter program. The remainder of the total water yield was the proportion contributed by stream-flow.

The average monthly simulated and observed total stream-flows were $37.11 \mathrm{~m}^{3} \mathrm{~s}^{-1}$ and $40.21 \mathrm{~m}^{3} \mathrm{~s}^{-1}$ respectively. The NSE computed for both the calibrated and validated models were $92 \%$ and $97 \%$ with 
simulation biases (PBIAS) of $+7.7 \%$ and $+1.9 \%$ respectively; implying that the model is capable of accounting for $92 \%$ of the variance in the calibration period and $97 \%$ of the variance in the model for the validation period. The inclusion of ponds and other smaller reservoirs from data prepared by CAST had insignificant impact on the total stream-flow volume.

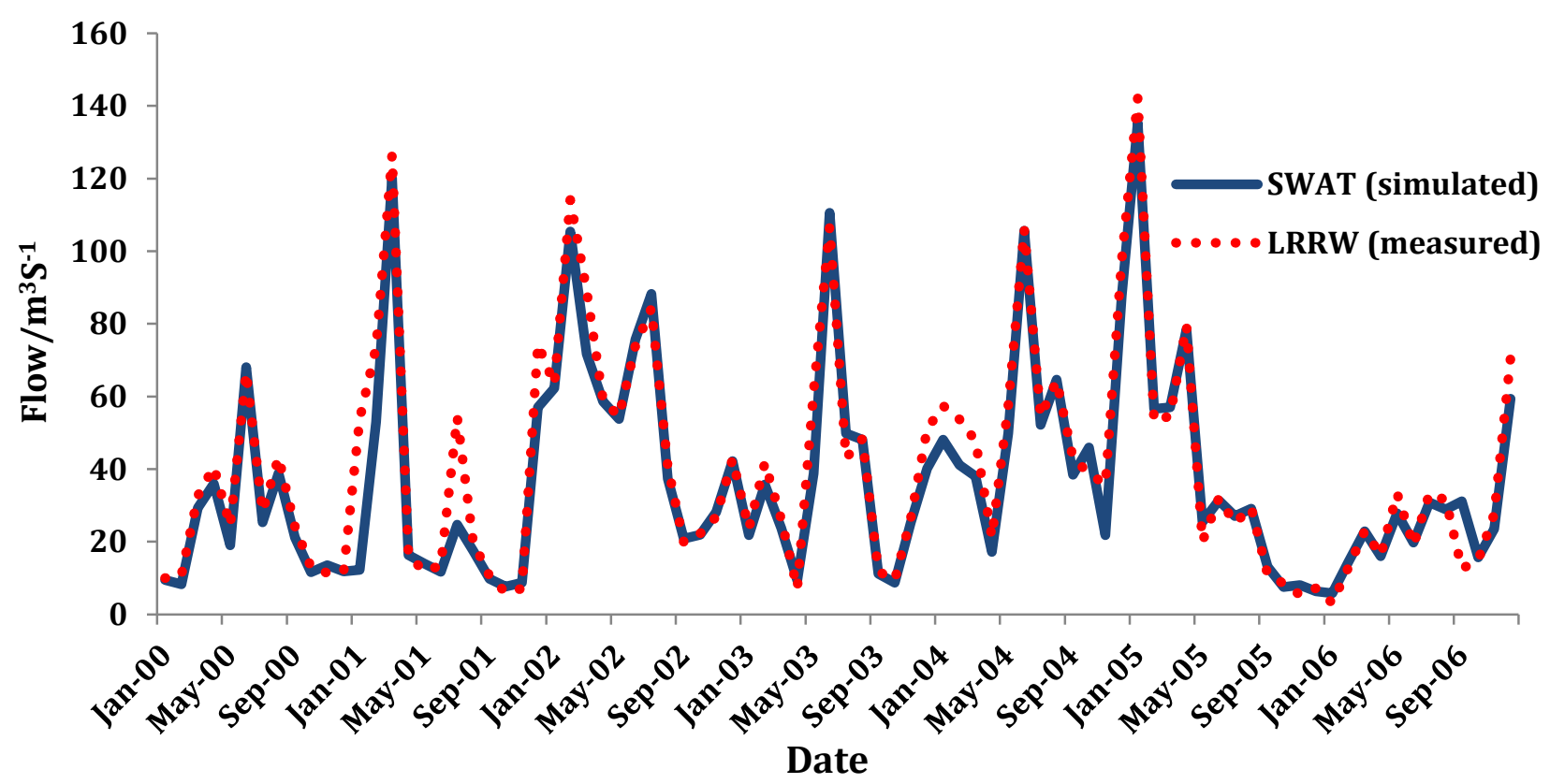

Figure 49: Calibrated monthly SWAT total flow model with low-resolution LULC data.

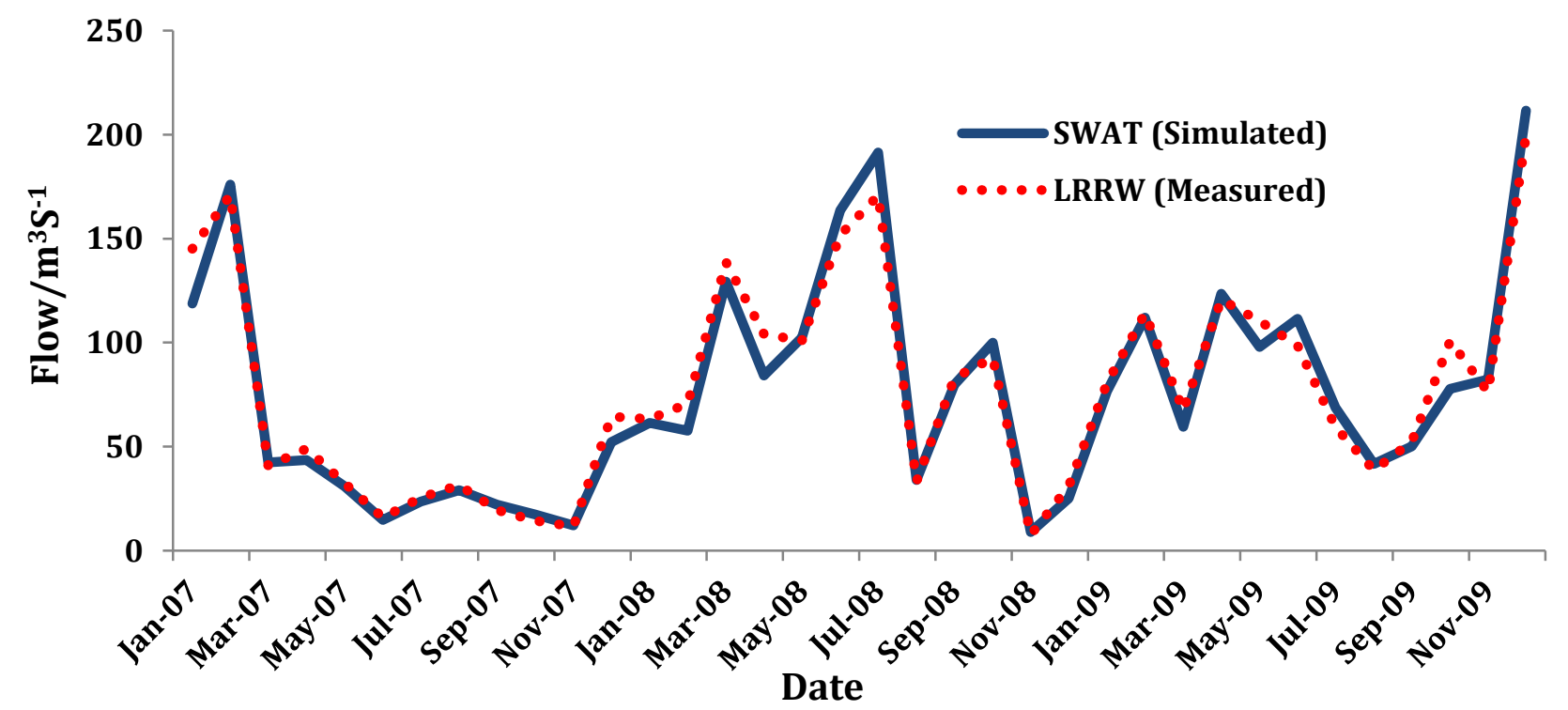

Figure 50: Validated monthly SWAT total flow model with low-resolution LULC data. 


\subsection{MANUAL CALIBRATION AND VALIDATION RESULTS FOR HIGH-RESOLUTION LULC DATA}

MODEL

Results for calibration and validation for the high-resolution LULC data model were similar to the lowresolution LULC data model. As in the low-resolution model, parameters identified to be sensitive to flow from literature search (Betrie et al., 2011; White and Chaubey, 2005) were iteratively changed between successive runs. Among these the most sensitive parameters to flow simulations identified through sensitivity analysis in our study are listed in Table 10 . The average monthly simulated and observed total stream-flow was $36.81 \mathrm{~m} \mathrm{~s}^{3} \mathrm{~s}^{-1}$ and $40.01 \mathrm{~m}^{3} \mathrm{~s}^{-1}$ respectively. The computed NSE for both the calibrated and validated models were $91 \%$ and $97 \%$ with simulation biases (PBIAS) of $+10.78 \%$ and $+3.23 \%$ respectively; implying that the model is capable of accounting for $91 \%$ of the variance in the calibration period and similarly for the validation period.

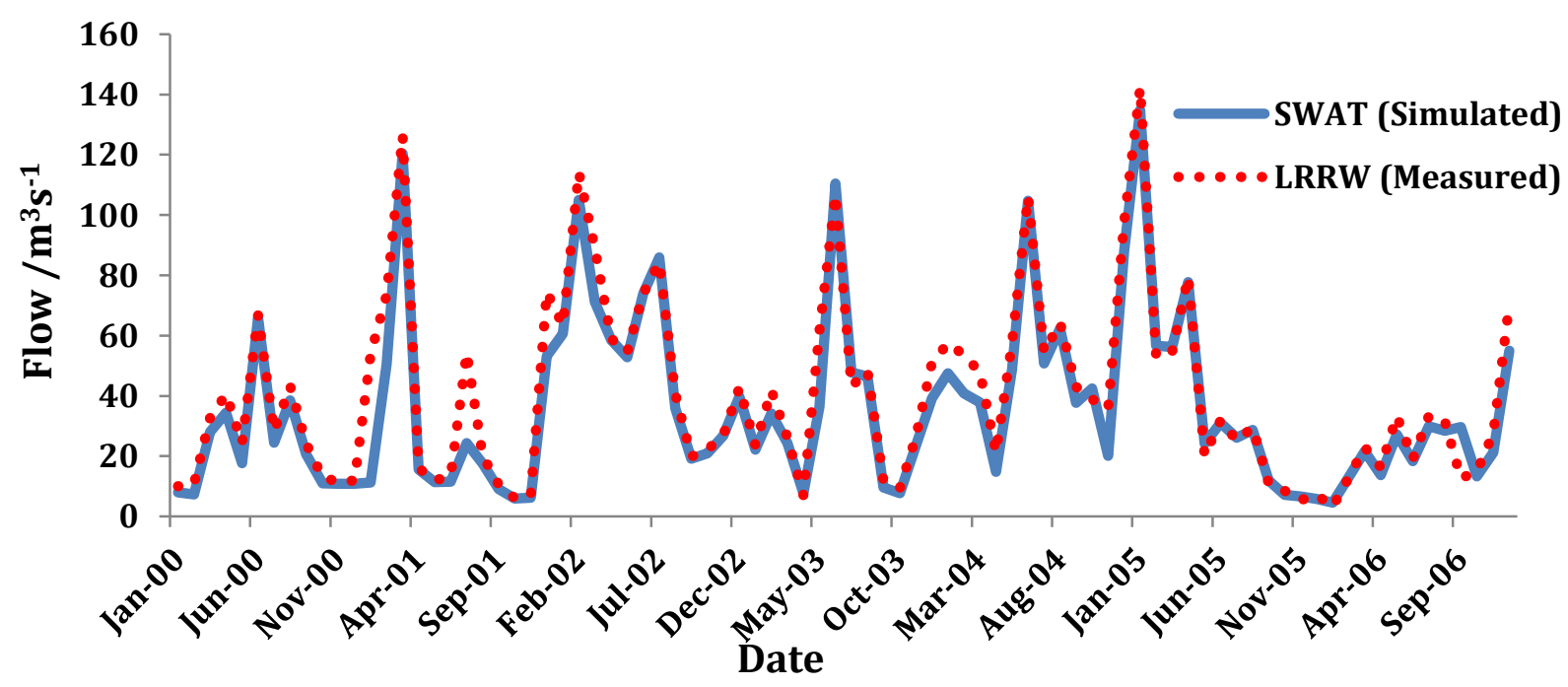

Figure 51: Calibrated monthly SWAT total flow model with High-resolution LULC data.

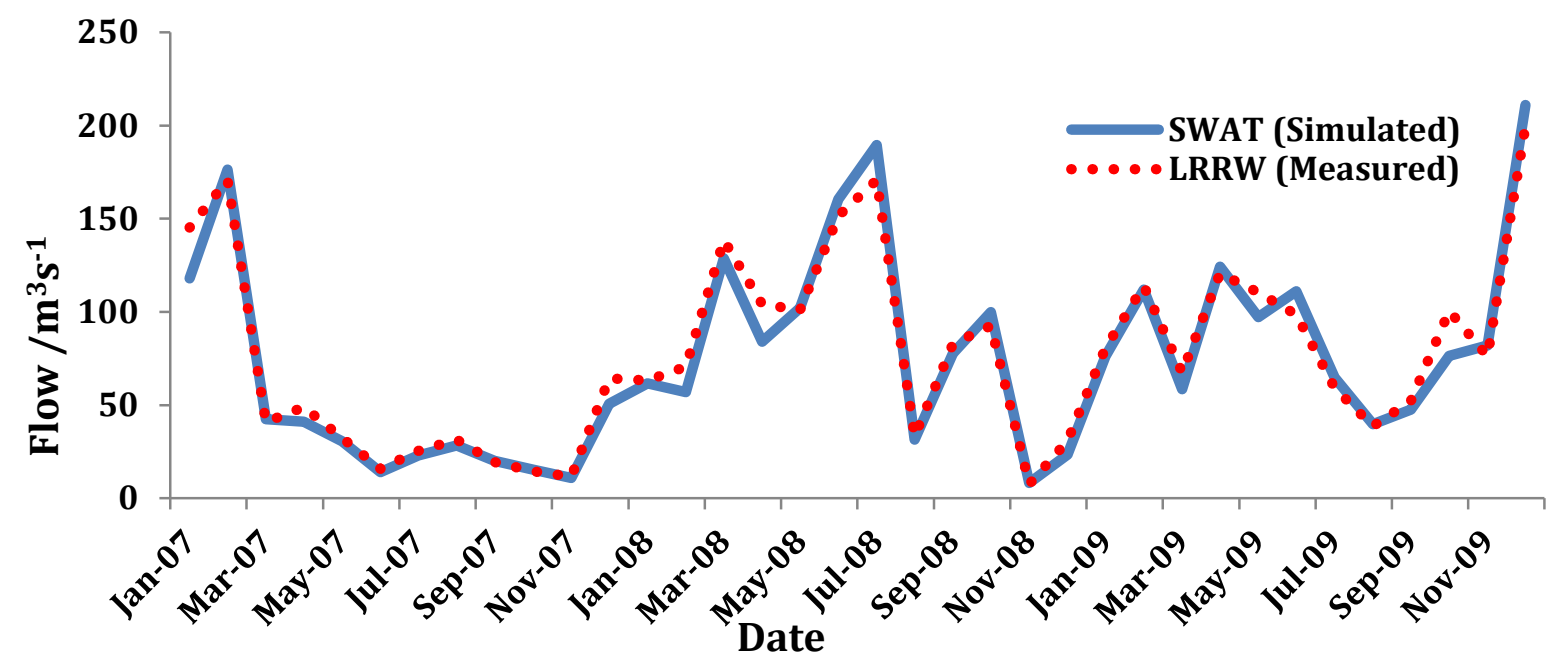

Figure 52: Validated monthly SWAT total flow model with high-resolution LULC data. 
Table 11: Sensitive parameters and parameter ranges in decreasing order of sensitivity.

\begin{tabular}{|c|c|c|c|c|c|}
\hline \multirow[t]{3}{*}{ *Parameter } & \multirow{3}{*}{$\begin{array}{l}\text { Min } \\
* * *\end{array}$} & \multirow{3}{*}{$\begin{array}{l}\text { Max } \\
* * *\end{array}$} & \multicolumn{2}{|l|}{ Values } & \multirow[t]{3}{*}{ Parameter Description } \\
\hline & & & \multicolumn{2}{|c|}{$* *$ Average } & \\
\hline & & & HR & LR & \\
\hline r_CN2.mgt & -0.2 & 0.2 & 78 & 83 & Curve Number \\
\hline v_GW_DELAY.gW & 1.0 & 30 & 20 & 10 & Groundwater Delay Time/days \\
\hline r_SOL_BD.sol & -0.5 & 0.6 & 1.45 & 1.45 & Soil Moist Bulk Density/gcm ${ }^{-3}$ \\
\hline v_ALPHA_BNK.rte & 0.0 & 1.0 & 0 & 0 & Base Flow Alpha Factor for Bank Storage/days \\
\hline v_GW_REVAP.gW & 0.0 & 0.2 & 0.09 & 0.05 & Groundwater re-evaporation Coefficient \\
\hline v_ESCO.hru & 0.8 & 1.0 & 0.2 & 0.9 & Soil evaporation compensation factor \\
\hline v_GWQMN.gw & 0.0 & 2.0 & 1 & 0 & Shallow aquifer threshold depth $/ \mathrm{mm}$ \\
\hline r_SOL_K.sol & -0.8 & 0.8 & 9.993 & 9.993 & Saturated Hydraulic Conductivity/kmhr ${ }^{-1}$ \\
\hline r_SOL_AWC.sol & -0.2 & 0.4 & 0.11 & 0.11 & Soil Available Water Capacity/mm/mm \\
\hline v_CH_K2.rte & 5 & 15 & 5 & 5 & Channel Hydraulic Conductivity/mmhr ${ }^{-1}$ \\
\hline v_CH_N2.rte & 0.0 & 0.3 & 0.014 & 0.014 & Manning's n Value for main channel \\
\hline v_ALPHA_BF.gw & 0.0 & 1.0 & 0.048 & 0.0112 & Base Flow Alpha Factor/days \\
\hline v_SFTMP.bsn & -5.0 & 5.0 & 1 & 1 & Snowfall Temperature $/{ }^{\circ} \mathrm{C}$ \\
\hline
\end{tabular}

\subsection{AUTO-CALIBRATION RESULTS FOR LOW-RESOLUTION LULC DATA MODEL}

The GLUE method was used in a coupled SWAT software system (SWAT-CUP) (Abbaspour, 2011) to automatically calibrate the models with model parameters constrained to limits that depict the prevailing watershed. The GLUE method allows for the evaluation of the models based on the uncertainties associated with the sampled parameter sets.

From 7000 simulations, 6997 of the simulations had NSE values of $50 \%$ or above (termed behavioral model runs). The NSE for the best simulation was $92 \%$ with RMSE of 8.3; determined from the validation period. The predictive reliability of the model was evaluated based on uncertainty quantifications as determined from two main parameters output from the GLUE analysis; the $P$-factor and $R$-factor. A larger $P$-factor indicates a good fit and ranges between 0 and $100 \%$ whiles $R$-factor ranges from 0 to $\infty$ with lower values depicting a good fit (Abbaspour, 2011).

With the low-resolution model, auto-calibration resulted in $P$ and $R$-factors of $37 \%$ and $14 \%$ respectively. This essentially implies that $37 \%$ of the observed flow data can be accounted for by the model at the $95 \%$ prediction uncertainty level. We assumed that all the uncertainty in the model is attributable to the uncertainty in the observed data as other system uncertainties were deemed improbable to quantify with our knowledge of the watershed.

$P$ and $R$-factors results for the simulations run to validate the calibration model were $32 \%$ and $18 \%$ respectively. Figure 53 shows a graph of the calibration output with the best simulation and uncertainty band. 


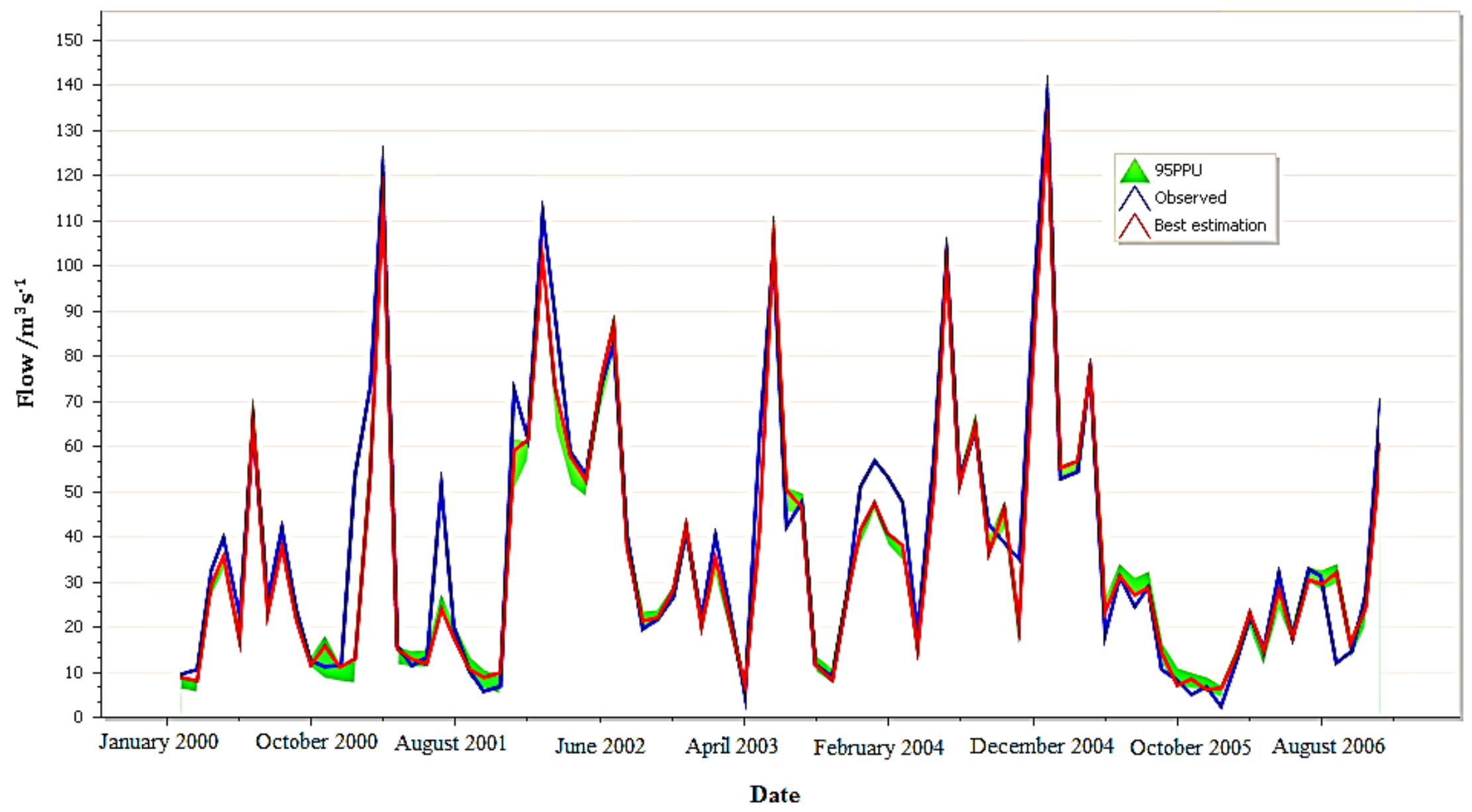

Figure 53: Auto-calibration output of low-resolution LULC model with best simulation and 95 percent prediction uncertainty band. 


\subsection{AUTO-CALIBRATION RESULTS FOR HIGH-RESOLUTION LULC DATA MODEL}

Similar to the low-resolution model simulations, 7000 auto-calibration runs were performed for the high-resolution data model; out of which 6997 (same as in the low-resolution) were behavioral. The calibration NSE for the best simulation was $92 \%$ with RMSE of 8.3 at $P$ and $R$-factors of $39 \%$ and $14 \%$ respectively. Therefore, the model is able to account for $39 \%$ (slight increase from $37 \%$ of the lowresolution LULC model) with the same uncertainty band of $14 \%$ (Figure 54). This implies that in spite of the higher number of HRUs which also implies a more detailed discretization of the model, the highresolution LULC model could account for $39 \%$ of the measured discharge data; this represent a slight increase of $2 \%$ over the low-resolution data model. The model was further validated for same period as in the low-resolution LULC model; results of the validation showed obtained $P$ and $R$-factors values of 0.32 and 0.17 respectively.

Furthermore, among the 13 parameters that were optimized (listed in table 2), groundwater delay (GW_DELAY), evapotranspiration compensation factor (ESCO), soil bulk density (SOL_BD), curve number for antecedent moisture condition II (CN2), soil available moisture content (SOL_AWC) and soil hydraulic conductivity (SOL_K) (in decreasing order of sensitivity) were determined to be most sensitive through sensitivity analysis performed in SWAT-CUP (Abbaspour, 2011). 


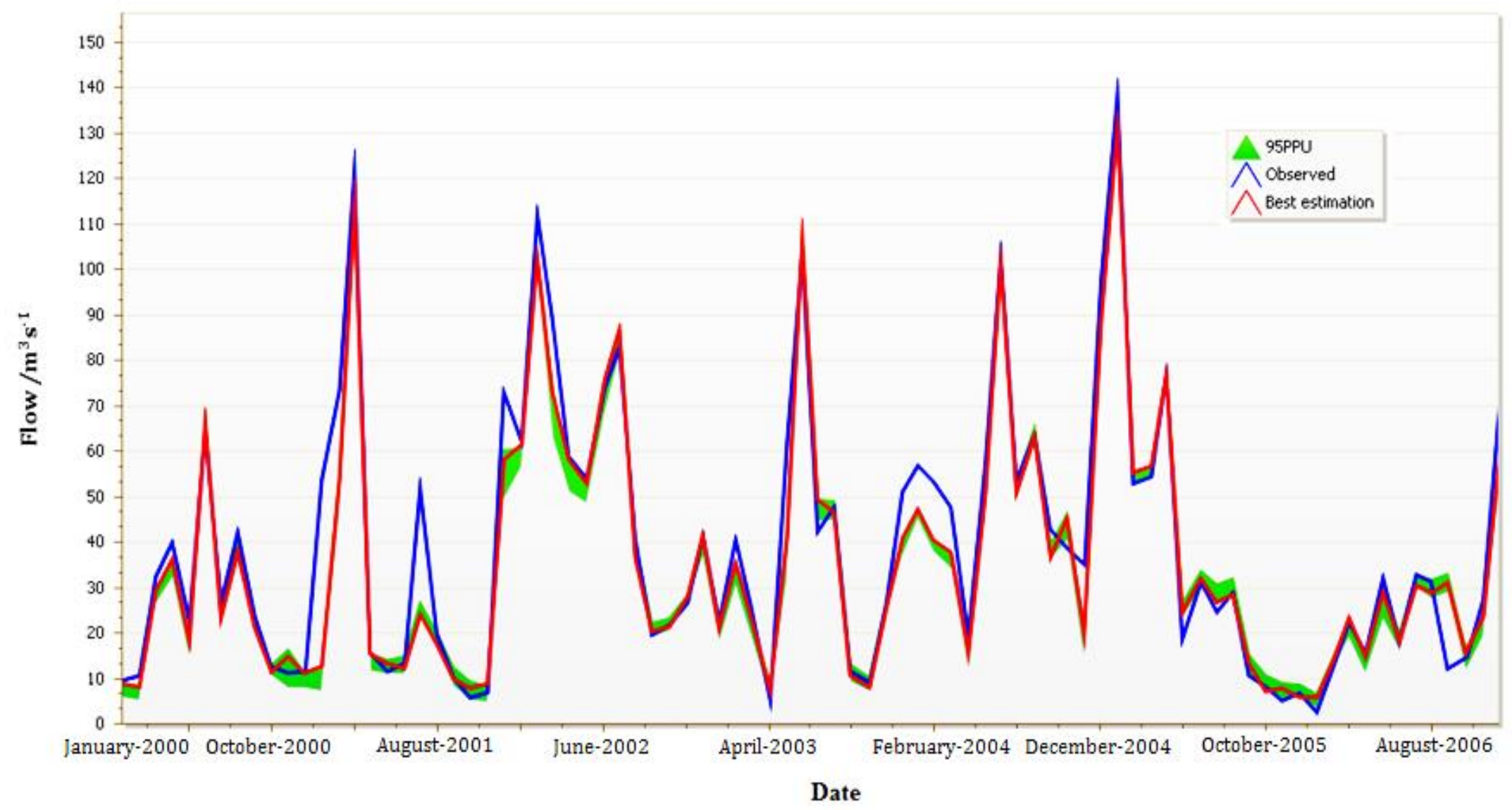

Figure 54: Auto-calibration output of high-resolution LULC model with best simulation and 95 percent prediction uncertainty band. 


\subsection{NLCD LAND-COVER DATA MODEL RESULTS}

This model was calibrated with LULC data of $30 \mathrm{~m}$ resolution, classified with unsupervised classified method (USGS, 2007) with DEM, soils data and slope specified in the same way as the previous models. Over all, 522 HRUs were discretized for this model compared to the 367 and 735 for low and high LULC models. The results of the flow calibrations and validation were also determined similarly to the previous LULC data models; calibrated and validated against observed monthly stream-flow from 2000 to 2006 and 2007 to 2009 respectively.

The simulated monthly stream-flow showed acceptable results for the calibration period with NSE, PBIAS, RSR, $\mathrm{R}^{2}$ and RMSE values $0.91,10.84 \%, 0.24,0.93$ and 0.99 respectively according to multi-criteria outlined in Moriasi et al., (2007). For the validation period, the measured aggreement between observed and simulated flow values was indicated by NSE, PBIAS, RSR, $\mathrm{R}^{2}$ and RMSE values of 0.96 , $3.24 \%, 0.19,0.97$ and 10.2 respectively. By this, it is can be inferred that the model slightly underpredicts the system stream-flow response by $3.24 \%$ while showing a correlation of $97 \%$ of the simulated stream-flow to the observed stream-flow.

Through auto-calibration using GLUE, the NLCD model was determined to capture $36 \%$ of the observation with $r$-factor of 0.14 at the $95 \%$ prediction uncertainty level, correlation coefficient of $92 \%$ and NSE of 0.92 . Out of the 7000 simulations, 6997 were determined to provide acceptable results; the same number as the previous models. 


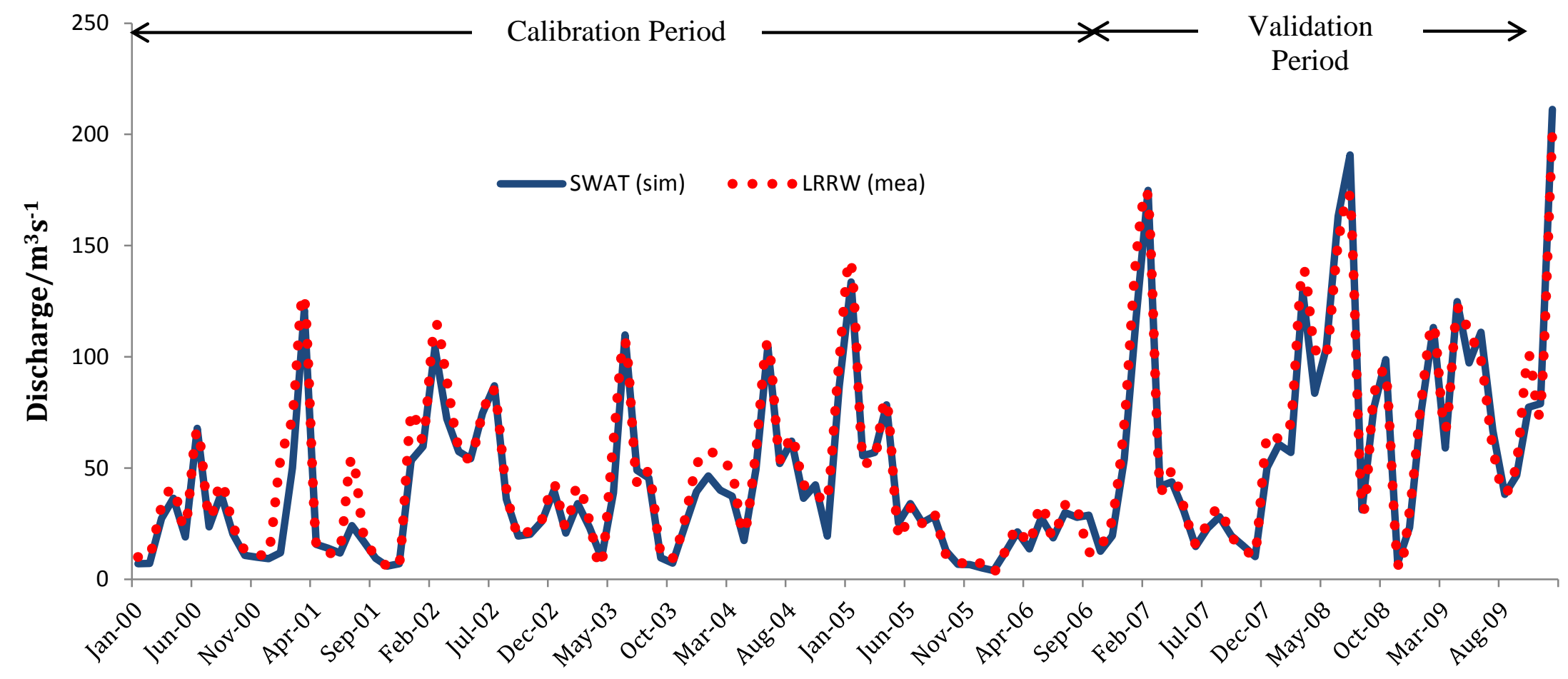

Figure 55: SWAT monthly total flow model with NLCD LULC data (Manual Calibration). 


\subsection{MODEL PREDICTION BIAS FOR HIGH AND LOW-FLOW REGIMES}

In the watershed, water-yield is generally low in August (shown in Figure 51). For the entire period of the simulation (2000 to 2009) in the NLCD LULC data model, the simulated flow represented a general over-prediction. August stream-flow was under-predicted for all the ten years of simulation. Similarly for high water-yield which normally occurs around the months of March, April and May, the model under and over-predicted the system stream-flow; in May-2001, 2005 and2008, the model over-predicted the stream-flow by $17 \%, 25 \%$ and $2 \%$ respectively. The lowest under-prediction occurred in May-2003 (under-predicted by $37 \%$ ). Generally the model under and over-predicted stream-flow in the high-flow season by an average value of $15 \%$ respectively.

For the low and high-resolution LULC models, there was only a slight over-prediction of August low stream-flow of $2 \%$ and $7 \%$ respectively for two (2008 and 2009) out of the ten years of simulation in the case of the low-resolution LULC model. For the high-resolution LULC data model, low stream-flow for August was slightly over-predicted one out of the ten simulation years; by $3 \%$ for 2009 . The average under-prediction was $7 \%$ for both low and high-resolution models respectively. Again to offer some more perspective on these two model results, the NLCD model generally over-predicted August streamflow by an average value of $8 \%$. Table 11 shows the comparison of model results for the average simulation prediction bias for high and low stream-flow periods in the watershed.

In highly managed watersheds, primary controlling hydrological processes take a secondary role in dictating the hydrological responses of the entire watershed (Abbaspour, 2011). This is certainly the case in our study with regards to the calibration site. It does not take a keen observation to realize that the calibration and validation values of the two LULC dataset models are near "perfect". This is inferred to be contributed by the fact of the presence of the Greers Ferry Lake from which water is released at specific times of the day. The measured release rate we incorporated into the models in order to ensure an accurate calibration. This however, introduces the problem of a highly managed watershed as discussed in Abbaspour (2011). In the above model calibrations, the primary controlling hydrological processes in the system take a secondary role in the model. In other words, our models as calibrated do not adequately reflect the other prevailing environmental processes that might affect the hydrology of the system if Greers Ferry Lake had not been present in the system.

Table 12: Model average percentage prediction bias for low and high-flow regimes.

\begin{tabular}{ccccc}
\hline Model & \multicolumn{2}{c}{ High-Flow Regime } & \multicolumn{2}{c}{ Low-Flow Regime } \\
\hline & Under-Predicted & Over-Predicted & Under-Predicted & Over-Predicted \\
\hline NLCD LULC Model & 15.47 & -15.37 & 8.14 & None \\
Low-Resolution LULC Model & 10.62 & -8.83 & 6.93 & -3.36 \\
High-Resolution LULC Model & 11.64 & -6.74 & 7.12 & -3.22 \\
\hline
\end{tabular}

*-ve values represent over-prediction and vice versa 


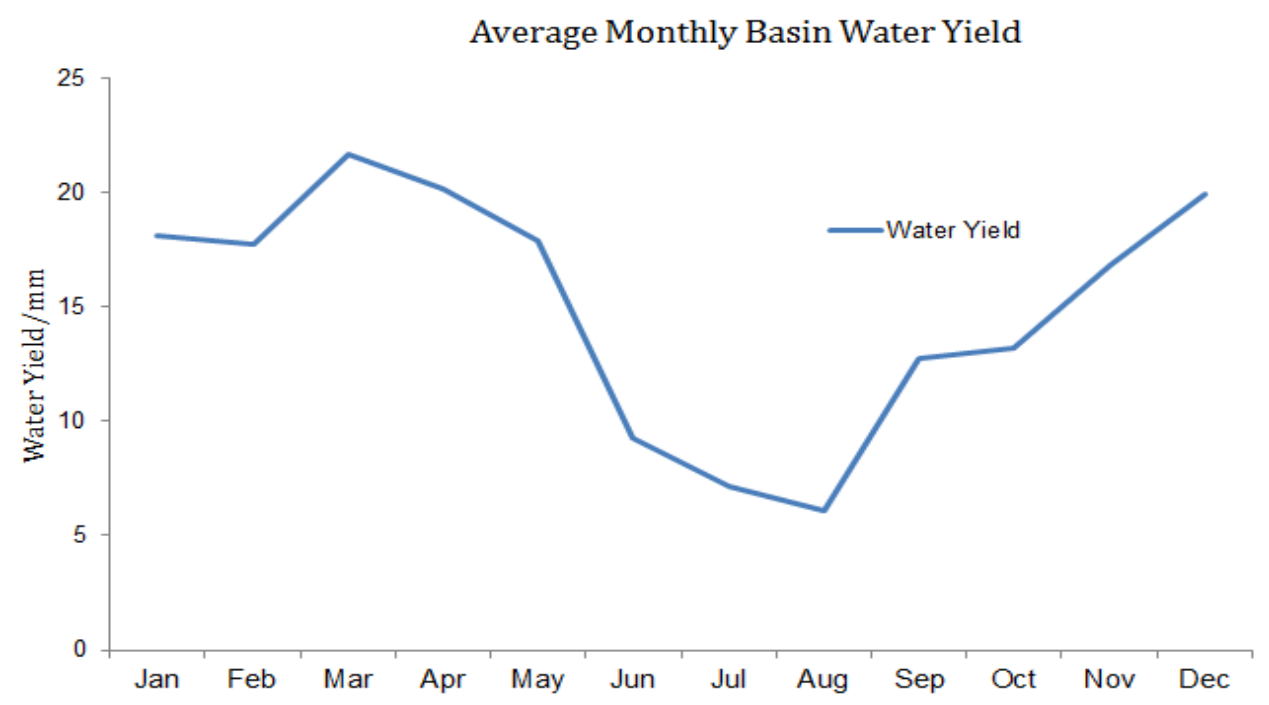

Figure 56: Average monthly basin water yield for the entire simulation period (2000-2009).

To account for this short-coming in the study, the models were calibrated against data from a gaging station located upstream of the Greers Ferry Lake. The results from the manual and automatic calibrations are provided in Table 13.

Table 13: Model calibration for high-resolution LULC model (Upstream gaging station).

\begin{tabular}{|l|r|r|}
\hline \multicolumn{3}{|c|}{ Calibration } \\
\hline Criterion & Hi-Res LULC Value & Low-Res LULC Value \\
\hline NSE & 0.58 & 0.6 \\
\hline$R^{2}$ & 0.6 & 0.6 \\
\hline BIAS & -1.32 & -2.31 \\
\hline RSR & 0.87 & 0.83 \\
\hline Total Water Yield /mm & 472.04 & 469.25 \\
\hline & Validation & 0.88 \\
\hline NSE & 0.87 & 0.9 \\
\hline$R^{2}$ & 0.9 & 11.39 \\
\hline PBIAS & 13.96 & 0.44 \\
\hline RSR & 0.48 & 322.6 \\
\hline Total Water Yield /mm & 363.6 & 0.73 \\
\hline r-factor & 0.33 & 0.55 \\
\hline p-factor & 0.27 & \\
\hline
\end{tabular}




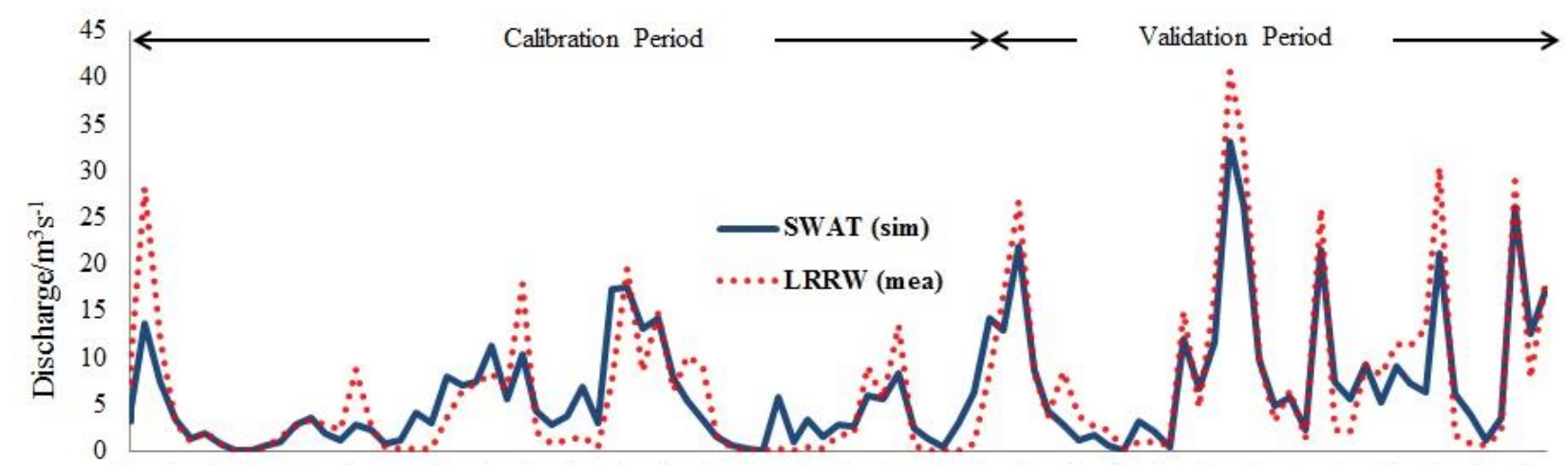

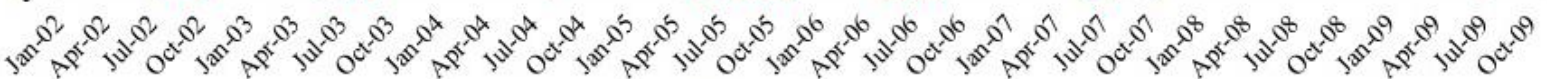

(a)

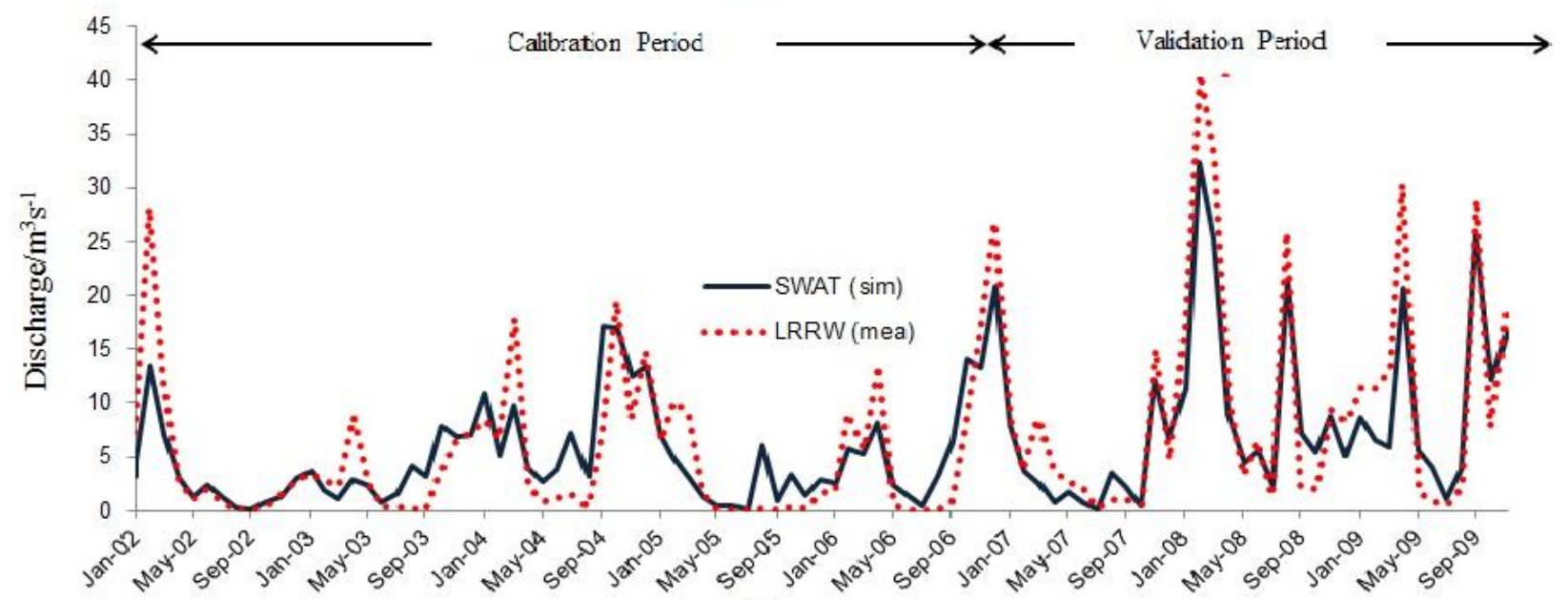

(b)

Figure 57: Hydrograph of low-resolution LULC model (a) and high-resolution LULC model (b) calibrated at the upstream gaging station. 
One key question of interest with regards to this study is as to how low-resolution imagery classified with object-oriented image classification method performs with the SWAT flow model calibration and subsequent predictive reliability. This question becomes particularly pertinent to the study in view of the fact that the object-oriented image classification technique is optimized for high resolution imagery hence most studies in literature are based on high resolution imagery. To account for this in the study, a $30 \mathrm{~m}$ Landsat imagery acquired in $\mathbf{2 0 0 5}$ for the study area was classified with the object-oriented technique and supplied as input land use data to calibrate a SWAT flow model matching the exact same criteria as the two main data models in the study; this model is here-to-fore referred to as the Landsat model.

It was observed during the calibration process that with the same criteria, the Landsat model was more difficult to calibrate manually. After several iterations, the best manual calibration yielded NSE of 0.41 with an approximate total stream flow over-prediction rate of $12 \%$. The model was further subjected to the outlined auto-calibration method using GLUE as implemented in SWAT-CUP software. Due to the effect of the incorporated reservoir outflow data masking out the primary hydrologic process, more credence in our results is given to the calibrated model in the upstream gage location. However, the results from both stations are presented. At the upstream location, the auto-calibrated model produced NSE of 0.57 with a $p$-and $r$-factors of 0.28 and 0.32 respectively. This implies that the calibrated model captures $28 \%$ of the observation data with an uncertainty band of 0.32 around the best simulation which is expressed in terms of the observed data standard deviation. Results for the downstream calibration station showed NSE of 0.96 with a $p$ - and r-factors 0.58 and 0.4 respectively. Figure 58 presents the hydrographs of the manual calibration results. 


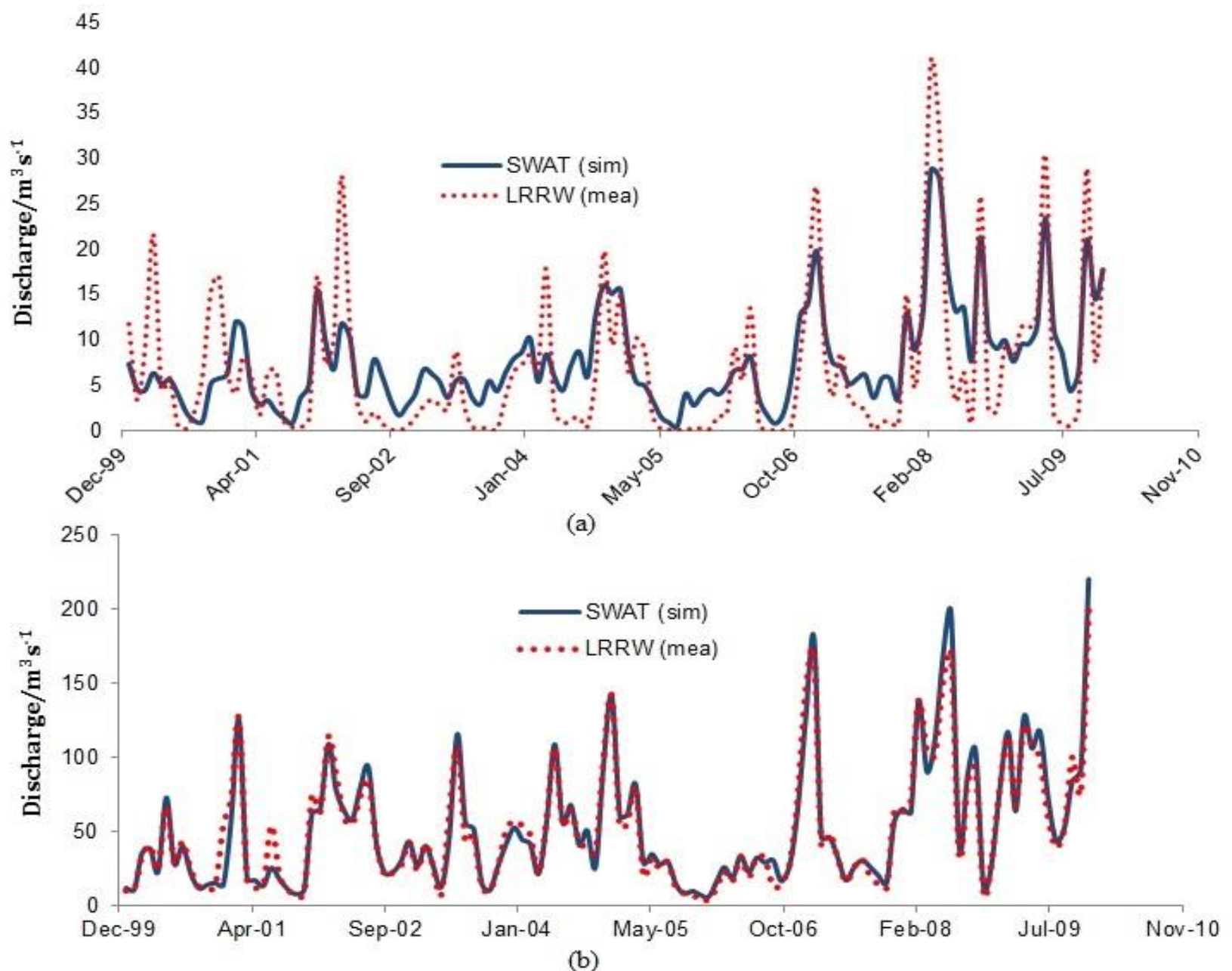

Figure 58: (a) Upstream and (b) downstream manual calibration hydrograph of Landsat model.

\subsubsection{DISCUSSION}

Examination of the low and high-resolution model results from both manual and automatic calibration procedures largely confirms the results obtained by previous researchers such as Cheng et al., (2005) and Bosch et al., (2004). Differences in model behaviour with respect to low and high resolution LULC data and the respective methods of classification on stream-flow prediction reliability, are easier to identify when periods of high and low stream-flow regimes are considered. This approach becomes necessary in this study because all the models have high NSE values and thus how the model captures system variabilities is harder to identify with manual calibration when only NSE values are considered.

The percentage bias in prediction at low and high-regimes in the watershed therefore gives a much better insight into model behavior. This information is presented in table 3. It is clear that the NLCD model over and under-predicts the stream-flow in high-flow regime with much higher bias than both low and high-resolution models. Both low and high-resolution LULC data models have similar over and under-prediction biases when compared to the NLCD data model. It is also worth noting that there was no over-prediction bias with the NLCD model in the low-flow regime. 
The results from both high and low-resolution LULC data models can be explained by the fact that, much as the high-resolution model had higher HRU discretization and slightly higher NSE values, the slightly lower classification accuracy for the high-resolution LULC data could be a factor in the model's inability to account for a greater percentage of the observed discharge data over the low-resolution data model. With the results from the Landsat LULC model indicating a higher predictive reliability at the downstream gaging station, there appears to to an apparent trend in the model results. The trend is that the models with the the lower resolution LULC data appear to offer a much higher stream flow predictive reliability. The main inference for this is that the lack of spatial heterogeneity in the low resolution imagery appear to be that the watershed is itself dominated by forest land cover therefore the main controling process are much better influenced by a cover type which is more generally categorized. By the same reasoning the introduction of spatial heterogeneity as evident in the high resolution LULC data introduces uncertainties in the model that are much less quantifiable with streamflow as a metric of model result reliability determination.

\subsubsection{CONCLUSION}

The objective of this study was to determine the respective impact of high-resolution LULC data classified with the object-oriented image analysis technique and low-resolution LULC data also classified with pixel-based maximum-likelihood technique on the stream-flow predictive reliability of the SWAT model. It was shown that at the manual calibration level, model efficiency were high (NSE of over 90\%) for both models. However, due to significant impact of equifinality (Beven and Binley, 1992) on the nature of the study (also with regards todifferent HRU numbers and model calibration done separately), auto-calibration with GLUE (Beven and Binley, 1992) was a necessary and integral part of the study. Out of which the predictive reliability were determined based on $p$ and $r$-factors.

Both models braketed less than $40 \%$ of the observation data; $32 \%$ and $37 \%$ for high-resolution models respectively. The uncertainty band around the best estimation in each case was higher for the highresolution model as shown by $\mathrm{r}$-factors of 0.17 and 0.14 respectively. It was also clear from our results that a high-resolution imagery classified with the object-oriented method does not enhance the predictive reliability of a SWAT flow model. Furthermore, the object-oriented image analysis albeit it has been shown to provide LULC classification of significantly higher classification accuracy than the pixelbased maximum-likelihood method (Platt and Rapoza, 2008; Yan, 2003), it is also clear from our results that in a watershed with similar characteristics, the object-oriented method has no clear advantage over a pixel-based method in producing LULC data that enhance the predictive reliability of a SWAT flow model. This conclusion is drawn from our study due to the fact that the classification accuracies of the two respective data and mothed combinations, were shown to have no statistically significant difference. Nonetheless, there were some general trends which include the fact that the monthly simulated total water yield were largely similar for both models in the calibration and validation periods. This brings the question of how the model would perform with a significantly better object-oriented classified LULC data; which ultimately requires further studies. Furthermore, a third model set-up with $30 \mathrm{~m}$ NLCD LULC data showed similar result to the low-resolution LULC model; with predictive reliability higher than the high-resolution LULC model. A possible limitation of this study is that, the presence of a reservoir with daily discharge data incorporated in the model makes the system a managed watershed at the chosen outlet. In such a system, natural processes take a secondary role in flow production (Abbaspour, 2011). 


\subsubsection{LAND USE CHANGE SCENARIOS}

\subsubsection{ABSTRACT}

No study can currently be located that is done to quantify the relative change in land-cover particularly regarding shale-gas infrastructure since active exploration and production began in the Fayetteville Shale Play in north-central Arkansas. An object-oriented land-cover change quantification paradigm developed in eCognition was applied on two sets of high-resolution imagery obtained in 2006 and 2010 of the Little Red River watershed (LRRW). The classified land-use land-cover (LULC) data was used to evaluate impact of shale-gas infrastructure change on stream-flow in the South Fork of the Little Red River (SFLRR) which is a sub-watershed of the LRRW.

Results showed that since the upsurge in shale-gas related activities in the Fayetteville Shale Play (between 2006 and 2010), shale-gas related infrastructure in the SFLRR have increase by 78\%. This change in land-cover in comparison with other land-cover classes such as forest, urban, pasture, agricultural and water indicates the highest rate of change in any land-cover category for the study period. A Soil and Water Assessment Tool (SWAT) flow model of the SFLRR simulated from 2000 to 2009 showed a $10 \%$ increase in storm water runoff. A forecast scenario based on the assumption that 2010 land-cover does not see any significant change over the forecast period (2010 to 2020) also showed a

$10 \%$ increase in storm water runoff. Further analyses showed that this change in the stream-flow regime for the forecast period is attributable to the increase in land-cover as introduced by the shale-gas infrastructure.

\subsubsection{INTRODUCTION AND BACKGROUND}

Substantial reserves of natural gas are estimated to be locked up in shale formations found throughout conterminous United States. Various estimates put the total gas in place in the range of 500 tcf to over 600 tcf (tcf: trillion cubic feet); which roughly represent 102 billion barrels of crude oil (Andrews et al., 2009). Owing to their low-matrix-permeability, almost all shale-gas wells require some form of stimulation in order to produce the gas at economically viable rates (Curtis, 2002). One such well stimulation method known as hydraulic fracturing ("fracking") has in addition to technologies such as horizontal drilling has transformed this unconventional natural gas resource into an economically viable one. As a direct consequence of this technological advancement various shale formations have seen a steady increase in exploration and production activities. Among such shale plays is the Fayetteville Shale lay (FSP) located in north-central Arkansas.

Exploration and production of shale-gas in the FSP involve the clearing of vegetation for well-pad, retention ponds, access roads, drilling, etc. These have various environmental impacts including stormwater runoff and sediment loading of downstream water bodies. Environmental considerations of modern shale-gas exploration and production range from issues pertaining to water management, water availability, water handling and transportation, the release of Naturally Occurring Radioactive Materials (NORM), storm-water runoff, management of fracturing fluids, water disposal, urban drilling etc (Arthur et al, 2010). This study however investigates the specific problem of the quantification of LULC change with particular emphasis on shale-gas infrastructure and the subsequent differential effect of the increase in shale-gas related infrastructure on runoff and stream-flow generation in a subwatershed of the Little Red River Watershed (LRRW). Currently, no study can be located to that has been done to quantify the differential impact of shale-gas infrastructure on the relative change in LULC in the FSP. This study employs the object-oriented image analysis paradigm embedded in eCognition 
software to quantify the relative increase in well-pads in the LRRW from readily available and highresolution National Agricultural Imagery Program (NAIP) aerial imagery acquired in 2006 and 2010.

Object-oriented image analysis (OOIA) is a knowledge driven digital image processing technique that mainly involves two stages; segmentation and classification. In the OOIA paradigm, segmentation is a pre-classification step that essentially aggregates pixels into image objects or divides an image into discrete objects based on homogeneity criteria determined by the spatial and spectral properties of the image (Laliberte et al., 2004; Ryherd and Woodcook, 1996). The classification stage involves the assignment of the created objects to classes based on the desired properties of the determined class (Lang et al., 2006). This is done by two main methods; nearest-neighbor based on knowledge samples and membership function based on fuzzy logic (Laliberte et al., 2004). The method has been applied in various studies involving the use of remotely sensed images. These studies bother on investigations in medicine (Baatz et al., 2006), environmental monitoring (Laliberte et al., 2004), ecology (Burnett and Blaschke, 2003), etc. The method has also been applied in change detection in nuclear monitoring studies (Niemeyer et al., 2005), pre and post-conflict damage analysis (Al-Khudhairy et al., 2005), the development of other change detection techniques (Im et al., 2008) etc. Studies have shown that OOIA offers significantly higher classification accuracy than pixel-based methods (Platt and Rapoza, 2008; Blaschke and Strobl, 2001; Yan, 2003).

This study further augments the literature by providing quantifications of change in land-cover as attributable to well-pad placement in a shale-gas watershed using the object-oriented image analysis paradigm embedded in eCognition. The detected change in the LULC data is further employed as input land-cover data to study the differential change in stream-flow in an active shale-gas exploration and production sub-watershed in the study area (LRRW). This is to help quantify shale-gas activity impact on watershed hydrology with respect to other land-cover changes as influenced by categories such as agriculture and urbanization.

The runoff or stream-flow generation and sediment loading potential of well-pad placement in naturalgas producing watersheds has been well documented (Wachal, 2008; Matherne, 2006; Sandahl et al., 2007 and Williams et al., 2007). The South Fork of the Little Red River Sub-watershed (SFLRR) is recognized by the Arkansas Department of Environmental Quality (ADEQ) to contain ecologically sensitive tributaries of the upper Little Red River that are considered Extraordinary Resource and Ecologically Sensitive water bodies (USFWS, 2009). The SFLRR is approximately $387 \mathrm{~km}^{2}$ in area representing roughly $8 \%$ of the total LRRW watershed area. However, this sub-watershed is among the sub-watersheds that see the bulk of shale-gas exploration and production activities in the LRRW (Funkhouser, 2012). Therefore issues such as runoff and sedimentation are of prime importance in order to ensure the survival of such endangered species such as the yellow-cheek darter (which occur nowhere else in the world) (USFWS, 2012). Much as sedimentation is known to adversely impact fresh water species (Henleya et al., 2000), this study does not tackle sedimentation. Rather runoff is tackled as controlling mechanism of sedimentation (Dendy and Bolton, 1976; Easton et al., 2010). The decision to exclude sediment modeling in this study was necessitated by the lack of available long term field observed sediment data.

\subsubsection{STUDY AREA AND METHODOLOGY}

The Little Red River Watershed (LRRW) encompasses the counties of Cleburne, Independence, Pope, Searcy, Stone, White and Van Buren all located in north-central Arkansas. The LRRW is one of the 
watersheds in the Fayetteville Shale Play that is entirely located within the Play and also sees majority of shale-gas related activities. Three main physiographic regions make up the watershed. These are the Mississippi Alluvial Valley, Arkansas Valley and Ozark Mountains. The Mississippi Alluvial Valley is found in the lower-lying portions of the watershed and is relatively level terrain with unconsolidated sediments such as sands, gravel, clay and loess. The Arkansas Valley Region encompasses a part of the mid-section of the watershed with surface rocks consisting of sandstone and relatively higher general elevation than the Mississippi Alluvial Valley. Lastly the Ozark Mountain Region is fairly mountainous with high elevations and steep rock valley walls (AGS, 2011).

The Little Red River is the major water body that flows through the watershed in a generally north-west to south-east direction (Figure 59). Another major water body, the Greers Ferry Lake is also located centrally within the Ozark Mountains physiographic region of the watershed. With an approximate surface area of roughly 30,000 acres (USACE, 2011), this lake plays a major role in the entire watershed hydrology. Between $65 \%$ and $70 \%$ of the watershed's $4668 \mathrm{~km}^{2}$ area land-cover is forest land, with agricultural and urbanized land making up the rest. Located in the lower upstream portion of the LRRW is the South Fork of the Little Red River (SFLRR) sub-watershed. This is a 10-digit HUC (Hydrologic Unit Code) sub-watershed roughly $387 \mathrm{~km}^{2}$ in area with almost $90 \%$ of its land-cover being forest land (CAST, 2006). The SFLRR is selected for the determination of the differential effect of shale-gas related infrastructure on stream-flow due to the fact that this sub-watershed sees the majority of exploration and production activities in comparison to the other sub-watersheds within the LRRW. Also there is a USGS stream gage located at the outlet of the SFLRR sub-watershed with observation data. 

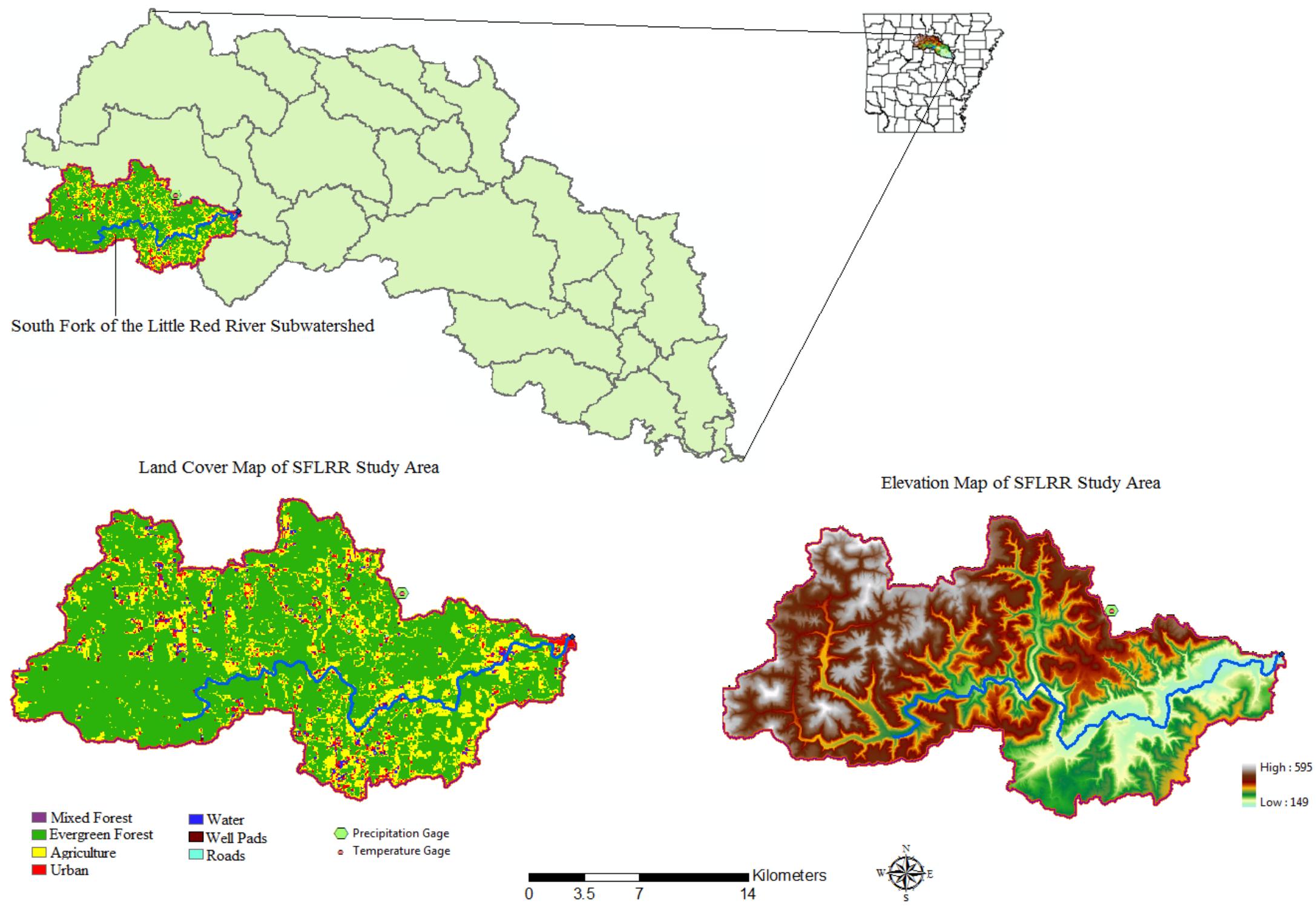

Figure 59: Land-cover and elevation characteristics of the study area: Little Red River Watershed (LRRW). 


\subsubsection{OBJECT-ORIENTED IMAGE CLASSIFICATION AND LAND-COVER CHANGE QUANTIFICATION}

The object-oriented image analysis (OOIA) method involves the two main stages of image segmentation and classification. Segmentation is the division of an image into discrete objects based on the inherent homogeneity or heterogeneity of the pixels that make up the image. The aim of this process is to optimize the correlation between the image objects and the geographical features of the real world which the objects are supposed to represent. Segmentation methodology can be categorized into histogram-based methods, which depend on the feature space, edge-based which depend on searching for edges that occur between heterogeneous objects and region-based which depends on the use of "seed pixels" from which a uniform region is aggregated (Lang et al., 2006).

National Agricultural Imagery Program data from 2006 and 2010 with $1 \mathrm{~m}$ resolution were resampled to $4 \mathrm{~m}$ in order to optimize the segmentation in eCognition, segmented and subsequently classified. Extra image layers were added comprising of infra-red bands and rasterize layer of urban areas located in the study area. Also, thematic layers for transportation network and inventory of hydrologic data (reservoirs, ponds and rivers) were incorporated. This was done to aid classification by introducing further spectral and spatial variability. In this study a fractal net evolutionary approach (FNEA) methodology of image segmentation embedded in eCognition software is used for the segmentation of the images before classification. This method of segmentation allows for the incorporation of scale in the segmentation process and is referred to as multi-resolution segmentation (MRS) (Laliberte et al., 2004). Two segmentation levels with two different scales (100 and 35 respectively) were used in this study. Objects created through the first segmentation level (level 100) were further segmented into smaller objects at the second segmentation level with a scale parameter of 35; both levels using shape and compactness values of 0.1 and 0.5 respectively. These scales were chosen through a trial and error procedure with the goal of optimizing objects size for each classification category. The classification categories are as follows; agriculture, barren land, forest, transitional forest (forest with deciduous trees), urban, transportation (roads), water and well-pads. Classification of the segmented objects were subsequently carried out using a combination of rulesets (based on fuzzy logic) and the nearest neighbor classification method based on user-supplied object samples. This procedure was repeated for both 2006 and 2010 images to produce classified LULC data of the study area. Change detection was primarily performed based on a comparison of the calculated total percentage change in the individual land-cover class of respective areas that were correctly classified in both 2006 and 2010 datasets. This was done for the entire sub-basin in order to obtain a quantification of the well-pads in respect of the other landcover classes in the sub-basin and also obtain a contribution of shale infrastructure to the overall subbasin land-use change.

\subsubsection{THE SOIL AND WATER ASSESSMENT TOOL (SWAT) MODEL DESCRIPTION}

SWAT is a physically based and continuous time semi-distributed parameter model that is developed to simulate the effects of land management practices on water, sediment, and agricultural chemicals in large and complex watersheds over long periods of time (Arnold et al., 1998). The version of the model that was used for this study is ArcSWAT; an ArcGIS extension that provides a graphical user interface for SWAT within a GIS environment. The model has been used to study the impact of biofuel production on water quality (Wu et al., 2012), climate change studies (Gurung and Bharati, 2012; Zhang et al., 2007). The model requires input data in DEM, land-use data, soils and slope classes for the delineation of Hydrologic Response Units (HRUs). HRUs are created through an overlay of respective slope classes, soils 
and land-use data. Aggregations of overlays of the same slope class, land-use and soil type are grouped into the same HRU. Figure 2 illustrates the creation of HRUs in the ArcSWAT environment.

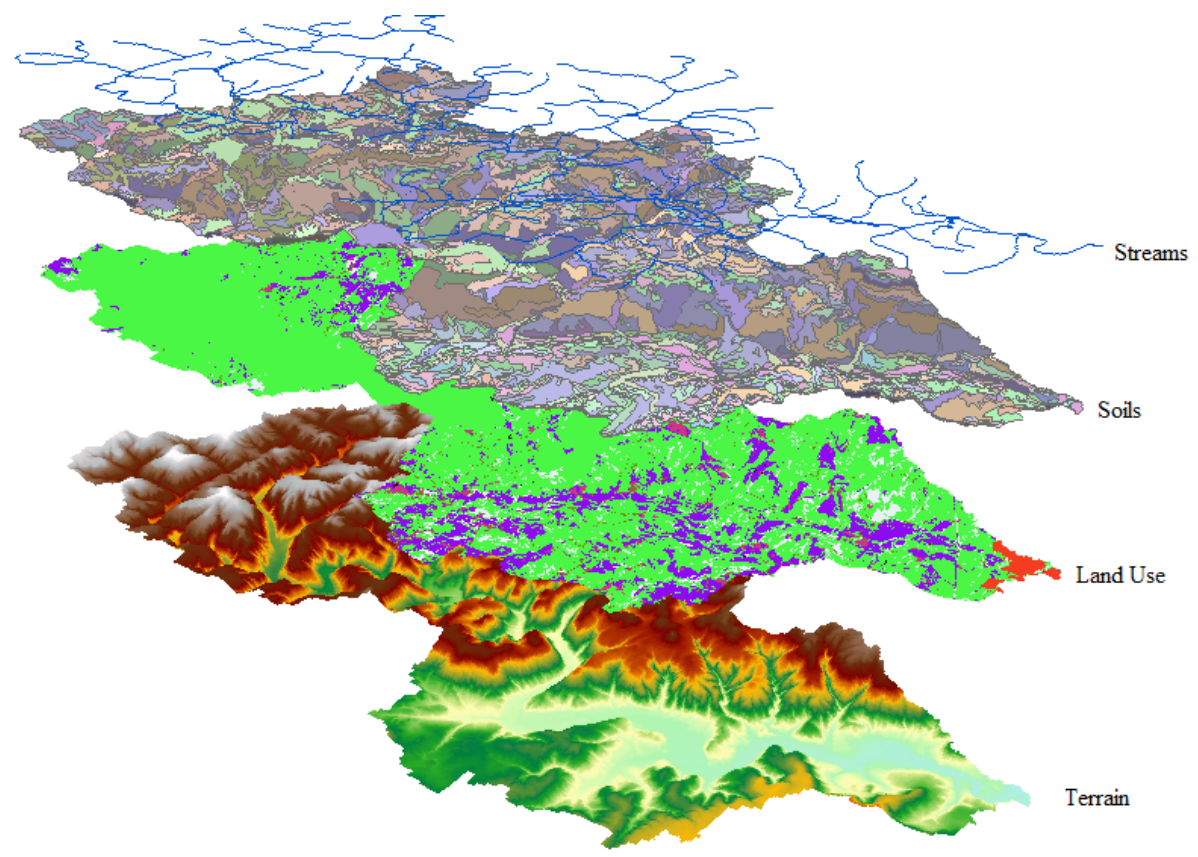

Figure 60: Illustration of Overlay in GIS for HRU Delineation in ArcSWAT.

The HRU is the basic computational unit of the model and helps to ensure efficient computation. The ArcGIS interface of the 2005 version of the SWAT model (Di Luzio et al., 2001) was used to set up the model in a GIS environment in this study. This ensures a seamless integration of DEM for the delineation of the watershed, flow lines, reservoirs and basin outlets. SWAT simulates the hydrology at each HRU using the water balance equation, comprising precipitation, runoff, evapotranspiration, percolation and base flow components as shown in equation 1. Runoff is computed with either the Soil Conservation Service Curve Number method (USDA-SCS, 1972) or the Green and Ampt infiltration method (Green and Ampt, 1911) and routed to the closest channel using the Muskingum method (Chow, 1959). Key model components include hydrology, sediment yield, nutrient fate, evapotranspiration, groundwater, etc.

\subsubsection{BASELINE AND WELL-PAD IMPACTED SCENARIOS}

To isolate and quantify the impact of well-pads on the overall storm-water runoff volume, the following methodology was adopted. Two main scenarios were calibrated for each of the LULC data models; one with well-pads present (SFLR10W) and another with the well-pads land-cover replaced with mixed forest land-cover (SFLR10). The latter scenarios involved the representation of well-pads with the mixed forest land-cover class (FRST) in SWAT. It was assumed that this land-use class will most closely represent the hydrologic response of the hitherto undeveloped land area; these individual scenario models were then assumed to represent the baseline scenarios in 2006 and 2010 respectively. Baseline in this case is used to denote a condition where no well-pads existed as in pre-2006 and when well-pads existed as in 2010.

The second set of model scenarios involved forecast simulations performed for a 10-year projected period (duration from 2010 to 2020); this was done in order to determine the fractional impacts (in comparison to the other land-cover classes) of the current (2010) level of well-pad activity on stream- 
flow for the projected forecast period. The SWAT model does not have a land-use code specification for well-pads; to account for this the urban industrial land-use categorization code in the SWAT land-use database was selected. This is the land-use categorization in the SWAT land-use database that most closely has the hydrologic response of surface such as a well-pad. The models were calibrated and validated from 2000 to 2006 and 2007 to 2009 respectively.

\subsubsection{RESULTS AND DISCUSSIONS}

\subsection{IMAGE CLASSIFICATION RESULTS}

The accuracy of image classification results was assessed through the use of test and training area mask (TTA mask) created through selected samples for each class. A minimum of thirty samples were selected for each class except the Barren class which had fewer samples due to lack of ample samples that represent that class in the study area. An error matrix was then created using the TTA mask. Three measures for assessing the accuracy of the classification were used; the user's, producer's accuracy and the overall accuracy. The user's accuracy measures the probability of a classified pixel representing the category on the ground whiles the producer's accuracy measures the probability of a reference pixel being correctly classified (Congalton, 1991). For the 2006 classified data, user's accuracy was over 80 percent for all the classes except for the deciduous forest class just as was seen in the user's accuracy for the $\mathbf{2 0 1 0}$ classification. Producer's accuracy was over 66 percent for all classes.

The user's accuracy for all classes for the 2010 classified data was over 68 percent with the exception of the deciduous forest and barren classes that had user's accuracies of less than 10 percent. Producer's accuracy was over 64 percent for all classes except for perennial and deciduous forest classes. Figures 2 and 3 present the respective error matrices calculated for the assessment of the individual accuracies associated with the classifications of the two datasets. Two levels of segmentation were used and subsequently followed by classification. Overall, the two classifications were similar in accuracy as is evident from the overall accuracies of $83 \%$ and $84 \%$ for 2006 and 2010 classifications respectively.

To investigate the relative changes in percentages of the total watershed area covered by individual land-cover types from 2006 to 2010, the following generalizations were made. The respective user's accuracy measure was multiplied by the classified area for each class to obtain a theoretical accurate area as persists on the ground. A super class of the forest land-cover types was then created by the addition of the respective watershed area percentages of the mixed forest, deciduous forest and the evergreen forest; the barren class was also added to the urban class to form a super class known generally as urban. This resulted in six main classes for the percentage change analysis for the two years; these are Agricultural range land, Forest, Roads, Urban, Water and Well-pads. Results showed that the well-pad class had the most significant change (1043\%) in land-cover class from 2006 to 2010, followed by agricultural range land with $4.6 \%$. Road, forest and urban classes had negative changes indicating a reduction in total area from 2006 to 2010 . However, this might be attributable to the respective lower user's accuracies obtained for these classes with the 2010 data as compared to that obtained with the 2006 data. Table 14 presents the various land-cover classes with their respective area coverage in the watershed for each year and percentage change in calculated from percentage of the total watershed area occupied by the individual land-cover from 2006 to 2010. The calculations in Table 14 involve the assumption that the user's accuracy captures the true cover type as it exists on the ground and therefore this accuracy measure is taken as having the best measure of individual land-cover classification accuracy. However when the respective overall classification accuracies of $83 \%$ and $84 \%$ 
for 2006 and 2010 were applied, the relative percent change in well-pads was $1205 \%$ with that of agriculture being $18 \%$.

Albeit the forest and agriculture classes had seen the highest changes in acreage, this does not present a true picture of the relative overall watershed changes since the user's accuracy associated with both classes from 2006 to 2010 had significant differences in classification accuracy. The forest cover reduced from $71 \%$ to $66 \%$; a reductive change of $7 \%$. This change might reasonably to attributable to an increase in agricultural land-cover much more than it might be due to well-pad construction. The reason for this being that agriculture land-cover had a significantly higher change in acreage than well-pad cover even with the high rate of change for well-pads within the period of study. The percentage change in water cover type increased slightly by $1.5 \%$; this is well correlated with the increase in agricultural cover from the attendant construction of agricultural ponds and irrigation trenches. Figure 61 depicts the percentage changes per class. Tables 15 and 16 show the respective error matrices for the 2006 and 2010 classifications.

Table 14: Land-cover Classes with Respective Area Coverage and Percentage Change from 2006 to 2010 in LRRW.

\begin{tabular}{llllllll}
\hline $\begin{array}{l}\text { Land- } \\
\text { cover } \\
\text { Class }\end{array}$ & $\begin{array}{l}\text { Area in } \\
\text { 2006/(acres) }\end{array}$ & $\begin{array}{l}\text { \% of SLRR } \\
\text { in 2006 }\end{array}$ & $\begin{array}{l}\text { Area in } \\
\text { 2010/(acres) }\end{array}$ & $\begin{array}{l}\text { \% of SLRR } \\
\text { in 2010 }\end{array}$ & $\begin{array}{l}\text { \% Change } \\
(2006-2010)\end{array}$ & $\begin{array}{l}\text { Class Accuracy } \\
(2006) / \%\end{array}$ & $\begin{array}{l}\text { Class Accuracy } \\
(2010) / \%\end{array}$ \\
\hline Water & 4394.53 & 4.60 & 4690.68 & 4.91 & 6.74 & 98.00 & 99.30 \\
Road & 1566.74 & 1.64 & 1060.42 & 1.11 & -32.32 & 80.80 & 68.90 \\
Agri & 11989.41 & 12.55 & 11702.81 & 12.25 & -2.39 & 88.90 & 77.00 \\
Forest & 76522.08 & 80.10 & 76206.82 & 79.77 & -0.41 & 66.85 & 36.58 \\
Well-pad & 812.03 & 0.85 & 1442.55 & 1.51 & 77.65 & 100.00 & 68.90 \\
Urban & 248.39 & 0.26 & 429.90 & 0.45 & 73.08 & 97.00 & 87.99 \\
\hline
\end{tabular}

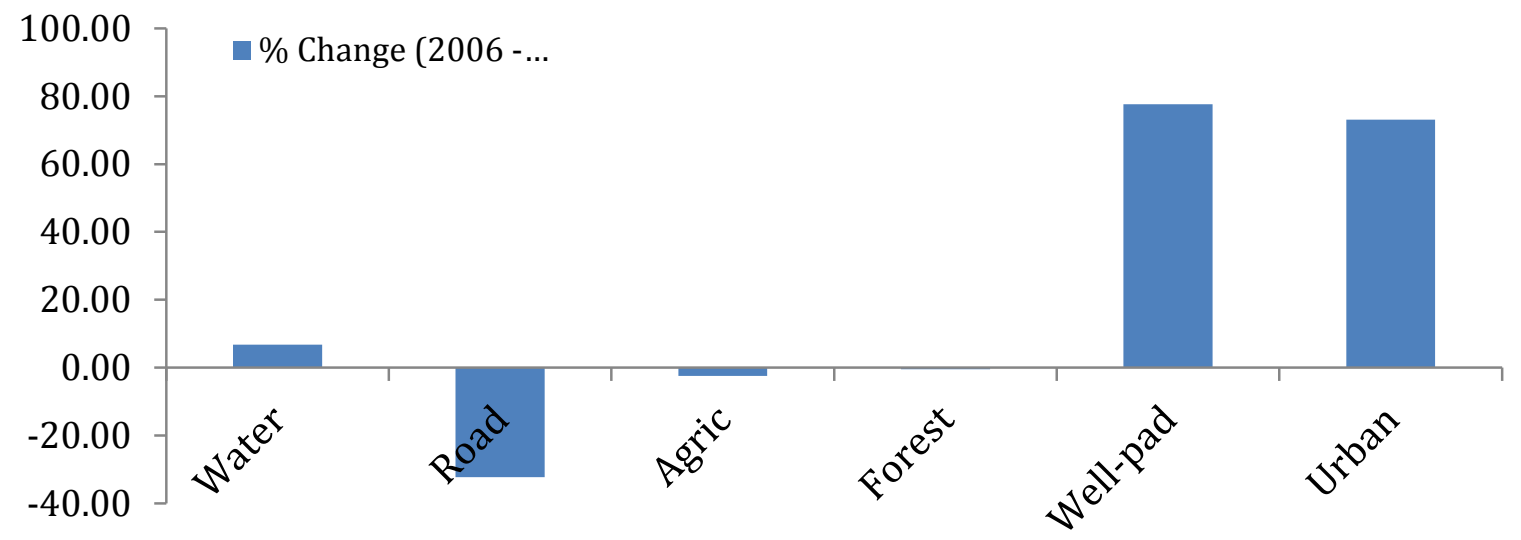

Figure 61: Graph Illustrating the Percentage Changes per Class. 
Table 15: Error Matrix for OOIA classification of 2006 LRRW Land-cover.

\begin{tabular}{|l|r|r|r|r|r|r|r|r|r|}
\hline UserIPreference Class & Water & R & A & F & FT & B & WP & U & Sum \\
\hline Water & $505 \mathrm{~K}$ & 0 & 2373 & 0 & 9381 & 0 & 0 & 0 & $516 \mathrm{~K}$ \\
\hline Road & 0 & $28 \mathrm{~K}$ & 0 & 0 & 0 & 0 & 0 & 6761 & $35 \mathrm{~K}$ \\
\hline Agriculture & 0 & 2706 & $260 \mathrm{~K}$ & 4524 & 19610 & 0 & 0 & 5631 & $292 \mathrm{~K}$ \\
\hline Forest & 4699 & 0 & 0 & $502 \mathrm{~K}$ & 101202 & 0 & 0 & 0 & $608 \mathrm{~K}$ \\
\hline Forest Transition & 349 & 0 & $131 \mathrm{~K}$ & $70 \mathrm{~K}$ & $289 \mathrm{~K}$ & 0 & 0 & 0 & $491 \mathrm{~K}$ \\
\hline Barren & 0 & 0 & 0 & 0 & 0 & 0 & 1077 & 0 & 1077 \\
\hline Well-pads & 0 & 0 & 0 & 0 & 5703 & 0 & 0 & $184 \mathrm{~K}$ & $190 \mathrm{~K}$ \\
\hline Urban & 0 & 0 & 0 & 0 & 0 & 7617 & 0 & 0 & 7617 \\
\hline Unclassified & 0 & 0 & 0 & 0 & 0 & 0 & 0 & 0 & 0 \\
\hline Sum & $510 \mathrm{~K}$ & $31 \mathrm{~K}$ & $393 \mathrm{~K}$ & $577 \mathrm{~K}$ & $42 \mathrm{~K}$ & $7.6 \mathrm{~K}$ & $1 \mathrm{~K}$ & $196 \mathrm{~K}$ & \\
\hline
\end{tabular}

Table 16: Error Matrix for OOIA classification of 2010 LRRW Land-cover.

\begin{tabular}{|l|r|r|r|r|r|r|r|r|r|}
\hline User\Preference Class & Water & R & A & F & FT & B & WP & U & Sum \\
\hline Water & $2,433 \mathrm{~K}$ & $\begin{array}{r}134 \\
\text { Road }\end{array}$ & 9875 & 1221 & 2065 & 0 & 0 & 2818 & $2,450 \mathrm{~K}$ \\
\hline Agriculture & 0 & $39 \mathrm{~K}$ & 0 & 0 & 0 & 0 & 0 & 17859 & 57430 \\
\hline Forest & 0 & $9 \mathrm{~K}$ & $323 \mathrm{~K}$ & 82370 & 3167 & 0 & 1779 & 234 & $419 \mathrm{~K}$ \\
\hline Forest Transition & 1567 & 0 & 41241 & $222 \mathrm{~K}$ & 20504 & 0 & 0 & 3932 & $289 \mathrm{~K}$ \\
\hline Barren & 4374 & 0 & 32435 & $230 \mathrm{~K}$ & $27 \mathrm{~K}$ & 0 & 0 & 5581 & $300 \mathrm{~K}$ \\
\hline Well-pads & 0 & 0 & 0 & 0 & 0 & 0 & 831 & 0 & 831 \\
\hline Urban & 0 & 70 & 6646 & 279 & 0 & 0 & $15 \mathrm{~K}$ & 103 & $23 \mathrm{~K}$ \\
\hline Unclassified & 10385 & 641 & 86678 & 0 & 0 & $6 \mathrm{~K}$ & 0 & $788 \mathrm{~K}$ & $892 \mathrm{~K}$ \\
\hline Sum & 0 & 0 & 2 & 41671 & 100126 & 0 & 0 & 0 & $142 \mathrm{~K}$ \\
\hline
\end{tabular}




\subsection{MODEL CALIBRATION AND VALIDATION RESULTS FOR THE SFLRR WATERSHED}

Simulated stream flow was calibrated against monthly measured rates by manually adjusting model parameters identified from sensitivity analysis and literature (White and Chaubey, 2005) to be sensitive to flow simulation until a best fit criterion was achieved. Model initial parameters were calculated from 1997 to 1999 (model warm-up period). Multi-criteria goodness of fit measures was employed in this study; among these measures, the most popular is the Nash-Sutcliffe Efficiency (NSE) criteria. This efficiency measure $\left(E_{f}\right)$ essentially measures the proportion of the total variance in the system that the model is able to account for or explain. The equation is as follows:

$$
\boldsymbol{E} \boldsymbol{f}=1-\left[\sum_{i=1}^{n} \frac{\left(\widehat{Y}_{l}-Y_{i}\right)}{\left(Y_{i}-\bar{Y}_{l}\right)}\right]
$$

Where $\mathrm{n}=$ sample size, $\widehat{Y}_{l}$ and $Y_{i}$ predicted and measured values of dependent variable, $\bar{Y}_{l}=$ mean of measured values of $\mathrm{Y}$. In general a stream-flow model simulation is judged satisfactory if $E_{f} \geq 0.5$ (Moriasi et al., 2007). The results of the multi-criteria measures for the calibration and validation periods for both models are presented in table 4. The calibration NSE for both models was 0.51 and 0.52 for SFLR10 and SFLR10W respectively; implying that on the average both models can account for $51.5 \%$ of the total variance in the calibration dataset. The validated model NSE was 0.9 and 0.89 respectively for SFLR10 and SFLR10W. SWAT simulates total flow as a sum of the separated base flow and surface flow components. Graphical plots (hydrographs) of the base flow and surface flow are presented for the calibration and validation periods in Figures 57 and 58.

Table 17: Multi-criteria model efficiency measures for respective calibration and validation.

\begin{tabular}{|c|c|c|c|c|}
\hline & \multicolumn{4}{|c|}{ Total Flow } \\
\hline Efficiency Criteria* & \multicolumn{2}{|l|}{ Calibration } & Validation \\
\hline & SFLR10 & SFLR10W & SFLR10 & SFLR10W \\
\hline NSE & 0.52 & 0.51 & 0.89 & 0.90 \\
\hline $\mathrm{R}^{2}$ & 0.51 & 0.51 & 0.94 & 0.95 \\
\hline PBIAS & 1.57 & -0.56 & 11.12 & 10.20 \\
\hline RSR & 0.29 & 0.26 & 0.45 & 0.44 \\
\hline RMSE & 0.45 & 0.45 & 3.65 & 3.55 \\
\hline
\end{tabular}

NSE: Nash-Sutcliffe Efficiency (satisfactory if $\geq 0.5$ ),

$\mathbf{R}^{\mathbf{2}}$ : Coefficient of determination,

PBIAS: Percent bias (PBIAS) measures the average tendency of the simulated data to be larger or smaller than the corresponding observed data. Positive $=$ under-prediction and vice versa (satisfactory if $\pm 25 \%$ ),

RSR: ratio of RMSE to standard deviation of observations (satisfactory if $\leq 0.7$ ) 


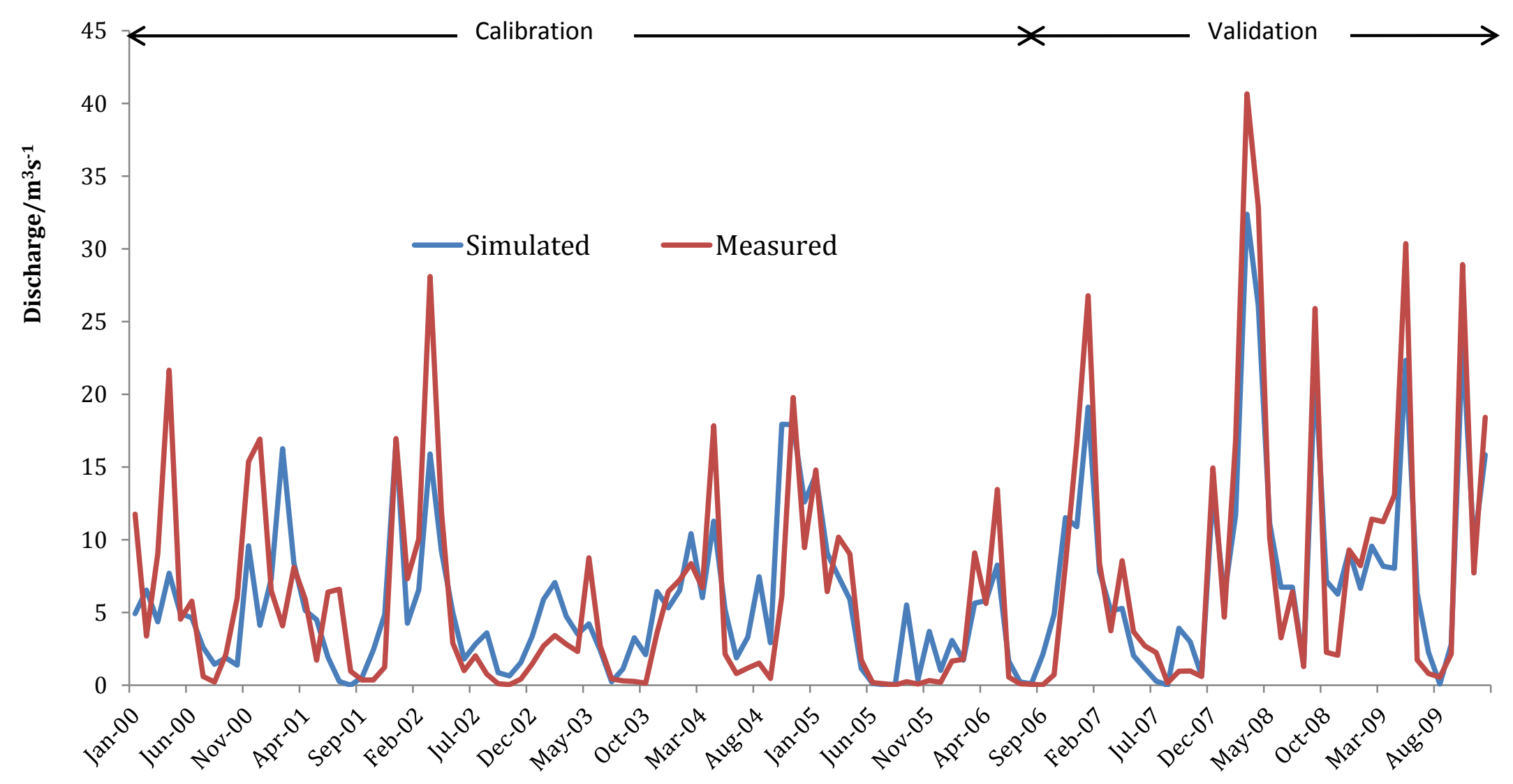

Figure 62: SFLR10 discharge hydrographs for total flow. 


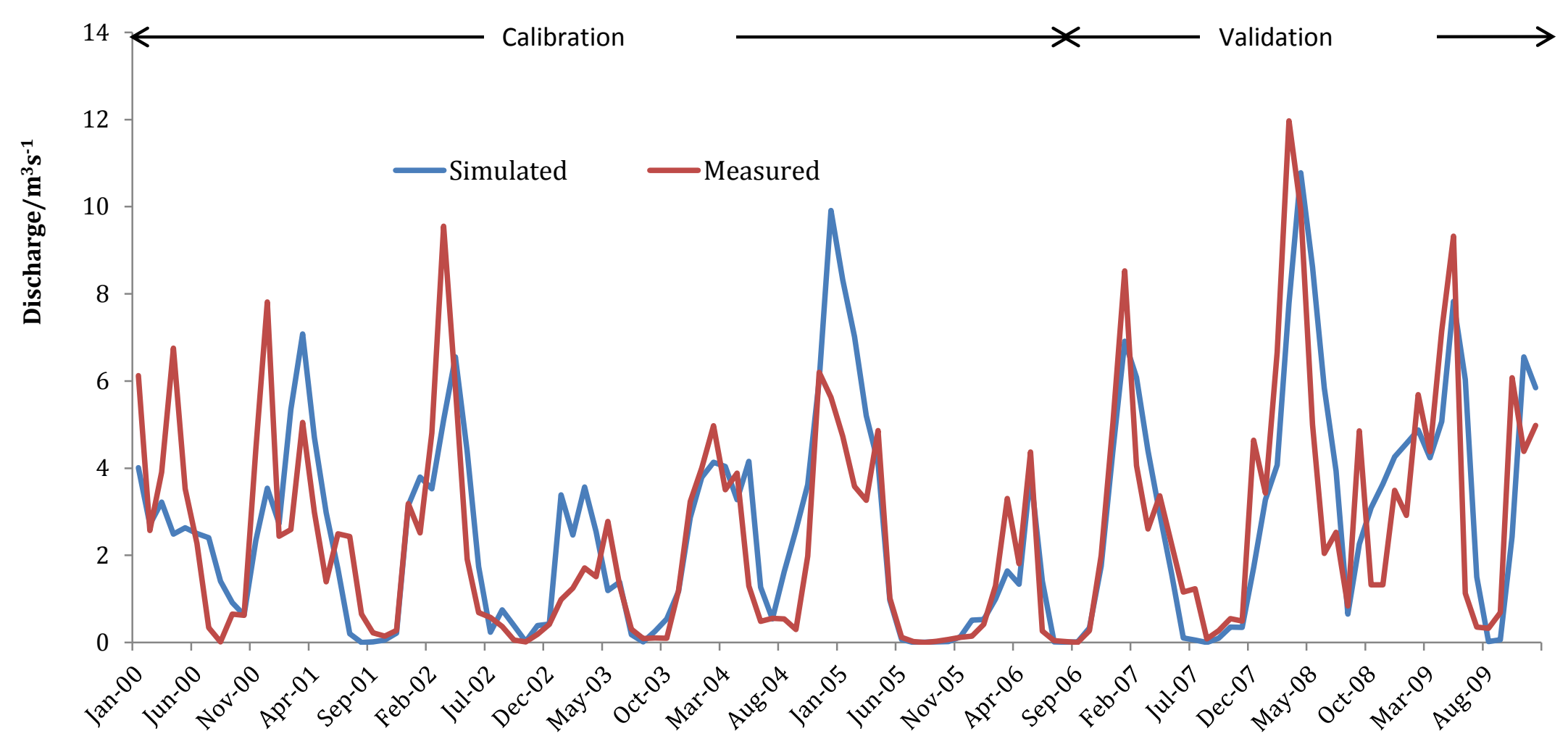

Figure 63: SFLR10 discharge hydrographs for sub-surface flow. 


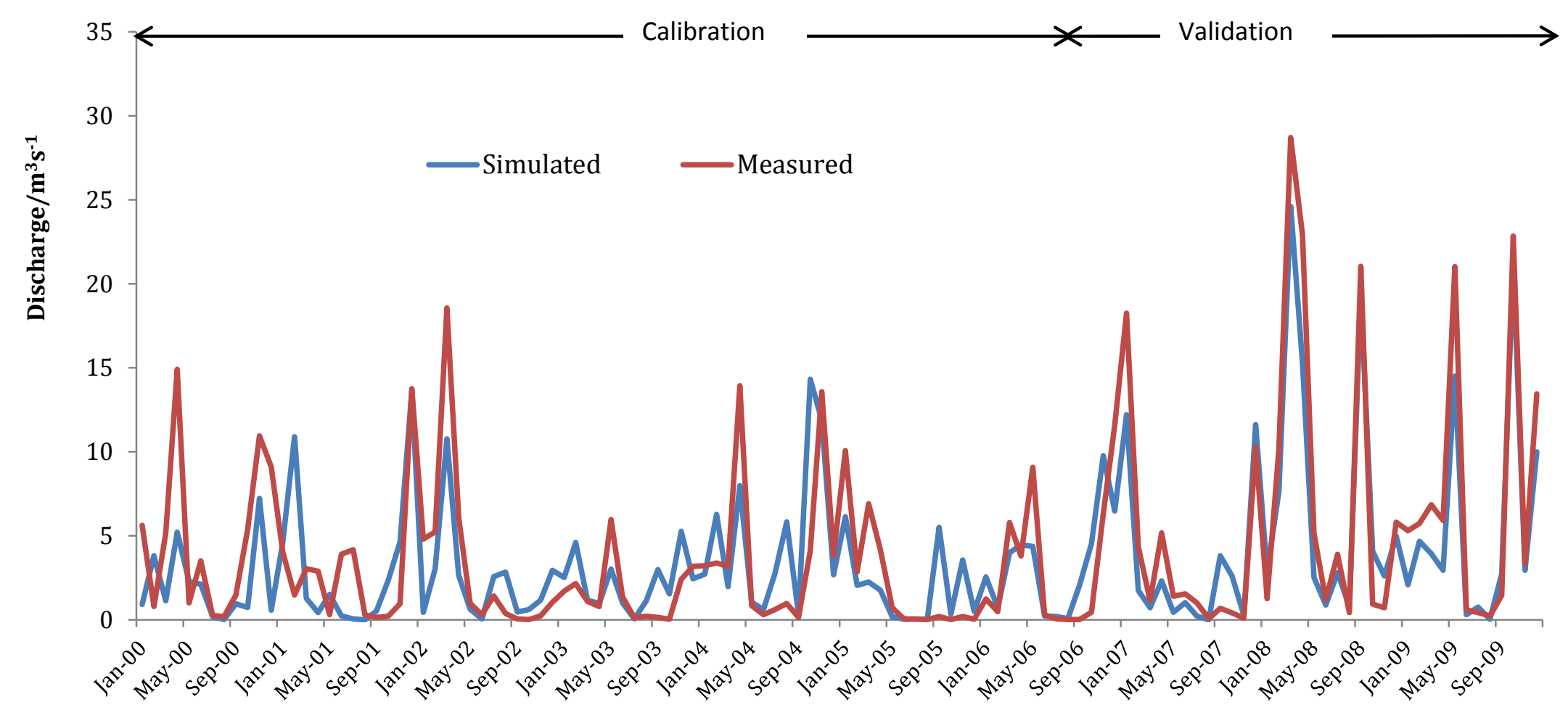

Figure 64: SFLR10 discharge hydrographs for surface flow. 


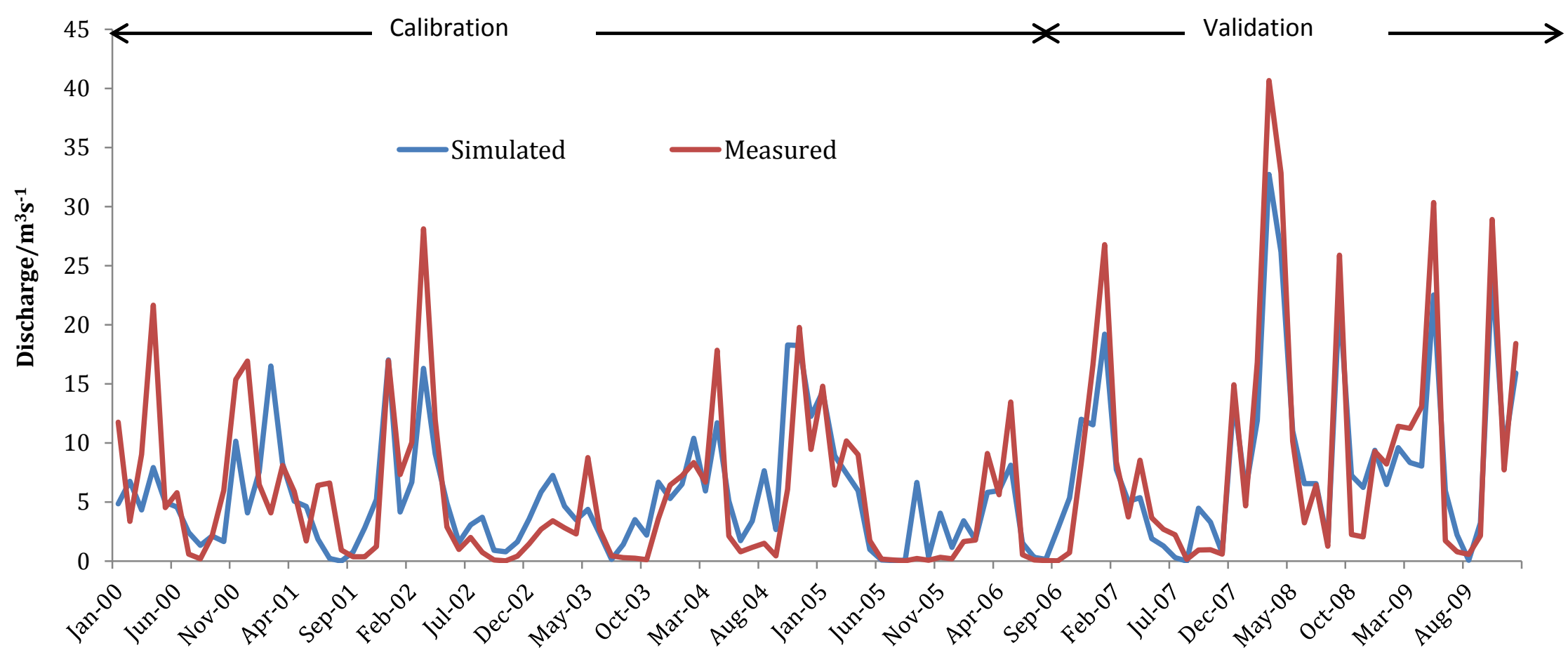

Figure 65: SFLR10W discharge hydrographs for total flow. 


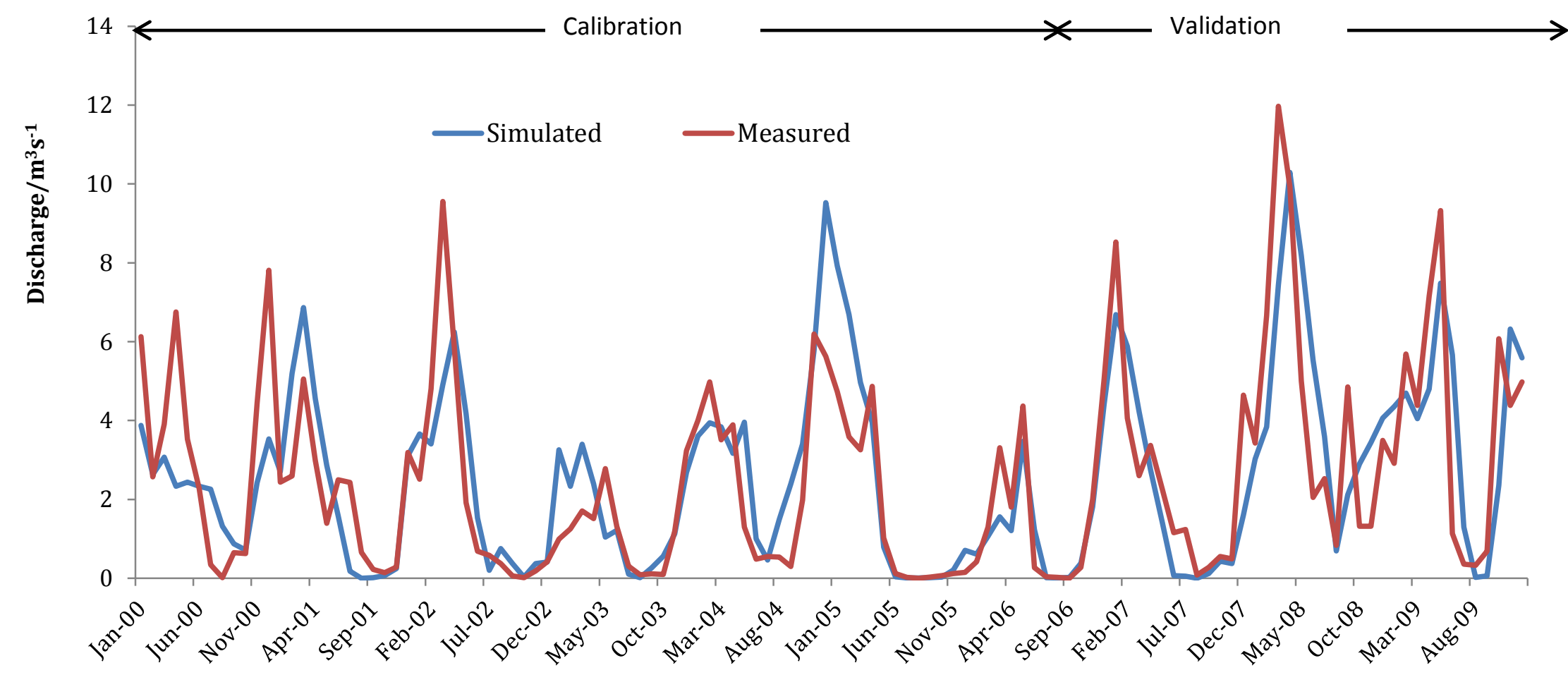

Figure 66: SFLR10W discharge hydrographs for sub-surface flow. 


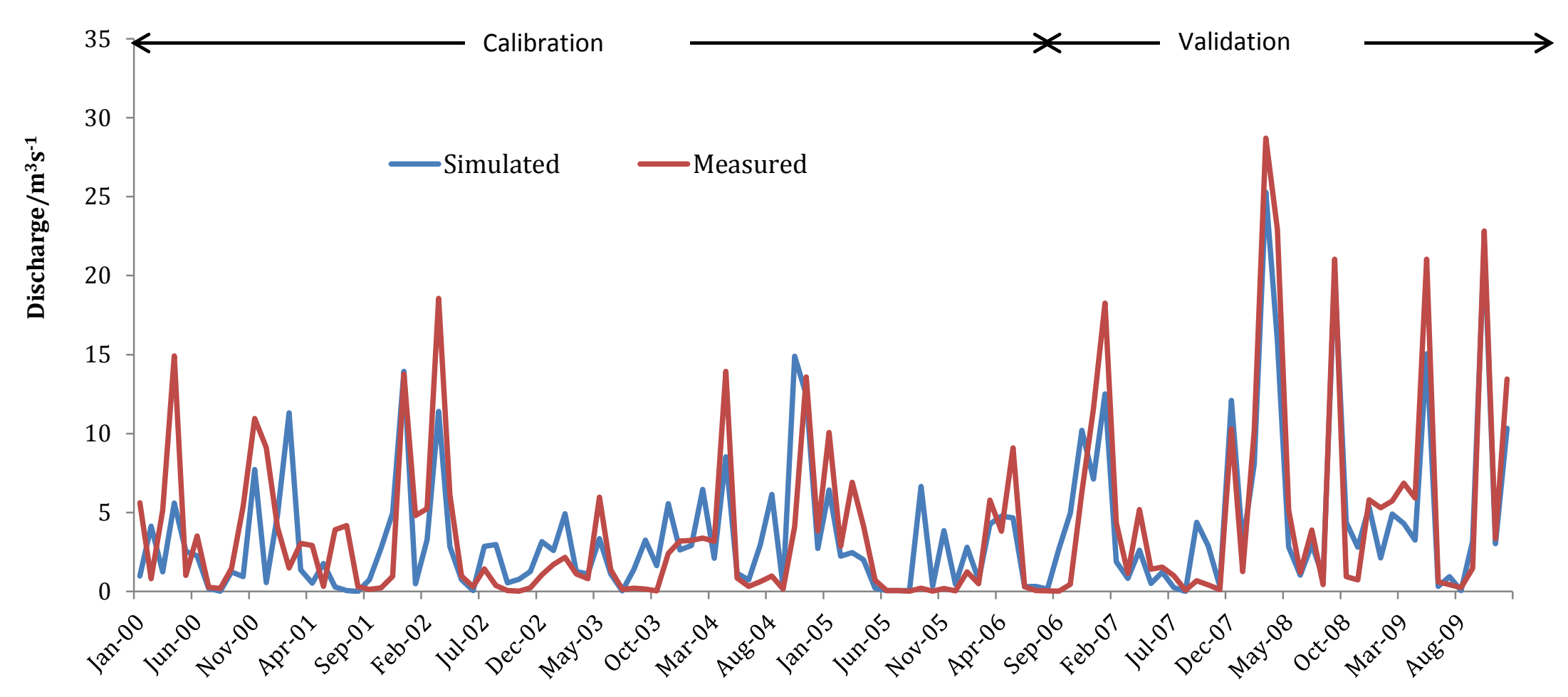

Figure 67: SFLR10W discharge hydrographs for surface flow. 
The validated models showed an increase in surface runoff depth for the scenarios where well-pads were present in the watershed over when the well-pads were represented by the mixed forest landcover. Simulated average annual flow depth for the validation period for both scenarios increased from $226.33 \mathrm{~mm}$ to $249.61 \mathrm{~mm}$ (a change of $\sim 10.3 \%$ ). Since these two scenarios representing the 2006 and 2010 land-cover scenarios, it implies that the identified 78\% change from 2006 to 2010 in well-pad landcover corresponds to a $10 \%$ increase in storm water runoff depth measured at the sub-basin outlet. The validity of the preceding statement holds only when it is considered that classification accuracies are fairly similar and equifinality is reduced to a minimum. Since the various land-cover classes had corresponding changes from 2006 to 2010, the identified 10\% change in runoff depth cannot be differentially attributed to well-pads alone.

To account for this differential impact of well-pad activity on the storm water runoff depth in the subbasin, forecast simulations were performed with the two baseline scenarios. The forecast scenarios essentially predict the projected differential impact on runoff depth if the level of well-pad activity in 2010 is maintained for a projected 10-year period (up to 2020). That is basically predicting the impact of shale-gas related infrastructure on runoff if no more of such infrastructure is constructed for the next 10 -years and the general land-cover in the sub-basin remains fairly the same. For the model with wellpads present, runoff depth was predicted to marginally increase from $249.61 \mathrm{~mm}$ in 2010 to $249.81 \mathrm{~mm}$ by 2020 . Considering the scenario where no well-pads or shale-gas related infrastructure existed in the sub-basin, runoff depth was predicted to also marginally increase from $226.33 \mathrm{~mm}$ in 2010 to 226.51 $\mathrm{mm}$ by 2020 . From these forecast results, runoff is predicted to increase by $23.3 \mathrm{~mm}$ from when wellpads were introduced for the projected 10-year period (a change of $10.3 \%$ ); this change is the differential impact of the presence of shale-gas infrastructure in the sub-basin.

\subsection{LIMITATIONS OF THE FLOW MODEL}

There are several limitations of the model as detailed in the previous sections. First among these is the fact that the model is highly limited by the level of accuracy associated with the classified LULC image. The respective overall accuracies of $83 \%$ and $84 \%$ for 2006 and 2010 LULC classifications presented by the error matrices in tables 2 and 3 . It is important to note there are other measures of classification accuracy that are of peculiar importance especially as a specific land-cover type such as well-pads is being studied. One such measure is the user's accuracy which essentially measures the certainty that a classified pixel actually represents that cover type on the ground. The distributions of 2006 and 2010 user's accuracies for all classes within their respective matrices have standard deviations of 0.13 and 0.34 with means of 0.88 and 0.61 respectively. These distributions have disparate variances indicating a lack of consistency in classifications among the individual classes across the two datasets. This is a limitation that requires further studies to assess classification accuracy impacts on model outputs.

Other sources of limitation for the model are the fact that the model was only manually calibrated and no extensive automatic calibration or uncertainty analyses were performed on the calibrated models. The lack of an uncertainty analysis in the model calibration stage introduces bias in the interpretation of model results owing to equifinality (Beven and Binley, 1992). This also limits the ability to use the model as an effective tool to analyze the inherent dynamics between the interactions human activities and the natural systems in the catchment. 


\subsubsection{CONCLUSION}

The main objectives of the study are to: 1) quantify the land-use land-cover change in the South Fork of the Little Red River Watershed (SFLRR) with specific emphasis on natural gas related activities (wellpads) and 2) use the quantified data to examine the impact of natural gas related activities on storm water runoff generation in the South Fork of the Little Red River (SFLRR). There were generally decreases in land-cover for the forest, road and urban classes; albeit changes in the road and urban classes might be logically taken to be much more skewed by classification accuracy than in the case of the forest class. Agricultural land, water and well-pads on the other hand consistently increased in coverage from 2006 to 2010. Well-pads significantly increased in land-cover from 2006 to 2010 by 630.55 acres (representing $0.65 \%$ of the total SFLRR area). Other land-cover classes that increased in coverage were urban and water; totaling slightly over $5 \%$ of the sub-basin area. On the other hand, agriculture and forest cover types decreased by $2.39 \%$.

The next objective of the study was to examine the impact of the identified change in land-cover attributable to well-pads on storm water runoff generation in the sub-basin. The result from calibration and validation periods is inconclusive in that the differential effect of the change in well-pads alone could not be isolated. For a 10-year forecast scenario, runoff is projected to increase by $23.3 \mathrm{~mm}$ which is roughly a $10 \%$ projected increase in runoff. This represents the change in runoff that is attributable the differential change in shale-gas related infrastructure. Therefore, for a $78 \%$ in well-pad land-cover, runoff is projected to increase by roughly $10 \%$ over a 10 -year period assuming current conditions in the sub-basin stays fairly constant.

\section{TASK 4.1 - AdD WEATHER AND STREAM GAGE DATA TO FSDSS}

The study area includes the area encompassing the entire Fayetteville region but the prominence is given to the area where major gas well development and production activities are highest. This area mostly includes the Cadron, Dardenelle, Little Red, Lower White Bayou DesArc and Lake Conway Remove watersheds. These 8 digit Hydrologic Unit Codes (HUCs) are used to extract the data for these watersheds and have been placed in the data repository for the project. Therefore the overall study area is composed of the region of the shale with these watershed and the corresponding HUCs. More detail is provided in Tasks 3.1 and 3.2 sections. Table 1 contains a list of data gathered during the course of this project.
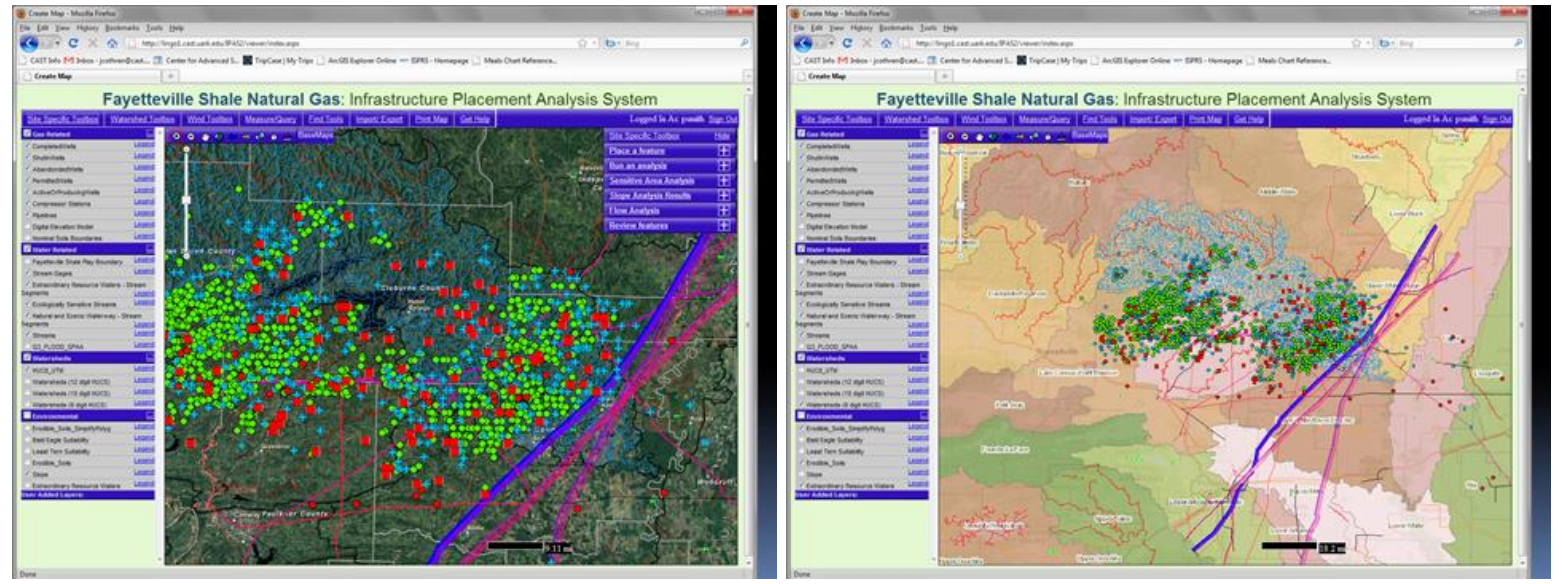

Figure 68: Screenshot of prototype enhanced FSDSS showing links to USGS stream gage data and internally developed watershed boundaries. 


\section{TASK 4.2 - EXTRACT PONDS FROM IMAGERY}

\subsubsection{RULESET DEVELOPMENT.}

From the rule-based example given above we can see that a set of feature attribute criteria must be developed. These criteria must work consistently with all the aerial images within our diverse study area. At present we are accurately identifying over $93 \%$ of the ponds with NO false positives. Conversely, we can identify $95 \%$ of the ponds, but with a high incidence of false positives. We are refining both the segmentation and classification parameters to improve accuracy. We are also looking into utilizing other datasets, such as lower resolution satellite imagery, in the process. In this scenario the high resolution of the image segments, derived from aerial images, would be retained while adding the spectral information from the satellite data.

Automation tasks. This project involved nearly 1 TB of aerial image data. OBIA techniques are very memory intensive, so the data must be processed in hundreds of individual pieces over hundreds of processing hours. Therefore, the tasks must be automated. We are working on a methodology for implementing our automated processes on grid-based computing system running two programs: 1) Definiens GRID and 2) eCognition. GRID handles the distribution of tasks over multiple CPUs. eCognition handles the OBIA tasks. Initial test runs look good.

The goal of this Task is to identify and map surface water features (ponds) within the Fayetteville Shale Play. While visually identifying water bodies on an aerial photograph is a simple task for an image analyst, the process of mapping these features poses significant challenges. Historically, the digital mapping of surface features from aerial photography has been a time-consuming and painstaking process. This method required an image analyst to manually "outline" the features to be mapped from a hardcopy photograph mounted on a digitizing tablet. Digital aerial imagery made this task easier, but the analyst was still required to manually outline each and every feature because aerial photographs lack the spectral information necessary for traditional digital image processing classification techniques. More recently, satellite imagery has been employed for feature extraction. The multispectral nature of satellite imagery such as Landsat TM data made it possible to automatically classify (separate) one landcover type from another. The problem with low resolution satellite imagery is that small features cannot be delineated. Spatial data layers, such as the NHD water data, for example, are incomplete because they leave out small features. High resolution satellite imagery may eventually provide a way to map small features, such as ponds, using standard image classification techniques, but, for the time being, the high price of high resolution satellite imagery prevents its widespread use.

Our research with the NETL-Water project involves the automated extraction of surface water features from digital aerial photographs using a fairly new set of image processing tools referred to collectively as Object-base Image Analysis (OBIA). OBIA techniques were first utilized in the medical imaging field, but it was soon realized that these tools would be useful for other kinds of images including images from Earth remote sensing platforms. OBIA centers on a process known as image segmentation. Image segmentation is used to divide an image into a patchwork of segments or regions, in which each segment is "homogeneous", that is, the "same" in some sense. Once generated, image segments can be labeled (classified). The method for classifying segments is straightforward. Each segment has certain characteristics such as color, texture, shape, size, etc. These characteristics are stored for each segment in a spatial (vector polygon) database. Segments can be classified based on both their spatial and 
spectral characteristics. For example, one could, theoretically, set the following classification rules for classifying water ponds:

1) Ponds will have a value of 40 or less in the infrared layer of the digital photo.

2) Ponds will have a length-width ration less than a value of 3.

3) Pond will have a GLCM "homogeneity" value greater than .25

From the rule-based example given above we can see that a set of feature attribute criteria must be developed. These criteria must work consistently with all the aerial images within our diverse study area. At present we are accurately identifying over $93 \%$ of the ponds with NO false positives.

Conversely, we can identify $95 \%$ of the ponds, but with a high incidence of false positives. We are refining both the segmentation and classification parameters to improve accuracy. We are also looking into utilizing other datasets, such as lower resolution satellite imagery, in the process. In this scenario the high resolution of the image segments, derived from aerial images, would be retained while adding the spectral information from the satellite data (Figure 64).

This project involved nearly 1 TB of aerial image data. OBIA techniques are very memory intensive, so the data must be processed in hundreds of individual pieces over hundreds of processing hours. We have made significant progress this quarter in implementing our automated processes on grid-based computing system running two programs: 1) Definiens GRID and 2) eCognition. GRID handles the distribution. However, we have not yet established a binding agreement with Definiens allowing us access to multiple licenses of the software. We are negotiating terms with the company now and expect resolution during the 3rd quarter. We have identified another alternative in the ERDAS Feature Analyst tool suite for which we currently have licenses.

The importance of this task is its contribution to water quantity modeling in the five 8-digit HUCs in the Shale Play. The National Hydrology Dataset is generally used to estimate the amount of water available in a given basin. However, in many parts of the country, including Central Arkansas, the construction of retention ponds can significantly change the amount of water available in the basin. In the Quitman SE quadrangle, we have found that the NHD layer has both errors of omission and false positives. Some of these errors may be due to year-to-year changes in pond locations between the date of the NHD data creation and the date of the CIR image. The NHD also makes errors associated with pond shape, size, and location. The NETL layer, on the other hand does a fairly good job of capturing the true shape, size, and location of the ponds. NETL errors are generally associated with a spectral classification problem dealing with distinguishing water bodies from deep shadows adjacent to water bodies. 

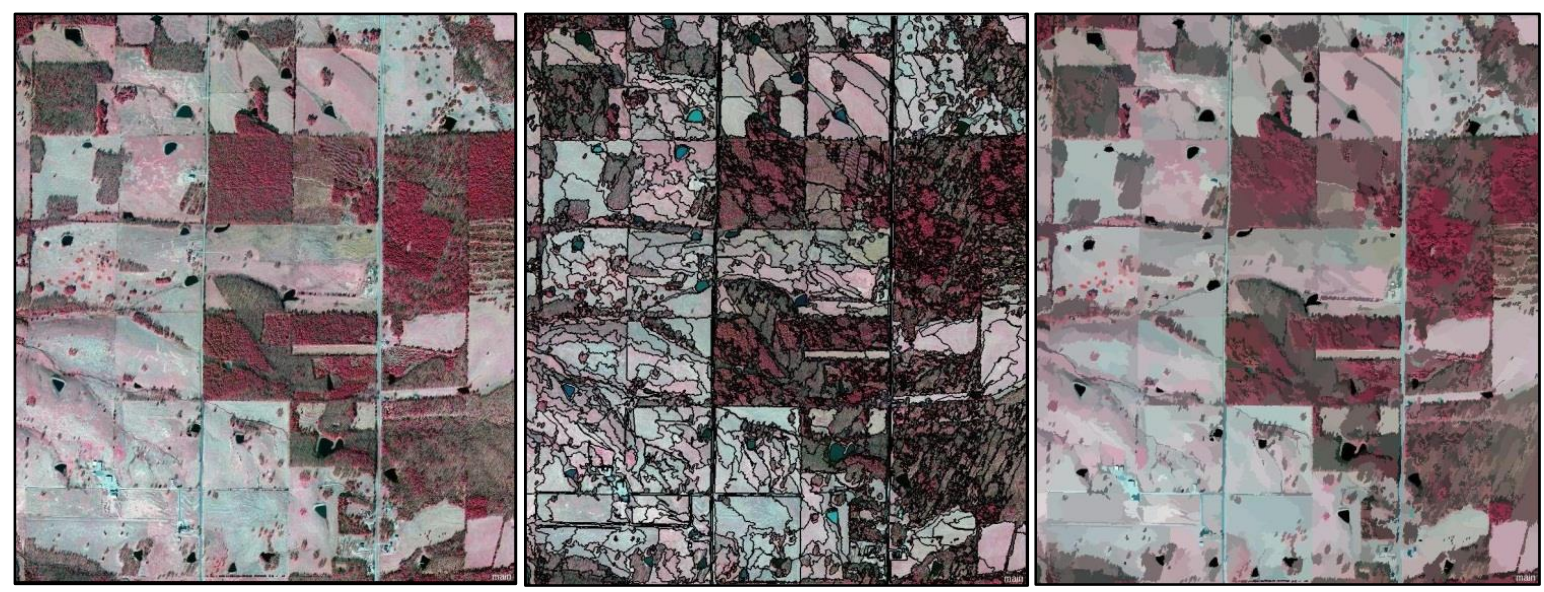

Figure 69: (left) This is a false color (color-infrared) image depicting the Quitman SE quarter quadrangle. On this image water is dark, with colors ranging from black to dark greenish-blue. (middle) This image overlay shows image objects (segments) generated with eCognition's multi-resolution segmentation algorithm with the "scale" parameter set to 100. (right) This is a hybrid of the false color (CIR) image and the image objects. In essence, this image is a generalization of the CIR image.

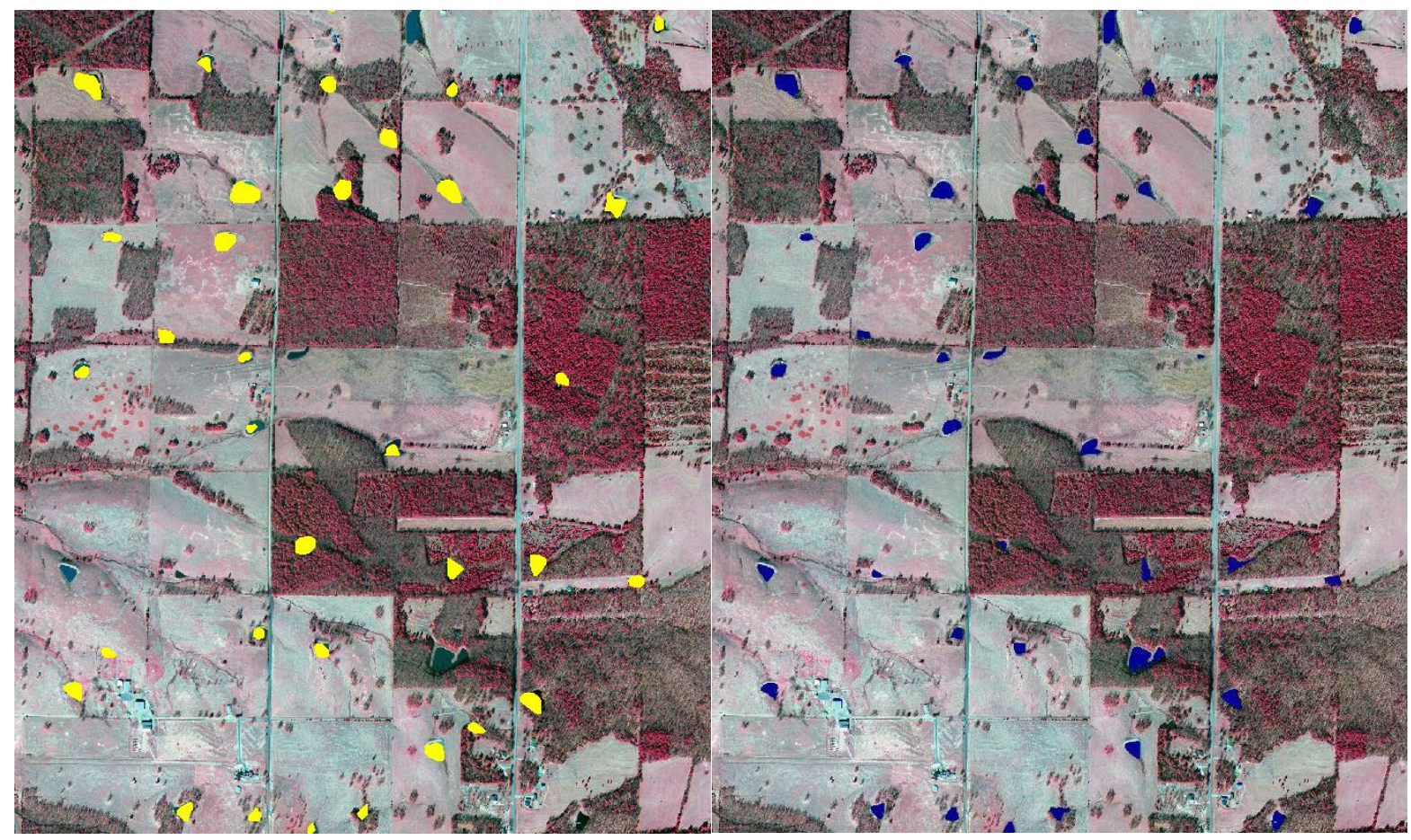

Figure 70: (left) NHD high-resolution water layer. Water is shown as yellow-filled polygons. (right) Water extracted from the color-infrared imagery using the segmentation/classification process. Water is shown as blue-filled polygons. 

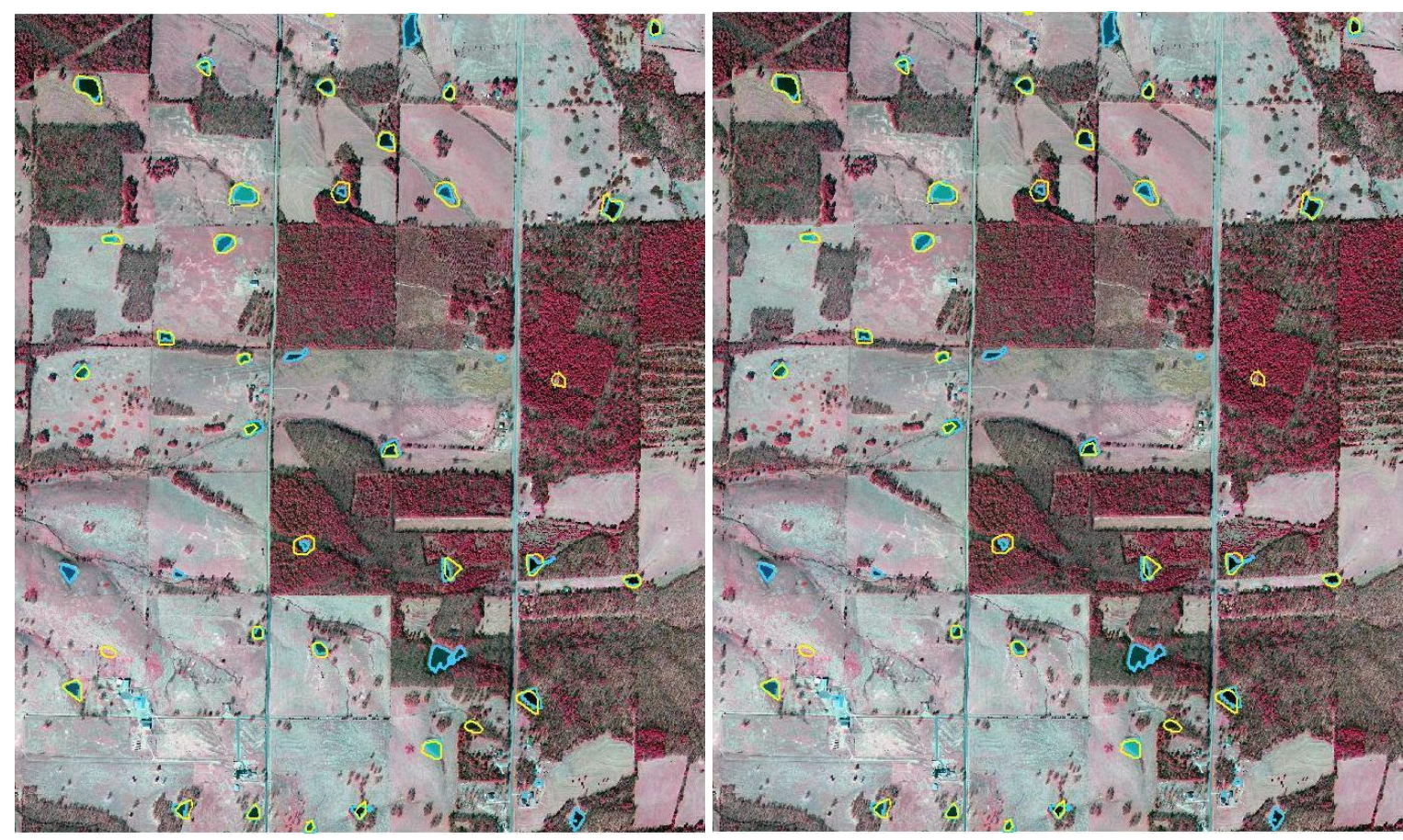

Figure 71: This image compares NHD and NETL water layers. NHD layer shown with yellow polygon outlines. NETL layer shown with light blue polygon outlines.

The research team is using object oriented imagery analysis to identify small retention ponds (as small as $300 \mathrm{~m} 2$ ) and their drainage areas using over 1 terabyte of high-resolution, color-infrared aerial imagery of the entire Fayetteville Shale area form 2006. The methodology for this task has been established and processing of this large dataset continues. Preliminary results show that the existing National Hydrology Dataset (USGS) generally used to estimate the amount of water available in a given basin has both errors of omission and false positives. Some of these errors may be due to year-to-year changes in pond locations between the date of the NHD data creation and the date of the CIR image. The NHD also makes errors associated with pond shape, size, and location. The layer we have developed, on the other hand does a fairly good job of capturing the true shape, size, and location of the ponds. Our errors are generally associated with a spectral classification problem dealing with distinguishing water bodies from deep shadows adjacent to water bodies. After the processing is complete, drainage areas for each retention pond will be computed from the USGS National Elevation Data (30m postings) using the D-infinity upslope calculation method. Drainage area polygons for each pond will be attributed with soil types (from the Soil Survey Geographic (SSURGO) Database), land cover type (from the classification of ADOP and NAIP imagery) and topographic statistics (e.g.

$\mathrm{min} / \mathrm{max} /$ median slope and aspect). In our effort to better model drainage, we have been investigating more complex flow models, erosion processes and sediment. Mathematical models that calculate the volume of discharge and velocity field are important but solutions to the shallow water equations commonly referred to as the St. Venant equations - are difficult. We have had success reformulating these models to be more stable and expect them to enhance the current run-off/spill models available in the FSDSS. 


\section{TASK 5.1 - DEVELOP SPATIAL DATABASE FOR FSDSS/SWAT INTEGRATION}

The current SDSS (www.fayshale.cast.uark.edu, Figure 67) is under review by Ken Brazil and his team at the Arkansas Natural Resources Commission (ANRC) to determine whether the level of reporting is adequate (or excessive) and that the interface presents relevant information. ANRC has also supplied the research team with the latest withdrawal records dating from 2010 to the present. CAST met with Ken Brazil and the Water Supply Availability Working Group during the quarter and decided, based on draft requirements for the Arkansas Water Plan, to the watersheds in the Fayetteville Shale Play as exemplars of the kind and scale of information modeling efforts can achieve.

SWAT produces complex modeling results that must be summarized in some meaningful way for the decision maker. Based on the result of the modeling efforts described in this report, which found that individual withdrawals had little if any measurable effect given the location and number of stream gauges and other reservoir data, and after detailed discussions with ANRC, CAST and BREC decided on the following methodology.

- Calibrate (from 2000-2006) and validate (2006-2009) water flow models in the five major basins (HUC8) covering the Fayetteville Shale Play boundary.

- Verify that precipitation and temperature regimes during the period $1950-2012$ are similar to regimes during the calibration and validation period.

- Using the model developed in the first step, simulate flow conditions at HUC12 outlets in each of the four HUC8 using temperature, precipitation, and release data from $1950-2012$.

- Summarize the 62-year history at each HUC12 by month using a conventional boxplot showing the median, the inner quartile range, minimum and maximum of flow rates.

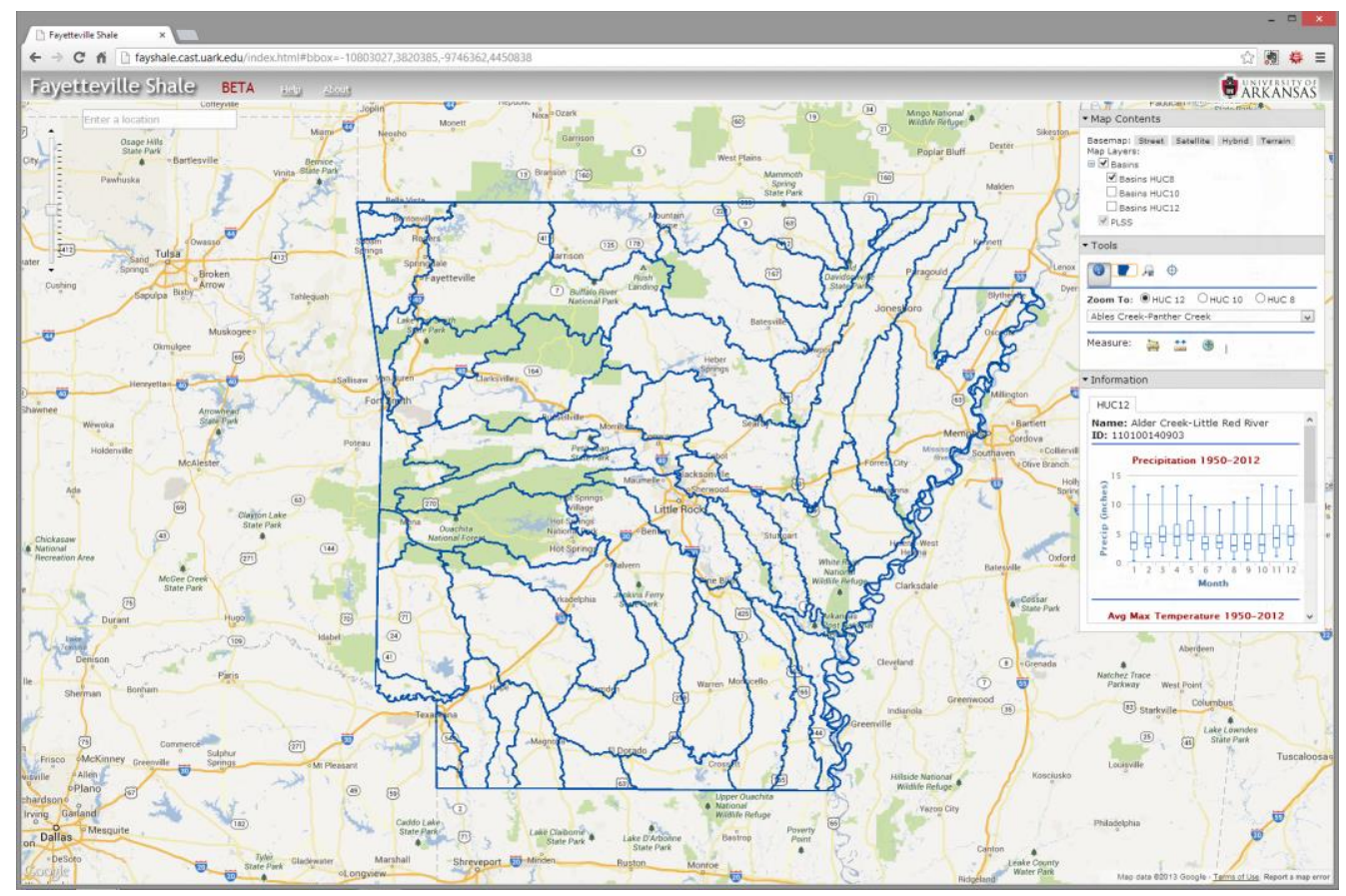

Figure 72: Screenshot of www.fayshale.cast.uark.edu showing the HUC8 watersheds in AR and the 62year precipation history of the Little Red River Watershed. 


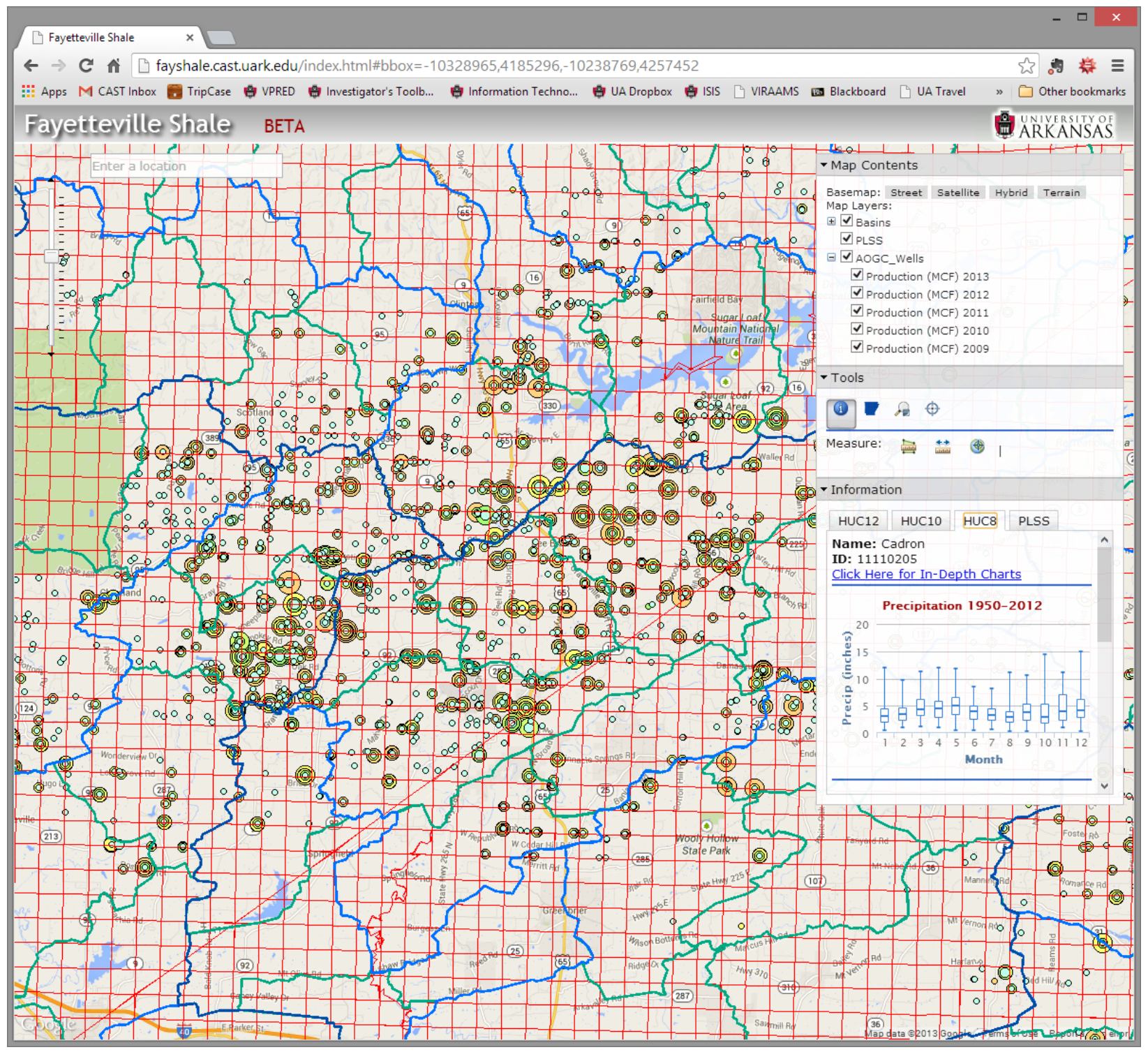

Figure 73: A closer look at the Cadron watershed area show precipitation summaries in the HUC8 over the last 62 years and production rates (in MCF) over the last five years of wells permitted by the Arkansas Oil and Gas Commission. 


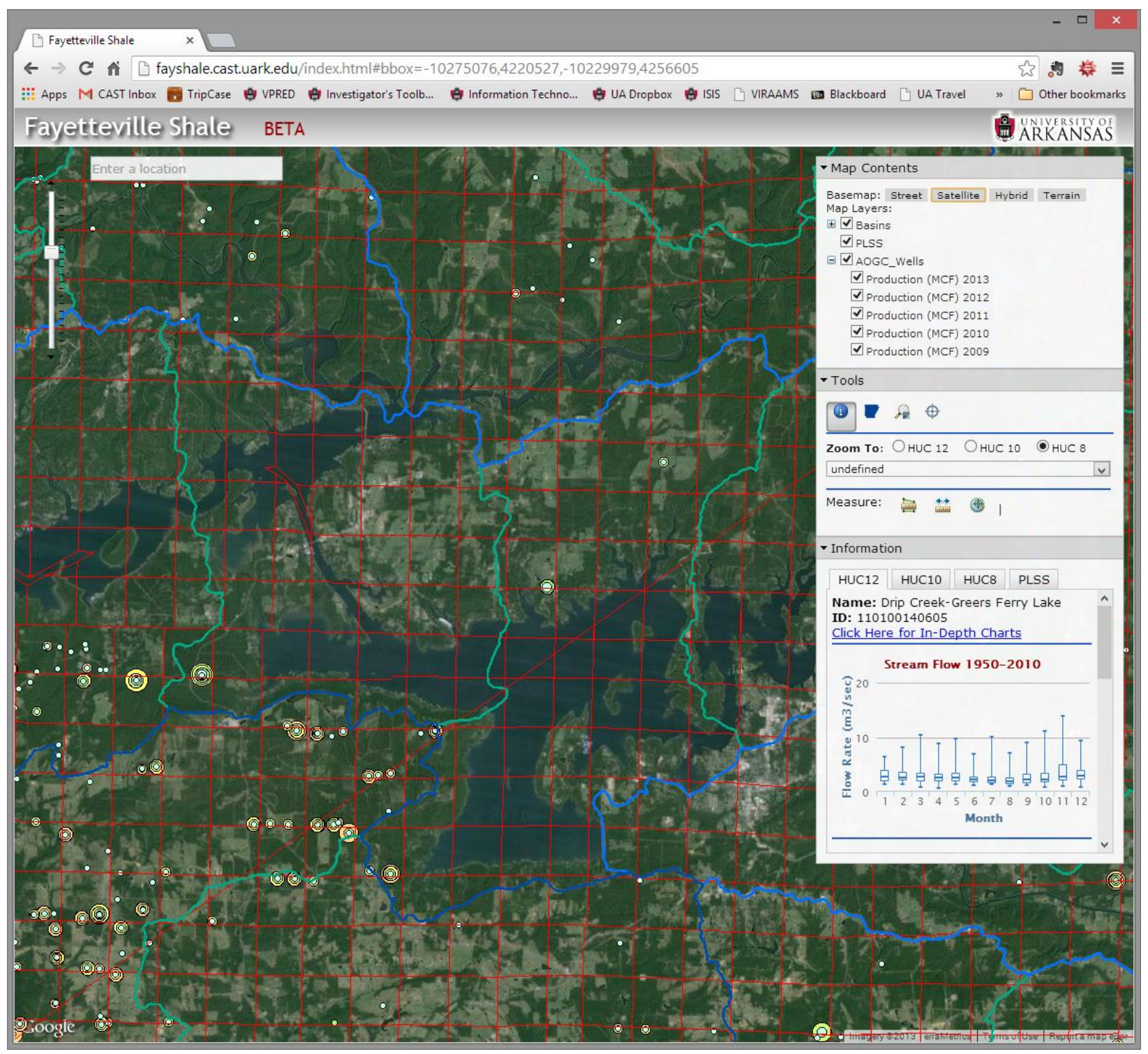

Figure 74: A view of the Drip Creek-Greers Ferry Lake watershed and predicted stream flow from 19502012. Selecting "In-Depth Charts" results in the webpage shown in Figure 70. 


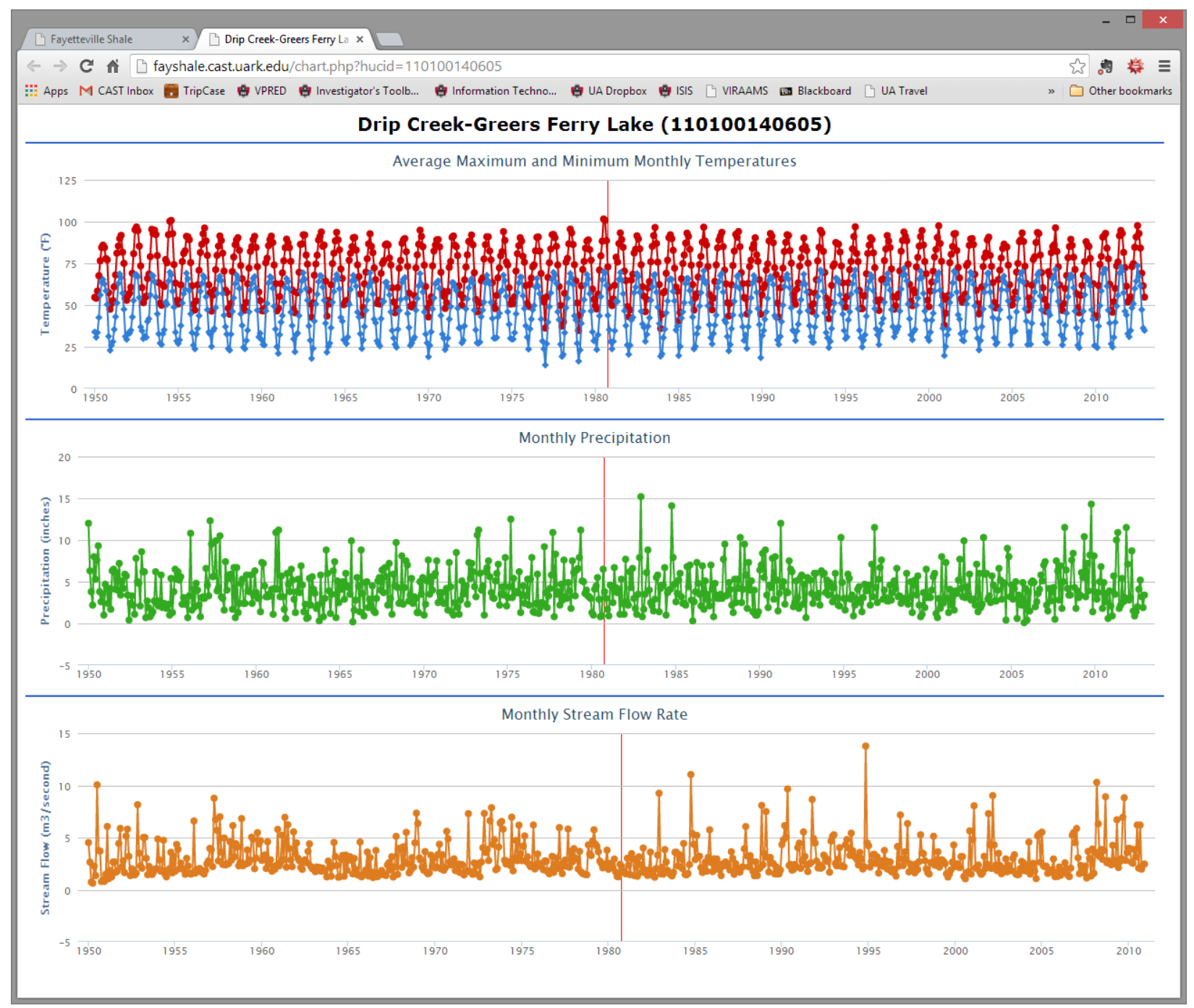

Figure 75: Time series data from Drip Creek-Greers Ferry Lake. The upper time series shows min (blue) and max (red) temperatures in the watershed from 1950-2012. The middle time series (green) shows monthly precipitation averages throughout the same time period. The monthly stream flow rates (orange) shows the SWAT predict outflow from this watershed through the same time period. Taken together, this information provides information to regulators that allow them to see variability in stream flow as a function of temperature and precipitation. These time series are interactive. 


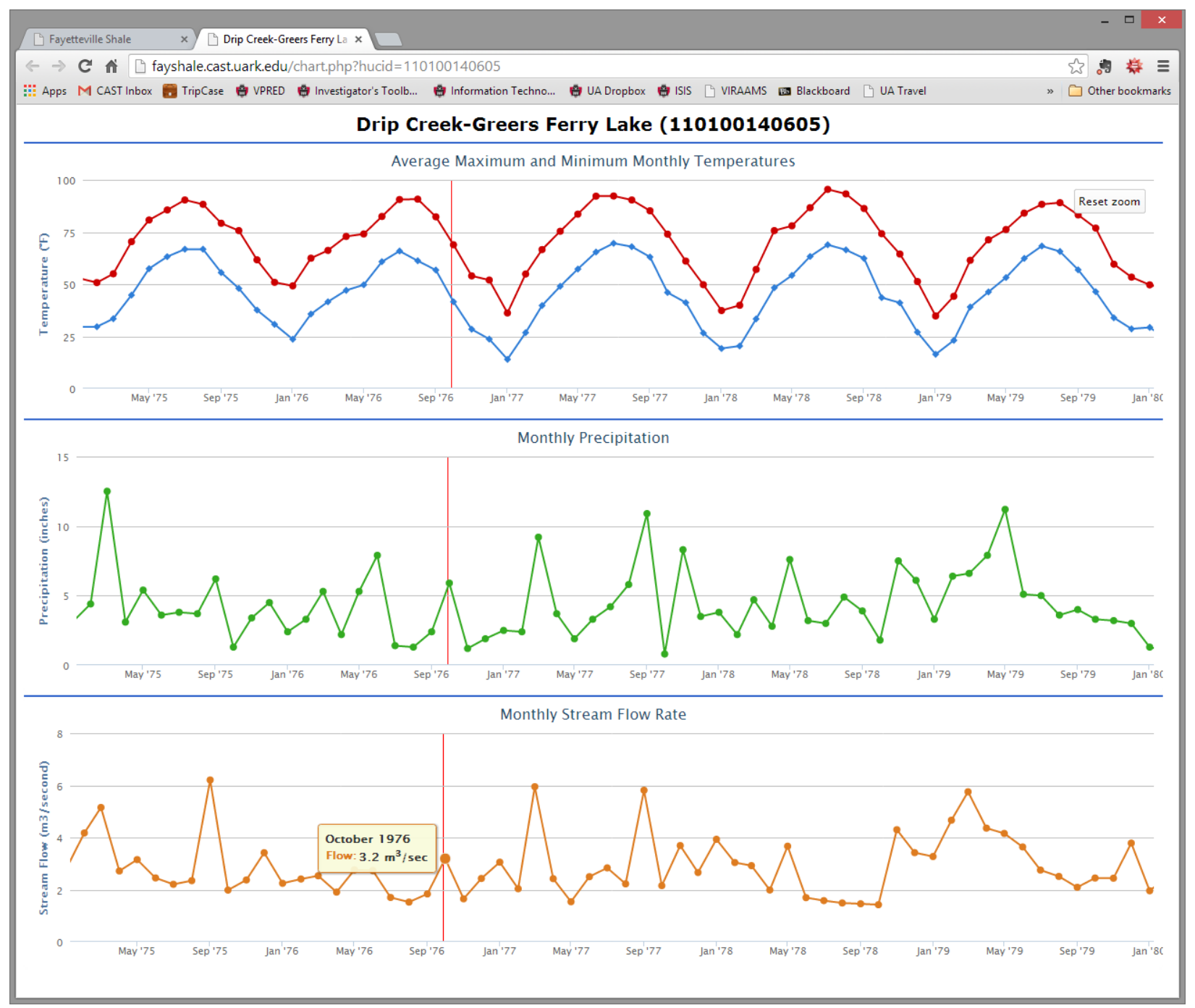

Figure 76: Time series data from from Drip Creek-Greers Ferry Lake watershed from 1975-1980 show flow responses to temperature and precipitation conditions.

Within the website, the decision maker will has access to summarized precipitation and temperature ( $\min , \max$ ) data over the last 62 years as well as modeled flow from each of the HUC12's in the Play. ANRC will be able to make better informed decisions about withdrawal volumes, duration and timing throughout the year using a combination of these four statistical plots. This website will also be used to demonstrate the methodology and reporting strategy to the Arkansas Water Supply Availability Working Group as a possible strategy for the upcoming AWP. All five 8-digit HUC's will have flow modeled over the 62 year period. Currently, the Little Red River watershed is available. The remaining watersheds in the play area will be included by the end of CY2013. 


\section{GRAPHICAL MATERIALS LIST}

\section{FIGURE LIST}

Figure 1. Fayetteville Shale Information System (http://lingo.cast.uark.edu).

Figure 2. Interpolated production maps generated from the Fayetteville Shale Information Site. The maps are generated using Kernel Density Estimators and production numbers from active wells.

Figure 3. Enhanced Fayetteville Shale Information System screenshots showing production by section. 11

Figure 4. Enhanced Fayetteville Shale Information System screenshots showing (left) water shed layers

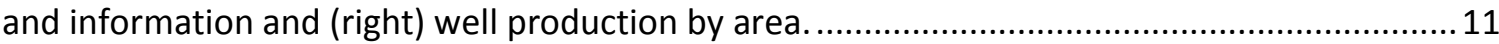

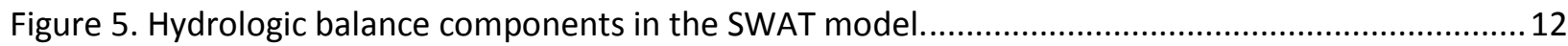

Figure 6. Spatial tessellation and input files in the SWAT model. ......................................................13

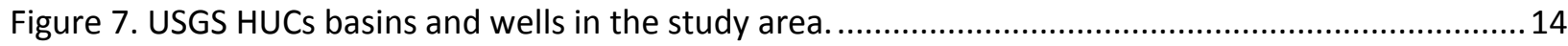

Figure 8. USGS HUCs basins, wells, and USGS stream gages in the study area. Suitable gages are plotted in green. Dismissed or unsuitable stations are plotted in red................................................... 16

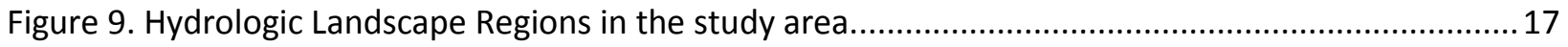

Figure 10. Data sets used to estimate the basic characteristics of ponds and reservoirs.........................20

Figure 11. Procedure used to estimate the basic characteristics of ponds and reservoirs......................21

Figure 12. Drainage area-volume regressions for reservoirs in the study area......................................2 21

Figure 13. Landscape modeling configuration strategy for reservoirs in the study area......................... 22

Figure 14. Stream gage stations in the study area. Cadron near Guy station is highlighted....................23

Figure 15.Observed and simulated discharge in the calibration (top) and validation (bottom) period at

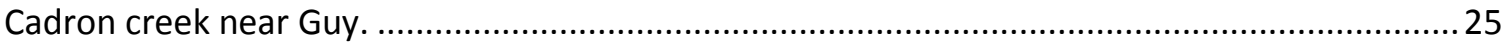

Figure 16. Average annual ponds and reservoirs water budget at Cadron creek near Guy watershed..... 27

Figure 17. Mean annual discharge as percentage of precipitation and mean annual water used for hydraulic fracturing as percentage of discharge for seven watersheds/stream gages in the Fayetteville shale area.

Figure 18. Mean monthly discharge, as percentage of precipitation, and mean monthly water used for hydraulic fracturing as percentage of discharge for the stream gage station 07261000 (Cadron near Guy).

Figure 19. Mean monthly discharge and mean monthly water used for hydraulic fracturing as percentage of discharge for the stream gage station 07260673 (West Fork Point Remove Creek near Hattieville).

Figure 20. a) Cove Creek-Cadron Creek (111102050106) and b) Jacks Fork-Upper Cadron Creek

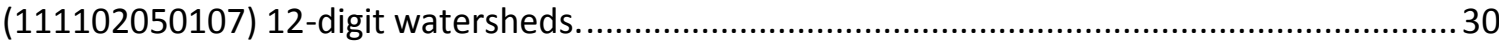

Figure 21. Flow duration curve from SWAT model simulation at Cove Creek-Cadron (1980-2009).......... 31

Figure 22. : Monthly grouped flow duration curve at a) Cove Creek-Cadron Creek and b) Jacks Fork-

Upper Cadron Creek. ............................................................................................................ 32

Figure 23. Environmental Flow Components (EFCs) simulated at Cove Creek-Cadron Creek (1980-2009).

Figure 24. Extreme and low flows simulated at daily time steps at Cove Creek-Cadron Creek (1980-2009).

Extreme low flow threshold identified on monthly values is highlighted...................................33

Figure 25: Extreme low flows simulated at daily time steps at Cove Creek-Cadron Creek (1980-2009)...33

Figure 26: Monthly low flow discharge, monthly discharge and monthly water used for hydraulic fracturing as percentage of discharge for the simulated location at Cove Creek-Cadron Creek. . 34 
Figure 27: Monthly low flow discharge and monthly water used for hydraulic fracturing as percentage of low flow discharge for the simulated location at Cove Creek-Cadron Creek..............................35

Figure 28: Fayetteville Shale, Arkansas............................................................................................ 36

Figure 29: Location of the USGS stream gages in the Fayetteville shale area....................................... 37

Figure 30: Calibration in the Little Red watershed at the stream gage ID 07076517 during the period (2002-2007) 39

Figure 31: Validation Calibration in the Little Red watershed at the stream gage ID 07076517 during the

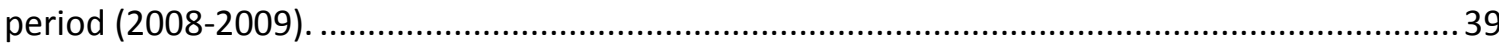

Figure 32: Impact of hydraulic fracturing at large scale using measured stream discharge data............. 40

Figure 33: Hydraulic fracturing scenario assumptions. ......................................................................... 41

Figure 34: Hydraulic fracturing scenario: time and frequency of water withdrawn. .............................. 41

Figure 35: Water balance components for the baseline and the generated scenario.............................42

Figure 36: Flow duration curve: Environmental flow components and thresholds. ............................... 43

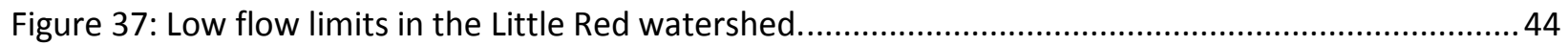

Figure 38: Impact of hydraulic fracturing on monthly stream discharge. ............................................... 45

Figure 39: Monthly stream discharge change during specific months of the year. ................................ 45

Figure 40: Frequency of change of the flow condition...................................................................... 46

Figure 41: Spatial repartition of flow alteration frequency on the Little Red watershed. .......................47

Figure 42: Feature space illustration (Jensen, 2001) as depicted in Gao (2003).....................................50

Figure 43: Illustration of terrain elevation differences on scale effects in aerial image acquisition.......... 53

Figure 44: Soils and elevation characteristics of the study area: Little Red River Watershed (LRRW). .....62

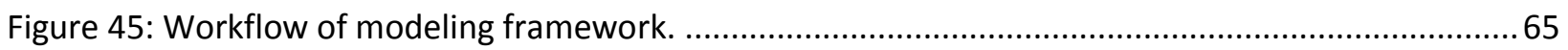

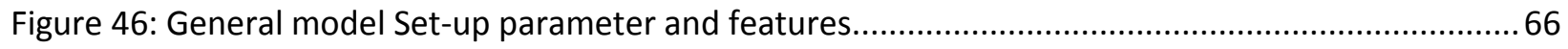

Figure 47: Low and High-Resolution LULC data models after model set-up. ..........................................67

Figure 48: Illustration of high- and low- resolution LULC data as derived with both methods................. 72

Figure 49: Calibrated monthly SWAT total flow model with low-resolution LULC data. .......................... 74

Figure 50: Validated monthly SWAT total flow model with low-resolution LULC data............................. 74

Figure 51: Calibrated monthly SWAT total flow model with High-resolution LULC data.........................75

Figure 52: Validated monthly SWAT total flow model with high-resolution LULC data........................... 75

Figure 53: Auto-calibration output of low-resolution LULC model with best simulation and 95 percent prediction uncertainty band.

Figure 54: Auto-calibration output of high-resolution LULC model with best simulation and 95 percent

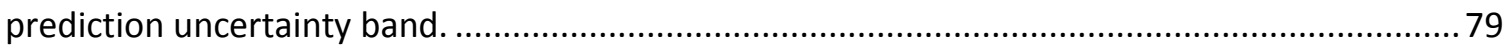

Figure 55: SWAT monthly total flow model with NLCD LULC data (Manual Calibration)..........................8 81

Figure 56: Average monthly basin water yield for the entire simulation period (2000-2009).................. 83

Figure 57: Hydrograph of low-resolution LULC model (a) and high-resolution LULC model (b) calibrated

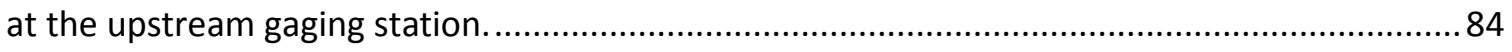

Figure 58: (a) Upstream and (b) downstream manual calibration hydrograph of Landsat model............. 86

Figure 59: Land-cover and elevation characteristics of the study area: Little Red River Watershed

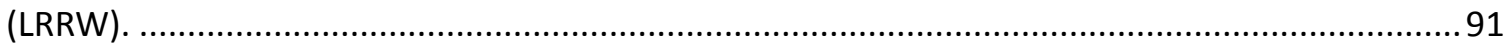

Figure 60: Illustration of Overlay in GIS for HRU Delineation in ArcSWAT............................................ 93

Figure 61: Graph Illustrating the Percentage Changes per Class........................................................95

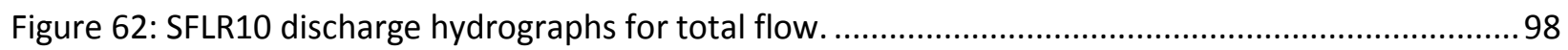

Figure 63: SFLR10 discharge hydrographs for sub-surface flow....................................................... 99 


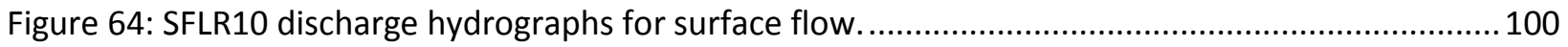

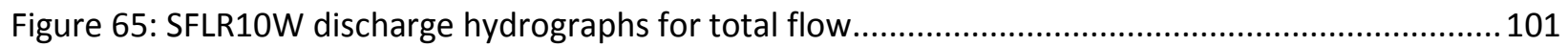

Figure 66: SFLR10W discharge hydrographs for sub-surface flow. ..................................................... 102

Figure 67: SFLR10W discharge hydrographs for surface flow. ........................................................ 103

Figure 68: Screenshot of prototype enhanced FSDSS showing links to USGS stream gage data and internally developed watershed boundaries.

Figure 69: (left) This is a false color (color-infrared) image depicting the Quitman SE quarter quadrangle. On this image water is dark, with colors ranging from black to dark greenish-blue. (middle) This image overlay shows image objects (segments) generated with eCognition's multi-resolution segmentation algorithm with the "scale" parameter set to 100. (right) This is a hybrid of the false color (CIR) image and the image objects. In essence, this image is a generalization of the CIR image.

Figure 70: (left) NHD high-resolution water layer. Water is shown as yellow-filled polygons. (right) Water extracted from the color-infrared imagery using the segmentation/classification process. Water is shown as blue-filled polygons. 108

Figure 71: This image compares NHD and NETL water layers. NHD layer shown with yellow polygon outlines. NETL layer shown with light blue polygon outlines. 109

Figure 72: Screenshot of www.fayshale.cast.uark.edu showing the HUC8 watersheds in AR and the 62year precipation history of the Little Red River Watershed.

Figure 73: A closer look at the Cadron watershed area show precipitation summaries in the HUC8 over the last 62 years and production rates (in MCF) over the last five years of wells permitted by the Arkansas Oil and Gas Commission.

Figure 74: A view of the Drip Creek-Greers Ferry Lake watershed and predicted stream flow from 19502012. Selecting "In-Depth Charts" results in the webpage shown in Figure 70.

Figure 75: Time series data from Drip Creek-Greers Ferry Lake. The upper time series shows min (blue) and max (red) temperatures in the watershed from 1950-2012. The middle time series (green) shows monthly precipitation averages throughout the same time period. The monthly stream flow rates (orange) shows the SWAT predict outflow from this watershed through the same time period. Taken together, this information provides information to regulators that allow them to see variability in stream flow as a function of temperature and precipitation. These time series are interactive.

Figure 76: Time series data from from Drip Creek-Greers Ferry Lake watershed from 1975-1980 show flow responses to temperature and precipitation conditions. 
TABLE LIST

Table 1. Source of input datasets. .18

Table 2. Average annual observed and simulated discharge at Cadron station (1984-2009)...................23

Table 3. Nash and Sutcliffe simulation index at Cadron near Guys station (1984-2009).........................24

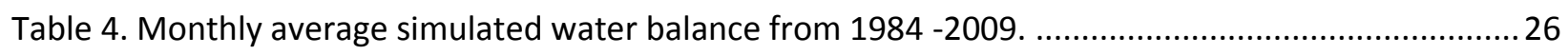

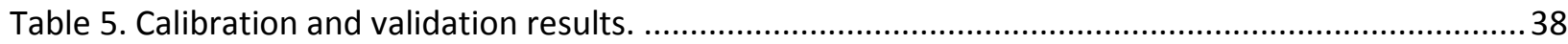

Table 6: Example of an error matrix (for demonstration purpose): modified from Congalton (1991)......55

Table 7: Percentage of the total watershed area occupied per class from both methods. .......................69

Table 8: Error matrix for accuracy assessment of object-oriented classification.....................................69

Table 9: Error matrix for accuracy assessment of maximum-likelihood classification............................... 70

Table 10: Pre-Calibration Results for Models with different LULC data................................................ 73

Table 11: Sensitive parameters and parameter ranges in decreasing order of sensitivity. ...................... 76

Table 12: Model average percentage prediction bias for low and high-flow regimes............................ 82

Table 13: Model calibration for high-resolution LULC model (Upstream gaging station)........................83

Table 14: Land-cover Classes with Respective Area Coverage and Percentage Change from 2006 to 2010

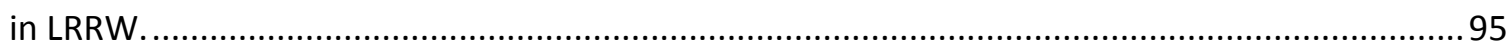

Table 15: Error Matrix for OOIA classification of 2006 LRRW Land-cover................................................96

Table 16: Error Matrix for OOIA classification of 2010 LRRW Land-cover..............................................96

Table 17: Multi-criteria model efficiency measures for respective calibration and validation.................97 


\section{REFERENCES}

(CAST), Center for Advanced Spatial Technologies. 2006. "Arkansas Watershed Information System." http://watersheds.cast.uark.edu/viewhuc.php?hucid=11010014.

CAST, 2006. "Land Use Land Cover Fall 2006 (raster).

http://www.geostor.arkansas.gov/G6/Home.html?id=490250db4c86be523e551f285951f3ad

(USFWS), U. S. Fish and Wildlife Service. 2009. “Arkansas Best Management Practices for Natural Gas Pipeline Construction and Maintenance Activities in the Fayetteville Shale Area, Upper Little Red River Watershed." Conway, Arkansas: U. S. Fish and Wildlife Service, Arkansas Ecological Services Field Office.

(NOAA), National Oceanic and Atmospheric Administration. 2012. "Arkansas, Climate Division Temperature January-May 1895-2012. http://www.ncdc.noaa.gov/temp-and-precip/timeseries/index.php?parameter=tmp\&month=5\&year=2012\&filter=ytd\&state=3\&div=2.

(USDA-ARS), United States Department of Agriculture - Agricultural Research Service. 2012. Grassland Soil and Water Research Laboratory, Temple, Texas : US Climatic Data.

http://ars.usda.gov/Research/docs.htm?docid=19388.

(USGS), U.S. Geological Survey. 2007. National Land Cover Database 2006 (NLCD2006). http://www.mrlc.gov/nlcd2006.php.

NHD, 2009. Medium Resolution: National Hydrography Dataset Line Feature (line). http://www.geostor.arkansas.gov/G6/Home.html?id=8b089ebe17516470245dd905b4965bf4.

Abbaspour K C, 2011. SWAT-CUP: SWAT Calibration and Uncertainty Programs - A User Manual.

AEO, 202. U.S.Energy Information Administration. Annual Energy Outlook 2012 Early Release Overview.

Al-Khudhairy, D.H.A, I Caravaggi, and S Giada. 2005. "Structural Damage Assessments from Ikonos Data Using Change Detection , Object-Oriented Segmentation , and Classification Techniques."

Photogrammetric Engineering and Remote Sensing 71 (7): 825-837.

Andersen F H, 2008. Hydrological Modeling in a Semi-arid Area Using Remote Sensing Data. PhD Thesis, University of Copenhagen, Copenhagen, Denmark.

Andrews, A., P. Folger, M. Humphries, M., Copeland, C., Tiemann, and R. Meltz. 2009. Unconventional Gas Shales: Development, Technology, and Policy Issues. Congressional Research Service Report. http://www.fas.org/sgp/crs/misc/R40894.pdf.

Arkansas Geological Survey. 2012. "Arkansas Physiographic Regions." http://www.geology.ar.gov/education/physio_regions.htm.

Arnold J G, Allen P M, Muttiah R S and Bernhardt G,1995. Automated Baseflow Separation and Recession Analysis Techniques. Ground Water 33 (6): 1010-1018.

Arnold J G, Srinivasan R, Muttiah R S and Williams J R, 1998. Large Area Hydrologic Modeling and Assessment: Part I. Model Development. Journal of American Water Resource Association 34 (1): 73-89. 
Arthur, J, B Coughlin, B Bohm, and ALL Consulting. 2010. "Summary of Environmental Issues, Mitigation Strategies, and Regulatory Challenges Associated with Shale Gas Development in the United States and Applicability to Development and Operations in Canada." In Proceedings of the Canadian Unconventional Resources and International Petroleum Conference . Society of Petroleum Engineers., 18. Calgary.

Atkinson P M, and Lewis P, 2000. Geostatistical Classification for Remote Sensing: An Introduction. Computers and Geosciences 26 (4): 361-371.

Aylward B, 2002. Report to the World Bank as Part of the Program for the Sustainable Management of the Rural Areas in the Panama Canal Watershed. Falls Church, VA.

Baatz M and Schäpe A, 2000. Multiresolution Segmentation: An Optimization Approach for High Quality Multi-scale Image Segmentation. Angewandte Geographische Informationsverarbeitung. Heidelberg: Wichmann-Verlag.

Beven K and Binley A, 1992. The Future of Distributed Models: Model Calibration and Uncertainty Prediction." Hydrological Processes 6: 279-298.

Blaschke, Thomas, and Josef Strobl. 2001. "What' s Wrong with Pixels ? Some Recent Developments Interfacing Remote Sensing and GIS." Geolnformation Systems 14 (6): 12-17.

http://courses.washington.edu/cfr530/GIS200106012.pdf.

Bosch D D, Sheridan J M, Batten H L and Arnold J G, 2004. Evaluation of the swat model on a coastal watershed. Transactions of the ASAE 47 (5): 1493-1506.

Bronstert A, Niehoff,D and Berger G, 2002. Effects of Climate and Land-use Change on Storm Runoff Generation: Present Knowledge and Modelling Capabilities. Hydrological Processes 16 (2) (February 15): 509-529. doi:10.1002/hyp.326. http://doi.wiley.com/10.1002/hyp.326.

Burnett, C, and T Blaschke. 2003. A Multi-scale Segmentation/object Relationship Modeling Methodology for Landscape Analysis. Ecological Modeling 168 (3): 233-249.

Carlson T N and Arthur S T, 2000. The Impact of Land Use - Land Cover Changes Due to Urbanization on Surface Microclimate and Hydrology: a Satellite Perspective." Global and Planetary Change 25 (1-2) (July): 49-65. doi:10.1016/S0921-8181(00)00021-7. http://linkinghub.elsevier.com/retrieve/pii/S0921818100000217.

Chesapeake Energy. Managing Water Resource Challenges in Select Natural Gas Shale Plays. Presented at GWPC Annual Forum, September 20-24, 2008.

Chen, Pei-yu, DiLuzio Mauro, and Jeffrey G. Arnold. 2005. "Impact of Two Land-Cover Data Sets On Stream Flow and Total Nitrogen Simulations Using a Spatially Distributed." In Pecora 16: Global Priorities in Land Remote Sensing, 23-27.

Chow, V. T. 1959. Open-channel Hydraulics, McGraw-Hill, New York.

Congalton, Russell G. 1991. "A Review of Assessing the Accuracy of Classifications of Remotely Sensed Data." Remote Sensing of Environment 46 (October 1990): 35-46. 
Congalton, R.G., and Green K. 1999. Assessing the Accuracy of Remotely Sensed Data: Principles and Practices. Lweis Publishers.

Congalton, Russell G. 2005. "Thematic and Positional Accuracy Assessment of Digital Remotely Sensed Data." In Proceedings of the Seventh Annual Forest Inventory and Analysis Symposium, 149-154.

Curtis, John B, and Scott L Montgomery. 2002. "Recoverable Natural Gas Resource of the United States: Summary of Recent Estimates" 10 (10): 1671-1678.

Deck, Kathy, and Viktoria Riiman. 2012. Revisiting the Economic Impact of the Natural Gas Activity in the Fayetteville Shale : Vol. 1201.

Dendy, F.E, and G.C Bolton. 1976. "Sediment Yield-Runoff-Drainage Area Relationships in the United States." Journal of Soil and Water Conservation 31 (6): 264-266.

Devi, Y Aruna Suhasini, and I V Murali Krishna. 2012. "Pixel-based and Object-oriented Classification of High Resolution Satellite Images." Canadian Journal on Electrical and Electronics Engineering 3 (1): 1-4.

District, United States Army Corps of Engineers (USACE) Little Rock. 2011. “Greers Ferry Lake." http://www.swl.usace.army.mil/parks/greersferry/index.htm.

Easton, Z. M., D. R. Fuka, E. D. White, a. S. Collick, B. Biruk Asharge, M. McCartney, S. B. Awulachew, a. a. Ahmed, and T. S. Steenhuis. 2010. "A Multi Basin SWAT Model Analysis of Runoff and Sedimentation in the Blue Nile, Ethiopia." Hydrology and Earth System Sciences Discussions 7 (3) (June 25): 3837-3878. doi:10.5194/hessd-7-3837-2010. http://www.hydrol-earth-syst-sci-discuss.net/7/3837/2010/.

F. Malcolm Conly, Garth van der Kamp. 2001. "Monitoring the Hydrology of Canadian Prairie Wetlands to Detect the Effects of Climate Change and Land Use Changes." Environmental Monitoring and Assessment 67 (1-2): 195-215. doi:10.1023/A:1006486607040.

http://link.springer.com/article/10.1023/A:1006486607040.

Funkhouser, Jaysson E. 2012. Personal Communication.

Gorham, Bruce. 2013. Personal Communication.

Green, W. H., and G. A. Ampt. 1911. "Studies on Soil Physics, J. Agric. Sci., 4(1), 1 - 24." Journal of Agricultural Science 4 (1): 1-24.

Gurung, P., and L. Bharati. 2012. "Downstream Impacts of the Melamchi Inter-Basin Water Transfer Plan (MIWTP) Under Current and Future Climate Change Projections." Hydro Nepal: Journal of Water, Energy and Environment April 2012: 23-29.

http://www.iwmi.cgiar.org/offices/asia/south_asia/nepal/pdf/specia_issue_hn_bulletin_final_web.pdf.

Henleya, W. F., M. A. Pattersona, R. J. Nevesa, and A. Dennis Lemlyb. 2000. "Effects of Sedimentation and Turbidity on Lotic Food Webs: A Concise Review for Natural Resource Managers." Reviews in Fisheries Science 8 (2): 125-139.

Huang, Jinliang, Pei Zhou, Zengrong Zhou, and Yaling Huang. 2013. "Assessing the Influence of Land Use and Land Cover Datasets with Different Points in Time and Levels of Detail on Watershed Modeling in the North River Watershed, China." International Journal of Environmental Research and Public Health 10 (1) (January): 144-57. doi:10.3390/ijerph10010144. 
http://www.pubmedcentral.nih.gov/articlerender.fcgi?artid=3564134\&tool=pmcentrez\&rendertype=ab stract.

Im, J., J. R. Jensen, and J. a. Tullis. 2008a. “Object-based Change Detection Using Correlation Image Analysis and Image Segmentation." International Journal of Remote Sensing 29 (2) (January): 399-423. doi:10.1080/01431160601075582.

http://www.tandfonline.com/doi/abs/10.1080/01431160601075582.

Im J, 2008b. "Object-based Change Detection Using Correlation Image Analysis and Image

Segmentation." International Journal of Remote Sensing 29 (2) (January): 399-423.

doi:10.1080/01431160601075582.

http://www.tandfonline.com/doi/abs/10.1080/01431160601075582.

Johansen, K, L A Arroyo, S Phinn, and C Witte. 2007. “OBJECT-ORIENTED CHANGE DETECTION OF RIPARIAN ENVIRONMENTS FROM HIGH SPATIAL RESOLUTION MULTI-SPECTRAL IMAGES." ISPRS Journal of Photogrammetry and Remote Sensing (1).

Laliberte, Andrea S., Albert Rango, Kris M. Havstad, Jack F. Paris, Reldon F. Beck, Rob McNeely, and Amalia L. Gonzalez. 2004. "Object-oriented Image Analysis for Mapping Shrub Encroachment from 1937 to 2003 in Southern New Mexico." Remote Sensing of Environment 93 (1-2) (October): 198-210. doi:10.1016/j.rse.2004.07.011. http://linkinghub.elsevier.com/retrieve/pii/S0034425704002147.

Lang, S, F Albrecht, and T Blaschke. 2006. OBIA Tutorial - Introduction to Object-Based Image Analysis. Salzburg, Autria.

Matherne, Anne Marie. 2006. Effects of Roads and Well-pads on Erosion in the Largo Canyon Watershed, New Mexico, 2001-02. Denver, CO. http://pubs.usgs.gov/sir/2006/5039/pdf/sir2006-5039.pdf.

Mcdermid, Gregory J, Alysha Pape, Michael S Chubey, and Steven E Franklin. 2012. "Object Oriented Analysis for Change Detection." http://www.ecognition.com/sites/default/files/354_1.pdf.

Moriasi, D N, J G Arnold, M W Van Liew, R L Bingner, R D Harmel, and T L Veith. 2007. "Model Evaluation Guidelines for Systematic Quantification of Accuracy in Watershed Simulations." Transactions of the ASABE 50 (3): 885-900.

Myint, Soe W., Patricia Gober, Anthony Brazel, Susanne Grossman-Clarke, and Qihao Weng. 2011. "Perpixel Vs. Object-based Classification of Urban Land Cover Extraction Using High.pdf." Remote Sensing of Environment 78 (31): 17.

Nash, J. E. and J. V. Sutcliffe (1970), River flow forecasting through conceptual models part I - A discussion of principles, Journal of Hydrology, 10 (3), 282-290.

NID-USACE. 2009. "National Inventory of Dams, United States Army Corps of Engineers (NID-USACE)." http://geo.usace.army.mil/pgis/f?p=397:101:1547957062223601::NO.

Niemeyer, I., S. Nussbaum, and M.J. Canty. 2005. "Automation of Change Detection Procedures for Nuclear Safeguards-related Monitoring Purposes." Proceedings. 2005 IEEE International Geoscience and Remote Sensing Symposium, 2005. IGARSS '05. 3: 2133-2136. doi:10.1109/IGARSS.2005.1526439. http://ieeexplore.ieee.org/lpdocs/epic03/wrapper.htm?arnumber=1526439. 
Pai, N., and D. Saraswat. 2011. "SWAT2009_LUC: A tool to activate the land-use change module in swat 2009." Transactions Of The Asabe 54 (5): 1649-1658.

Peterson, L.C., G.H. Haug, K.A. Hughen, and Ursula Röhl. 2000. "Rapid Changes in the Hydrologic Cycle of the Tropical Atlantic During the Last Glacial." Science 290 (5498) (December 8): 1947-1951.

doi:10.1126/science.290.5498.1947. http://www.sciencemag.org/content/290/5498/1947.abstract.

Pham, Cu Van, Thi Hang Thuy Nguyen, and Dong Phan Nguyen. 2009. "Comparison of Pixel Based and Object Oriented Classifications in Land Cover Mapping in the Red River Delta - Example of Duy Tien District, Ha Nam Province, Vietnam Comparison of Pixel Based and Object Oriented Classifications in Land Cover Mapping in Th." In 7th FIG Regional Conference, 1-9.

Pitman, a. J. 2004. "Impact of Land Cover Change on the Climate of Southwest Western Australia." Journal of Geophysical Research 109 (D18): 1-12. doi:10.1029/2003JD004347.

http://www.agu.org/pubs/crossref/2004/2003JD004347.shtml.

Platt, Rutherford V, and Lauren Rapoza. 2008. "An Evaluation of an Object-Oriented Paradigm for Landuse / Land-cover Classification *." The Professional Geographer 60 (1): 87-100.

Ryherd, S., and C. E. Woodcock. 1996. "Combining Spectral and Texture Data in the Segmentation of Remotely Sensed Image." Photogrammetric Engineering and Remote Sensing 62 (2): 181-194.

Scanlon, Bridget R., Robert C. Reedy, David a. Stonestrom, David E. Prudic, and Kevin F. Dennehy. 2005. "Impact of Land Use and Land Cover Change on Groundwater Recharge and Quality in the Southwestern US." Global Change Biology 11 (10) (October): 1577-1593. doi:10.1111/j.1365-2486.2005.01026.x. http://doi.wiley.com/10.1111/j.1365-2486.2005.01026.x.

S, Lang, F Albrecht, and T Blaschke. 2006. "Lang S, F Albrecht \& T Blaschke (2006) OBIA-Tutorial Introduction to Object-based Image Analysis, V 1.0." Salzburg, Autria.

Sandahl, J. F., D. H. Baldwin, J. J. Jenkins, and N. L. Scholz. 2007. "A Sensory System at the Interface Between Urban Storm Water Runoff and Salmon Survival." Environmental Science \& Technology 41 (8): 2998-3004. http://www.ncbi.nlm.nih.gov/pubmed/17533870.

Survey, Arkansas Geological (AGS). 2011. “Arkansas Physiographic Regions.” http://www.geology.ar.gov/education/physio_regions.htm.

Tang,Yuqi, Xin Huang, Kanako Muramatsu, Liangpei Zhang, Remote Sensing, and Luo Yu Road. 2010. "OBJECT-ORIENTED CHANGE DETECTION FOR HIGH-RESOLUTION IMAGERY." International Archives of Photogrammetry and Remote Sensing and Spatial Information Science XXXVIII.

Tang, Z, B a Engel, B C Pijanowski, and K J Lim. 2005. "Forecasting Land Use Change and Its Environmental Impact at a Watershed Scale." Journal of Environmental Management 76 (1) (July): 3545. doi:10.1016/j.jenvman.2005.01.006. http://www.ncbi.nlm.nih.gov/pubmed/15854735.

Texas Agricultural and Mechanical University (TAMU). 2011. "SWAT Calibration Techniques." http://swat.tamu.edu/media/1315/swat-calibration-techniques_slides.pdf.

Trimble. 2012. “eCognition Developer 8." http://www.ecognition.com/products/ecognition-developer. 
U.S. Department of Agriculture - Soil Conversation Service (USDA-SCS). 1972. Estimation of Direct Runoff From Storm Rainfall. U.S. Department of Agriculture, Soil Conservation Service, Washington, D.C., Pp. 10.1-10.24. SCS National Engineering Handbook, Section 4, Hydrology. Chapter 10.

United States Geological Survey (USGS). 2002. "Base Flow Index Grid for the Conterminous United States." http://water.usgs.gov/GIS/metadata/usgswrd/XML/bfi48grd.xml\#stdorder.

USDA-ARS. 2012. "United States Department of Agriculture's Agricultural Research Service (USDA-ARS)." http://ars.usda.gov/Research/docs.htm?docid=19422.

Veil, J.A., 2010, "Water Management Technologies Used by Marcellus ShaleShale Gas Producers,"

ANL/EVS/R-10/3, prepared for the U.S. Department of Energy, National Energy Technology Laboratory, July. Available at http://www.ead.anl.gov/pub/dsp_detail.cfm?PubID=2537; accessed May 24, 2011.

Wachal, D.J. 2008. "Characterizing Storm Water Runoff from Natural Gas Well Sites in Denton County, Texas. Denton, Texas". University of North Texas. digital.library.unt.edu/ark:/67531/metadc11064/.

Weih, Robert, Jr., Norman D. Riggan, Jr. 2013. “A Comparison of Pixel-based Versus Object-based Land Use/Land Cover Classification Methodologies."

http://www.featureanalyst.com/feature analyst/publications/success/comparison.pdf.

Wegehenkel, M., U. Heinrich, St. Uhlemann, V. Dunger, and J. Matschullat. 2006. “The Impact of Different Spatial Land Cover Data Sets on the Outputs of a Hydrological Model - a Modelling Exercise in the Ucker Catchment, North-East Germany." Physics and Chemistry of the Earth, Parts $A / B / C 31$ (17) (January): 1075-1088. doi:10.1016/j.pce.2006.07.006.

http://linkinghub.elsevier.com/retrieve/pii/S1474706506001793.

White, Kati L, and Indrajeet Chaubey. 2005. "SENSITIVITY ANALYSIS , CALIBRATION , AND VALIDATIONS FOR A MULTISITE AND MULTIVARIABLE SWAT MODEL 1." Journal of the American Water Resources Association 41 (5): 1077-1089.

White, Michael D., and Keith A. Greer. 2006. "The Effects of Watershedurbanization on the Streamhydrology and Riparian Vegetation of Los Peñasquitos Creek, California." Landscape and Urban Planning 74: 125-138.

Williams, H. F. L., D. L. Havens, K. E. Banks, and D. J. Wachal. 2007. "Field-based Monitoring of Sediment Runoff from Natural Gas Well Sites in Denton County, Texas, USA." Environmental Geology 55 (7): 14631471. doi:10.1007/s00254-007-1096-9.

Williams, J.R., and H.D. Berndt. 1977. "Sediment Yield Prediction Based on Watershed Hydrology." Transactions of the ASAE: 1100-1104.

Winchell, M., R. Srinivasan, M. Di Luzio, and J. G. Arnold. 2009. "ArcSWAT2009 Interface for SWAT2009."

Wu, M., Y. Demissie, and E. Yan. 2012. "Simulated Impact of Future Biofuel Production on Water Quality and Water Cycle Dynamics in the Upper Mississippi River Basin." Biomass and Bioenergy 41: 44-56. doi:10.1016/j.biombioe.2012.01.030.

Yan, Gao. 2003. "Pixel Based and Object Oriented Image Analysis for Coal Fire Research." 
Zampella, Robert a, Kim J Laidig, and Rex L Lowe. 2007. "Distribution of Diatoms in Relation to Land Use and pH in Blackwater Coastal Plain Streams." Environmental Management 39 (3) (March): 369-84. doi:10.1007/s00267-006-0041-0. http://www.ncbi.nlm.nih.gov/pubmed/17219257.

Zhang, L., W.R. Dawes, and G.R. Walker. 1999. Catchment Hydrology: Predicting the Effect of Vegetation Changes on Catchment Average Water Balance.

Zhang, X, R Srinivasan, and F Hao. 2007. "Predicting Hydrologic Response to Climate Change in the Luohe River Basin Using the SWAT Model." American Society of Agricultural and Biological Engineers 50 (3): 901-910. 


\title{
APPENDIX 1
}

This appendix contains a complete manuscript prepared for submission to a peer reviewed journal (TBD). The manuscript presents similar information provided in this report, though in a sometimes more compact format.

\section{Evaluation of Environmental flow components in the Fayetteville Shale Area (Arkansas, USA)}

\section{Évaluation des composantes environnementales du régime hydrologique au niveau de la région du Fayetteville (Arkansas, États-Unis)}

\author{
A. Abouabdillah, M. Di Luzio, J. Cothren, M. Williamson, W. E. Fox
}

Aziz Abouabdillah

National School of Agriculture, Meknes, Morocco. km. 10, Route Haj Kaddour, B.P. S/40, Meknès, 50001.

Morocco aziz.abouabdillah.com

Texas AgriLife Research, Blackland Research and Extension Center 720 East Blackland Road, Temple, TX 76502

Email: aziz.abouabdillah.com

Mauro Di Luzio Texas AgriLife Research, Blackland Research and Extension Center 720 East Blackland Road, Temple, TX 76502 Email: mdiluzio@brc.tamus.edu

Jackson Cothren

Center for Advanced Spatial Technologies, Department of Geosciences, University of Arkansas. JBHT 304

University of Arkansas Fayetteville, AR 72701. Email: jcothren@ cast.uark.edu

Malcolm Williamson

Center for Advanced Spatial Technologies, Department of Geosciences, University of Arkansas. JBHT 304

University of Arkansas Fayetteville, AR 72701. Email: malcolm@ cast.uark.edu

William E. Fox

Texas AgriLife Research, Blackland Research and Extension Center 720 East Blackland Road, Temple, TX 76502

Email: bfox@brc.tamus.edu

Abstract: Natural gas production in the Fayetteville Shale area (Arkansas, USA) has the potential to create critical levels of water discharge due to diversion of surface water used for horizontal hydraulic fracturing. In fact, each well requires between $12000 \mathrm{~m}^{3}$ and $26500 \mathrm{~m}^{3}$ of water for hydraulic fracturing and the number of wells is expected to grow in the future. This usage, combined with municipal and agricultural needs, could pose water resource management concerns. 
This paper presents current hydrology simulation results obtained by applying the Soil and Water Assessment Tool Model (SWAT) and using specific georeferenced landscape input layers. Several physical processes are simulated and different water use management issues are taken into account. Based on Best Management Practices, simulation scenarios were generated to support strategies to help the gas industry and the regulatory agencies facing the related water management problems. These scenarios point out the impact of the hydraulic fracturing on the water balance at both large and small scales and at different time periods, as well as the impact on hydrological regime and the environmental flow components.

Preliminary results indicate that, when managed correctly, surface water diversions related to hydraulic fracturing do not create extraordinary low-flow conditions in affected tributaries. However on small scale and particularly on specific dates, hydraulic fracturing could have heavy impact on the environmental flow component leading to disequilibrium of the aquatic community on the river.

The overall goal is to support future water resources planning in the Fayetteville Shale area and eventually in other watersheds with similar conditions

Résumé: La production du gaz naturel dans la région du Fayetteville (Arkansas, États-Unis) a le potentiel de créer des niveaux critiques de décharge de l'eau à cause du détournement des eaux de surface utilisées pour la fracturation/creusement hydraulique horizontale. En effet, un puits a besoin d'une quantité d'eau entre $12000 \mathrm{~m}^{3}$ et $26500 \mathrm{~m}^{3}$ afin d'être fracturé. Le nombre de puits est appelé à croître dans l'avenir. Cet usage, combiné avec les besoins urbains et agricoles, pourrait causer des problèmes de gestion des ressources hydriques.

Cet article présente les résultats actuels de simulation obtenus en appliquant le modèle hydrologique intégré "Soil and Water Assessment Tool" (SWAT) et en utilisant spécifiques données géo-référencées. Plusieurs processus physiques sont simulés et différentes techniques de gestion de l'utilisation de l'eau sont prises en compte. Basé sur les meilleures pratiques de gestion, des scénarios de simulation ont été générés pour soutenir les stratégies d'aide à l'industrie du gaz ainsi que les organismes de réglementation face aux problèmes liés à la gestion de l'eau. Ces scénarios soulignent l'impact de la fracturation hydraulique sur le bilan hydrique à l'échelle tant petite et grande, à différentes périodes, ainsi que l'impact surle régime hydrologique et les composants environnementales du flux. Les résultats préliminaires indiquent qu'avec une utilisation raisonnée des eaux, les dérivations d'eau de surface liées à la fracturation hydraulique ne créent pas des conditions extraordinaires du faible débit dans les affluents touchés. Cependant à petite échelle et en particulier à des dates précises, la fracturation hydraulique pourrait avoir un impact lourd sur les composantes environnementales du flux en conduisant à un déséquilibre de la communauté aquatique au niveau de la rivière. L'objectif global est de soutenir la planification de la gestion des ressources en eaux de la région du Fayetteville et éventuellement dans d'autres bassins versants avec des conditions similaires. 


\section{Introduction}

In the last decade, unconventional development of energy hydrocarbon based resource Shales has become a growing source of natural gas in the United States. Since 1998, unconventional natural gas production has increased nearly 65\% (Navigant consulting, 2008). This change in production has resulted in unconventional gas production becoming an increasingly larger component of total domestic natural gas production in the United States, shifting from $28 \%$ in 1998 to $46 \%$ of total production in 2007 (Navigant consulting, 2008). The Energy Information Administration, in its Annual Energy Outlook 2011, projects that natural gas demand in the United States could be 751 trillion liters by the year 2035 (AEO, 2012). The United States production of natural gas is expected to exceed consumption early in the next decade. The United States is projected to become a net exporter of liquefied natural gas (LNG) in 2016, a net pipeline exporter in 2025, and an overall net exporter of natural gas in 2021(AEO, 2012).

Shale gas plays are unconventional reservoirs containing gas-bearing rocks which have poor or limited natural permeability relative to the transmission of fluids (Cramer, 2008). As such, developing these resources requires a means to increase permeability through stimulation, specifically hydraulic fracturing (Cramer, 2008). Hydraulic fracturing is a well stimulation technique that has been employed in the oil and gas industry since the late 1940s and is intended to increase the exposed flow area of the productive formation, connecting the fractured area to the well by creating a highly conductive path extending a carefully planned distance outward from the well bore into the targeted hydrocarbon-bearing formation, so that hydrocarbons can flow easily to the well (Schlumberger, 2008).

Current practices for hydraulic fracturing of gas Shale reservoirs are commonly sequenced events requiring thousands of barrels of water based fracturing fluids mixed with proppant materials pumped into target Shale formations above the fracture (Schlumberger, 2008). Single fracturing operation in a shallow gas well (such as a coal bed methane well) may use several hundreds of thousands of gallons of water. Slickwater fracs, which are commonly used in Shale gas formations, have been known to use up to five million gallons of water to fracture on one horizontal well (Burnett and Vavra, 2006). Many wells have to be fractured several times over the course of their lives.

In the U.S., an estimated 35,000 wells are hydraulically fractured annually and it is estimated that over one million wells have been fractured since the first well in the late 1940s (Bolin and David, 2007). As production from conventional oil and gas fields continues to mature and the shift to non-conventional resources increases, the importance and impact of hydraulic fracturing are expected to expand. 
The Fayetteville Shale located in Central Arkansas shows great promise for continued development, partially because of successful technological advances in horizontal drilling and hydraulic fracturing. Fracture treatments in Fayetteville Shale gas wells involve an average of $5962 \mathrm{~m}^{3}$ bbls of fracture water in what might typically be applied through 4 to 8 stages (US Department of Interior, 2008). Environmental considerations associated with water acquisition, use, and management in hydraulic fracturing operations are the source of water acquired, the volume needed and the timing of withdrawal. Availability of water for fracturing operations has received considerable attention over recent months.

Multiple options are available for obtaining water for fracture use, such as water supply wells, private water sources including private lakes, ponds and stock tanks, surface water, and recycled flow-back water from previous fracturing operations (Chesapeake Energy, 2008).

To support its Fayetteville Shale play in Arkansas, Chesapeake Energy is constructing a 616740 $\mathrm{m}^{3}$ impoundment to store water withdrawals. The objective would be to withdrawal water from the Little Red River during periods of high flow (storm events or power generation releases from Greer's Ferry Dam upstream of the intake) when excess water is available. Current permits allow for up to a maximum of 1550 acre-ft annually to be collected (Chesapeake Energy Corporation, 2008). Monitoring of in-stream water quality and game and non-game fish species within the reach of river surrounding the intake is part of the conditions of the permit. The design provides a water storage and recovery system similar in concept to municipal water facilities. Because surface water withdrawals are limited to times of excess flow in the Little Red River, impacts on local water supplies are anticipated to be minimal.

This usage, combined with municipal and agriculture, poses water resource management concerns. Water withdrawals from sources have led non-governmental organizations (NGOs), politicians, government agencies, and the public to express concerns regarding the associated environmental implications (Veil, 2010). Additional considerations in evaluating potential impacts on the environment include the location and the availability of water, as well as the timing of withdrawals.

Understanding local water needs can help in the development of water acquisition and management plans that will be acceptable to the communities neighboring oil and gas developments. Although the water needed for drilling and fracturing operations may represent a small volume relative to other requirements, withdrawals associated with large-scale developments, conducted over multiple years, may have a cumulative impact to watersheds and/or groundwater. This potential cumulative impact can be minimized or avoided by working with local water resource managers to develop a plan of when and where withdrawals will occur and optimizing those withdrawals based upon source sustainability. 
Significant issues can be associated with the timing, location, and volume of withdrawals as impacted watersheds may be sensitive, especially in drought years, during low flow periods, or during periods of the year when activities such as irrigation place additional demands on the surface supply of water. Significant energy production and associated water withdrawals may have a cumulative impact to watersheds over the short-term. Hence, hydraulic fracturing based on water withdrawal could potentially create shifts in the timing and magnitude of low or high flow events or change the magnitude of river flow at daily, monthly, seasonal, or yearly time scales. These changes in flow regimes can result in dramatically altered river systems. Currently little is known about the impact of fracturing on stream flow behavior. Within this context the objective of this study is to assess the impact of the hydraulic fracturing on the water balance of the Fayetteville Shale play area and examine the potential impacts of hydraulic fracturing on river flow regime at subbasin scale.

The Soil and Water Assessment Tool has gained international recognition as is evidenced by a large number of applications of this model (Gassman et al., 2007). A number of papers and reports can be found in literature providing the application of this model to study the impact on low flow condition (Cibin et al., 2010; Rahman et al., 2010; Steher et al., 2008). In Arkansas the SWAT model has been applied in different watershed, although, they deal more with water quality modeling (Baskaran et al., 2010; Gitau et al., 2010; Chaubey et al., 2005). Furthermore, emphasis has been placed upon the study of environmental flow component and hydrologic indices. This is widely documented in several studies by integrating the SWAT model and the Indicator of Hydrologic Alteration (IHA) software at sub-watershed scale (Abouabdillah, et al., 2010, Jeong et al., 2011). This program, available from the Nature Conservancy (TNC), has been used by scientists and water managers in river basins throughout the United States (U.S.) and worldwide (TNC, 2005, 2007). TNC recently made substantive enhancements to the IHA to include new capabilities to support environmental flow assessments.

In this paper the results of a study in the basins and composing watershed of the Fayetteville Shale area are presented. The Soil and Water Assessment Tool (SWAT) model was used to simulate the across-scale water balance and the respective impact of hydraulic fracturing. A second hypothetical scenario was designed to assess the current and future impacts of water withdrawals for hydraulic fracturing on the flow regime and on the environmental flow components (EFCs) of the river. The shifting of these components, which present critical elements to water supply and water quality, could influence the ecological dynamics of river systems. For this purpose, we combined the use of SWAT model and Richter et al.'s (1996) methodology to assess the shifting and alteration of the flow regime within the river and streams of the study area.

\section{Methodology}

1.1 Description of the study area 
The Fayetteville Shale is an unconventional natural gas reservoir located on the Arkansas side of the Arkoma Basin, ranging in thickness from 15 to 152 meter (m) and ranging in depth from 457 to $1981 \mathrm{~m}$. The Shale is a Mississippian-age Shale that is the geologic equivalent of the Caney Shale found on the Oklahoma side of the Arkoma Basin and the Barnett Shale found in north Texas.

The area under study covers three 8-digit USGS Hydrologic Unit Codes watersheds (Fig. 1). It extends over an area of approximately $8004 \mathrm{~km}^{2}$, and includes around 1158 wells counted in 2009. The three 8-digit USGS Hydrologic units are:

- Little Red watershed $\left(4642 \mathrm{~km}^{2}\right)$ lies within the Arkansas River Basin in North Central Arkansas. The hydrologic unit code for this watershed is 11010014. There is no upstream watershed. The Lower White-Bayou Des Arc (08020301) is downstream.

- Cadron Creek watershed $\left(1961 \mathrm{~km}^{2}\right)$ lies within the Arkansas River Basin, North of Central Arkansas. The hydrologic unit code for this watershed is 11110205 . There is no upstream watershed. Lake Conway-Point Remove (11110203) is downstream.

- Lake Conway-Point-Remove watershed lies within the Arkansas River Basin in Central Arkansas. The hydrologic unit code for this watershed is 11110203 . Only the part covered by the oil and natural gas wells is considered in this study $\left(1377 \mathrm{~km}^{2}\right)$.

The river network in the Little Red watershed has an overall length of approximately $2289 \mathrm{~km}$ $(1509 \mathrm{~km}$ tributaries and $779 \mathrm{~km}$ main channel), $975 \mathrm{~km}$ within the Cadron watershed $(644 \mathrm{~km}$ tributaries and $330 \mathrm{~km}$ main channel), and $581 \mathrm{~km}$ in the Lake-Conway-Point-Remove watershed (290 km tributaries and $290 \mathrm{~km}$ main channel).

The mean annual discharge ranges from $6.65 \mathrm{~m}^{3} \mathrm{~s}^{-1}$ measured at South fork USGS stream gauge at Clinton (AR) (07075300), and $55.12 \mathrm{~m}^{3} \mathrm{~s}^{-1}$ measured at Little Red river USGS stream gauge near Dewey (AR) (07076517). These watersheds present a rolling topography (Fig. 1) (altitude between $53 \mathrm{~m}$ and $623 \mathrm{~m}$ with a mean elevation value of $338 \mathrm{~m}$ ) and have diversified condition of geology, morphology, vegetation, and land-use. From 2000 to 2010, the average annual rainfall varied between $1066 \mathrm{~mm}$ in the plain $(80 \mathrm{~m})$ and $1460 \mathrm{~mm}$ in the highest part of the watersheds (260 $\mathrm{m}$ in the Cadron and Lake Conway and $418 \mathrm{~m}$ in the Little Red watershed).

The highest rainfall often occurs between March and May, (between 100 to $140 \mathrm{~mm} / \mathrm{month}$ ) and the lowest between August and September $(70 \mathrm{~mm} / \mathrm{month})$. The annual mean temperature is $15^{\circ} \mathrm{C}$, with a maximum of $36^{\circ} \mathrm{C}$ in August and minimum of $-16^{\circ} \mathrm{C}$ in January. The mean annual potential evapotranspiration extracted from the CGIAR-CSI Global Potential EvapoTranspiration (Global-PET) Climate Database ranges between 1260 mmyear $^{-1}$ in the Cadron and the Little Red watersheds and 1350 mmyear-1 in the Lake Conway watershed (Trabucco et al., 2009). These characteristics have great influence on the flow regime, erosion, and nutrient/sediment delivery processes. 
The Land cover is dominated by mixed forest (from 70 to $80 \%$ ) throughout most all of the watersheds with smaller areas converted to pasture. The urbanized area in the watersheds remains very low (1\%) with a population density of $17 / \mathrm{km}^{2}$ in the Little Red, $16 / \mathrm{km}^{2}$ in Cadron and $36 / \mathrm{km}^{2}$ in Lake Conway Point Remove. The population is concentrated around the Greers Ferry Lake and the southwestern part of the Little Red watershed, central part of the Cadron watershed, and at the southern part of the Lake Conway watershed.

Water stress within this area can be summarized as a resource facing an increasing water demand. Recent natural gas well reports for the Fayetteville Shale area have noted increases from 24 active wells in 2004 to 33 in 2005, 129 in 2006, 428 in 2007, and 481 through October 7, 2008 (AOGC, 2008). According to Arkansas Oil and Gas Commission Fayetteville Shale, in 2009, 513 wells were located in Little Red watershed, 355 in the Cadron and 311 in the Lake Conway point remove watersheds (AOGC 2009) (Fig1). 


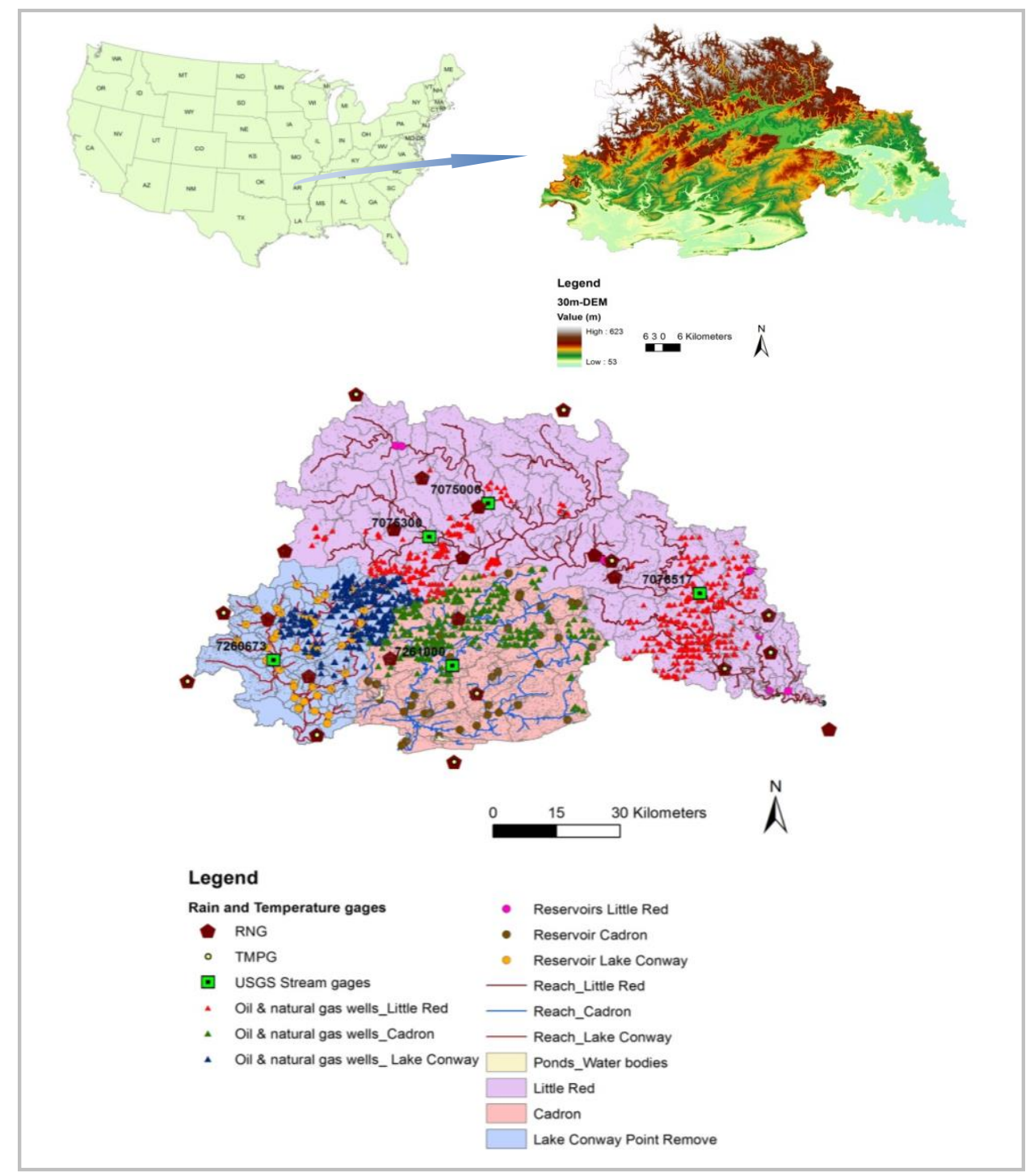

Figure 1. The Fayetteville Shale study area in Arkansas.

Furthermore, the continuous construction of retention ponds and small water bodies (Fig.1) has taken place within this area. Over $40 \mathrm{~km}^{2}$ has been impounded by new water retention structures (ponds and reservoirs). The reservoirs are located on the main channel of the river network and receive the water from all sub-basins upstream. The small dams (ponds) collecting headwater flow and providing supplemental water for irrigation are scattered along the river. Some big reservoirs are located in this area such as the Greers Ferry Dam within the Little Red River in Cleburne County, which impounds Greers Ferry Lake. The dam is located north of Little Rock. Construction of the dam was completed in December 1962. This reservoir has a capacity of storage equal to 1147 million cubic meters $\left(\mathrm{Mm}^{3}\right)$ at its principal spillway. The lake serves the Heber Springs area flood control, and is a site for recreation and power generation. 


\subsection{Hydrological modeling}

\subsubsection{Modeling principles (SWAT)}

SWAT is a basin scale, continuous time model that operates on a daily time step and is designed to predict the impact of management on water, sediment, and agricultural chemical yields in river basins (Arnold et al., 1998). The SWAT model interface uses ArcGIS version 9.3.1 as the platform for inputting and processing spatial datasets (Winchell et al., 2010). The interface requires a number of input GIS layers and parameter sets, including a digital elevation model (DEM), soil map and list of soil parameters, a land use map, and climate data. Climate information is entered as irregularly-space point data, and any number of climate data points can be entered to allow for spatial variation of climate across a catchment. SWAT uses physicallybased equations which allow greater confidence when applied to non-monitored watersheds (Grayson and Blöschl, 2001), and it has been widely-used for basin hydrology and water quality modeling (Gicas et al., 2006). Recently, this model has been used to evaluate the potential impact of various management strategies on surface water, to test the effectiveness of agricultural conservation practices (Arabi et al., 2008; Schmalz et al., 2008).

The model divides the simulation area into sub-watersheds with assumed homogenous physical characteristics, linked in a cascade structure following the river network. Each sub- watershed is further divided into Hydrological Response Units (HRUs), areas with a specific combination of land use, soil type and slope. The central component of the model is the daily calculation of the hydrological balance for each sub-basin, which takes into account precipitation, evapotranspiration, surface runoff, subsurface runoff, and deep aquifer recharge. In this study, potential evapotranspiration (PET) was simulated using Hargreaves method (Hargreaves and Samani, 1985), selected because only rainfall and temperature daily data were available. Surface runoff is calculated using the Curve Numbers method (SCS, 1972). Soil erosion calculation is based on runoff using the Modified Universal Soil Loss Equation (MUSLE) (Neitsch et al., 2002; Williams, 1975). Groundwater flow contribution to total stream flow is simulated by routing a shallow aquifer storage component to the stream (Arnold and Allen, 1996). Default values provided by SWAT crop database were used.

SWAT provides results on daily time scale of all the components of the hydrological cycle, including soil moisture, water quality, soil erosion, and vegetation productivity, per HRU and sub-basin. The SWAT model was chosen as it had been extensively used in related studies that had similar objectives of assessing the impact of intensive water use on the water balance and its components.

\subsubsection{Input Data}


A 30-meter DEM was sourced from the National Hydrography Dataset (NHD) (source: Table 1). In order to improve hydrographic, segmentation, and sub-watershed boundary delineation, we burned-in a stream network of the catchment derived from the flowlines included in the NHD medium resolution. The burn-in strategy consists of super-imposing a high-quality stream network onto the DEM to improve the definition of the DEM-derived stream network. This feature is most useful in situations where the DEM does not provide enough detail to allow accurately defining the DEM-derived stream network.

A 28.5 meter land-use-cover map for the year 2004 was provided by the Center for Advanced Spatial Technologies (CAST). The default soil layer included with the SWAT model is the State Soil Geographic Database (STATSGO) (scale of 1:250,000, USDA NRCS) and used in this study. STATSGO is developed by generalizing the detail county soils survey data to produce a level mapping designed for broad planning and management uses in covering state, regional, and multi-state areas, thus, giving the proportionate extent of the component soils and their properties for each map unit. Soil texture was classified according to the USDA methodology; sandy loam (49\%), silty loam (48\%) and loam (3\%) are the dominant soil textures. Following the U.S. Natural Resources Conservation Service (NRCS) soil classifications, the major soil series in the basin $(97 \%)$ fall within hydrological group B (final infiltration rate is between 3.8 and $7.6 \mathrm{mmh}$ 1). Climate data (rainfall and temperature) were obtained from an updated serially complete (no missing values) daily total precipitation and maximum-minimum temperature time series extending the National Weather Service (NWS) Cooperative Observer Program (COOP) datasets (Eischeid et al., 2000). Other meteorological data required by SWAT (solar radiation, wind speed, and relative humidity) are estimated at run-time using the SWAT built-in weather generator. There are a total of 32 rainfall stations and 13 temperature gauges located within, or in close proximity to, the study area (Fig. 1).

Spatial data for water bodies such as ponds and reservoirs (Fig.1) are provided from the Center for Advanced Spatial Technologies for the year 2010 and completed from the National Hydrography dataset. Parameters used to model the movement of water through reservoirs such as the volume to the principal and emergency spillways are sourced from the National Inventory of Dams (NID 2009), NHD datasets, and from US Corp of Engineers for some water bodies. For the remainder of reservoirs which are not included in the cited datasets, the volumes have been estimated using a regression between drainage area and storage volume for those listed. The drainage area of the reservoirs was calculated from the SWAT GIS delineation tool.

Water management operation such as the daily release for the "Greers Ferry Dam" from 20002009, were obtained from the U.S. Army Corps of Engineers, Little Rock District Water Management dataset. The remaining reservoirs are considered as uncontrolled reservoirs. In this case, we assume that the reservoir releases water whenever the volume exceeds the principal spillway volume. Measured stream discharge data for five available USGS stream gauges (Fig. 1) in the basin were acquired from the USGS Arkansas Water Science Center. These data are used to calibrate and validate hydrologic components of the water balance. Oil and natural gas wells location (Fig.1) were obtained from the Arkansas Oil and Gas Commission for the period 2006-2009 (AOGC). Information about water withdrawal operations for hydraulic fracturing purposes was obtained from the Arkansas Natural Resources Commission (ANRC). These data 
regroup the non-riparian permits that have matching "Water Use Report" records and provide information about the amount of the water withdrawn, time of withdrawal, and location of the water source.

Table 1 summarizes the input used in this work and their relative sources.

Table1. Source of input dataset

\begin{tabular}{|c|c|}
\hline Types of data & Sources of data \\
\hline 30-meter DEM & $\begin{array}{c}\text { National hydrography dataset } \\
\text { http://www.horizon-systems.com/nhdplus/data.php }\end{array}$ \\
\hline Stream network & $\begin{array}{c}\text { National Hydrography Dataset } \\
\text { http://www.horizon-systems.com/nhdplus/data.php }\end{array}$ \\
\hline $\begin{array}{l}\text { Land use and land cover } \\
\qquad \text { LULC } 2004\end{array}$ & $\begin{array}{l}\text { Center for Advanced Spatial Technologies } \\
\text { http://www.geostor.arkansas.gov/G6/Home.html }\end{array}$ \\
\hline Soils data & $\begin{array}{c}\text { Geographic STATSGO soil map (scale of 1:250,000, USDA NRCS) } \\
\text { http://soildatamart.nrcs.usda.gov/ }\end{array}$ \\
\hline $\begin{array}{l}\text { Climate data } \\
\text { (rainfall and temperature): } \\
\text { NNDC }\end{array}$ & $\begin{array}{l}\text { Texas AgriLife Blackland Research Center } \\
\qquad \text { www.brc.tamus.edu }\end{array}$ \\
\hline Stream discharge & $\begin{array}{c}\text { USGS Arkansas Water Science Center (http://ar.water.usgs.gov) } \\
\underline{\text { http://ida.water.usgs.gov/ida/. }} \\
\underline{\text { http://waterdata.usgs.gov/ar/nwis/sw/ }}\end{array}$ \\
\hline $\begin{array}{l}\text { 1) Water bodies-NHD } \\
\text { 2) water bodies: pond and reservoirs: } \\
\text { 3) dams-NID-2009 }\end{array}$ & $\begin{array}{c}\text { 1) National Hydrography Dataset } \\
\text { http://www.horizon-systems.com/nhdplus/data.php } \\
\text { 2) Center for Advanced Spatial Technologies } \\
\text { 3) National Inventory of Dams - NID } 2009 \text { dataset } \\
\text { http://geo.usace.army.mil/pgis/f?p=397:1:4229727166433088::NO }\end{array}$ \\
\hline Water management dams & $\begin{array}{l}\text { U.S. Army Corps of Engineers, } \\
\text { Little Rock District Water Management } \\
\text { http://www.swl-wc.usace.army.mil/mcharts.htm }\end{array}$ \\
\hline Wells- Oil And Natural Gas & $\begin{array}{c}\text { State Of Arkansas Oil And Gas Commission } \\
\text { http://www.aogc.state.ar.us/JDesignerPro/JDPArkansas/default.htm }\end{array}$ \\
\hline
\end{tabular}




\subsubsection{Model set-up and calibration}

The SWAT model (SWAT2009 version) was run on daily time step from January 2000 to December 2009 for the 3 watersheds. The study area was divided into 111 subbasins for the Little Red watershed, 99 subbasins for the Cadron watershed, and 101 sub-basins for the LakeConway-Point-Remove watershed. In order to eliminate minor land-uses, soils, and slopes, a threshold level was selected in each sub-basin of $10 \%, 10 \%$ and $10 \%$, respectively. Given these thresholds, 454 HRUs were created within the Little Red, 426 HRUS within the Cadron, and 432 HRUs within the Lake Conway Point Remove watershed. Each pond drains water of the subbasin where it is located; they cannot receive water originating from other sub-basins. In contrast, reservoirs receive water contributed to the channel network from all upstream subbasins.

\subsection{Indicators of Hydrologic Alteration (IHA)}

The quantity, timing, and duration of river flow are critical components to water supply and water quality. The five components of flow regime (magnitude, frequency, duration, timing, and rate of change) influence the ecological dynamics of river systems directly and indirectly through their effects on other primary regulators (Karr, 1991; Poff et al., 1997). Hence, hydraulic fracturing based on water withdrawal could create shifts in the timing and magnitude of low or high flow events or change the magnitude of river flow daily, monthly, seasonally, or yearly; thus resulting in dramatically altered river systems.

The potential impacts of hydraulic fracturing on river flow characteristics were assessed using the Indicators of Hydrologic Alteration (IHA) methodology (The Natural Conservancy, 2007). The associated software (version 7) was developed by The Nature Conservancy (TNC) as an easy-to-use tool for calculating the characteristics of natural and altered hydrologic regimes.

Flow regimes from the basic simulation (with water withdrawal) and from a generated scenarios (without water withdrawal) were evaluated using Richter et al. (1996) Indicators included on IHA along with environmental flow component (EFC) parameters.

IHA was designed to examine changes in flow regimes caused by dams, but its ability to compare flow regimes makes it an ideal tool for this study. The program takes daily stream-flow values and characterizes flow regime in terms of five ecologically significant factors: magnitude, duration, frequency, timing, and rate of change. Since we were assessing the impact of water withdrawal on flow regime, we decided to focus on a specific subset of 37 statistics calculated by the program that were more likely to be sensitive to any alteration. Specifically, we focused on magnitude of monthly low flow, magnitude of the 1-, 3-, 7-, 30- and 90-day maximum and minimum flows, timing of the 1-day maximum and minimum flows, and the frequency and duration of high and low pulses. 
Concerning the EFCs, the IHA calculates parameters for 5 different types of them; large flood, small floods, high flow pulse, low flows, extreme low flows. This delineation of EFCs is based on the realization by research ecologists that river hydrographs can be divided into a repeating set of hydrographic patterns that are ecologically relevant. It is the full spectrum of flow conditions represented by these five types of flow events that must be maintained in order to sustain riverine ecological integrity (The Nature Conservancy, 2009).

\subsection{Calibration setup and analysis}

The SWAT model is a distributed-parameter model that has hundreds of parameters. Some of these parameters present initial or boundary conditions while others are forcing factors. Therefore, prior to the calibration, the sensitivity analysis was conducted to assess the most sensitive parameters.

Sensitivity analysis, calibration, validation, and uncertainty analysis were performed for the hydrology using river discharge. As these components of SWAT involve a large number of parameters, a sensitivity analysis was performed to identify the key parameters across different sub-bains and watersheds. For the sensitivity analysis 15 parameters integrally related to stream flow (Lenhart et al., 2002; Holvoet et al., 2005; White and Chaubey, 2005; Abbaspour et al., 2007) were initially selected (Table 2). We refer to these as the 'global' parameters. Some of these global parameters were further differentiated by soil and land use in order to account for spatial variation in soil and land use (i.e. SCS curve number CN2 of agricultural areas was assigned differently from that of forested areas).

The SUFI-2 (Abbaspour et al., 2007) algorithm was used for parameter optimization. In this algorithm all uncertainties (parameter, conceptual model, input, etc.) are mapped onto the parameter ranges, which are calibrated to bracket most of the measured data in the $95 \%$ prediction uncertainty (Abbaspour et al., 2007). The overall uncertainty in the output is quantified by the $95 \%$ prediction uncertainty (95PPU) calculated at the $2.5 \%$ and $97.5 \%$ levels of the cumulative distribution of an output variable obtained through Latin hypercube sampling. Two indices are used to quantify the calibration/uncertainty performance: the P-factor, which is the percentage of data bracketed by the 95PPU band (maximum value 100\%), and the R-factor, which is the average width of the band divided by the standard deviation of the corresponding measured variable. Ideally, we would like to bracket most of the measured data (plus their uncertainties) within the 95PPU band (P-factor $\rightarrow 1$ ) while having the narrowest band (R-factor $\rightarrow 0)$.

The objective function used was the Nash-Sutcliffe (1970) coefficient calculated as

$N S=1-\frac{\sum_{i}\left(Q_{m}-Q_{s}\right)_{i}^{2}}{\sum_{i}\left(Q_{m, i}-\bar{Q}_{m}\right)^{2}}$ 
This objective function was optimized in each of the 5 stream discharge by running different iterations several times changing the range of the global parameters.

The other parameter used to compare the measured and simulate daily discharge is the coefficient of determination $\mathrm{R}^{2}$

$R^{2}=\frac{\left[\sum_{i}\left(Q_{m, i}-\bar{Q}_{m}\right)\left(Q_{s, i}-\bar{Q}_{s}\right)\right]^{2}}{\sum_{i}\left(Q_{m, i}-\bar{Q}_{m}\right)^{2} \Sigma_{i}\left(Q_{s, i}-\bar{Q}_{s}\right)^{2}}$

where Qm is measured discharge, and Qs is simulated discharge. Qm,i is measured discharge at time $\mathrm{t}$, and bars indicate averages.

The sensitivity analysis showed that most of the 15 global parameters of hydrology were sensitive to river discharge. These parameters are listed in Table 2 along with their t-value and p-value statistics representing their relative sensitivities in USGS stream discharge gauge 0707500.

Table 2: Selected input parameters in the calibration process

\begin{tabular}{|c|c|c|c|}
\hline Parameter Name $^{\mathrm{a}}$ & Definition & $\mathrm{t}-\mathrm{Stat}^{\mathrm{b}}$ & P-Value \\
\hline $\mathrm{r} \_\mathrm{CN} 2 . \mathrm{mgt}$ & SCS runoff curve number for moisture condition II & 8.82 & 0.00 \\
\hline v__ALPHA_BF.gw & Base flow alpha factor (days) & 6.05 & 0.00 \\
\hline a_SOL_AWC(3).sol & Soil available water storage capacity (mm H2O/mm soil) & 1.36 & 0.18 \\
\hline v__GWQMN.gw & $\begin{array}{l}\text { Threshold depth of water in the shallow aquifer } \\
\text { required for return flow to occur }(\mathrm{mm})\end{array}$ & 1.18 & 0.24 \\
\hline v__GW_REVAP.gW & Groundwater revap. Coefficient & 0.57 & 0.57 \\
\hline v__GW_DELAY.gw & Groundwater delay time (days) & 0.24 & 0.81 \\
\hline v_RES_K.res & Hydraulic conductivity through bottom of reservoir $(\mathrm{mm} / \mathrm{hr})$ & -0.05 & 0.96 \\
\hline r_SOL_AWC(1).sol & Soil available water storage capacity (mm H2O/mm soil) & -0.07 & 0.94 \\
\hline v__PND_K.pnd & Hydraulic conductivity through bottom of pond $(\mathrm{mm} / \mathrm{hr})$ & -0.54 & 0.59 \\
\hline v__ESCO.hru & Soil evaporation compensation factor & -0.61 & 0.54 \\
\hline r__SOL_K(1).sol & Soil conductivity $\left(\mathrm{mm} \mathrm{hr}^{-1}\right)$ & -0.69 & 0.49 \\
\hline a__SOL_AWC(2).sol & Soil available water storage capacity ( $\mathrm{mm} \mathrm{H} 2 \mathrm{O} / \mathrm{mm}$ soil) & -2.55 & 0.01 \\
\hline v_CH_N2.rte & Manning's $\mathrm{n}$ value for main channel & -2.93 & 0.00 \\
\hline
\end{tabular}




\begin{tabular}{l|l|l|l|}
\hline v__CH_K2.rte & Effective hydraulic conductivity in the main channel $\left(\mathrm{mm} \mathrm{hr}^{-1}\right)-12.41$ & 0.00
\end{tabular}

av : parameter value is replaced by given value or absolute change; $r$ : parameter value is multiplied by $(1+$ a given value) or relative change (Abbaspour, 2007).

bt-value indicates parameter sensitivity: the larger the t-value, the more sensitive the parameter

cp-value indicates the significance of the t-value: the smaller the p-value, the less chance of a parameter being accidentally assigned as sensitive

As expected, parameters such as CN2 (SCS runoff curve number), and available soil water content (SOL AWC) were most sensitive.

The calibration procedures produced a goodness-of-fit within the 5 stream gages in terms of the objective function, the $\mathrm{P}$ factor and the $\mathrm{R}$ factor.

In this study, SUFI2 was used with 5 different objective functions. Table 3 presents the calibration results for the 5 stream gauges.

Table3. Calibration and validation performances

\begin{tabular}{|c|c|c|c|c|c|c|c|}
\hline \multirow[b]{2}{*}{$\begin{array}{l}\text { Watershed } \\
\text { name }\end{array}$} & \multirow{2}{*}{$\begin{array}{c}\text { USGS } \\
\text { Station ID }\end{array}$} & \multirow[b]{2}{*}{$\begin{array}{c}\text { Calibration } \\
\text { period }\end{array}$} & \multicolumn{2}{|c|}{ Calibration } & \multirow[b]{2}{*}{$\begin{array}{c}\text { Validation } \\
\text { period }\end{array}$} & \multicolumn{2}{|c|}{ Validation } \\
\hline & & & $\begin{array}{c}\text { Nash } \\
\text { Sutcliffe }\end{array}$ & $\mathbf{R}^{2}$ & & $\begin{array}{c}\text { Nash } \\
\text { Sutcliffe }\end{array}$ & $\mathbf{R}^{2}$ \\
\hline \multirow{3}{*}{$\begin{array}{l}\text { Little Red } \\
\text { watershed }\end{array}$} & 07075300 & $2002-2006$ & 0.56 & 0.57 & $2007-2009$ & 0.61 & 0.67 \\
\hline & 07075000 & 2006-2008 & 0.72 & 075 & 2009 & 0.45 & 0.5 \\
\hline & 07076517 & $2002-2007$ & 0.78 & 0.78 & $2008-2009$ & 0.77 & 0.79 \\
\hline Cadron & 07261000 & $2002-2006$ & 0.42 & 0.5 & 2007-2009 & 0.62 & 0.71 \\
\hline $\begin{array}{c}\text { Lake } \\
\text { Conway } \\
\text { Point } \\
\text { Remove }\end{array}$ & 07260673 & 2005-2008 & 0.21 & 0.29 & 2009 & 0.26 & 0.34 \\
\hline
\end{tabular}

In Figure 2, examples of calibration and validation results are illustrated for individual stations in the Little Red, Cadron, and the Lake Conway watersheds. In general, the results of calibration and validation analysis based on river discharge were quite satisfactory for the whole area 

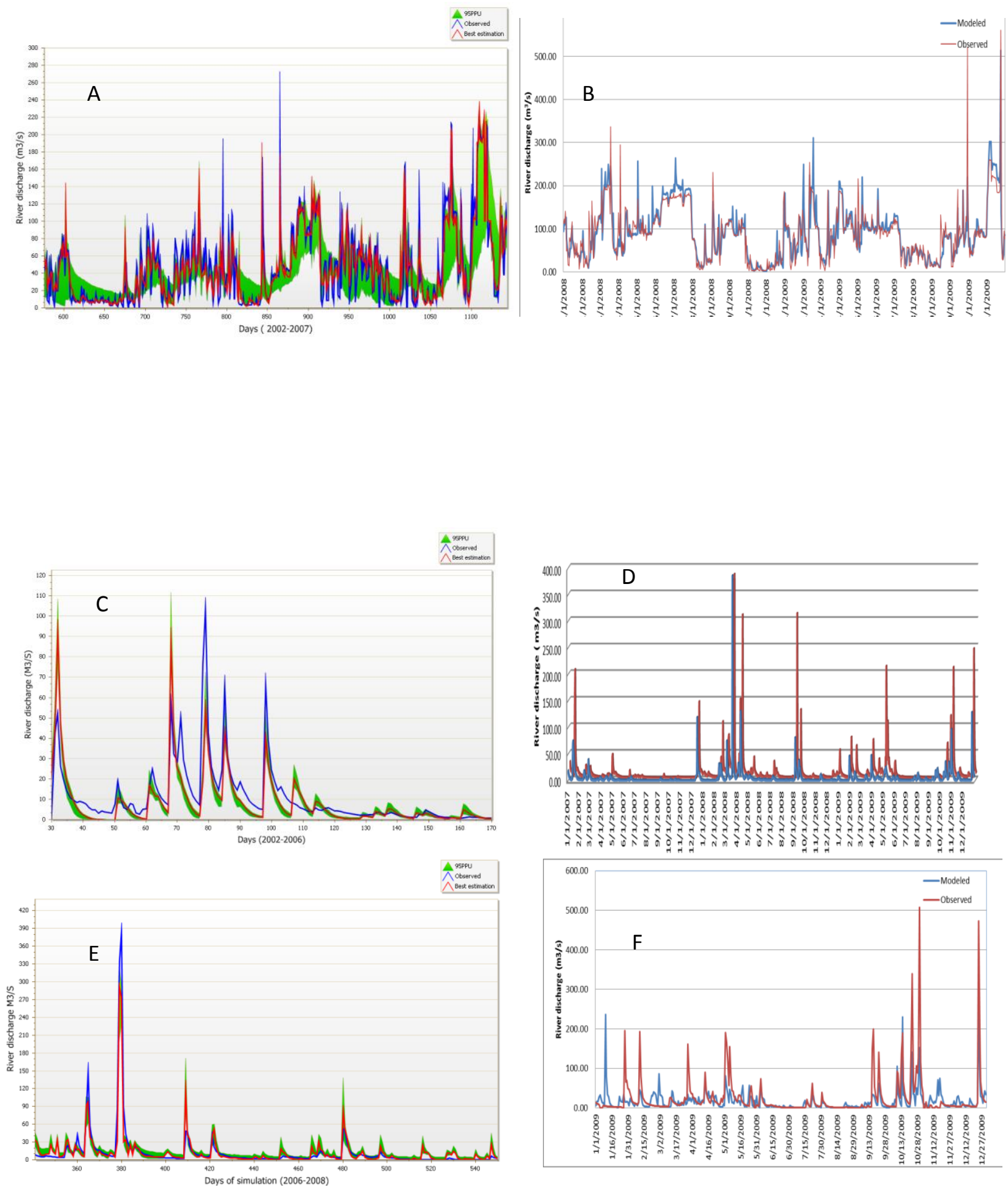
Figure 2. Comparison of the observed (Blue line) and simulated(red line) discharges as well as the 95\% prediction uncertainty band for 3 stream gauge stations located in Little Red(A, B), Cadron $(C, D)$, and Lake Conway watersheds $(E, F)$. Calibration (left) and validation (right) results are shown.

\section{Results}

\subsection{Water balance}

The water balance at the main watershed scale was calculated over the period 2000-2009. The most important elements of water balance of a basin are precipitation, surface runoff, lateral flow, aquifer recharge, and evapotranspiration. Among these, all the variables, except precipitation, need prediction for quantifying as their measurement is not easy. The predicted values of the annual water balance components by the calibrated SWAT model for the 3 watersheds are shown in fig 3 . It can be seen that major portion of the rainfall received by the basin is lost as evapotranspiration (43 to 52\%). The surface runoff ranges from 23 to $30 \%$ of the total annual rainfall, while the total aquifer recharges varies for $7 \%$ in the Little Red watershed to the $20 \%$ in the Lake Conway watershed.

Figure 4 provides a general overview of the hydrological components in the Fayetteville Shale area at the sub-basin level. The spatial distribution for the year (2000-2009) was illustrated for various components such as precipitation, total water yield (TWY: river discharge plus groundwater recharge), and actual evapotranspiration (ETA). In the precipitation map spatial distribution of the rain gauge stations is also shown. The average precipitation for each sub-basin was calculated from the closest station. There is a pronounced variation in the spatial distribution of the hydrological variables across the area. In many sub-basins within the Little Red watershed in the south east and central Little Red watershed, where precipitation and total water yield are small, actual evapotranspiration is large mainly due to the existence of reservoirs and dams such as the Greers Ferry Lake.

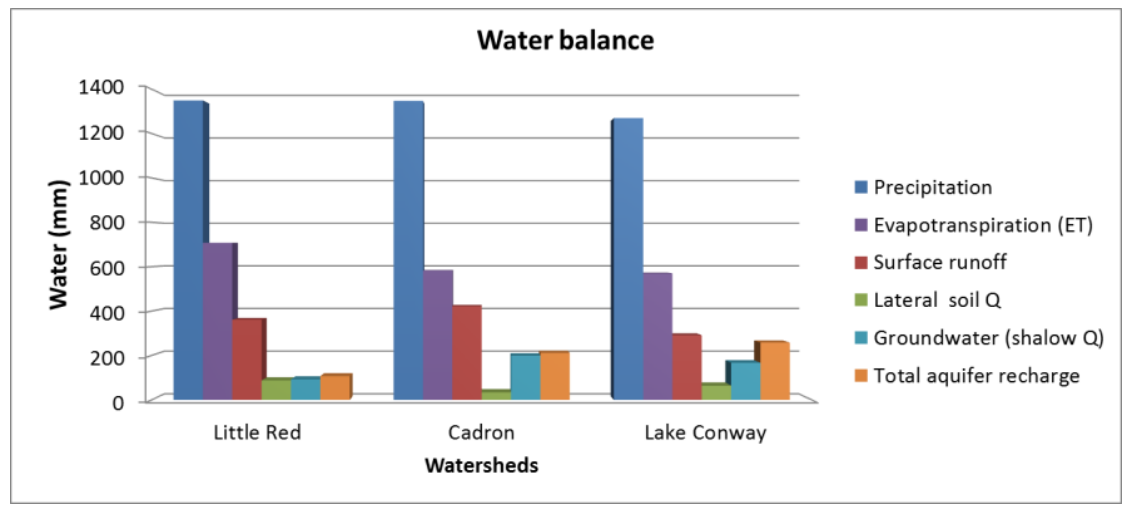


Figure 3. Simulated water balance for the 3 watersheds of the Fayetteville Shale area.
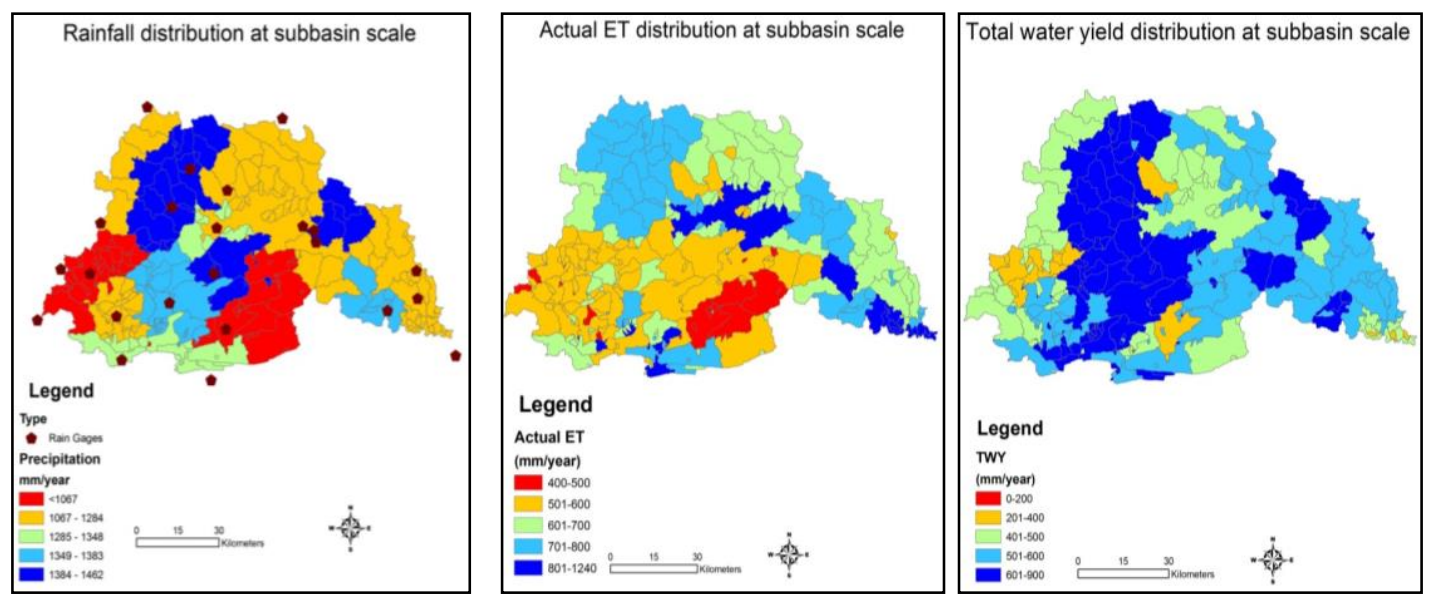

Figure 4. Average (2000-2009) simulated annual precipitation, actual evapotranspiration (ET) and Total water Yield (TWY) at subbasin level for the entire area

\subsection{Scenario 1: Hydraulic fracturing}

Information and data associated with water hydraulic fracturing operations such as the source of water acquisition, the volume needed, and the timing of withdrawal are quite restricted. This constitutes a limit both in modeling activities and in water resources management; however, we present an attempt to model the water withdrawal for hydraulic fracturing based on the available information and reasonable assumptions.

Data available is limited to the location of the natural gas wells, the date of the drilling, and the first date of production. Based on this information we generate a scenario as follows:

- Quantity of water withdrawn for the purpose of hydraulic fracturing: $18927 \mathrm{~m}^{3}$ (5 million of gallons) for each natural gas well.

- Water Source: among the options (stream, reservoir, ponds, lake, or impoundment created by producer), it was assumed that water was withdrawn from the closest stream reach (least favorable scenario) to the natural gas well. 
- Time distribution: the hydraulic fracturing occurs in different stages. An average of 5 months is noted between the SPUD date (the date selected by the Arkansas Oil and Gas Commission as the date on which the ground was first penetrated for the purposes of drilling the well) and the first production date. During these months the hydraulic fracturing takes place. Based on the background investigated, it was assumed that $3,785 \mathrm{~m}^{3} /$ month (1MG/month) of water was uniformly withdrawn during 5 consecutive months

\subsubsection{Scenario results: Yearly scale}

Figures 5.A, B and C show the actual water balance components at basin scale for both cases (basic simulation vs. scenario 1) respectively at the Little Red, Cadron, and Lake Conway watersheds. At large spatial and temporal scale, no difference is noted comparing the water balance components of the baseline (without withdrawing the water) and the generated scenario (with water withdrawn).

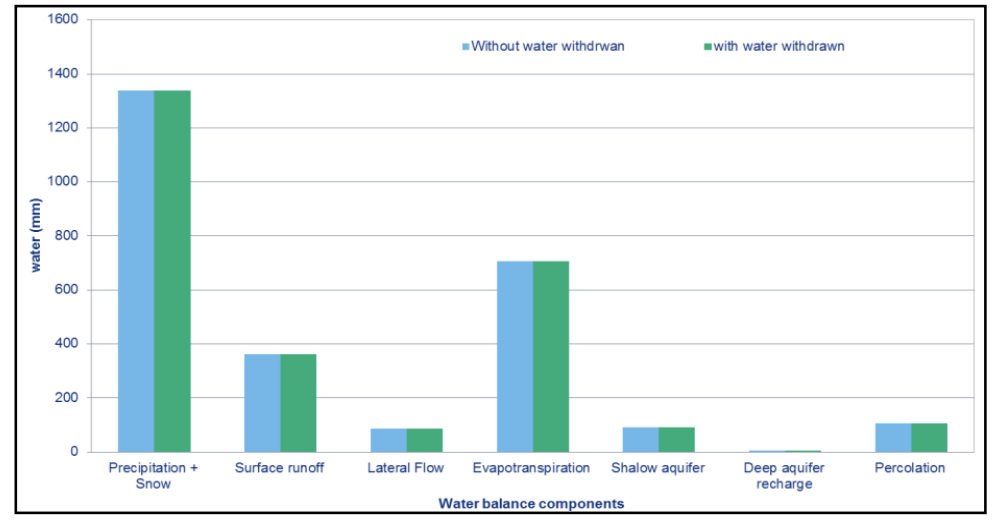

Fig5.A

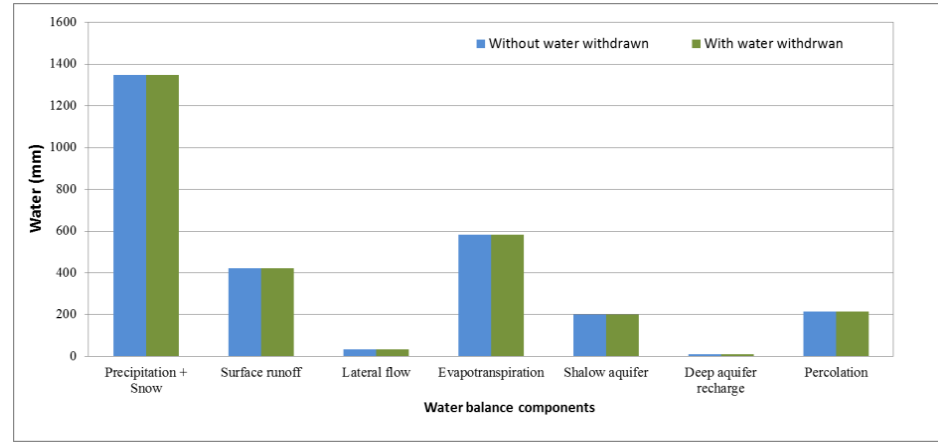

Fig. 5B 


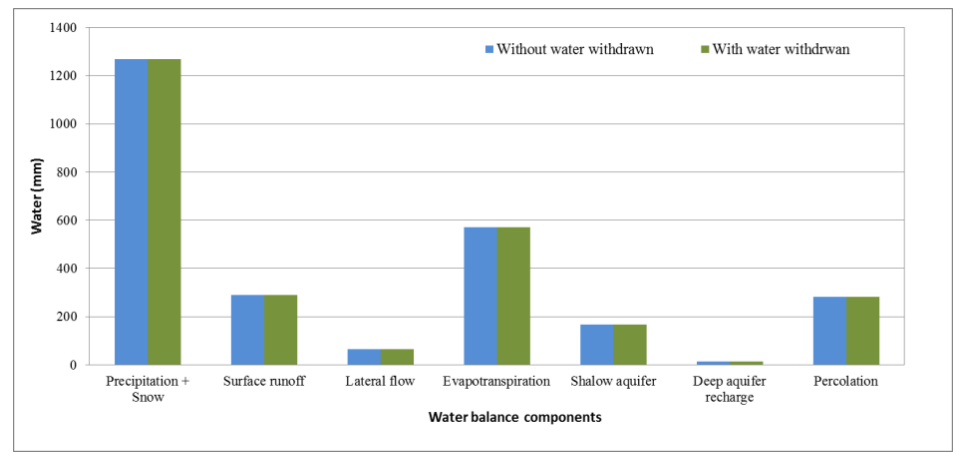

Fig. 5C

Figure .5 Comparison scenario 1 Vs basic simulation: Water balance components at large scale for the 3 watersheds( Little red (Fig. 5A ), Cadron ( Fig. 5B), Lake Conway ( Fig.5C) )

2.2.2 Scenario results: Environmental Flow Components

The EFCs were evaluated using the daily simulated discharges obtained after calibration for each subbasin of the study area. This allowed defining respective thresholds (Extreme Low Flow and Low Flow). Figures 6A, B, and $\mathrm{C}$ show the distribution of the extreme low flow limits (ExtLFlow) within the 3 watersheds of the Fayetteville Shale area. The oil and natural gas wells are also located in these figures. It is also worth noting that these limits are higher surrounding the edge of main channel (from 0.8 to $9.26 \mathrm{~m}^{3} / \mathrm{s}$ ), and lower in the small tributaries $(0.01$ to 0.35 $\mathrm{m} 3 / \mathrm{s})$. Hence, the risk of withdrawing increase while moving away from the main channel.

In the Little Red watershed (Fig 6.A) 211 wells are located within or near the main channel and the Greers Ferry reservoir (ExtLF limit between 0.5 and $9.26 \mathrm{~m}^{3} / \mathrm{s}$ ). Therefore, we can expect low risk on the alteration of the flow regime in this area. However 302 wells are fractured within an area where the extreme low flow limit is less than $0.35 \mathrm{~m}^{3} / \mathrm{s}$ which could result in an alteration of the flow regime during a specific time mainly dry period.

In the Cadron watershed (Fig 6.B) 189 wells are located close to the main channel with an extreme low flow limit ranging from 0.26 to $1.6 \mathrm{~m}^{3} / \mathrm{s}$. The rest of the wells $(125)$ are located within areas with small extreme low flow limit $\left(<0.26 \mathrm{~m}^{3} / \mathrm{s}\right)$. In the Lake Conway watershed (Fig 6.C), 159 wells and 150 wells were respectively drilled in the area with the lowest extreme lowflow threshold $\left(<0.07 \mathrm{~m}^{3} / \mathrm{s}\right)$ and between 0.08 and $0.6 \mathrm{~m}^{3} / \mathrm{s}$. No well is drilled in the area with high extreme low flow limit $\left(>1.6 \mathrm{~m}^{3} / \mathrm{s}\right)$ within the Cadron and the Lake Conway watershed. These maps could help identifying the area with high and low risk of withdrawing. 


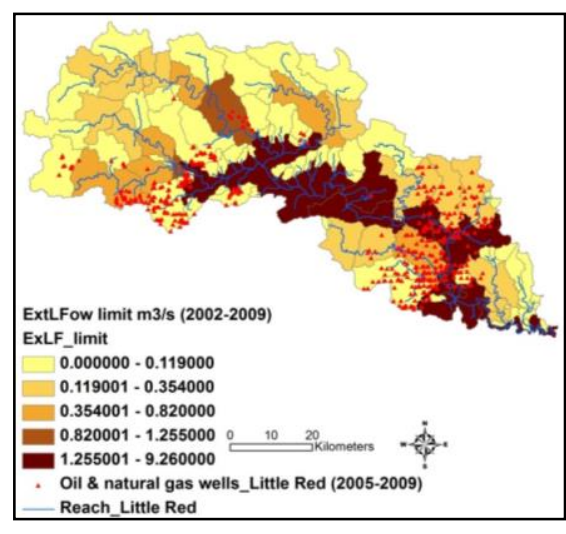

Fig. 6A

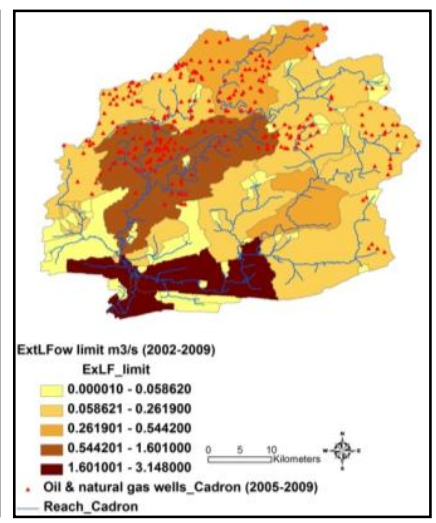

Fig. 6B

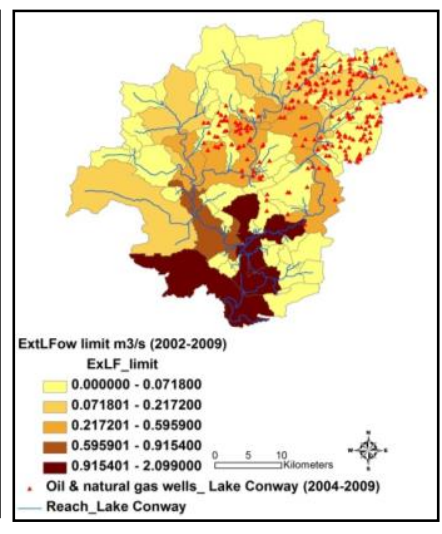

Fig. 6C

Figure 6. Extreme low flow limits at subbasin scale within the Little Red (Fig. 6A), Cadron (Fig.6B) and Lake Conway (Fig. 6C) watersheds.

Based on this analysis, we compare the daily stream discharge in each subbasin main channel for the scenarios (with and without water withdrawal). On the daily time step the hydrologic regime changed several times from high flow to low flow condition, as well as from low flow to extreme low flow condition within different locations in the study area. Table 4 presents the increment of number of transitions of the hydrologic regime during 2006 and 2009 while the water withdrawal takes place in the 3 different watersheds.

Table 4. Increment of number of transition of the hydrologic regime in the 3 watersheds (HF: High Flow, LF: Low Flow, ExtLF (extreme Low Flow)

\begin{tabular}{|l|c|c|c|}
\hline Watersheds & $\begin{array}{c}\text { Number of wells } \\
2004-2009\end{array}$ & $\begin{array}{c}\text { Increment of number of } \\
\text { transition of the hydrologic } \\
\text { regime } \\
\text { HF to LF }\end{array}$ & $\begin{array}{c}\text { Increment of number of } \\
\text { transition of the hydrologic } \\
\text { regime } \\
\text { LF to ExtLF }\end{array}$ \\
\hline Little-Red & 513 & 90 & 190 \\
\hline Cadron & 355 & 143 & 0 \\
\hline Lake Conway & 311 & 94 & 354 \\
\hline
\end{tabular}

Figures 7A, B, and $\mathrm{C}$ show respectively the yearly repartition of the increment of number of transition of the hydrologic regime in the Little Red (Fig. 7A), Cadron (Fig. 7B), and the Lake Conway (Fig. 7C) watersheds (number of wells drilled and yearly precipitation is shown). In the Little Red watershed, the frequency of change is high during the years 2007 and 2008, when the number of natural gas wells drilled within the watershed has increased dramatically. The change from low flow to extreme low flow occurred 85 times in 2007, and the change from high flow to 
low flow reaches occurred 62 times in 2008. The increase of precipitation during 2008 could result in expanding the high flow period matching the water withdrawal period. Hence the number of flow alteration from high flow to low flow condition might increase. In the Cadron watershed, the change from high flow to low flow occurred 108 times in 2008. During this year 175 wells were drilled within this area. No changes from low flow to the extremes low flow were noted in the Cardon watershed during the period of analysis (2004-2009). In the Lake Conway watershed, the increment number of shifting of the flow regime from low flow to extreme low flow condition is more relevant (132 times and 101 times in 2005 and 2006 respectively). These flow alterations within this watershed occurred more from August to October (Fig. 8).

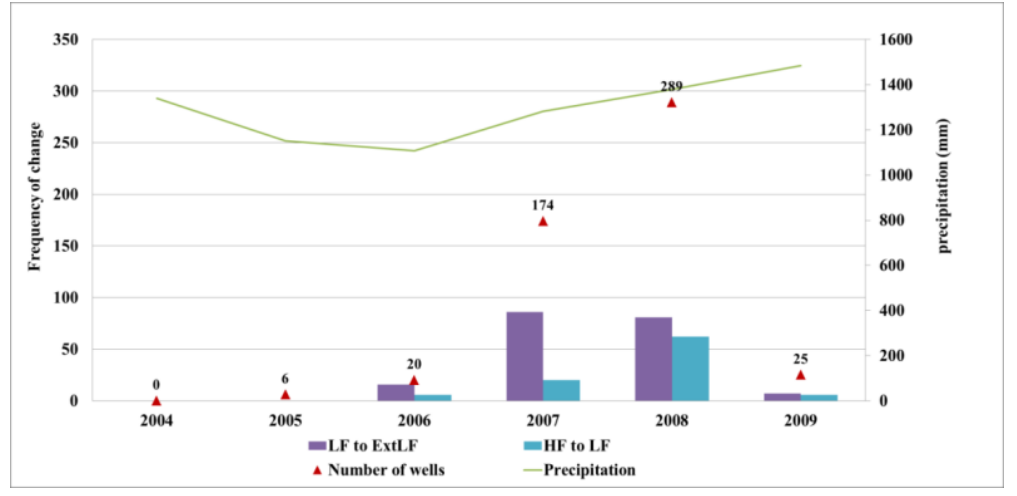

7A

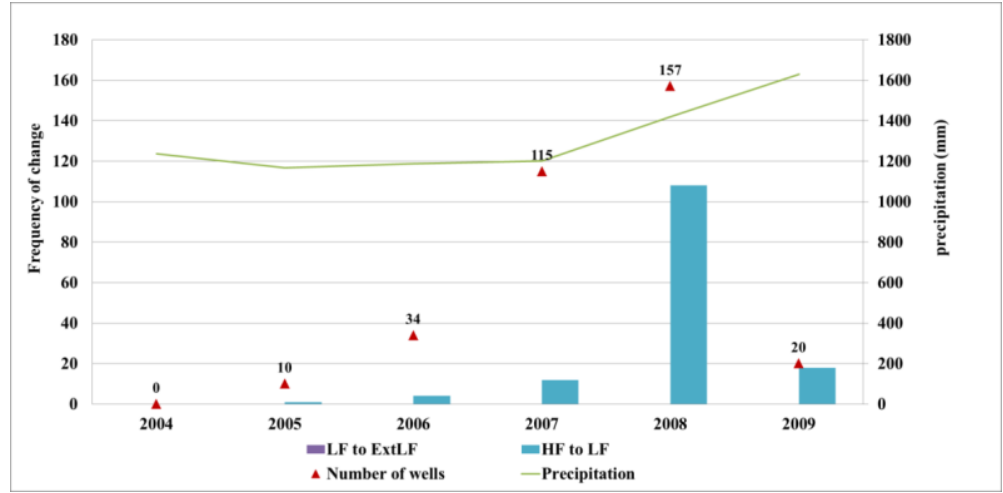

7B

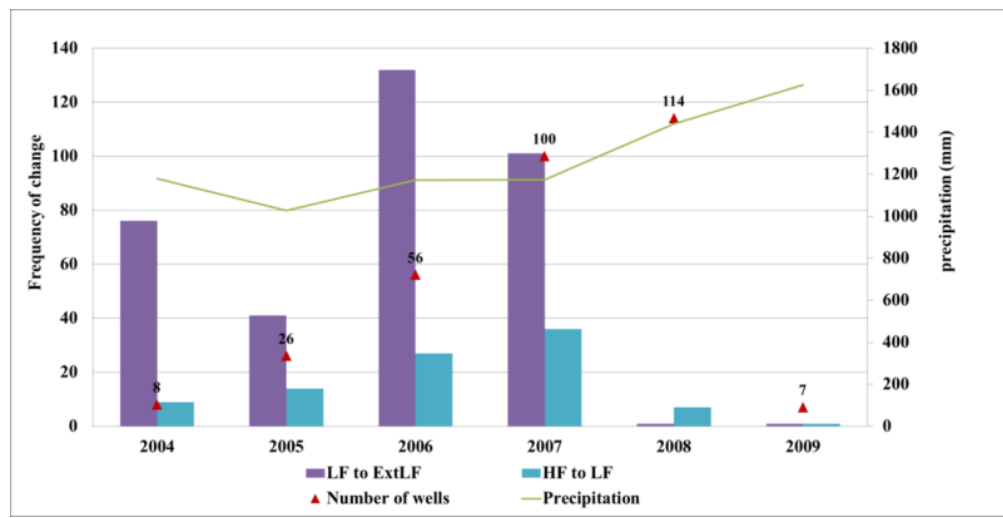


Figure7. Increment of number of transitions of the hydrologic regime for the period 2004-2009 within the 3 watersheds: Little Red (Fig.7A), Cadron, (Fig. 7B), and Lake Conway (Fig.7c)

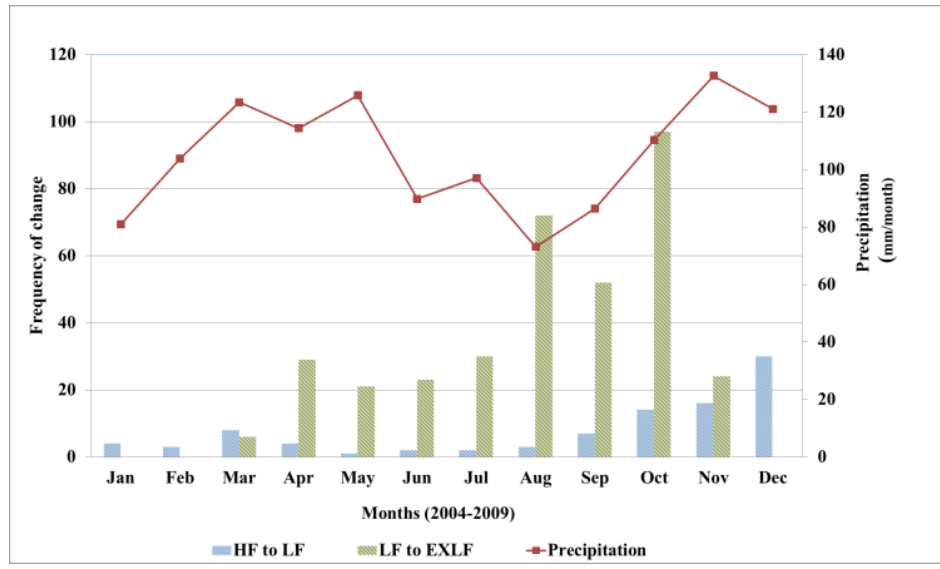

Figure8. Monthly distribution of the increment of the flow alteration within the Lake Conway watershed

The frequency of the flow alteration due to the increase of hydraulic fracturing operations in the Fayetteville Shale area during the period 2004-2009, is diverse across sub-basins. Figures 9A, 9B, and 9C show respectively the spatial reparation of the increment of this frequency within the Little Red, Cadron, and Lake Conway watershed. The maximum number of changes from low flow condition to extreme low flow condition at sub-basin scale occurred 20 times in the Little Red watershed and 37 times in the Lake Conway watershed. The maximum number of changes from high flow to low flow condition occurred 9 times within the Little Red watershed, 34 times within the Cadron watershed, and 7 times in the Lake Conway watershed. 

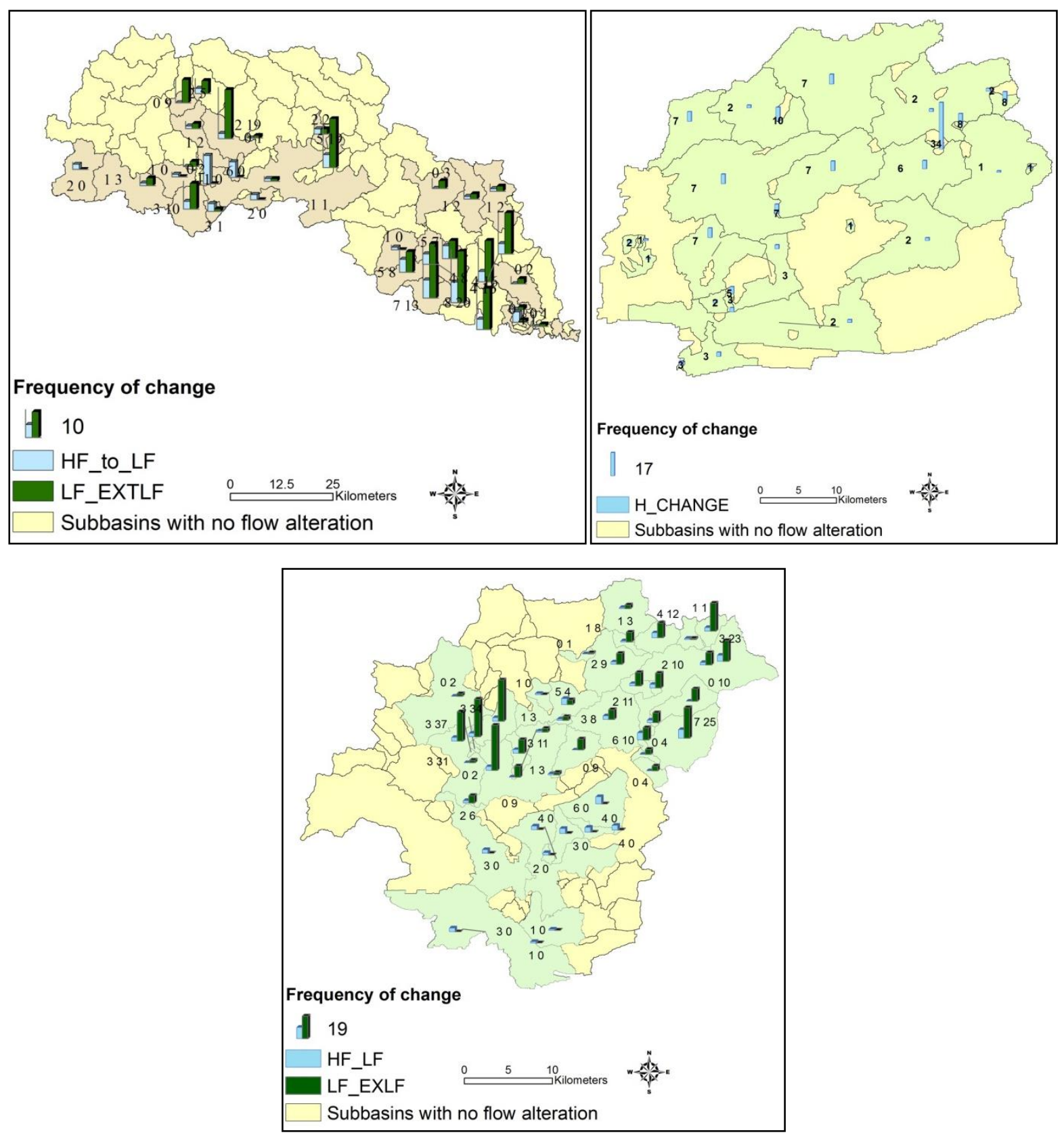

Figure 9. Spatial repartition of flow alteration increment frequency on the 3 watersheds: Little Red (Fig.9A), Cadron, (Fig. 9B), and Lake Conway (Fig.9c)

The above analysis of the environmental flow components is restricted only to shows some disturbance of the flow regime in specific times and locations while the water withdrawal takes place. Each of these flow conditions plays an important role in the long-term health of a river ecosystem. For better evaluation of these changes and their impact on the aquatic life within the river, interaction between the IHA and other ecological information is needed. Unfortunately, limited data on the ecological component were available. Another difficulty was the short length 
of data about hydraulic fracturing operation. A number of reports can be found in the literature providing assessment of flow regime and the influence eon the ecological and aquatic life. Mathews and Richter, 2007, described how to use the IHA interactively with other ecological information to evaluate environmental flow needs and demonstrate its application in the Green River in Washington state, USA. They found that extreme low flows that occur during times of drought may alter water chemistry, concentrate prey species, and dry out low-lying areas in the floodplain, and are often associated with higher water temperature and lower dissolved oxygen conditions. These very low flows can reduce connectivity, thereby restricting movement of some aquatic organisms.

\subsection{Scenario 2: Empirical data of water withdrawal}

ANRC data processed by CAST at the University of Arkansas about the hydraulic fracturing operations schedule relates to some of the assumptions we considered in the previous scenarios: Time of withdrawal, location, and quantity.

These data regroup the non-riparian permits point location (Figs. 10A, B and C) (where actual withdrawals have been documented). One key point is it is unknown which well is associated with a given withdrawal; however, as long as it is being used for fracturing and the water is always permanently removed from the watershed of the withdrawal, the assumption maintains. The oil and natural gas well drilled during the years 2008 and 2009 are also presented in these figures

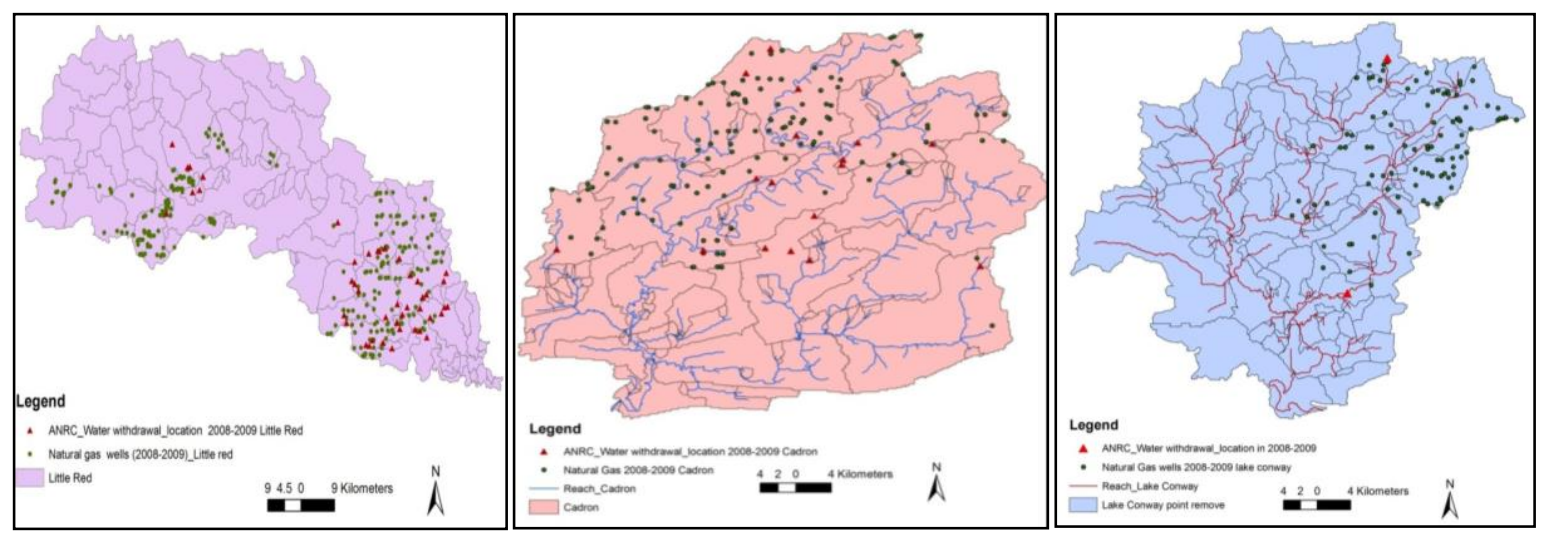

Figure 10. Location of water withdrawal in the 3 watersheds (Little Red (Fig. 10A), Cadron (Fig. 10B), and Lake Conway (Fig. 10C)) during the years 2008-2009 


\subsubsection{Scenario 3 results: Assessment of hydrologic regime}

In order to assess the change on the hydrologic regime, we used the same analysis with IHA as previously illustrated in the first scenario. We evaluate this change using the daily simulated stream discharge in each of the subbasins of the study area. These data were then input to the IHA software calculates a total of 67 statistical parameters. These parameters are subdivided into 2 groups, the EFC parameters and the IHA parameters.

\section{Environmental Flow Component (EFC)}

Available climatic data used in this simulation cover the period 2000-2009, while the water report regroups data permits from 2008 to 2011 . Hence the analysis has been carried out only during the year 2008-2009 where water withdrawals data are available.

During these two years, no significant changes on the flow and the hydrologic regime have been highlighted except for specific days when water withdrawals have increased.

Three hundred fourteen wells were fractured within the Little Red watershed during the years 2008 and 2009 with a quantity of water equal to $1,764,625 \mathrm{~m}^{3}$ (based on the ANRC data); resulting in an average of $5,619 \mathrm{~m}^{3} / \mathrm{well}$.

The flow alteration can happen during a specific time period and is more extensive on a daily time step. The increment of number of transitions of the hydrologic regime during the two years has occurred 16 times (Fig. 11) The analysis of the flow during the 2008 and 2009 illustrate this change: six times the hydrologic regime has switched from small flood to low flow and eight times from low flow to extreme low flow conditions, one time from small flood to high flow, and one time from high flow pulse to low flow.

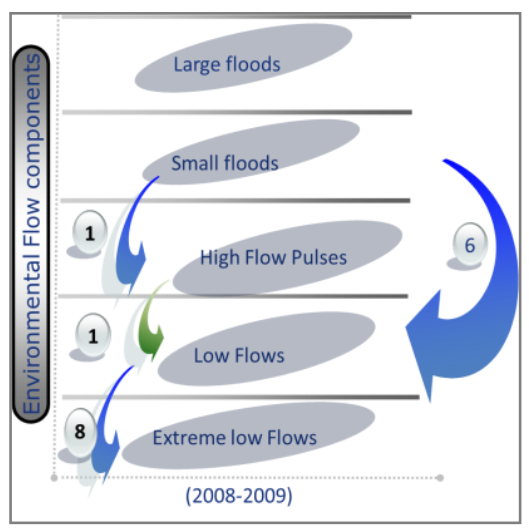

Figure 11. Frequency of daily change (increment number of transition) of the Hydrologic regime during the years 2008-2009 in the Little Red watershed 
One hundred seventy-four wells were fractured within the Cadron watershed during the years 2008 and 2009 with a quantity of water equal to $745,480.45 \mathrm{~m}^{3}$ (based on the ANRC data); resulting in an average of $3785 \mathrm{~m}^{3} /$ well. Figure shows the water withdrawal location as well as the wells fractured in 2008 and 2009.

The impact of water withdrawal was more accentuated within this watershed. This has been noted on the change of the hydrologic regime during these 2 years. The environmental flow components have been switched 132 times from a flow regime condition to another one (Fig 12).

The analysis of the flow during the 2008 and 2009 illustrates this change: 61 times the hydrologic regime has swished from small flood to high flow pulse, 58 times from high flow to low flow, eight times from small flood to low flow.

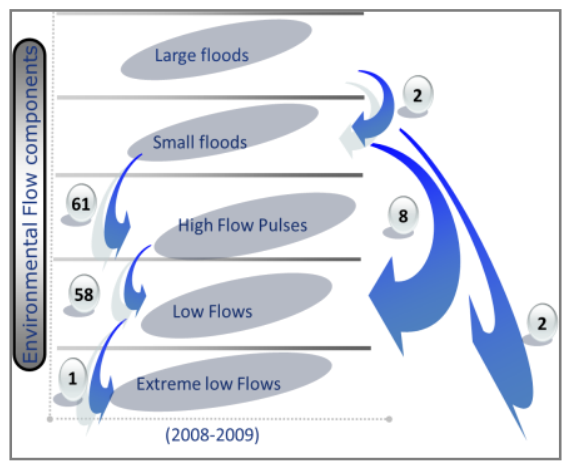

Figure 12. Frequency of daily change (increment number of transition) of the Hydrologic regime during the years 2008-2009 in the Cadron watershed

One hundred nineteen wells have been fractured within the Lake Conway - Point Remove watershed during the years 2008 and 2009 with a quantity of water equal to 45,777 m3 (based on the ANRC data), resulting in an average of $384 \mathrm{~m}^{3} /$ well. The analysis shows that no increase of number of transition has occurred to the hydrologic regime within this watershed during the years 2008-2009.

It is the full spectrum of flow conditions represented by these five types of flow events that must be maintained in order to sustain riverine ecological integrity. Not only is it essential to maintain adequate flows during low flow periods, but higher flows and extreme low flow conditions also perform important ecological functions.

Indicators of Hydrologic Alteration 
A deeper analysis was completed on the change of the Indicators of Hydrologic Alteration. First step for this analysis is to define the subbasins where any change on the daily stream discharge has occurred during the years 2008 and 2009. Then the 33 IHA parameters were calculated using daily simulated stream discharge from 2000 to 2009 for both cases (with and without water withdrawal) in all the defined subbasins.

The results reported here represent the changes in the annual water conditions (magnitude, duration and rate of the flow) during the years 2008 and 2009 within the Little Red and the Cadron watersheds.

- Group I Magnitude of monthly water conditions

Figure 13 illustrate the change on the monthly low flow within the Little Red and the Cadron watersheds. A net decrease of the monthly low flow during the month of June is noted while withdrawing the water for hydraulic fracturing. This change can reach $-10 \%$ within the Cadron watershed. A moderate change is noted during the other months.

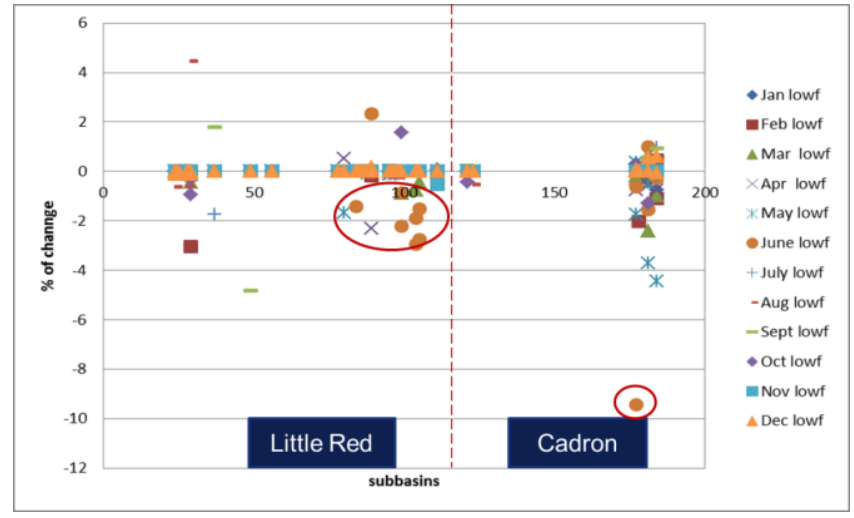

Figure 13. Change in the Magnitude of monthly water conditions

- Group II: Magnitude and duration of annual extreme water conditions

For parameter group 2 (extreme water conditions), the 3-, 7-, 30-, and 90-day minimums and maximums are taken from moving averages of the appropriate length calculated for every possible period that is completely within the water year.

The zero-flow days and base flow index parameters in group 2 are modeled after the suite of flow parameters described by Poff and Ward (1989). 
Figure 14 illustrates the change in the Magnitude and duration of annual extreme water conditions. Withdrawing water for hydraulic fracturing during the two years (2008-2009) has led to a significant reduction of the one-day minimum flow. This reduction can reach $100 \%$ in the Little Red watershed which means the river has dried out, and hence the first minimum flow during the year reaches the value $0 \mathrm{~m}^{3} / \mathrm{S}$. A light change has been noted also for the three-day min (up to -30\%). The results show a small reduction. This can be explained by the reduction of the low flow during the same period.

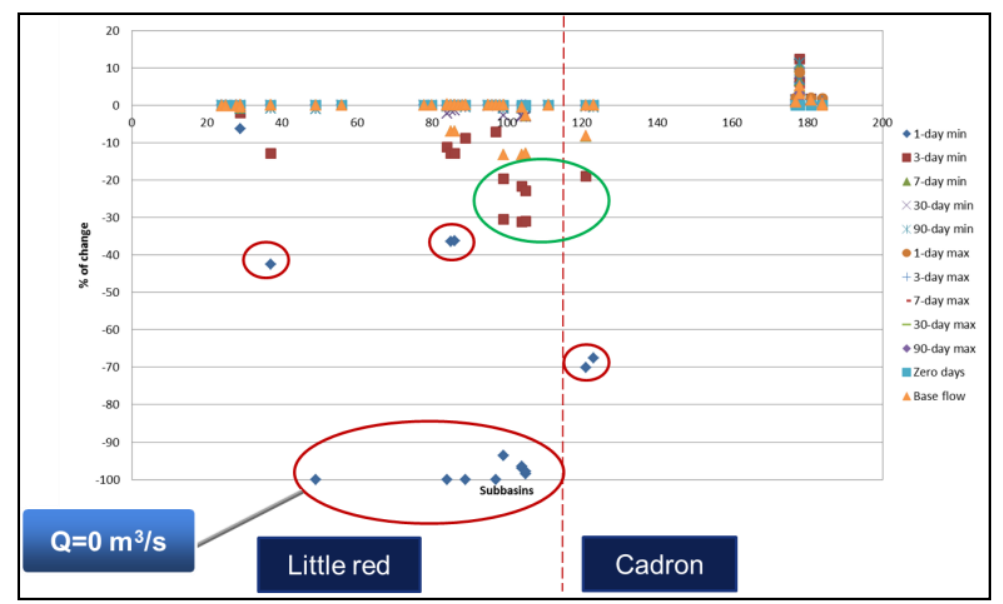

Figure 14. Change in the Magnitude and duration of annual extreme water conditions

- Group III: Timing of annual extreme water

For parameter group 3 (extreme water conditions), if there are multiple days in the water year with the same flow value, the earliest date is reported. Figure 15 shows the change on the timing of annual extreme water conditions.

The timing of the first day min has been switched in some sub-basins. It was between 223 days earlier and 213 days later under the scenario of water withdrawing. However this difference is not significant since the assessment has been done for two years only. 


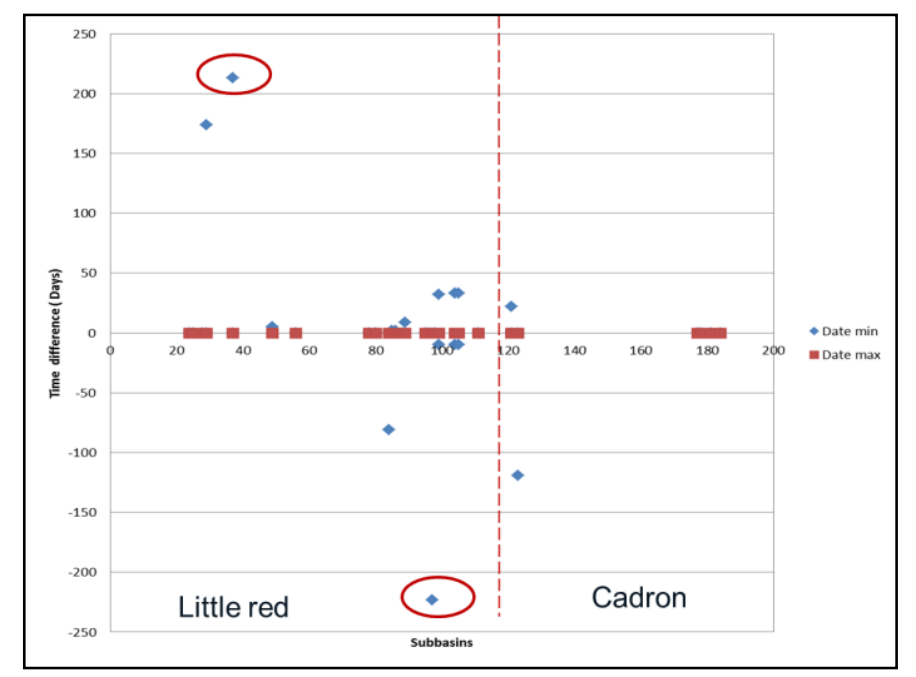

Figure 15. Change in the timing of annual extreme water conditions (days)

- Group IV Frequency and duration of high and low pulses

For parameter group 4 (high and low pulses), a day is classified as a pulse if it is greater than or less than a specified threshold (median plus or minus 25 percent).

There were significant changes in the frequency and duration of the low flow pulse during 2008 and 2009 (Figure 16). The number of low flow pulse (Lo pulse \#) has increased in four subbasins within the Little Red watershed (doubled in sub-bassin 97) while withdrawing the water for hydraulic fracturing. Whereas, the median duration of low flow pulses (Lo pulse L) has decreased (days). In the Cadron watershed there were a lightly disturbance of these parameters. 


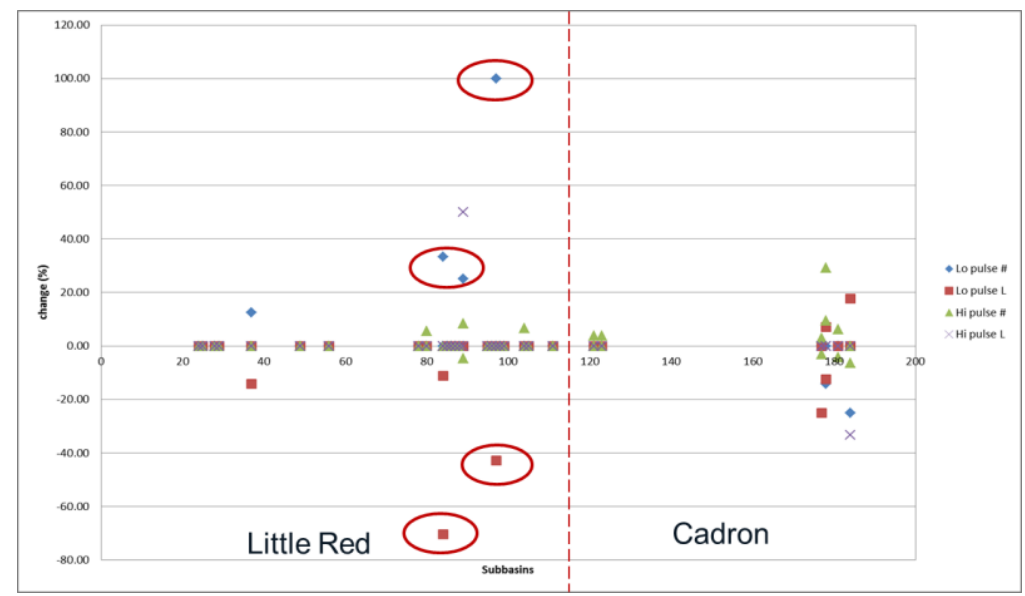

Figure 16. Change in the Frequency and duration of high and low pulses

- Group V. Rate and frequency of water condition changes

Rise rates: mean or median of all positive differences between consecutive daily values. Fall rates: mean or median of all negative differences between consecutive daily values. Reversals (in parameter group 5) are calculated by dividing the hydrologic record into "rising" and "falling" periods, which correspond to periods in which daily changes in flows are either positive or negative, respectively. The number of reversals is the number of times that flow switches from one type of period to another.

Figure 17 shows a highly disturbance on the rate of rising and falling of the flow. This was evident since withdrawing a big quantity of water on one day will lead to a change on the difference between consecutive daily values. As a consequence the number of reversal has gradually changed. This was notable within the Cadron watershed.

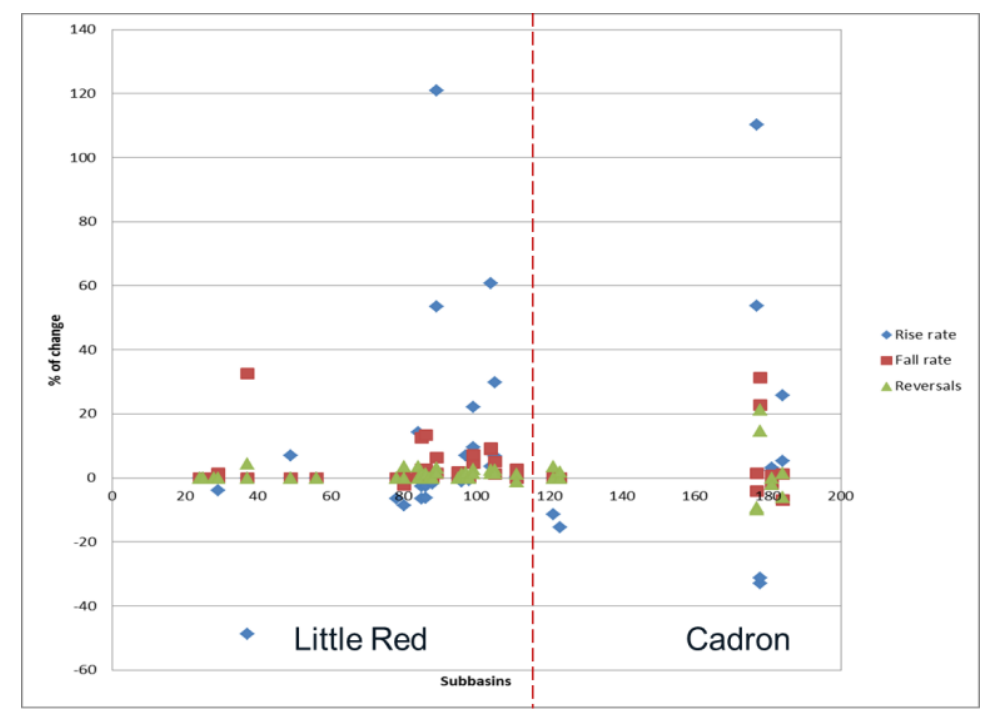


2.4 Scenario 3: Future potential impact of hydraulic fracturing on water balance

Since data about water withdrawal is available for the years 2010 and 2011, a future scenario for the period 2015 was generated to assess the potential impact of increasing hydraulic fracturing on the hydrologic regime of the river in the near future. Within this scenario climatic data is predicted from 2010 to 2015 using the SWAT weather generated data and assuming a continuous increase of water withdrawn volume. An example of the Little Red watershed is presented.

We assume the same withdrawal location during the next years. The volume that has been withdrawn for the purpose of hydraulic fracturing within the Little Red watershed during the period 2008-2011 is equal to 6 Million of cubic meter $\left(\mathrm{Mm}^{3}\right)$. Figure 18 shows the total frequency of flow alteration (from high flow to low flow and from low flow to extreme low flow) while we multiply the volume withdrawal by 2, 4, 6, and 10 for the future period of (20122015). It can be speculated that the frequency of change increase while increasing the volume of water withdrawn. This change could lead to a disturbance of the water balance, create shifts in the timing and magnitude of low or high flow events, or change the magnitude of river flow at daily, monthly, seasonal, or yearly time scales. This could result in dramatically altered river systems. In other words, as production from conventional oil and gas fields continues to mature and the shift to non-conventional resources increases, the impact of hydraulic fracturing are expected to increase.

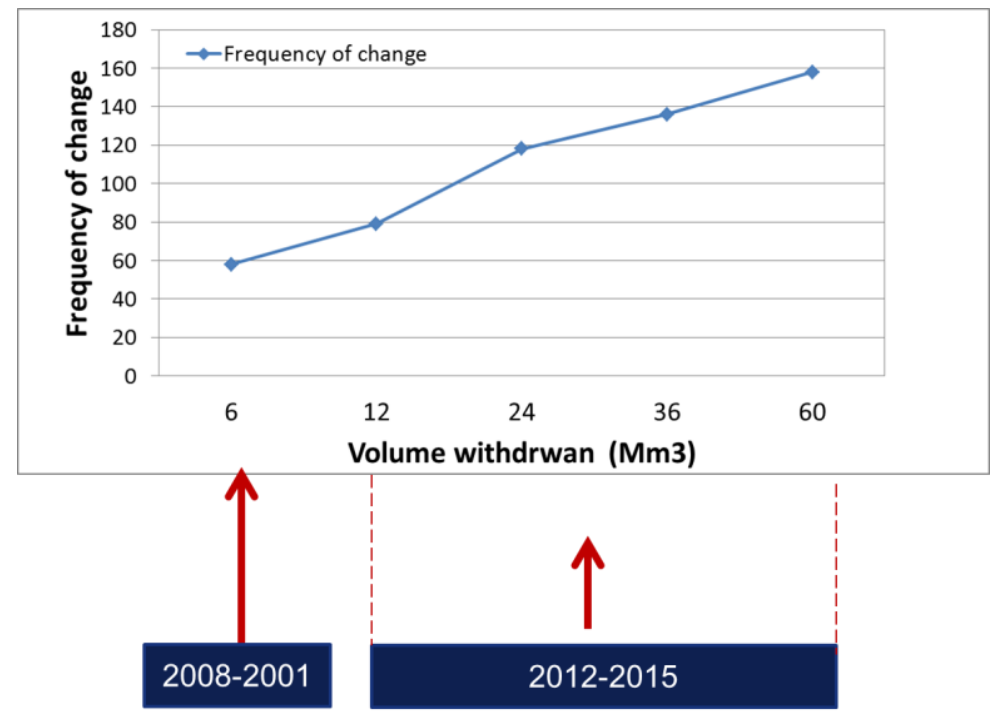

Figure 18. Total frequency of flow alteration the future period of 2012-2015 


\section{Conclusion}

The SWAT model provides good stream flow simulations in the study area. Simulation records in ungauged areas can be used to generate scenarios to assess the impact of hydraulic fracturing on the water balance and discharge. The current analysis of this impact was based first on some assumptions related to the quantity, the source, and the time of water withdrawal, and then to real data of water management across the Fayetteville Shale area. These scenarios can be properly modified based on data availability, which could provide more accurate results. The use of the above scenarios has shown different impact of hydraulic fracturing on the water balance and on the flow regime in different temporal and spatial scales. At the large scale, the impact does not appear significant, while on small scale and in specific periods, the hydraulic fracturing could lead to a number of occurrences of flow changes, which have the potential to alter the equilibrium of the aquatic community in the river.

Based on the analyzed scenario, the alteration from high flow to low flow and from low flow to the extreme low flow was more remarkable in 2007 and 2008, particularly during the summer period.

In addition to simply characterizing hydrologic variability and changes over time, the output from the IHA software, in particular the EFCs and their intra- and inter-annual characteristics, become the building blocks of flow-ecology models that lead to environmental flow recommendations, monitoring and research programs, and flow restoration and protection activities.

Improvement of data about the source of withdrawing, the timing, and the quantity could generate the most realistic scenario related to the hydraulic fracturing. Predicting critical periods of low flow and extreme low flow will help to maintain a sustainable management and generate the adequate scenario of hydraulic fracturing scheduling

\section{Acknowledgements}

This work was supported by the National Energy Technology Laboratory (NETL), U.S. Department of Energy Award number DE-FE0000804. "Integration of Water Resource Models with Fayetteville Shale Support \& Information System" project.

\section{References:}

- Abbaspour, K.C. (2007) User Manual for SWAT-CUP, SWAT Calibration and Uncertainty Analysis Programs, Swiss Federal Institute of Aquatic Science and Technology, Eawag, Duebendorf, Switzerland. 93 pp. 
- Abouabdillah A, Oueslati O., A.M De Girolamo. A. Lo Porto, 2010. Modeling the Impact of climate change in a Mediterranean catchment (Merguellil, Tunisia). Fresenius Environmental Bulletin. Volume 19 - No 10a. 2010.

- AEO, 202. U.S.Energy Information Administration. Annual Energy Outlook 2012 Early Release Overview.

- $A O G C$, 2008. State Of Arkansas Oil And Gas Commission

- $A O G C, 2009$. State Of Arkansas Oil And Gas Commission

- Arabi, M., Frankenberger, J.R., Engel, B.A., Arnold, J.G. (2008). Representation of agricultural conservation practices with SWAT. Hydrol. Process. 22, 3042-3055.

- Arnold, J.G., Srinivasan, R., Muttiah, R.S., and Williams, J.R. 1998. Large area hydrologic modeling and assessment part I: model development. J. Am. Water Resour. Assoc. 34 (1), 73-89.

- Arnold, J.G., and Allen, P.M. 1996. Estimating hydrologic budgets for three Illinois watersheds. J. of Hydrology 176(1996): 57-77.

- Baskaran, L. Jager, H. I.Schweizer, P. E. Srinivasan, R. 2010. Progress toward evaluating the sustainability of switchgrass as a bioenergy crop using the swat model. Transactions of the ASABE. Vol. 53(5): 1547-1556 _ 2010 American Society of Agricultural and Biological Engineers ISSN 2151-0032.

- Bolin, David E., Deputy Director of the State Oil and Gas Board of Alabama, Testimony before the House Committee on Oversight and Government Reform, October 31, 2007.

- Burnett, D.B. and Vavra, C.J. August, 2006. Desalination of Oil Field Brine - Texas A\&M Produced Water Treatment. $\quad$ p. $25 . \quad$ http://www.pe.tamu.edu/gprinew/home/BrineDesal/MembraneWkshpAug06/Burnett8-06.pdf and Global Petroleum Research Institute (Texas A\&M University) web site: 'Conversion of Oil Field Produced Brine to Fresh Water.' http://www.pe.tamu.edu/gprinew/home/BrineDesal/BasicProdWaterMgmnt.htm

- Chaubey'A. S. Cotter, T. A. Costello,T. S. Soerens, 2005. Effect of DEM data resolution on SWAT output uncertainty. Processes Special Issue: SWAT 2000 Development and Application Volume 19, Issue 3, pages 621-628, 28 February 2005.

- Chesapeake Energy. Managing Water Resource Challenges in Select Natural Gas Shale Plays. Presented at GWPC Annual Forum, September 20-24, 2008.

- Cibin, R. Sudheer K. P. and Chaubey, I. 2010 Sensitivity and identifiability of stream flow generation parameters of the SWAT model. Hydrological Processes, Hydrol. Process. (2010).

- Cramer, D.D. 2008. Stimulating unconventional Reservoirs: Lessons Learned, Successful Practices, Areas for Improvement. SPE 114172.

- Eischeid, J. K., P. A. Pasteris, H. F. Diaz, M. S. Plantico, and N. J. Lott, 2000: Creating a serially complete, national daily time series of temperature and precipitation for the western United States. J. Appl. Meteor., 39, 1580-1591.

- Gassman PW, Reyes MR, Geen CH, Arnold JG. 2007. The soil and water assessment tool: historical development, applications and future research directions. Transactions of the ASABE 50(4): 1211-1250.

- Gicas, G.D., Yiannakopoulou, T., Tsihrintzis, V.A., 2006. Modeling of non-point source pollution in a Mediterranean drainage basin, Environmental Modeling and Assessment 11, 219-233.

- Grayson, R., and Blöschl, G. (2001) Spatial modelling of catchment dynamics. In Spatial patterns in catchment hydrology- observations and modelling, Grayson R, Blöschl G (eds). Cambridge University Press: Cambridge; 51-81. 
- Hargreaves, G.H., Samani, Z.A. (1985). Reference crop evapotranspiration from temperature. Applied Engineering in Agriculture, 1, 96-99.

- Holvoet K, van Griensven A, Seuntjens P, Vanrolleghem PA. 2005. Sensitivity analysis for hydrology and pesticide supply towards the river in SWAT. Physics and Chemistry of the Earth 30: 518-526.

- Jeong, J., Kannan, N., and. Arnold, J. G. 2010. Effects of Urbanization and Climate Change on Stream Health in North-Central Texas. Journal of Environmental Quality. Special Section. Applications of the SWAT Model.

- Karr, JR. (1991). Biological integrity: a long-neglected aspect of water resource management. Ecological Applications 1: 66-84.

- Lenhart, T., Eckhardt, K., Fohrer, N., Frede, HG. 2002. Comparison of two different approaches of sensitivity analysis. Physics and Chemistry of the Earth 27: 645-654.

- Margaret, W., Gitau. and Chaubey, I. 2010. Regionalization of SWAT Model Parameters for Use in Ungauged Watersheds. Water 2010, 2, 849-871; doi:10.3390/w2040849.

- Nash, J. E. and Sutcliffe, J.V. (1970). River flow forecasting through conceptual models part I - A discussion of principles. J. Hydrol., 10, pp. 282-290.

- Navigant Consulting, Inc. 2008, North American Natural Gas Supply Assessment, Prepared for: American Clean Skies Foundation.

- Neitsch, S. L., Arnold, J. G., Kiniry, J.R., Williams, J. R., King, K.W. (2002). Soil and Water Assessment tool. Theoretical documentation. Version 2000. TWRI Report TR-191 Grassland, Soil \& Water Research Laboratory, Temple, Texas.

- Poff NL, Allan JD, Bain MB, Karr JR, Prestegaard KL, Richter BD, Sparks RE, Stromberg JC. (1997). The natural flow regime: a paradigm for river conservation and restoration. BioScience 47: 769784.

- Rahman, M., T. Bolisetti and R. Balachandar, 2010. Effect of climate change on low-flow conditions in the Ruscom River Watershed, Ontario. Transactions of the ASABE. 53(5). 15211532.

- Richter, B.D., Baumgartner, J.V., Powell, J., and Braun, D.P. (1996). A method for assessing hydrologic alteration within ecosystems. Conservation Biology. 10: 1163-1174.

- $\quad$ Schlumberger Fracturing Services PowerSTIM webpage. HUwww.slb.comUH September 2, 2008.

- Schmalz, B., Tavares, F., Fohrer, N. 2008. Modelling hydrological processe in mesoscale lowland river basin with SWAT - capabilities and challenges. Hydrological Sciences -Journal des Sciences Hydrologiques, 53(5). Special Issues: Advances in Ecohydrological Modelling with SWAT.

- SCS, 1972. Soil Conservation service. Section 4: Hydrology In National Engineering Handbook. SCS.

- Stehr, A., Debels, P., Romero, F., Alcayaga, H. 2008. Hydrological modelling with SWAT under conditions of limited data availability: evaluation of results from a Chilean case study. Hydrological Sciences Journal Volume 53, Issue 3, 2008.

- The national concervancy, Indicators of Hydrologic Alteration Version 7.1 help.

- The Nature Conservancy, 2009. Indicators of Hydrologic Alteration Version 7.1 User's Manual.

- Trabucco, A., and Zomer, R.J. 2009. Global Aridity Index (Global-Aridity) and Global Potential Evapo-Transpiration (Global-PET) Geospatial Database. CGIAR Consortium for Spatial Information. Published online, available from the CGIAR-CSI GeoPortal at: http://www.csi.cgiar.org

- US department of Interior. 2008. Arkansas Reasonably Foreseeable Development Scenario for Fluid Minerals. March 2008. 
- Veil, J.A., 2010, "Water Management Technologies Used by Marcellus ShaleShale Gas Producers," ANL/EVS/R-10/3, prepared for the U.S. Department of Energy, National Energy Technology Laboratory, July. Available http://www.ead.anl.gov/pub/dsp_detail.cfm?PubID=2537; accessed May 24, 2011.

- White KL, Chaubey I. 2005. Sensitivity analysis, calibration, and validations for a multisite and multivariable SWAT model. Journal of the American Water Resources Association 41: 10771089.

- Williams, J.R. (1975). Sediment routing for agricultural watersheds. Water Resour. Bull. 11(5):965-974.

- Winchell, M., Srinivasan, R., Di Luzio, M., Arnold, J. 2007. ARCSWAT Interface for swat 2005. User's Guide. 